\title{
CASA
}
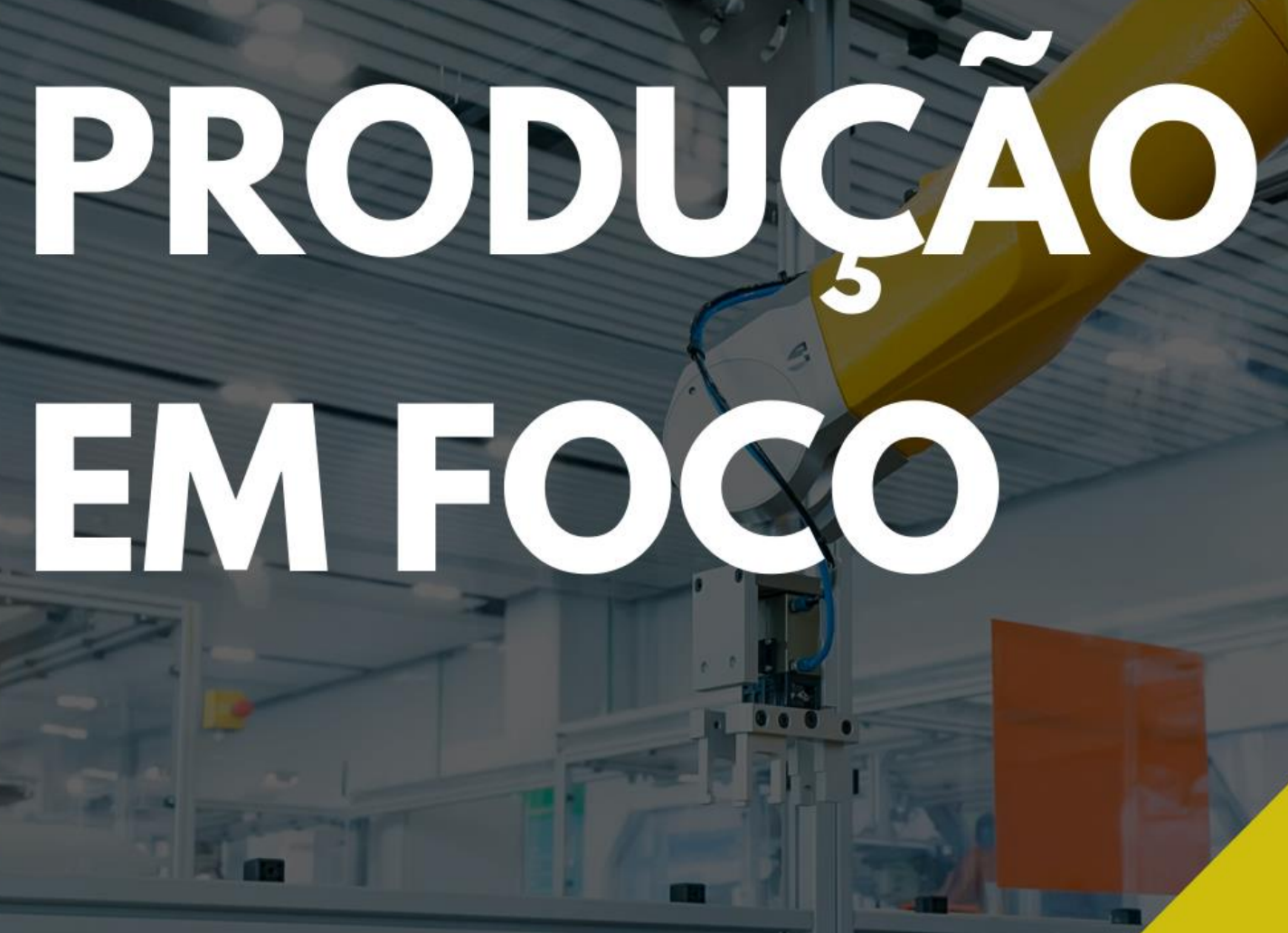

\section{VOLUME 46}

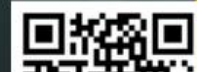


Rafael Alves Pedrosa

(Organizador)

\section{Gestão da Produção em Foco Volume 46}

1a Edição

Belo Horizonte

Poisson

2021 
Editor Chefe: Dr. Darly Fernando Andrade

\section{Conselho Editorial}

Dr. Antônio Artur de Souza - Universidade Federal de Minas Gerais

Ms. Davilson Eduardo Andrade

Dra. Elizângela de Jesus Oliveira - Universidade Federal do Amazonas

MS. Fabiane dos Santos

Dr. José Eduardo Ferreira Lopes - Universidade Federal de Uberlândia

Dr. Otaviano Francisco Neves - Pontifícia Universidade Católica de Minas Gerais

Dr. Luiz Cláudio de Lima - Universidade FUMEC

Dr. Nelson Ferreira Filho - Faculdades Kennedy

Ms. Valdiney Alves de Oliveira - Universidade Federal de Uberlândia

Dados Internacionais de Catalogação na Publicação (CIP)

\begin{tabular}{l} 
G393 Gestão da Produção em Foco - Volume 46/ Organização Rafael Alves \\
Pedrosa - Belo Horizonte - MG: Poisson, 2021 \\
Formato: PDF \\
ISBN: $978-65-5866-064-4$ \\
DOI: $10.36229 / 978-65-5866-064-4$ \\
Modo de acesso: World Wide Web \\
Inclui bibliografia \\
1. Gestão 2. Produção. 3. I. PEDROSA, Rafael Alves II. Título. \\
\\
Sônia Márcia Soares de Moura - CRB 6/1896 CDD-658 \\
\hline
\end{tabular}

O conteúdo dos artigos e seus dados em sua forma, correção e confiabilidade são de responsabilidade exclusiva dos seus respectivos autores.

Baixe outros títulos gratuitamente em www.poisson.com.br contato@poisson.com.br 


\section{SUMÁRIO}

Capítulo 1: Análise dos riscos físicos: Ruído e vibração em motocoveador manual .. 07 José Antonio Poletto Filho, João Eduardo Guarnetti dos Santos

DOI: 10.36229/978-65-5866-064-4.CAP.01

Capítulo 2: Análise ergonômica física do ambiente de trabalho de uma indústria de luminárias de emergência.

Marcos Vinicius Wendpap, Robson Luciano de Almeida, Adriana Aparecida Dambros da Silva

DOI: 10.36229/978-65-5866-064-4.CAP.02

Capítulo 3: Estudo preliminar sobre desconforto ergonômico em um curso de graduação em Engenharia de Produção 33

Glicia Maria Barbosa, Larissa Beatriz Fonseca Tavares, Hebert Roberto da Silva

DOI: 10.36229/978-65-5866-064-4.CAP.03

Capítulo 4: Estudo de caso para previsão dos resíduos industriais na produção de catalisadores para a área do petróleo. 41

Marcello Montillo Provenza, Marco Antonio Gaya de Figueiredo, Paula Martins de Souza

DOI: $10.36229 / 978-65-5866-064-4 . C A P .04$

Capítulo 5: Avaliação de desempenho da sustentabilidade em uma organização do setor de cosméticos 49

Filipe Brito Lima de Macedo, Gilson Brito Alves Lima, Luiz Paulo Marques Assumpção Resinente, Thiago Gomes Brito Lima

DOI: $10.36229 / 978-65-5866-064-4 . C A P .05$

Capítulo 6: A importância da economia circular nos sistemas de produção - Um estudo de caso da Kalundborg Symbiosis 59

Rayssa Gabrielle da Silva Soares, Ronniery Ilario Pereira, Gerson Luiz de Abreu Henriques, Sara Monaliza Sousa Nogueira, Ercilia de Stefano

DOI: 10.36229/978-65-5866-064-4.CAP.06

Capítulo 7: Barreiras e desafios para a implantação da Indústria 4.0 - Revisão de Literatura. 68

Davi Teixeira Pinheiro, José Artur Soares de Almeida Filho, Victor Igor Barros Farias

DoI: 10.36229/978-65-5866-064-4.CAP.07 


\section{SUMÁRIO}

Capítulo 8: 0 impacto do uso da tecnologia da Indústria 4.0 sobre a sociedade:

Resultados e transformações sociais

Fernanda Carlos da Fonseca, Sara Monaliza Sousa Nogueira, Ercilia de Stefano

DOI: $10.36229 / 978-65-5866-064-4 . C A P .08$

Capítulo 9: Reflexões sobre o potencial socioeconômico de uma Associação de Catadores em Nova Era/MG

Jean Carlos Machado Alves, João Pedro de Almeida Oliveira

DOI: 10.36229/978-65-5866-064-4.CAP.09

Capítulo 10: Explorando conexões para a formação de inovadores em ambientes multiculturais

Stephanie Felix Amaral, Emmanuel Paiva de Andrade, João Paulo Ferreira Martins, Walber Santos de Assis, Neide Lucia de Oliveira Almeida

DOI: $10.36229 / 978-65-5866-064-4 . C A P .10$

Capítulo 11: Análise do Terminal de Passageiros do Aeroporto Internacional Tom Jobim por meio de uma simulação 101

Pedro Henrique Campos da Costa, Pedro da Matta e Andrade Basilio, Ana Carolina Cellular Massone DOI: $10.36229 / 978-65-5866-064-4 . C A P .11$

Capítulo 12: Planejamento de sistemas de distribuição de energia elétrica por meio de uma metaheurística GRASP 110

Fábio Seiti Hadano, Gabriela Helena Bauab Shiguemoto, André Luís Shiguemoto

DOI: $10.36229 / 978-65-5866-064-4 . C A P .12$

Capítulo 13: Proposta de aplicação da Metodologia MASP para redução das perdas em estoque 120

Bruno Silva de Aguiar, Jonathan Gonçalves Figueiredo, Sophia Travesedo Cardoso

DOI: $10.36229 / 978-65-5866-064-4 . C A P .13$

Capítulo 14: Aplicação da Metodologia DMAIC em uma fábrica de baterias para o controle das perdas de chumbo. 129

Daniel de Freitas Barbosa, André Luiz Gazoli de Oliveira, William Rodrigues dos Santos, Marco Aurélio Reis dos Santos

DOI: 10.36229/978-65-5866-064-4.CAP.14 


\section{SUMÁRIO}

Capítulo 15: Synergy in the management of the civil construction industry: Applicability PDCA and DMAIC 140

Ana Celia Vidolin, Cezar Augusto Romano, Fernando Leonel Cuzzuol

DOI: 10.36229/978-65-5866-064-4.CAP.15

Capítulo 16: Tipos de polímeros utilizados como materia prima no método de manufatura aditiva por FDM: Uma abordagem conceitual

Luana Machado dos Santos, Daniela Sousa Guedes Meirelles Rocha, Marcos Lajovic Carneiro, Marta Pereira da Luz

DOI: $10.36229 / 978-65-5866-064-4 . C A P .16$

Capítulo 17: Análise de um processo de injeção de plástico para implementação das Cartas de Controle de Shewhart por Variáveis

Renan Ryuji Murashita Takenaka, Emerson José de Paiva, Ana Carolina Oliveira Santos, Tarcisio Gonçalves de Brito

DOI: $10.36229 / 978-65-5866-064-4 . C A P .17$

Autores: 


\section{Capítulo 1}

Análise dos riscos físicos: Ruído e vibração em motocoveador manual

\section{José Antonio Poletto Filho \\ João Eduardo Guarnetti dos Santos}

Resumo: 0 presente estudo buscou descrever a atividade dos profissionais que utilizam motocoveador manual, considerando para este fim: a metodologia do trabalho, as alterações na legislação e a intensidade dos agentes físicos: Ruído e vibração. com este objetivo, surgiu a necessidade de responder ao seguinte problema de pesquisa: Qual a efetividade das normas de segurança no trabalho na proteção do trabalhador ao manusearem equipamento que geram ruído e vibração? A pesquisa tem com justificativa o conhecimento e reconhecimento das lesões provocadas pelo agente analisado. concluiu-se que os níveis dos agentes em foco estão acima dos limites preconizados pela legislação.

Palavras-chave: segurança no trabalho; insalubridade; agentes físicos; perfurador de solo. 


\section{INTRODUÇÃO}

Segundo Casagrande (2015) a legislação referente à Higiene, Segurança e Medicina no trabalho são matérias de ordenamento jurídico constitucional, direito social dos trabalhadores segundo os quais estes devem exercer suas funções em um ambiente seguro e salubre, sendo que o empregador deverá providenciar medidas necessárias para eliminar os riscos provenientes da atividade conforme inciso XXII do art. $7^{\circ}$ da Constituição Federal que preconiza a redução dos riscos inerentes ao trabalho, por meio de normas de saúde, higiene e segurança. Os artigos $196^{\circ}$ a $200^{\circ}$ da carta constitucional inferem que a saúde é um direito de todos e dever do Estado, ainda no seu artigo $6^{\circ}$ garante o direito à saúde, trabalho, segurança e à previdência social, desta forma é dever do estado a regulamentação, fiscalização e controle, dos ambientes laborais. Já a Magna Carta também assegura o direito ao meio ambiente de trabalho equilibrado, por meio da utilização de técnicas, métodos e substâncias que não impliquem em risco para a vida dos que ali labutam.Já a Consolidação das Leis do Trabalho (CLT), nos seus artigos $154^{\circ}$ a 201으. com redação da Lei 6.514/77que trata das Normas Regulamentadoras relativas à Segurança e Medicina no Trabalho, impõem a responsabilidade pela fiscalização ao Poder Público, portanto não há discussão quanto à responsabilidade deste em fiscalizar e exigir o cumprimento das normas referentes à qualidade dos ambientes de trabalho, e a obrigação das empresas em se adequarem às Leis e Portarias publicadas pelo Ministério do Trabalho e Emprego (GARCIA, 2010).

Recentemente a Lei no13.467, aprovada em 13 de Junho de 2017, trouxe diversas alterações à CLT. Uma delas diz respeito ao adicional de insalubridade, um instrumento que integra o sistema geral de proteção ao trabalhador, e que segundo Porto (2017), está em descordo com a Convenção 155 da OIT, que trata das medidas de proteção adequadas quanto aos agentes e as substâncias químicas, físicas e biológicas no ambiente de trabalho.

Vibração: as alterações introduzidas em Agosto de 2014 pela Portaria no 1.297, que trata da nova legislação sobre a Vibração e altera a Norma Regulamentadora no9 (Programa de Prevenção de Riscos Ambientais) no Anexo n.o 8, pode não surtir o efeito previamente almejado. As alterações proposta pela referida portaria são: 1o - Inclusão do Anexo 1 (Vibração) no Programas de Prevenção de Riscos Ambientais; 2o - Alterado o Anexo 8 (Vibração) da Norma Regulamentadora n.o 15 - Atividades e Operações Insalubres; 3ำ - 0 item 2.3 do Anexo 1 - Vibração do Programa de Prevenção de Riscos Ambientais somente será válido para ferramentas fabricadas um ano após a publicação deste anexo, sem prejuízo das obrigações já estabelecidas em outras normas oficiais vigentes.

Assim sendo, antes da publicação dessa portaria não havia parâmetros para determinar se uma atividade era insalubre ou não em decorrência das atividades com vibração, e com o surgimento deste novo enfoque a insalubridade por vibração passa a ser caracterizada da seguinte maneira: exposição ocupacional diária a Vibração de Mãos e Braços (VMB) correspondente a um valor de Aceleração Resultante de Exposição Normalizada (aren) de $5 \mathrm{~m} / \mathrm{s}^{2}$. As situações de exposição àVibração de Mãos e Braços superiores aos limites de exposição ocupacional sãocaracterizadas como insalubres em grau médio.

Ruído: As máquinas agrícolas em geral expõem os trabalhadores a níveis de ruído acima do permitido pela legislação, conforme a Norma Regulamentadora no 15 da portaria 3.214 DE 1978 (SANTOS, 2004).

De acordo com Delgado, (1991) os níveis de ruídos que estejam no intervalo de 65 a 85 dB (A), causa efeitos psíquico fisiológicos no trabalhador agindo no sistema nervoso, podendo causar aumento da pressão sanguínea e de batimentos cardíacos, interferindo com o sono, a pressão arterial, causando stress. De acordo com Mendes (2005) normalmente ruído é definido como um som indesejável, já a NIOSH (1998) define ruído como um som errático, intermitente ou com oscilação estaticamente aleatória. Segundo a NIOSH (1996) perda auditiva ocupacional é um dos problemas os mais importantes da atualidade, afetando trabalhadores na indústria, construção civil, transporte, agricultura, entre outras atividades.

No estudo em tela foi discutido o ordenamento jurídico referente à legislação trabalhista, especificamente quanto aos agentes físicos: ruído e vibração, e a efetiva proteção ao trabalhador refletindo na melhoria das condições de trabalho e a diminuição das doenças e lesões causadas por este. 


\section{JUSTIFICATIVA}

Segundo Saliba (2014) o agente físico: vibração, não é tão estudado quando comparado com os outros agentes, mas a sua ocorrência nos locais de trabalho é frequente e seus efeitos sobre o trabalhador considerável, sendo desta forma o seu conhecimento, avaliação e controle muito importante, já o ruído, apesar de ser um agente mais estudado e conhecido pode trazer severas consequências para o trabalhador exposto.

\section{OBJETIVO}

A proposta deste trabalho foi analisar a exposição aos agentes físicos: ruído evibraçãoa que estão expostos os trabalhadores que utilizam perfurador de solo motorizadoou também denominado de motocoveador manual, e a evolução da legislação referente aos limites de tolerância encontrados no ordenamento jurídicobrasileiro referente à saúde e segurança no trabalho, especificamente na Norma Regulamentadora no 15 - Atividades e Operações Insalubres, anexos: 1 e 8.

\section{REVISÃO BIBLIOGRÁFICA}

As atividades profissionais que exponham os trabalhadores a níveis excessivos de vibração transmitida ao sistema mão-braço têm provocado consequências efeitosfunestasà saúde dos obreiros o que acaba por culminar em enfermidades denominadas por Síndrome de Reynolds (MENDES, 2005).

Considerando agora que a expansão da fronteira agrícola nacional foi acompanhada do aumento da mecanização no campo, forçada principalmente pela exigência de produtividade, neste sentido vários equipamentos tornaram-se presentes neste ambiente de trabalho, aumentando desta forma a preocupação com os operadores destas máquinas agrícolas, sujeitos aos riscos inerentes da operação destes equipamentos (EUCLIDES, et al, 2012). Entre estes riscos tem-se o ruído e a vibração, foco deste trabalho.

Para Vendrame (2005) a vibração provoca vários efeitos no trabalhador, dos quais cita: perda de equilíbrio, alteração do sistema cardíaco, efeitos psicológicos, distúrbios visuais, efeitos no sistema gastrointestinal, comprometimento de alguns órgãos e degeneração gradativa do tecido muscular e nervoso.

Ainda segundo o mesmo autor (2009),a eliminar da vibração é praticamente impossível, haja vista que todos os equipamentos mecânicos sempre produzem vibração em alguma frequência, assim sendo é importante procurar meios de mitigar os efeitos oriundos deste agente.

Segundo OSHA (2005), a Agência Europeia para a Segurança e a Saúde no Trabalho, a exposição dos trabalhadores a níveis de ruído, acime dos limites de tolerância além da perda de audição pode agravar o estresse, causar problemas gástricos, insônia, impotência sexual, depressão, aumentando o risco de acidentes.

Desta forma, medidas protetivas para o controle do agente em questão devem ser adotadas na tentativa de se evitar o potencial de risco à saúde do trabalhador (SOEIRO, 2011). Ainda o mesmo autor comenta que as medidas adotadas podem ser de caráter construtivo, consideras com proteção coletiva (projeto da máquina), caráter organizacional (reorganização do trabalho) e a o fornecimento de Equipamento de Proteção Individual.

Vibração: Os distúrbios vasculares observados em indivíduos expostos a vibrações de mãos e braços foram observados pela primeira vez por Reynaud (1969) em 1862e foi descrito na obra intitulada Local Asphyxia and Symmetrical Gangrene of the Extremities. Pesquisadores italianos, em 1911 descreviam a síndrome da vibração nos trabalhadores que operavam marteletes, correlacionando com o fenômeno de Reynaud (VENDRAME 2005).

Ainda segundo Vendrame (2005) um estudo realizado no ano de 1918 foi descrito em trabalhadores que utilizavam marteletes na atividade de mineração uma anemia das mãos denominada de síndrome da vibração também associada á utilização de motosserras no trabalho florestal.

No Brasil a Portaria no 1339 (1999), do Ministério da Saúde, considera as vibrações localizadas como agentes de risco de natureza ocupacional. 
Conforme define Iida (2005), movimento que se repete em intervalos de tempo constantes podem ser denominados de vibração, isto é,o estudo do movimento de oscilação de um corpo em torno de uma posição de equilíbrio, bem como das forças ou momentos a ele associadas. Já para Mendes (2005) a vibração é uma grandeza vetorial e, portanto com magnitude, direção e sentido, desta forma além destas variáveis outras devem ser levadas em consideração quando se trata de vibração localizada: área de contato com a vibração, força de contato, postura do dedo, mão ou braço e temperatura.

A vibração é um fenômeno natural presente em todos os corpos existentes, desta forma o corpo humano também possui uma vibração natural e quando coincide com a frequência do equipamento utilizado pelo trabalhador, implica em amplificação do movimento oscilatório, sendo assim a energia vibratória é absorvida pelo organismo devido a atenuação promovida pelos tecidos e órgãos (VENDRAME, 2005).

Regazzi e Ximenes, (2005) comentam que a sensibilidade a vibrações é diferente, dependendo do eixo cartesiano adotado: vibrações longitudinais, ao longo do eixo z, da coluna vertebral é distinta da sensibilidade transversal, eixos $\mathrm{x}$ ou $\mathrm{y}$, ao longo dos braços ou através do tórax, sendo que em cada direção, a sensibilidade varia com a frequência, assim, para determinada frequência, a aceleração tolerável é diferente daquela em outra frequência.

Segundo comenta Saliba (2014) as vibrações podem ser classificadas da seguinte forma: Vibração ocupacional de corpo inteiro - transmitidas ao corpo como um todo, geralmente por meio da superfície de suporte, tal como pé, costas, nádegas; Vibração ocupacional mão e braço ou localizada - atingem determinadas regiões do corpo do trabalhador, principalmente: mãos, braços.

A vibração pode causar desconforto intolerável, dependendo da atividade desenvolvida, desta forma os valores de conforto dependem de vários fatores, alguns até subjetivos. Desta forma a evolução da legislação referente ao agente físico em questão aconteceu a paris da Portaria MTE № 1297 de 13/08/2014 (BRASIL, 2014). Cabe ressaltar que não havia até o ano de 2014, normatização nacionaldefinida para o agente físico vibração,somente a partir desta data, com o advento da referida portaria a exposição ao agente pode ser definido com insalubre ou não (SALIBA,2014).

A comprovação ou não da exposição toma por base os limites da norma: vibrações de mão e braço (FUNDACENTRO, 2013). Esta norma define e a direção do movimento, que é dada em três eixos espaciais: $\boldsymbol{x}$ (sagital), das costas para frente, $\boldsymbol{y}$ (transversal),da direita para esquerda e $\boldsymbol{z}$ (vertical), dos pés à cabeça (ROCHA, 2010).

A Tabela 1, retirada da Norma NHO 10,apresenta o critério de avaliação do nível de da Exposição Ocupacional a Vibrações em Mãos e Braços segundo considerações técnicas e a atuação recomendada em função da Aceleração Resultante de Exposição Normalizada (aren) encontrada na condição de exposição avaliada (FUNDACENTRO, 2013).

Tabela 1: Critério de julgamento

\begin{tabular}{|c|c|c|}
\hline arem $\left(\mathrm{m} / \mathrm{s}^{2}\right)$ & Considerações & Atuação recomendada. \\
\hline $0 \ldots .2,5$ & Aceitável & Nenhuma \\
\hline $2,5 \ldots . .3,5$ & Acima do nível de ação & Medidas preventivas. \\
\hline $3,5 \ldots . .5,0$ & Incerteza & Medidas corretivas. \\
\hline Acima 5,0 & Acima limite de exposição & Fonte: NHO 10, Fundacentro, 2013 \\
\hline
\end{tabular}

Ainda de acordo com a norma NHO 10 (FUNDACENTRO, 2013), para determinação da vibração total transmitida ao sistema mão-braço $\left(a_{h v}\right)$ durante a realização da atividade com o equipamento em analise é determinado de acordo com a equação I.

$$
a_{h v}=\sqrt{a_{h w x}^{2}+a_{h w y}^{2}+a_{h w z}^{2}}
$$

Onde: $a_{h w x} ; a_{h w y} ; a_{h w z}$ são os valores das acelerações ponderadas em frequência para os eixosx, $y$ e $z$, respectivamente. 
Para determinação da exposição diária referente a 8 horas A(8) de trabalho utiliza-se a equação II.

$$
A(8)=a_{h v} \sqrt{\frac{T}{T_{0}}}
$$

Onde: $T$ é a duração diária total da exposição às vibrações (horas ou minutos) e $T_{0}$ é duração de referência de oitohoras (horas ou 480 minutos).

Ruído: Com relação ao agente físico ruído e de acordo com a norma NHO 01 da Fundacentro (2001) para fins de comparação com o limite de tolerância (Tabela 2) deve-se determinar o nível de exposição normatizado, por meio da equação III.

$$
N E N=N E+10 \log \frac{T_{e}}{480}
$$

Onde: NEN é nível de exposição normatizado [dB]; NE, nível médio representativo da exposição da ocupação diária [dB]; $\mathrm{T}_{\mathrm{e}}$, jornada diária [min].

Tabela 2: Limite de exposição NHO 01

\begin{tabular}{|c|c|}
\hline NEM [dB] & Tempo [min] \\
\hline 80 & $1.523,9$ \\
\hline 81 & $1.209,52$ \\
\hline 82 & 960,00 \\
\hline 83 & 761,95 \\
\hline 84 & 604,76 \\
\hline 85 & 480,00 \\
\hline 90 & 151,19 \\
\hline 95 & 47,62 \\
\hline 100 & 15,00 \\
\hline 115 & 0,46 \\
\hline
\end{tabular}

Fonte: NHO 01 - Fundacentro (2001)

Assim sendo a tabela acima indica resumidamente o tempo máximo diário de exposição permitida em função do nível de ruído.

Quando se considera o agente físico ruído tomando com referencia a Portaria 3.214/1978 (BRASIL, 78) especificamente a Norma Regulamentadora $\mathrm{n}^{0} 15$ no seu anexo 1: Limite de Tolerância para Ruído Contínuo ou Intermitente tem-se os níveis de exposição diária permitidos segundo a Tabela 3.

Tabela 3: Limite de exposição NR 15

\begin{tabular}{|c|c|}
\hline NEM $[\mathrm{dB}]$ & Tempo $[\mathrm{min}]$ \\
\hline 80 & -- \\
\hline 81 & -- \\
\hline 82 & -- \\
\hline 83 & -- \\
\hline 84 & -- \\
\hline 85 & 480 \\
\hline 90 & 240 \\
\hline 95 & 120 \\
\hline 100 & 60 \\
\hline 115 & 15 \\
\hline
\end{tabular}

Fonte: Portaria 3.214/1978, BRASIL, 1978. 
Para determinação da dose (D) utiliza-se a equação IV, conforme a Norma regulamentadora n. ${ }^{\circ} 15$ (Brasil, 1978).

$$
D=\frac{C_{1}}{T_{1}}+\frac{C_{2}}{T_{2}}+\frac{C_{3}}{T_{3}}+\cdots \frac{C_{N}}{T_{N}}
$$

Quando o resultadoexceder a unidade (D>1) a exposição estará acima do limite de tolerância.

Já o Nível Médio Representativo de Exposição Diária (NE) segundo a Norma Regulamentadora no 15 poderá ser determinado por meio da Equação V:

$$
N E=10 \log \left(\frac{480}{T_{e}}+\frac{D}{100}\right)+85
$$

Onde: NE - Nível Médio Representativo de Exposição Diária [dB]; $\mathrm{T}_{\mathrm{e}}$ - Tempo de Exposição do trabalhador ao ruído [min]; D - dose [\%];

Ainda segundo a portaria 3.214/1978 (BRASIL, 1978) a determinação do Nível de Exposição Normalizado (NEN) é calculado por meio da equação (VI).

$$
N E N=N E+16,61 \log \left(\frac{T_{e}}{480}\right)
$$

Onde: NEN - Nível de Exposição Normalizado [dB]; NE - Nível Médio Representativo de Exposição Diária [dB]; $\mathrm{T}_{\mathrm{e}}$ - Tempo de Exposição do trabalhador ao ruído [min].

A Portaria n. ${ }^{0}$ 3.214/78 (BRASIL, 1978), na Norma Regulamentadora $\mathrm{n}^{0} 15$ define Limite de Tolerância como: "concentração ou intensidade máxima ou mínima, relacionada com a natureza e o tempo de exposição ao agente, que não causará dano à saúde do trabalhador, durante a sua vida laboral".

\section{METODOLOGIA}

Os procedimentos desta pesquisa foram submetidosao comitê de Ética e um Termo de Consentimento Livre e Esclarecido foi utilizado.

A crescente mecanização do setor agrícola, principalmente na pequena propriedade rural onde o agricultor que faz uso de equipamentos movidos a motor de combustão interna, vem proporcionando aumenta de produtividade, eficiência e melhoria do desempenho dos serviços realizados, carrega a reboque prejuízos à saúde do operador gerados principalmente pelos riscos presentes na operação destas ferramentas. Entre estes riscos pode-se citar: ruído e vibração, risco químico proveniente dos gases de combustão e riscos ergonômicos.

0 trabalho em tela não irá discutir as questões ergonômicas, nem tão pouco o riscoquímico, somente foi avaliando o agente físico vibração localizada, transmitida aos membros superiores dos trabalhadores e ruído na operação de motocoveador manual. Os valores encontrados foram comparados com os limites de tolerância preconizados na legislação atualmente em vigência e nas que as precederam.

Na atividade de coveamento semi-mecanizado o trabalhador deve levar o equipamentoaté o local de trabalho e lá se deslocar pelo terreno executando as perfurações, transportando uma massa de aproximadamente $20 \mathrm{~kg}$, a situação é agravada quando considerada a elevada carga de trabalho físico, nível de ruído, exigência de posturas inadequadas, e ainda geração de ruído e vibração, estesdois últimos agentessão o foco deste trabalho.

Para realização dos ensaios foram utilizados três equipamentos motocoveadores de fabricantes diferentes com as características descritas a seguir (Tabela 4). 
Tabela 4: descrição dos equipamentos utilizados.

\begin{tabular}{|c|c|c|c|}
\hline Equipamento & Potência (CV) & Cilindradas $\left(\mathrm{cm}^{3}\right)$ & Diâmetro da broca $(\mathrm{m})$ \\
\hline 1 & 2,0 & 52,0 & 0,15 \\
\hline 2 & 2,0 & 53,0 & 0,20 \\
\hline 3 & 2,2 & 51,7 & 0,20 \\
\hline
\end{tabular}

Fonte: Autor

0 operador realizou três furos com profundidade aproximada de $0,8 \mathrm{~m}$, com cada equipamento, isto é um total de nove furos, em terrenos com características semelhantes, sendo que cada perfuração teve duração de aproximadamente $120 \mathrm{~s}$ ( 2 minutos).

\section{RESULTADOS E DISCUSSÕES}

Vibração: Para o levantamento quantitativo do agente vibração, foi realizada a medição nos três eixos ortogonais $\mathrm{x}, \mathrm{y}$ e $\mathrm{z}$, metodologia esta adotada pelas normas atuais para que se possa estabelecer a severidade global da vibração.

Assim sendo e considerando a importância do setor agrícola a saúde e segurança dosoperadores deste tipo de equipamento, as medições foramrealizadas com a utilização de um analisador de vibração com o sensor montado na empunhadura do equipamento (Figura 1).

Figura 1: montagem do sensor de vibração
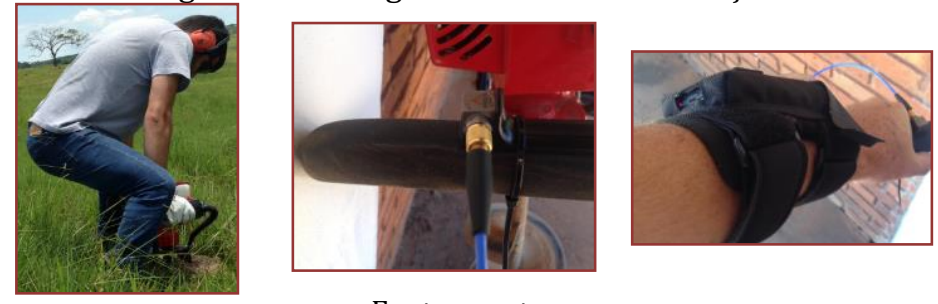

Fonte: o autor

0 ponto de referência das medições foi a palma da mão, área que entra em contato com a empunhadura do perfurador sendo realizada a medida da aceleração segundo os três eixos $x, y$ e $z$. 0 equipamento utilizado para avaliar a vibração foi um acelerômetro de três eixos (X, Y \& Z) HVM - 200 fabricado pela Larson Davis, que possibilita leituras simultâneas tri axial. 0 trabalhador procedeu a operação do equipamento com utilização de luvas e demais EPI's, e os procedimentos para o ensaio seguiram o preconizado pela norma da Fundacentro NHO 10 (2013).

Com aplicação da equação (I) determinou-se a aceleração ponderada transmitida ao sistema mão-braço $\left(a_{h v}\right)$. Como em cada perfuração foi gerado 120 leituras, tabulou-se apenas as três mais representativas em cada eixo, apresentadas na Tabela 5. A vibração final para cada equipamento e em cada perfuração $\left(a_{h v}^{x-y}\right)$, onde o índice " $\mathrm{x}$ " refere-se ao equipamento e o "y" à perfuração. 
Tabela 5: resultados tabulados segundo a equação (I)

\begin{tabular}{|c|c|c|c|c|c|c|c|c|c|c|c|c|}
\hline-1 & \multicolumn{4}{|c|}{ Primeira perfuração } & \multicolumn{4}{|c|}{ Segunda perfuração } & \multicolumn{4}{|c|}{ Terceira perfuração } \\
\hline 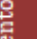 & $a_{\text {hwx }}$ & $a_{\text {hwy }}$ & $a_{\text {hwz }}$ & $a_{h v}$ & $a_{\text {hwx }}$ & $a_{\text {hwy }}$ & $a_{\text {hwz }}$ & $a_{h v}$ & $a_{\text {hwx }}$ & $a_{\text {hwy }}$ & $a_{\text {hwz }}$ & $a_{h v}$ \\
\hline & 13,48 & 5,11 & 4,89 & 15,22 & 10,33 & 4,72 & 10,02 & 27,00 & 11,92 & 7,34 & 16,54 & 16,54 \\
\hline ڤ̆. & 13,30 & 4,92 & 5,66 & 15,27 & 10,31 & 4,65 & 10,93 & 25,03 & 11,31 & 5,65 & 16,42 & 16,42 \\
\hline 官 & 12,57 & 4,80 & 5,70 & 14,62 & 9,61 & 4,80 & 12,23 & 21,92 & 8,65 & 8,90 & 16,74 & 16,74 \\
\hline w & \multicolumn{3}{|c|}{$a_{h \bar{p}}^{1}-1$} & 14,99 & \multicolumn{3}{|c|}{$a_{h v^{1}}^{12}$} & 24,65 & \multicolumn{3}{|c|}{$a_{h v}^{1}{ }^{3}$} & 16,56 \\
\hline N & \multicolumn{4}{|c|}{ Primeira perfuração } & \multicolumn{4}{|c|}{ Segunda perfuração } & \multicolumn{4}{|c|}{ Terceira perfuração } \\
\hline 预 & $a_{\text {hwx }}$ & $a_{\text {hwy }}$ & $a_{\text {hwz }}$ & $a_{h v}$ & $a_{\text {hwx }}$ & $a_{\text {hwy }}$ & $a_{h w z}$ & $a_{h v}$ & $a_{h w x}$ & $a_{\text {hwy }}$ & $a_{h w z}$ & $a_{h v}$ \\
\hline ్ㅛㄹ & 8,37 & 4,08 & 2,90 & 9,75 & 8,47 & 4,42 & 11,26 & 24,54 & 8,47 & 4,42 & 14,02 & 14,02 \\
\hline 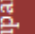 & 8,01 & 3,86 & 2,75 & 9,31 & 7,27 & 3,35 & 8,057 & 16,81 & 7,70 & 2,30 & 12,72 & 12,72 \\
\hline$\vec{E}$ & 7,45 & 3,84 & 3,02 & 8,92 & 7,70 & 3,71 & 7,461 & 18,09 & 7,70 & 3,71 & 12,03 & 12,03 \\
\hline 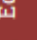 & \multicolumn{3}{|c|}{$a_{h i 1}^{2} 1$} & 9,17 & \multicolumn{3}{|c|}{$a_{h=2}^{2}$} & 19,44 & \multicolumn{3}{|c|}{$a_{h v}^{2}{ }^{3}$} & 12,57 \\
\hline 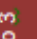 & \multicolumn{4}{|c|}{ Primeira perfuração } & \multicolumn{4}{|c|}{ Segunda perfuração } & \multicolumn{4}{|c|}{ Terceira perfuração } \\
\hline 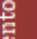 & $a_{\text {hwx }}$ & $a_{\text {hwy }}$ & $a_{\text {hwz }}$ & $a_{h v}$ & $a_{\text {hwx }}$ & $a_{\text {hwy }}$ & $a_{\text {hwz }}$ & $a_{h v}$ & $a_{\text {hwx }}$ & $a_{\text {hwy }}$ & $a_{\text {hwz }}$ & $a_{h v}$ \\
\hline & 7,17 & 3,46 & 2,60 & 8,37 & 6,57 & 3,55 & 12,87 & 17,76 & 6,57 & 3,55 & 14,88 & 14,88 \\
\hline & 8,13 & 4,91 & 5,12 & 10,80 & 6,70 & 4,04 & 9,82 & 18,34 & 6,71 & 3,03 & 12,28 & 12,28 \\
\hline & 8,24 & 5,52 & 4,67 & 10,96 & 6,37 & 3,68 & 10,78 & 16,82 & 7,37 & 4,65 & 13,06 & 15,70 \\
\hline t. & \multicolumn{3}{|c|}{$a_{h-1}^{3} \frac{1}{1}$} & 10,04 & \multicolumn{3}{|c|}{$a_{h y}^{3} v^{2}$} & 17,64 & \multicolumn{3}{|c|}{$a_{h v}^{3}{ }^{3}$} & 14,28 \\
\hline
\end{tabular}

Os valores de aceleração para cada equipamento foi determinada da mesma forma, isto é, a somatória dos valores de vibração de cada equipamento $\left(a_{h v}^{x \_y}\right)$ e dividindo-se Poe 3 e estão transcritas na Tabela 6.

Tabela 6: Nível de vibração para cada equipamento

\begin{tabular}{|c|c|c|c|}
\hline & Equipamento 1 & Equipamento 2 & Equipamento 3 \\
\hline Vibração $\left(\mathrm{m} / \mathrm{s}^{2}\right)$ & 18,73 & 13,90 & 13,98 \\
\hline
\end{tabular}

Fonte: o autor

Aplicando-se a equação (I) determinou-se a vibração total transmitida ao sistema mão-braço $\left(a_{h v}\right)$ para equipamento e perfuração, sendo que a média das três perfurações para cada equipamento $\left(a_{h v}^{x_{-} y}\right)$ é: $207,19 \mathrm{~m} / \mathrm{s}^{2}$. Para determinação da exposição diária, referente às 8 horas (A(8)), utilizou-se a equação (II), considerando que o tempo efetivo de trabalho (T) foi de duas horas, os resultados estão apresentados na Tabela 7.

Tabela 7: resultados

\begin{tabular}{|c|c|c|}
\hline Equipamento & $\boldsymbol{a}_{\boldsymbol{h v}}\left(\mathrm{m} / \mathrm{s}^{2}\right)$ & $\mathrm{A}(8)\left(\mathrm{m} / \mathrm{s}^{2}\right)$ \\
\hline 1 & 18,73 & 9,36 \\
\hline 2 & 13,90 & 6,95 \\
\hline 3 & 13,98 & 6,99 \\
\hline \multicolumn{3}{|l}{ Fonte: 0 autor }
\end{tabular}

Após a aplicação das equações pertinentes, realizou-se a análise dos resultados obtidos considerando-se os valores permissíveis da vibração segundo a norma da Fundacentro NHO 10 que estipula os níveis de ação e limites de exposição para vibração total transmitida ao sistema mão-braço $\left(a_{h v}\right)$ da exposição diária, referente a 8 horas $\mathrm{A}(8)$, de acordo com a Tabela 8.

Tabela 8: resultado - agente físico vibração

\begin{tabular}{|c|c|c|c|}
\hline Perfuração & $a_{h v}\left(\mathrm{~m} / \mathrm{s}^{2}\right)$ & $a_{h v}$ máx. $\left(\mathrm{m} / \mathrm{s}^{2}\right)$ & $\mathrm{A}(8)\left(\mathrm{m} / \mathrm{s}^{2}\right)$ \\
\hline Primeira & 18,73 & 15,27 & 9,36 \\
\hline Segunda & 13,90 & 27,00 & 6,95 \\
\hline Terceira & 13,98 & 16,74 & 6,99 \\
\hline \multicolumn{2}{|c|}{ Média } & 19,67 & 7,76 \\
\hline
\end{tabular}

Fonte: o autor

Foi observada variação da vibração captada pela mão do operador com pico máximo de $27,00 \mathrm{~m} / \mathrm{s}^{2} \mathrm{e}$ exposição diária referente a 8 horas $\mathrm{A}(8)$ de $7,76 \mathrm{~m} / \mathrm{s}^{2}$, não atendendo ao que preconiza a norma da Fundacentro NHO 10. Considerando o nível máximo aceitável como 2,5 m/s² a utilização do motocoveador 
causando dano ao operador já a partir de 40 minutos de operação, superando o Limite de ação exigindo medidas preventivas.

Ruído: para as avaliações deste agente foi utilizado medidor integrador de fabricação Instrutherm (DOS 600), sendo o microfone fixado próximo a orelha direita, conforme procedimentos propostos pela norma da Fundacentro NHO 01. Os ensaios de ruído e vibração foram realizados simultaneamente. Na Tabela 9 estão apresentados os níveis de pressão sonora projetadas para uma jornada de 8 horas, isto é, a dose de ruído $(A(8))$.

Tabela 9: dose de ruído

\begin{tabular}{|c|c|c|c|}
\hline & Primeira perfuração & $\begin{array}{c}\text { Dose - A(8) \% } \\
\text { Segunda perfuração }\end{array}$ & Terceira perfuração \\
\hline Equipamento 1 & 120,7 & 122,0 & 142,5 \\
\hline Equipamento 2 & 106,8 & 104,9 & 109,4 \\
\hline Equipamento 3 & 98,4 & 103,2 & 102,0 \\
\hline
\end{tabular}

Considerando que o limite de tolerância para o agente ruído, segundo a Norma Regulamentadora n.o 15 é $85 \mathrm{~dB}$ (A) para uma exposição de 8 horas, denota-se pelos dados da tabela acima que a dose diária foi suplantada em todos os ensaios o que poderá causar prejuízos à saúde do trabalhador.

\section{CONCLUSÃO}

As avaliações levadas a cabo e apresentadas neste artigo permitiram compreender o fenômeno da vibração e ruído em motocoveadores, onde foi possível identificar o elevado nível gerado pelo referido equipamento, indicando que o trabalhador não pode ser exposto a estes dispositivos por um período de tempo muito longo.

É importante que os fabricantes estejamatentos à norma NHO 10 da Fundacentro que estabelece os níveis de ação e limite exposição de acordo com a vibração que é transmitida ao sistema mão braço do operador, evitando prejuízo à saúde dos trabalhadores que utilizam estes equipamentos. Desta forma conclui-se quea evolução da legislação de saúde e segurança no trabalho, não é suficiente para proteger os operadores de máquinas e equipamentos, que como demonstrado, apresentam um alto nível de ruído e vibração, desta forma o tempo máximo de exposição ao agente deve ser corretamente estabelecido e obedecido para que não hajaproblemas com a saúde do operador. Não menos importante, são os trabalhadores que estão ao redor do operador da máquina, que devem merecer a mesma atenção, pois estão sujeitos aos mesmos agentes.

Sabe-se que o controle dos agentes estudados tem início no projeto da máquina em fatores como: facilidade de manejo, tamanho, design, massa, que devem ser estudados para mitigar os efeitos nocivos transmitidos aos operadores destes equipamentos. Do exposto no trabalho em foco conclui-se da necessidade de um processo de reengenharia do equipamento visando adequá-lo às normas de segurança e conforto. Os demais agentes e situações expostas e não abordadas no trabalho em tela devem ser consideradas para trabalhos futuros.

Finalizando deve-se considerar que os riscos da exposição a vibrações mecânicas e ruído ocupacional devem seguir o princípio da prevenção em Segurança, Higiene e Saúde no Trabalho, isto é: eliminar o risco na fonte ou reduzi-lo ao mínimo.

\section{REFERÊNCIAS}

[1] BRASIL, Portaria 1339 GM de novembro de 1999, disponível em <http://bvsms.saude.gov.br/bvs/publicacoes/doencas_relacionadas_trabalho_2ed_p1.pdf>, acesso em junho 2017.

[2] BRASIL, Portaria MTE no 1297 de 13/08/2014, Aprova o Anexo 1 - Vibração - da Norma Regulamentadora no 9 - Programas de Prevenção de Riscos Ambientais (PPRA), altera o Anexo 8 - Vibração - da Norma Regulamentadora no 15 - Atividades e Operações Insalubres, e dá outras providências., acesso em janeiro 2018, disponível em <https://www.legisweb.com.br/legislacao/?id=273605>;

[3] CASAGRANDE, R, 2015, o Adicional De Insalubridade: Um Direito Constitucional Trabalhista, Disponível Em <Https://Www.Direitonet.Com.Br/Artigos/Exibir/9195/O-Adicional-De-Insalubridade-Um-DireitoConstitucional-Trabalhista>, Acesso Em Janeiro/2018. 
[4] EUClideS Filho, K.,FOnTES, R. R., CONTINI, E., Campos, F. A. A., 2012, Revista Política Agrícola, Papel da ciência e da tecnologia na agricultura do futuro; disponível em <https://www.alice.cnptia.embrapa.br/bitstream/doc/930906/1/Opapeldaciencia.pdf>, acesso em janeiro 2018.

[5] FUNDACENTRO 2013, Avaliação da Exposição Ocupacional a Vibrações em Mãos e Braços, NHO 10.

[6] GARCIA, Gustavo Filipe Barbosa. Meio Ambiente do Trabalho e Direitos Fundamentais: Responsabilidade Civil do Empregador por Acidentes do Trabalho, Doenças Ocupacionais e Danos Ambientais. Revista IOB Trabalhista e Previdenciária, IOB, 2010.

[7] IIDA, I.,Ergonomia Projeto e Produção, Editora Edgard Blucher, 2005.

[8] ISO - INTERNATIONAL ORGANIZATION FOR STANDARDZATION (ISO 5349) - Mechanical Vibration Measurement and Evaluation of Human Exposure to Hand Transmitted Vibration.Part 1: General Requirements. Part 2: Practical Guidance for Measurement at the Workplace. Genebra, 2001.

[9] MENDES, R., Patologia do Trabalho, Editora Atheneu, 2005

[10] PORTO, Noemia, Associação Nacional dos Magistrados da Justiça do Trabalho, Direitos em Debate, Revista Cipa, n 455,

[11] RAYNAUD, M., On Local AsphyxiaAndSummetricalGengreneof The Extremities, 1969, disponível em <http://archneur.ama-assn.org/>, acesso em junho 2017.

[12] REGAZZI, R. D., XIMENES, G. M.,A Importância da Avaliação da Vibração no Corpo Human,. IMETRO, Rio de Janeiro, Brasil, 2005;

[13] SALIBA, T., M.,Manual Prático de Avaliação e Controle de Vibração,PPRA, 3ạ Edição, Ed. LTr, 2014

[14] Schutzer, V. M.; Santos, J. E. G.; Paschoarelli, L. C., Roçadeiras Costais Motorizadas: Análises Estatísticas Das Variáveis Ergonômicas Avaliadas, 2015, 15 ErgoDesign

[15] SOEIRO, N. S. Vibração e o Corpo Humano: uma avaliação ocupacional. In: 1o Workshop de vibração e acústica, 2011

[16] VENDRAME, A., C. Vibração Operacional. Revista Proteção. 2009.

[17] VENDRAME, A., C., “Aposentadoria Especial: Como Elaborar O PPP E LTCAT - As novidades do Manual editado pela Resolução INSS no 600/2017”, 2017

[18] VENDRAME,A., C.,Vibrações Ocupacionais, $\quad 2005, \quad$ disponível em<http://www.higieneocupacional.com.br/download/vibracoes_vendrame.pdf>, acesso em Junho de 2017.

[19] OSHA, 2005, 0 impacto do ruído no trabalho, disponível em <https://osha.europa.eu/pt/tools-andpublications/publications/factsheets/57>, acesso em janeiro 2019 


\title{
Capítulo 2
}

\section{Análise ergonômica física do ambiente de trabalho de uma indústria de luminárias de emergência}

\author{
Marcos Vinicius Wendpap \\ Robson Luciano de Almeida \\ Adriana Aparecida Dambros da Silva
}

Resumo: 0 presente trabalho apresenta os resultados obtidos na fase preparatória da implantação do programa Gerenciamento da Rotina do Trabalho do Dia a Dia em uma indústria de luminárias de emergência situada na cidade de Toledo, Paraná. 0 objetivo desta fase da implantação foi avaliar os riscos ergonômicos e de acidente presentes no ambiente de trabalho e realizar ações que possibilitassem a eliminação ou mitigação dos mesmos, melhor preparando o ambiente para a implantação do programa. Em seu desenvolvimento, realizou-se avaliações de riscos ergonômicos e de acidentes presentes no ambiente de trabalho, com base em exigências legais, normas regulamentadoras e princípios ergonômicos contidos no manual Pontos de Verificação Ergonômica, elaborado pela International Ergonomics Association (IEA) e traduzido pela FUNDACENTRO. Como resultado, situações com riscos ergonômicos foram minimizadas, como com a eliminação de ferramentas manuais que ofereciam riscos, a troca de assento inadequado dos colaboradores por assento ergonômico e a aquisição de um assento especial para o colaborador com sobrepeso. Da mesma forma, riscos iminentes de acidentes foram eliminados com, por exemplo, a aquisição de carrinhos para transporte, adequação dos moldes de injeção para eliminação da atividade de furação e aquisição de uma plataforma multiuso para a realização das atividades em altura. Além disso, promoveu-se diversos outros benefícios que produziram aumentos consideráveis de produtividade e que tornaram o processo mais fluido, como no caso da eliminação da atividade de furação dos invólucros no processo de pré-montagem.

Palavras-chave: Ergonomia, Ergonomia Física, Manual Pontos de Verificação Ergonômica, Riscos Ergonômicos, Acidentes de Trabalho. 


\section{INTRODUÇÃO}

De acordo com Maciel et al. (2010), é comum observar em pequenas e médias empresas brasileiras condições de trabalho inadequadas resultantes de um planejamento informal dos processos produtivos. Corroborando essa observação, Ferreira (2017), Fernandes (2019) e Ginani (2017) concluíram que em micro e pequenas empresas atuantes nos ramos de usinagem, produção de alimentos e construção civil, muitas vezes as questões relacionadas à saúde e segurança no trabalho eram negligenciadas, seja por irresponsabilidade, desconhecimento ou por falta de condições diversas. Segundo dados do Observatório de Segurança e Saúde no Trabalho, produzido pelo Ministério Público do Trabalho, não é mais possível as empresas se omitirem de tais responsabilidades, visto que, no Brasil, surge uma nova notificação de acidente de trabalhadores com carteira a cada 49 segundos, taxa considerada muito alta em comparação com países desenvolvidos (MPT, 2020).

Apesar de ter surgido uma maior mobilização nos últimos anos dentro das empresas a favor de uma maior segurança no ambiente de trabalho, trazendo bons resultados, a preocupação com a segurança e saúde do trabalho em micro, pequenas e médias empresas brasileiras ainda tem muito a evoluir. Segundo Costa (2007), limitações impostas nas ações para mitigação dos riscos relacionados à saúde ocupacional e segurança nas Pequenas e Médias Empresas (PMEs) surgem devido à limitação de recursos, escassez de informações e incompatibilidade com metodologias desenvolvidas para empresas de grande porte.

No entanto, apesar de parecer ser um problema típico de países em desenvolvimento, a European Agency for Safety and Health at Work (EU-OSHA) esclareceu, via Annual report on European SMEs 2018/2019, que este não é um problema exclusivamente brasileiro e reforçou que a segurança e saúde no trabalho, muitas vezes, não é bem gerida pelas micro e pequenas empresas, principalmente por fatores como restrições orçamentárias, disponibilidade de tempo e dificuldade técnica (EU-OSHA, 2019).

Com foco em melhorias na ergonomia e na segurança do trabalho, também considerando o contexto nacional descrito acima, este trabalho foi desenvolvido em uma indústria de luminárias de emergência situada na cidade de Toledo, Paraná, a qual se preparava para a implantação de um programa de qualidade em seu setor produtivo.

Esta indústria foi fundada em maio de 2014, a partir de um desmembramento de uma prestadora de serviços de montagem elétrica industrial e automação, da qual herdou um ambiente desestruturado e desorganizado. Com o passar do tempo, observou-se grande evolução em suas famílias de produtos e em seu processo produtivo. No entanto, mesmo com o amadurecimento da empresa, o nível de organização melhorou pouco nos primeiros anos, o que acabou justificando a adoção de programas de qualidade para melhoria de sua produção e do seu ambiente produtivo. Entre esses programas, optou-se inicialmente pela implantação do Gerenciamento da Rotina do Trabalho do Dia a Dia (GRD), com o objetivo de proporcionar uma organização geral inicial em todos os setores da empresa.

No processo produtivo realizado na indústria investigada, empregava-se uma mão-de-obra polivalente, em trabalhos majoritariamente manuais, repetitivos e minuciosos, além de haver alto grau de rotatividade nas atividades, o que aparentemente aumentava a possibilidade de riscos ergonômicos nas operações.

Diante desse cenário, com suspeitas da existência de riscos consideráveis no local de trabalho, tanto ergonômicos como de acidentes, que poderiam de alguma forma comprometer a eficácia do programa de GRD, o objetivo deste trabalho foi a eliminação ou minimização desses riscos, de forma a garantir um ambiente seguro para que a implantação desse programa não fosse prejudicada já em sua fase inicial.

\section{REFERENCIAL TEÓRICO}

Segundo a International Ergonomics Association - IEA (2019, n.p, tradução nossa), define-se ergonomia como sendo:

uma disciplina científica relacionada ao entendimento das interações entre os seres humanos e outros elementos ou sistemas, e à aplicação de teorias, princípios, dados e métodos a projetos a fim de otimizar o bem-estar humano e o desempenho global do sistema. Os ergonomistas contribuem para o planejamento, projeto e a avaliação de tarefas, postos de trabalho, produtos, ambientes e sistemas de modo a torná-los compatíveis com as necessidades, habilidades e limitações das pessoas. 
A ergonomia, de acordo com a IEA (2019) conta com três grandes ramos de atuação: a física, a cognitiva e a organizacional. A ergonomia física, foco deste trabalho, segundo a Associação Brasileira de Ergonomia ABERGO (2000), preocupa-se com a relação entre as atividades físicas desempenhadas e as características anatômicas, antropométricas, fisiológicas e biomecânicas dos seres humanos. Logo, preocupa-se com as posturas no trabalho, movimentação de materiais, movimentos repetitivos, distúrbios osteomusculares relacionados ao trabalho, layout do local de trabalho e segurança e saúde.

Segundo Másculo e Vidal (2011) dentre as premissas da Análise Ergonômica do Trabalho (AET), destacam-se: compreensão da situação de trabalho e suas implicações, verificação das competências e restrições ergonômicas, diagnóstico para investigação e priorização de circunstâncias, análise dos postos de trabalho, emissão de pareceres e busca por soluções de melhorias e adequações.

\subsection{NORMAS REGULAMENTADORAS E EXIGÊNCIAS LEGAIS}

Toda organização que tenha empregados regidos pela Consolidação das Leis do Trabalho (CLT) deve adequar-se obrigatoriamente às Normas Regulamentadoras de Segurança e Saúde no Trabalho. Tais normas promovem ações que buscam minimizar os acidentes de trabalho e as doenças ocupacionais (CORREAA; BOLETTI, 2015).

O capítulo V da CLT de 1978, apresenta 37 Normas Regulamentadoras - NRs voltadas à Segurança e Medicina do Trabalho dentre as quais destacam-se para este trabalho:

a) NR 4 - Serviços especializados em engenharia de segurança e em medicina do trabalho (SESMT);

b) NR 5 - Comissão interna de prevenção de acidentes (CIPA);

c) NR 6 - Equipamento de proteção individual (EPI);

d) NR 8 - Edificações;

e) NR 11 - Transporte, movimentação, armazenagem e manuseio de materiais;

f) NR 12 - Segurança no trabalho em máquinas e equipamentos;

g) NR 17 - Ergonomia

\subsection{MANUAL PONTOS DE VERIFICAÇÃO ERGONÔMICA}

O manual Pontos de Verificação Ergonômica foi elaborado pela IEA em parceria com o International Labour Office (ILO) e traduzido para a língua portuguesa pela Fundação Jorge Duprat Figueiredo de Segurança e Medicina do Trabalho (FUNDACENTRO).

Segundo Francisco (2018, p. 20), o manual propõe-se a "solucionar os problemas mais comuns encontrados nas empresas com métodos de fácil aplicação a fim de melhorar a segurança, saúde e as condições de trabalho." Apresenta 132 pontos de verificação distribuídos em oito seções: manipulação e armazenagem de materiais, ferramentas manuais, segurança do maquinário, design do posto de trabalho, iluminação, instalações, substâncias e agentes perigosos, instalações de bem-estar e organização do trabalho.

\section{PROCEDIMENTOS METODOLÓGICOS}

Para o desenvolvimento do trabalho, realizou-se avaliações de possíveis riscos ergonômicos e de acidentes presentes no ambiente de trabalho, com base em exigências legais, normas regulamentadoras e princípios ergonômicos. Foram avaliados os pontos de verificação presentes no manual Pontos de Verificação Ergonômica da IEA relacionados à manipulação e armazenagem de materiais, ferramentas manuais, design dos postos de trabalho, instalações e medidas para o bem-estar, de modo a identificar problemas de solução imediata e baixo custo, bem como problemas que requerem certo investimento, aos quais foram apresentadas sugestões para solução. Também se abordou a relação existente entre o ambiente inadequado e o arranjo físico dos postos de trabalho, empregando o software AutoCAD 2018. Os dados foram coletados por meio de medições e observações diretas do ambiente, utilizando equipamentos e ferramentas como medidor multifuncional ITPM-600 e planilhas do MS Excel. 


\section{RESULTADOS E DISCUSSÃO}

A macroanálise do ambiente de trabalho permitiu a identificação de algumas ameaças ergonômicas e de acidentes. Foi realizada focando no processo produtivo de luminárias de emergência autônomas, reproduzido pelo macrofluxograma apresentado na Figura 1, por serem os produtos com maior número de vendas.

Figura 1 - Macrofluxograma do processo produtivo de luminárias autônomas

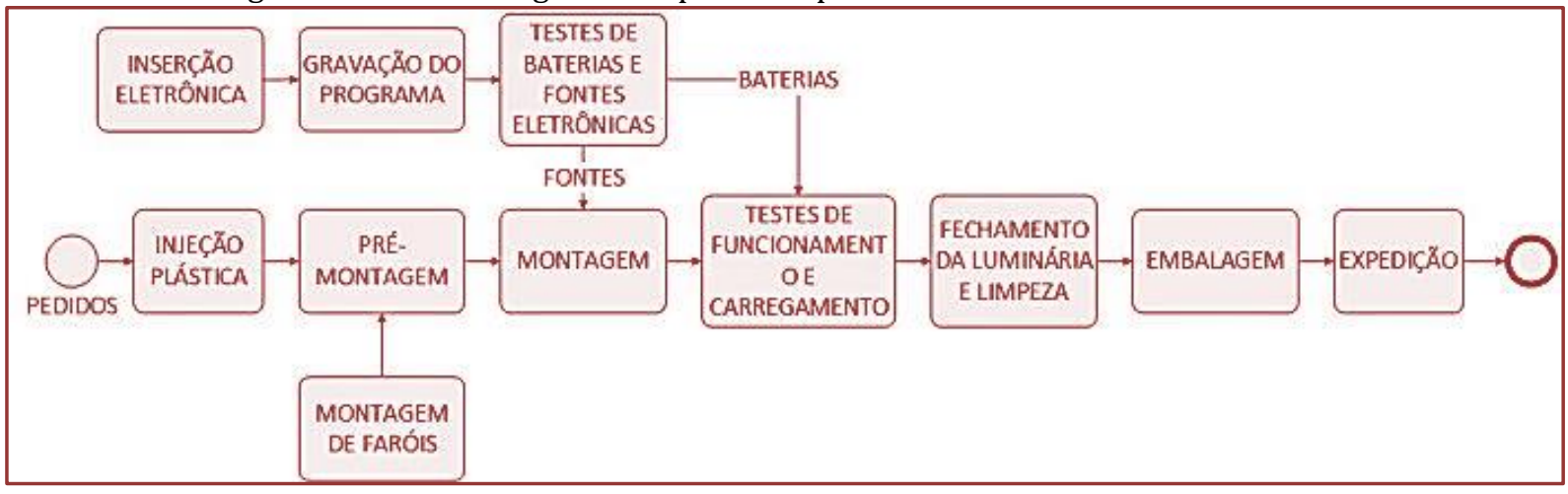

Fonte Os autores, 2019

Na sequência da análise, para uma melhor percepção das instalações da empresa, elaborou-se a planta baixa da organização com a identificação dos setores que a compõe, apresentada pelas Figuras 2 e 3.

Figura 2 - Planta baixa com divisão setorial (térreo)

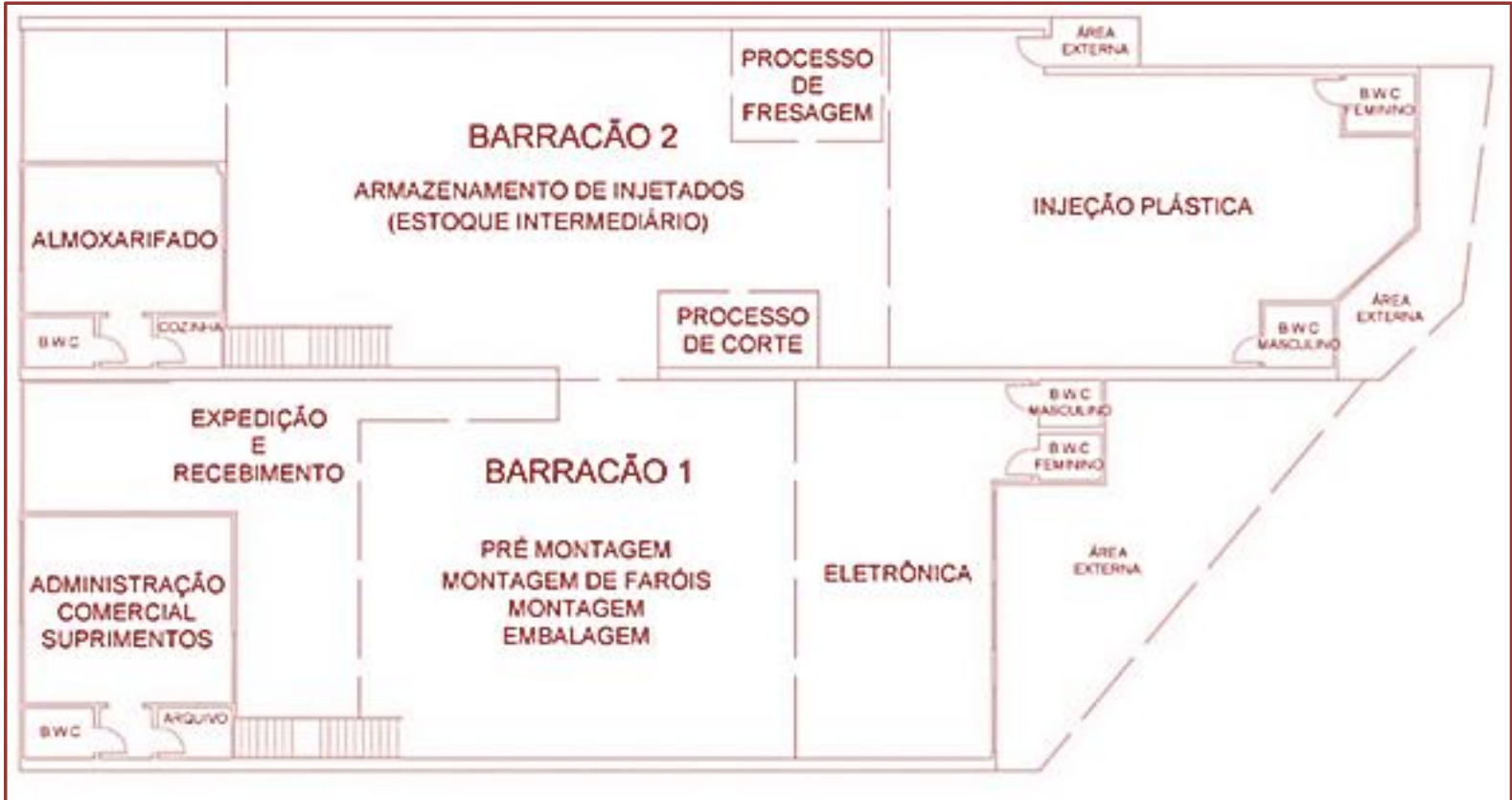

Fonte Os autores, 2019 
Figura 3 - Planta baixa com divisão setorial (primeiro pavimento)

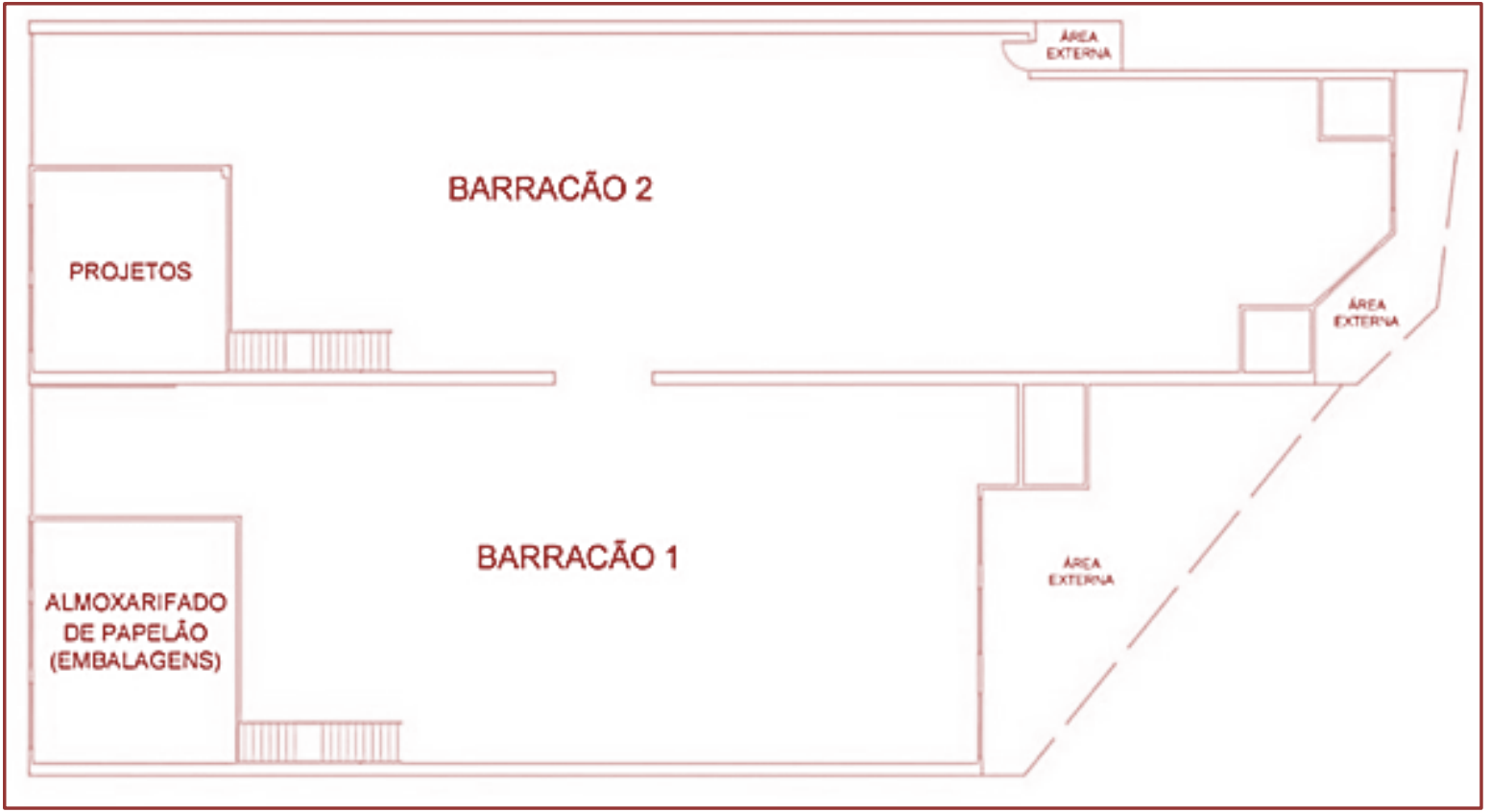

Fonte: Os autores, 2019

Conforme pode ser visto na Figura 2, o espaço físico era composto por dois barracões, identificados como 1 e 2. 0 barracão 1, com aproximadamente $350 \mathrm{~m}^{2}$, abrigava os setores administrativo, montagem, eletrônica, expedição e recebimento, além do estoque de baterias. Já o barracão 2, com aproximadamente $415 \mathrm{~m}^{2}$, abrangia o setor de injeção plástica, as operações de fresagem e corte, o estoque de injetados e o almoxarifado com os materiais utilizados pela eletrônica e montagem.

As ameaças e oportunidades de melhoria identificadas nesta investigação foram organizadas e apresentadas à direção da empresa por meio de um guia, que foi denominado Livro de Recomendações Ergonômicas e de Prevenção de Acidentes. Algumas dessas recomendações foram implantadas e seus resultados e discussões são apresentados a seguir. Outros pontos sugeridos permaneceram em estudo pela empresa para possível implantação futura.

\subsection{MANIPULAÇÃO E ARMAZENAGEM DE MATERIAIS}

No setor de montagem identificou-se, por meio do fluxograma do processo produtivo, uma descontinuidade na sequência das atividades desempenhadas. Isso acontecia, principalmente, porque os postos de trabalho eram dispostos em três linhas contínuas sem designação clara de quais atividades deveriam ser desempenhadas em cada uma delas e também porque a bancada de montagem dos faróis estava disposta fisicamente irregular à sua participação na sequência das atividades. A Figura 4 mostra como era o arranjo físico do setor de montagem antes das melhorias aplicadas. 
Figura 4 - Área produtiva do barracão 1

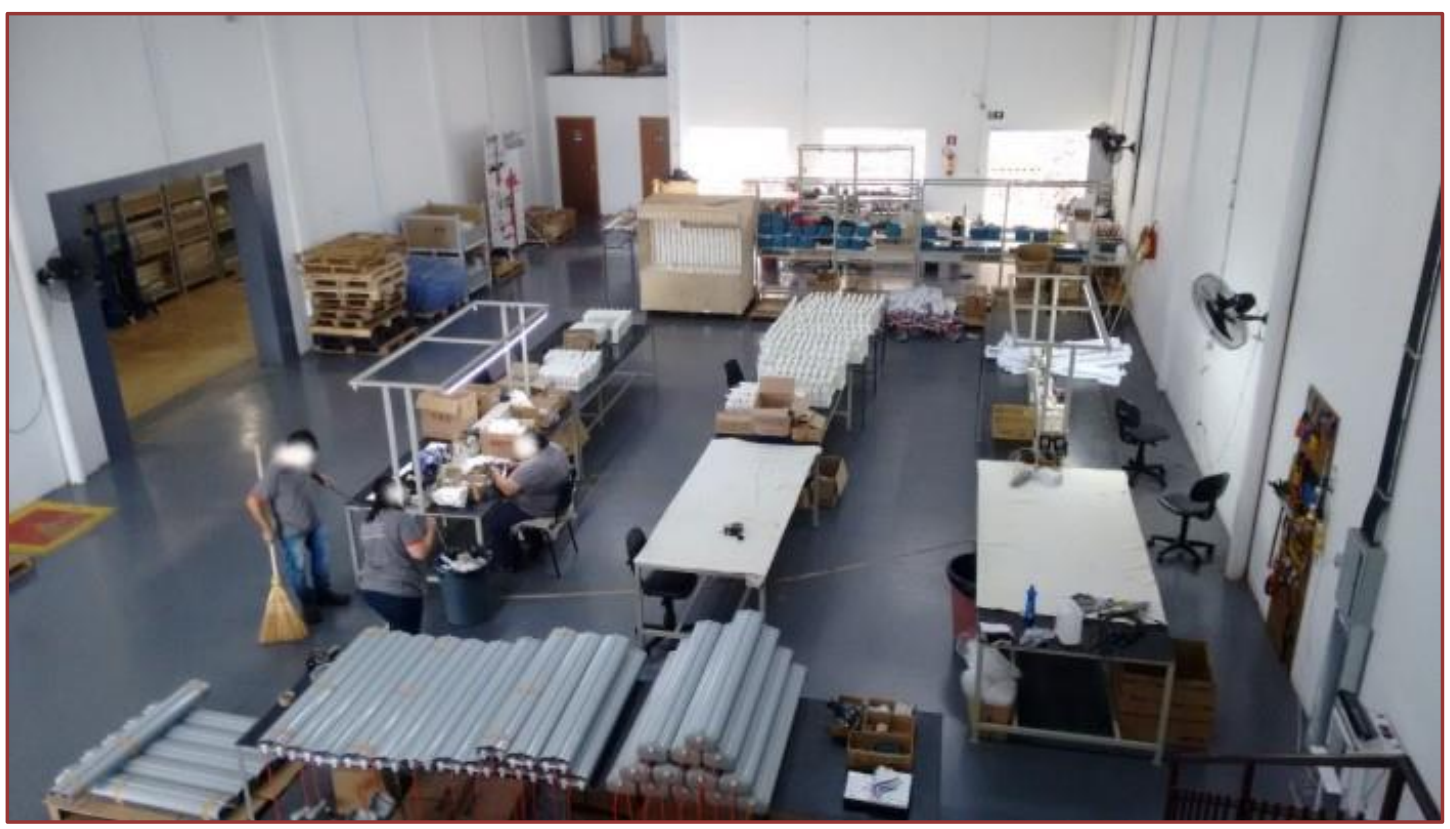

Fonte: Os autores, 2019

Em observância conjunta aos pontos de verificação 1, 2, 5, 83 e 108 do manual, verificou-se a necessidade de redesenhar o arranjo físico do setor de montagem de forma colaborativa, demarcar as vias de transporte, bem como sinalizar as rotas de fuga em caso de emergência, visando minimizar a movimentação de materiais e de pessoas, a ocorrência de acidentes, a obstrução de corredores e a indefinição dos locais de realização das tarefas e do fluxo de produção.

O novo layout foi projetado de modo celular e em formato de "U", de modo que as atividades passaram a ter locais de realização bem delimitados e sequenciais, facilitando o fluxo e reduzindo distâncias entre materiais e operações. A Figura 5 apresenta os postos de trabalho rearranjados e com as vias de transporte demarcadas.

Figura 5 - Área produtiva do barracão 1 após melhoria Fonte: Os autores, 2019

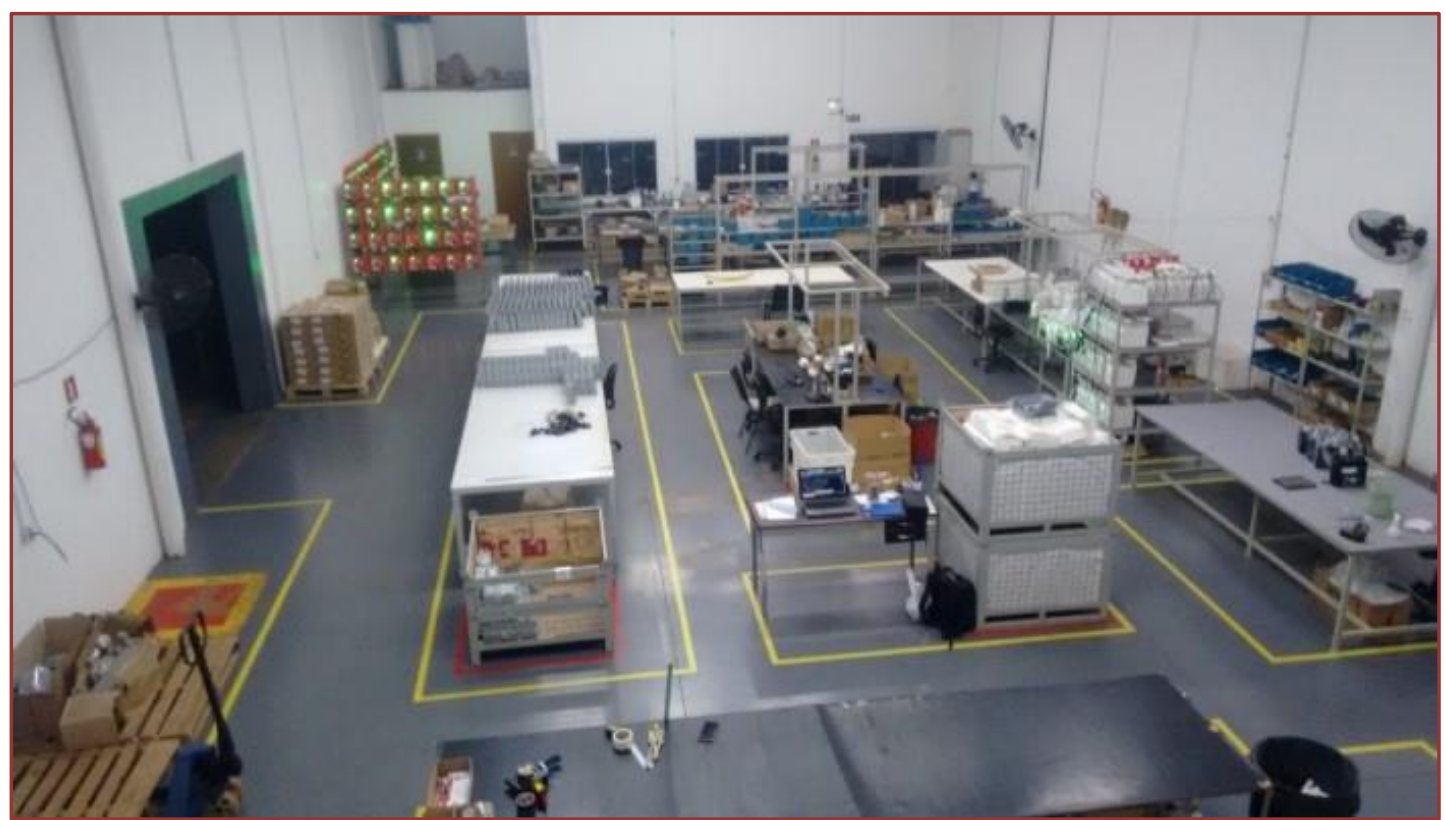


A observação do desenvolvimento das atividades também permitiu identificar práticas de transporte perigosas. Ao buscar materiais injetados no estoque intermediário, os funcionários carregavam o máximo que conseguiam sobre os braços, conforme ilustra a Figura 6.

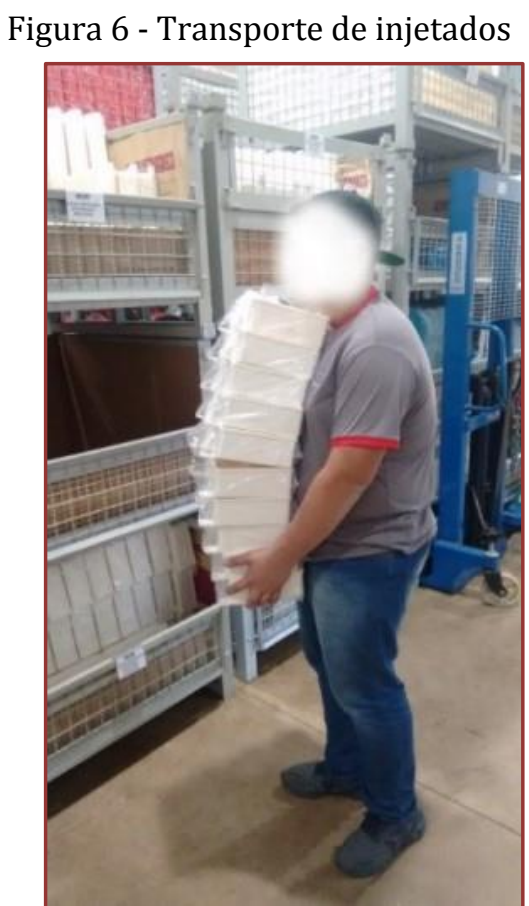

Fonte: Os autores, 2019

Como consequência, frequentemente aconteciam tropeços e quedas de materiais. Além disso, o transporte corriqueiro de caixas de baterias também representava um risco, devido ao peso considerável deste material. Para eliminar esses problemas, conforme observado no ponto de verificação 6, sugeriu-se à direção da empresa que adquirisse dois carrinhos compactos de transporte, com quatro rodas e repartições para a organização dos materiais transportados.

Outra situação observada foi a alta frequência com que os colaboradores se dirigiam ao barracão 2 para buscar ferramentas e materiais, gerando uma longa e morosa atividade de transporte. Em observância ao ponto de verificação 8, realizou-se a fixação de uma prateleira para armazenamento de materiais e ferramentas mais utilizados próxima aos postos de trabalho do setor de montagem. A Figura 7 mostra como era feita a armazenagem de materiais antes da implementação dessa ação e a Figura 8 ilustra como ficou a organização dos materiais após a implementação da ação.

Figura 7 - Armazenagem de materiais antes da implementação de melhorias

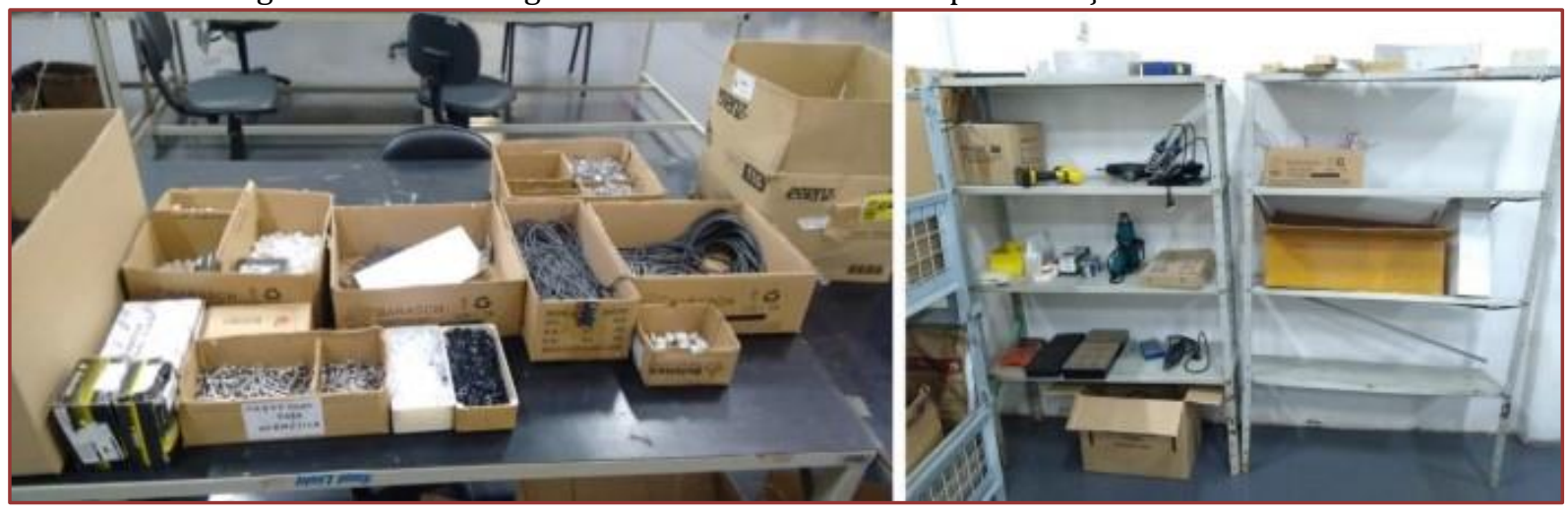

Fonte: Os autores, 2019 


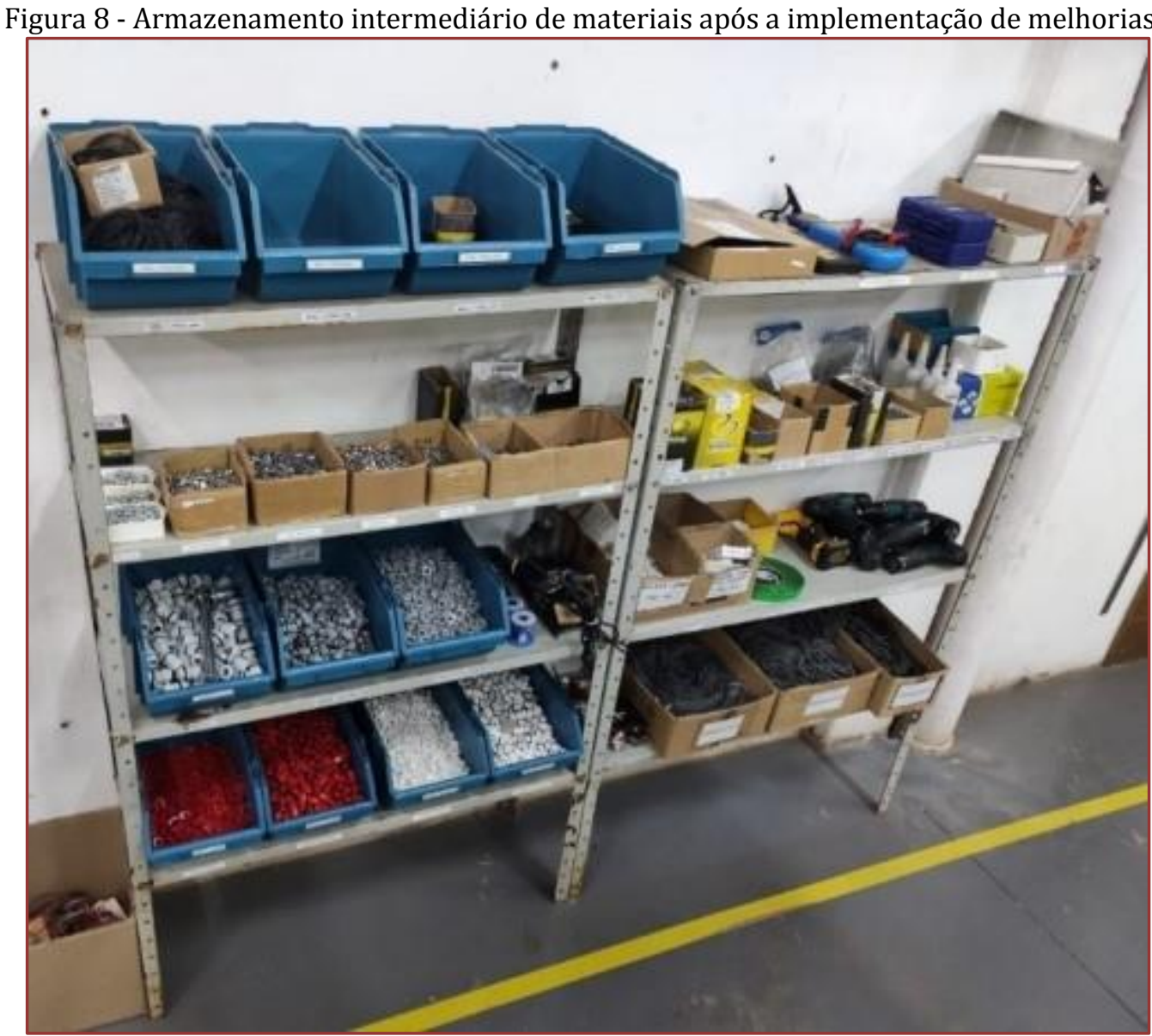

Ainda, considerando as recomendações do ponto de verificação 8 do manual, foi construída uma prateleira para armazenamento de luminárias prontas, evitando que ficassem acumuladas sobre as bancadas de trabalho. A Figura 9 demonstra como eram feitos os testes de funcionamento e carregamento das luminárias antes da construção da prateleira e a Figura 10 evidencia esse processo com a sua utilização.

Figura 9 - Testes das luminárias de emergência antes das melhorias

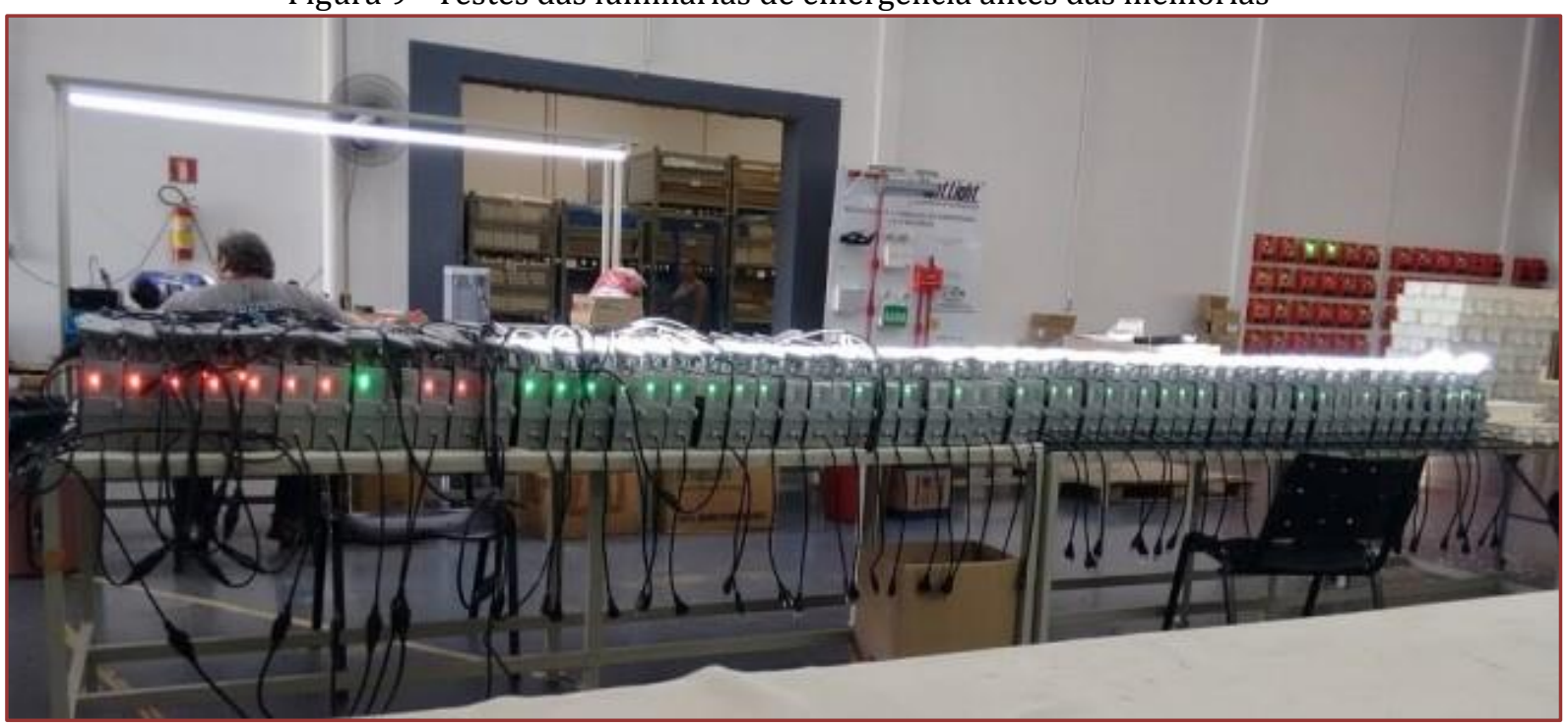

Fonte: Os autores, 2019 
Figura 10 - Prateleira com instalação elétrica para armazenamento das luminárias

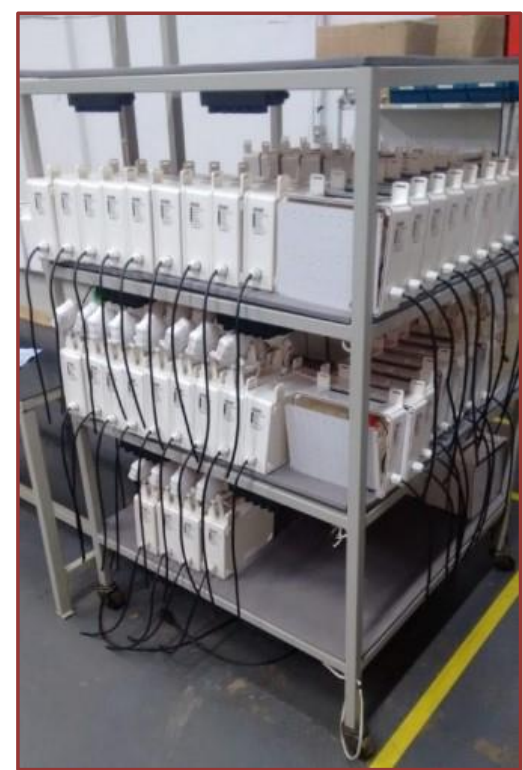

Fonte: Os autores, 2019

Ainda, conforme orientações do ponto de verificação 17, que relata a necessidade de fornecer recipientes adequados e bem localizados para o acondicionamento de refugos, instalou-se caixas plásticas próximas às bancadas de pré-montagem e montagem de faróis para destinação de refugos de peças de injeção e outra para o descarte de refugos de origem eletrônica.

\subsection{FERRAMENTAS MANUAIS}

Dentro do processo de pré-montagem existia a atividade de furação dos invólucros, que era desempenhada de acordo com o modelo de luminária a ser produzida. Em observância ao ponto de verificação 21 do manual, identificou-se nessa atividade um risco iminente de acidentes, visto que a peça furada não contava com nenhum instrumento de fixação que lhe prendesse e garantisse estabilidade durante a furação. Além disso, observou-se nessa atividade recorrentes queixas de cortes nas mãos ocasionados pelas brocas. Deve-se ressaltar ainda que aproximadamente $50 \%$ do tempo de pré-montagem era empregado para essa atividade de furação, ilustrada na Figura 11.

Figura 11 - Atividade de furação realizada no processo de pré-montagem

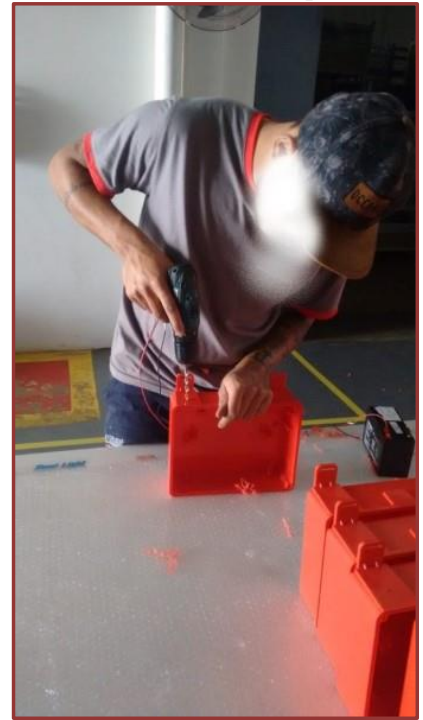

Fonte: Os autores, 2019 
Buscando minimizar os riscos de acidentes presenciados nessa atividade, desenvolveu-se um estudo, em conjunto com o setor de injeção plástica, para implantação de dispositivos do tipo "macho" nos moldes dos invólucros. Como resultado, em todos os moldes de invólucros foram adicionados tais dispositivos, de modo que as peças injetadas passaram a chegar na pré-montagem com as furações já realizadas. Essa ação promoveu maior segurança, comodidade aos colaboradores, ganho em produtividade e agilidade do processo. A Figura 12 mostra a parte interna de um dos moldes de invólucros utilizados, destacando os dispositivos do tipo "macho" e a peça plástica produzida a partir dele. As áreas contornadas em vermelho na peça representam os furos realizados pelos dispositivos do molde.

Figura 12 - Parte interna do molde de invólucro com destaque dos dispositivos tipo "macho" (à esquerda) e peça produzida a partir dele com destaque para os furos realizados pelos dispositivos citados (à direita)
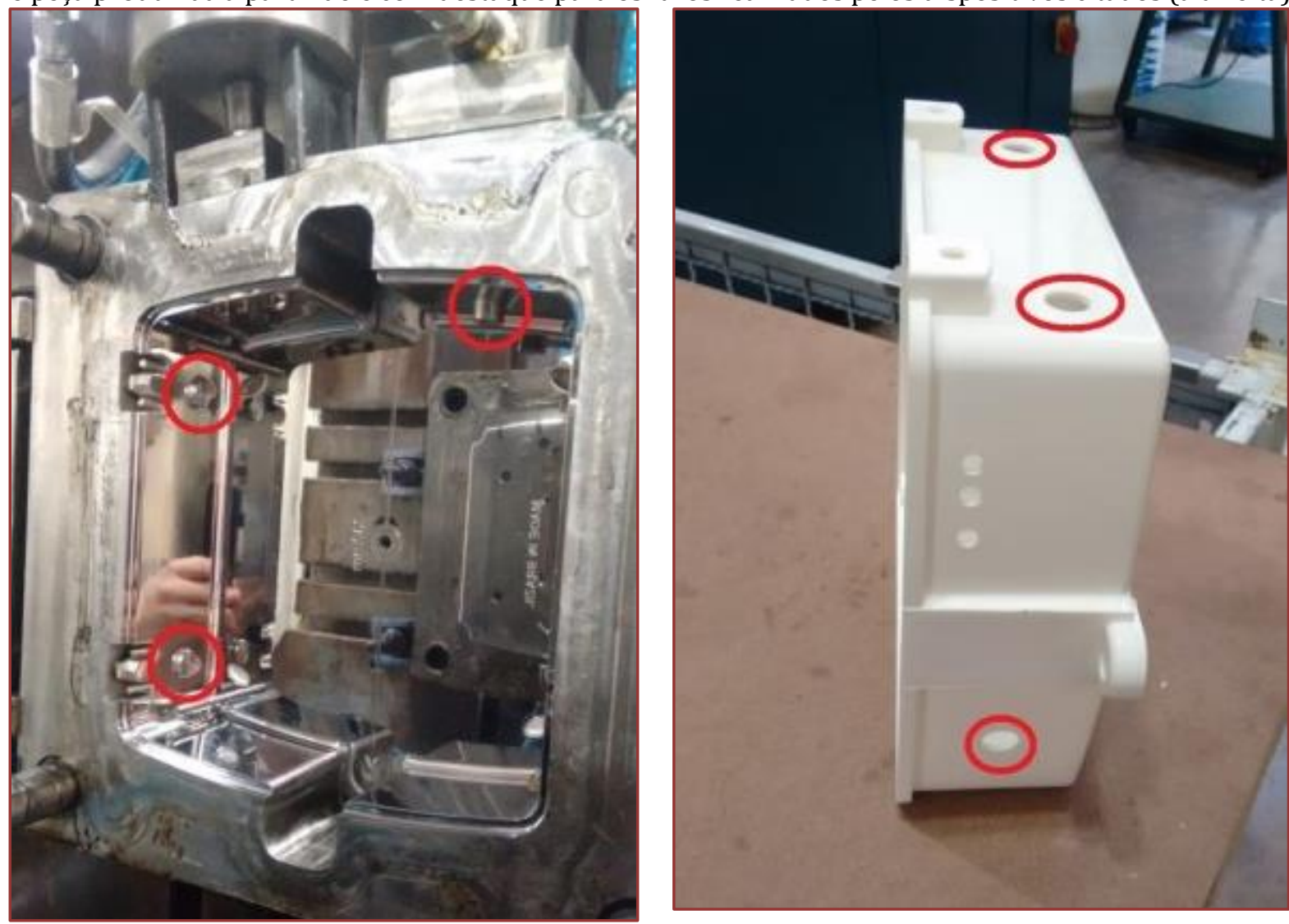

Fonte: Os autores, 2019

Com base no ponto de verificação 18, que alerta sobre a fadiga em pequenos músculos dos dedos, mãos e braços ao trabalhar com algumas ferramentas manuais especiais, realizou-se outra modificação, na atividade de emendas de fiação, dentro do processo de montagem, substituindo-se os terminais/luvas de pressão por terminais de torção, possibilitando que as emendas fossem feitas com menor esforço e sem o emprego de ferramentas desgastantes. Essa mudança é demonstrada na Figura 13. 
Figura 13 - Terminais de pressão e alicate empregados no processo antes da mudança (à esquerda) e terminais de torção empregados após a mudança (à direita)

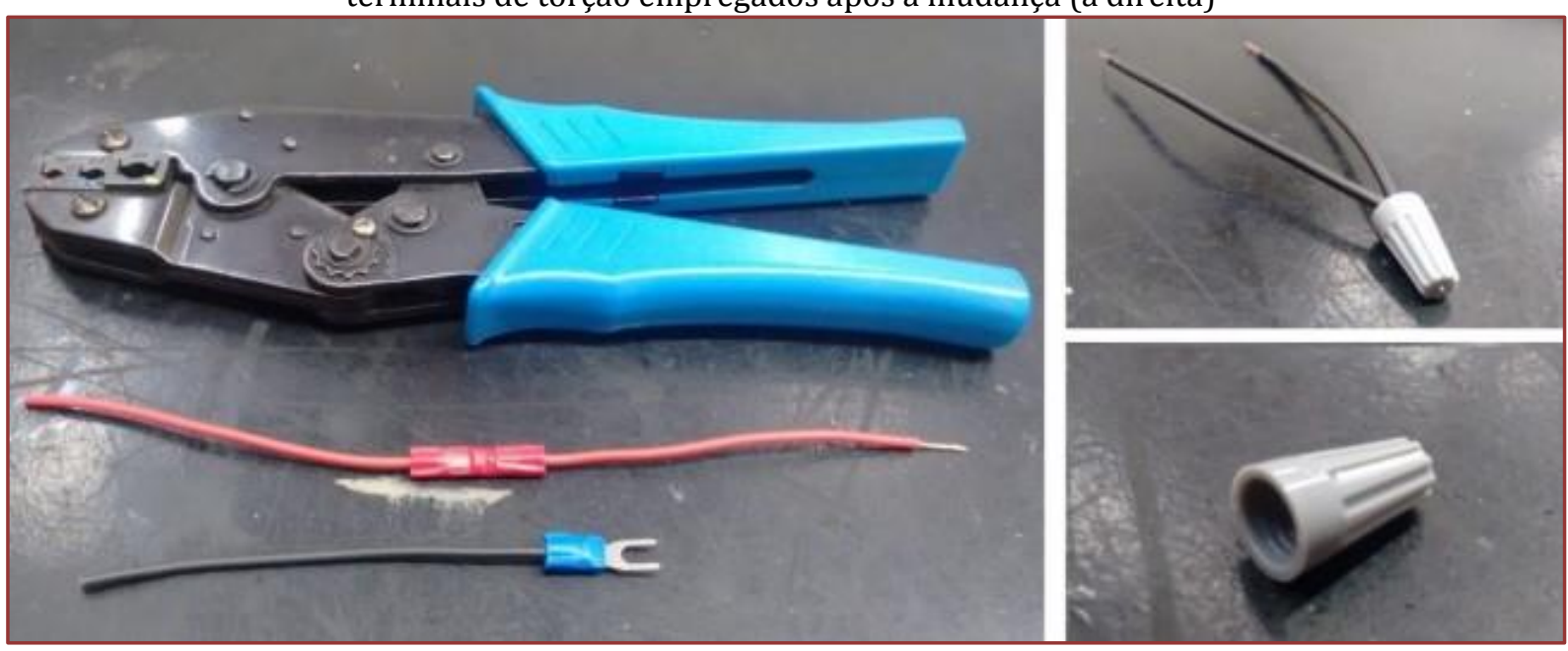

Fonte: Os autores, 2019

\subsection{DESIGN DO POSTO DE TRABALHO}

Em relação à análise feita dos postos de trabalho, verificou-se a necessidade de adquirir duas banquetas elevadas para que os trabalhos em pé pudessem ser intercalados com pausas rápidas para os colaboradores sentarem. Também se indicou a aquisição de duas cadeiras reguláveis comuns para as atividades realizadas na posição sentado, pois algumas das utilizadas pelos colaboradores eram inadequadas sob o ponto de vista ergonômico, além da compra de um assento para colaborador com necessidades especiais devido a sobrepeso. Ambas as situações estão evidenciadas na Figura 14.

Figura 14 - Cadeira ergonomicamente inadequada (à esquerda) e necessidade de assento especial (à direita)
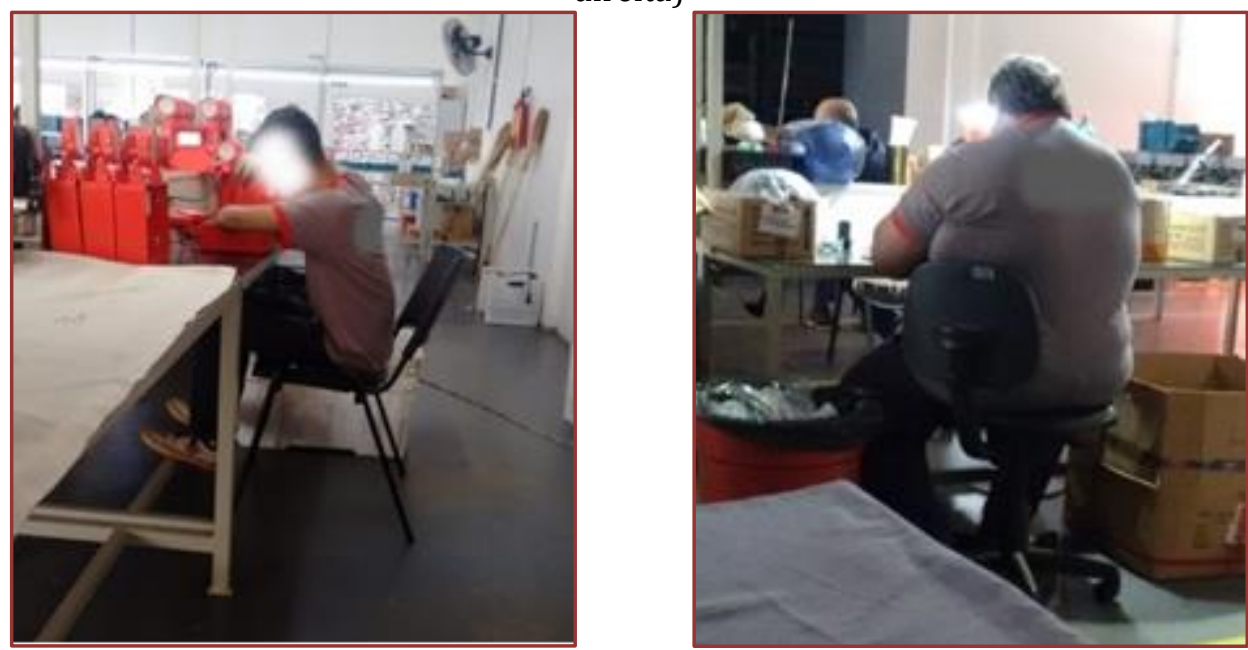

Fonte: Os autores, 2019

Devido aos problemas identificados, as características consideradas na compra dos assentos foram: regulagem de altura, regulagem vertical e horizontal do encosto, serem giratórios, possuírem base com cinco pernas com rodas, serem ergonomicamente confortáveis e construídos de materiais de boa qualidade.

0 ponto de verificação 62 adverte sobre a necessidade de bases sólidas, estáveis e seguras para a realização de trabalhos em lugares altos. Analisando o ambiente da indústria, verificou-se três situações de trabalhos em altura, com risco iminente de acidentes por queda, que são: limpeza das estufas de secagem das máquinas injetoras, reposição das embalagens de papelão no estoque e retirada de materiais injetados do estoque intermediário. A Figura 15 ilustra as três situações. 
Figura 15 - Limpeza da estufa 1 (à esquerda), transporte de embalagens (centro) e retirada de injetados do estoque intermediário (à direita)
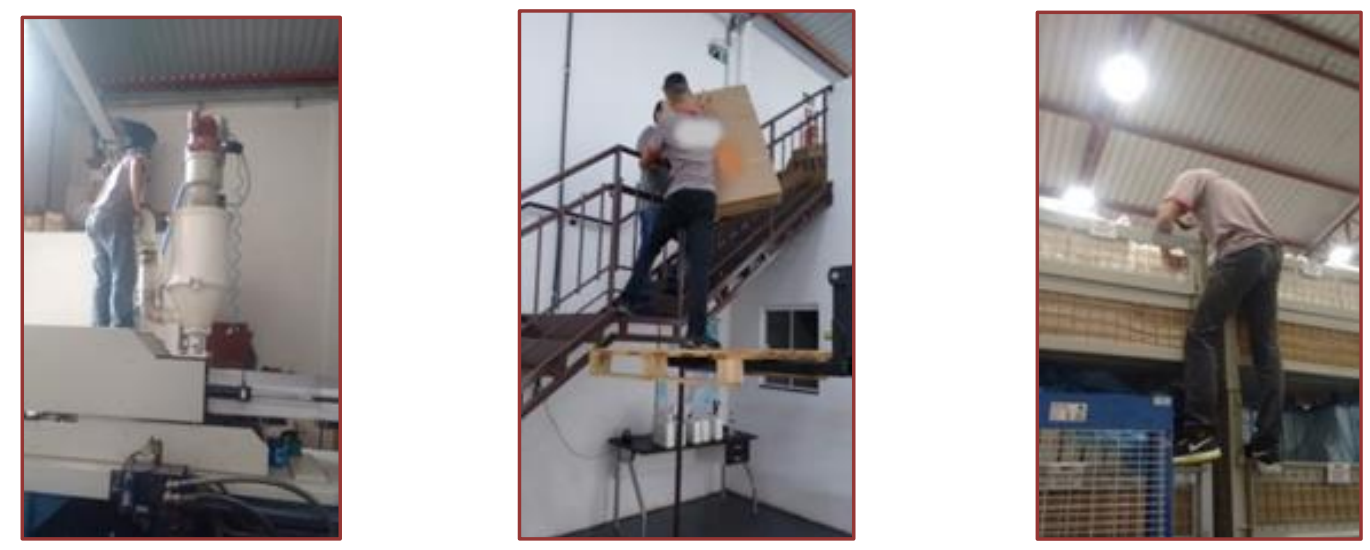

Fonte: Os autores, 2019

Na injetora 2, a estufa de secagem (Figura 16) é posicionada ao lado da máquina sob um suporte móvel, permitindo uma ação de limpeza visivelmente menos perigosa que o da injetora 1, por reduzir em aproximadamente um metro a altura para isso. No entanto, a escada de madeira utilizada (Figura 16) era inadequada para proteção do colaborador, por ser estreita e não apresentar guarda corpo para o caso de desequilíbrio.

Figura 16 - Escada utilizada na tarefa de limpeza da estufa de secagem da injetora 2 (à esquerda) e estufa de secagem utilizada na injetora 2 (à direita)
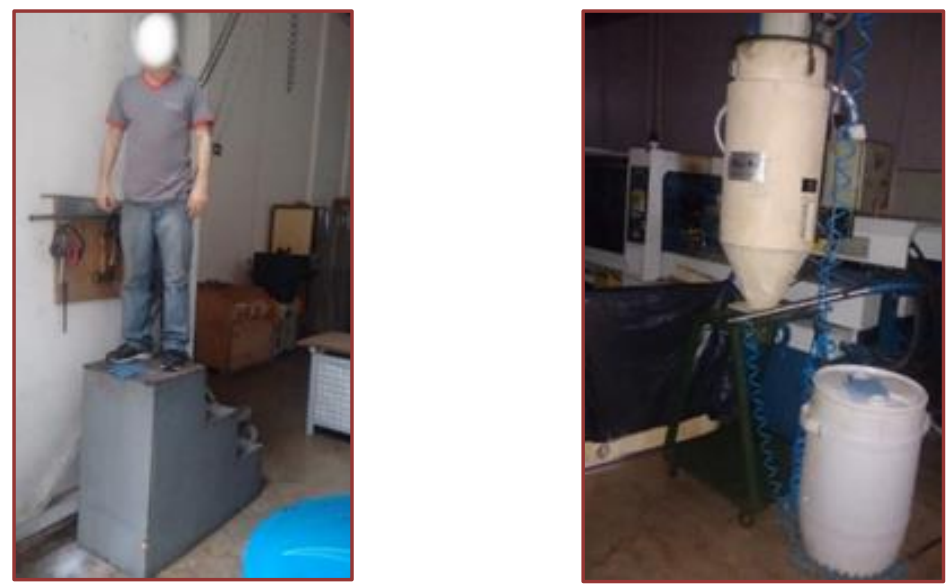

Fonte: Os autores, 2019

A solução encontrada para essas situações foi a confecção de uma plataforma multiuso, com rodas travantes e guarda corpo.

\subsection{INSTALAÇÕES}

0 ponto de verificação 73 do manual adverte sobre propiciar condições de trabalho que minimizem à exposição dos trabalhadores ao calor excessivo. Buscando atender essa recomendação, foram realocados o bebedouro e um ventilador, solicitado a compra de mais um ventilador, e implantadas pausas de 5 minutos por período, para os colaboradores se refrescarem e descansarem.

Esta seção do manual também está associada às disposições das NRs 4 e 5 pois trata de requisitos referentes a segurança e proteção do trabalhador. Portanto, verificou-se também a adequação da empresa à essas normas.

Para verificar a conformidade da empresa à NR 4, que trata dos serviços especializados em engenharia de segurança e em medicina do trabalho, SESMT, identificou-se o enquadramento da empresa na 
Classificação Nacional de Atividades Econômicas, CNAE. De acordo com o Quadro I da NR, a empresa enquadra-se no ramo de fabricação de lâmpadas e outros equipamentos de iluminação, com código CNAE 27.40-6 e, portanto, com grau de risco 3. Como a empresa possuía 18 funcionários, verificou-se que ela não se enquadra no Quadro II da norma. Dessa forma, a empresa pode dar assistência na área de segurança e medicina do trabalho a seus empregados através de SESMT comuns, organizados pelo sindicato ou associação da categoria econômica correspondente, ou ainda pela contratação de um técnico ou engenheiro de segurança do trabalho terceirizado.

A NR 5 trata da comissão interna de prevenção de acidentes, CIPA. Analisando as mesmas classificações utilizadas para a NR 4, o grupo respectivo para dimensionamento da CIPA identificado foi o C-14. Sendo assim, notou-se que a empresa também não se enquadra no Quadro II da NR 5 e que, portanto, deve cumprir o item 5.6.4 da norma, que informa a necessidade de designar um responsável do seu quadro de funcionários (chamado de designado) para averiguar e fazer cumprir as especificações necessárias, podendo envolver os outros colaboradores por meio de negociação coletiva. Seguindo tais orientações, a empresa designou, então, um funcionário para o cumprimento dessas funções, fornecendo-lhe treinamento adequado.

\subsection{INSTALAÇÕES DE BEM ESTAR}

Na seção de substâncias e agentes perigosos, bem como na seção de instalações de bem-estar identificouse diversos pontos de verificação $(91,92,100,101,102,103,104$ e 105) relacionados aos equipamentos de proteção individual (EPIs). Para adequação da empresa à essas recomendações, analisou-se, em conjunto com o manual, a NR 6, que trata justamente desta temática.

0 primeiro passo desta adequação se deu por meio da identificação dos riscos associados às atividades desenvolvidas, salientando que, nessas atividades, avaliou-se primeiramente a possibilidade de eliminação do risco. Dada a não possibilidade de eliminação, passou-se a classificação do risco quanto aos agentes causadores (físicos, químicos, biológicos, ergonômicos, de acidentes). Como resultado desta etapa, produziu-se o mapa de riscos do ambiente de trabalho, apresentado na Figura 17.

Figura 17 - Mapa de riscos do ambiente de trabalho

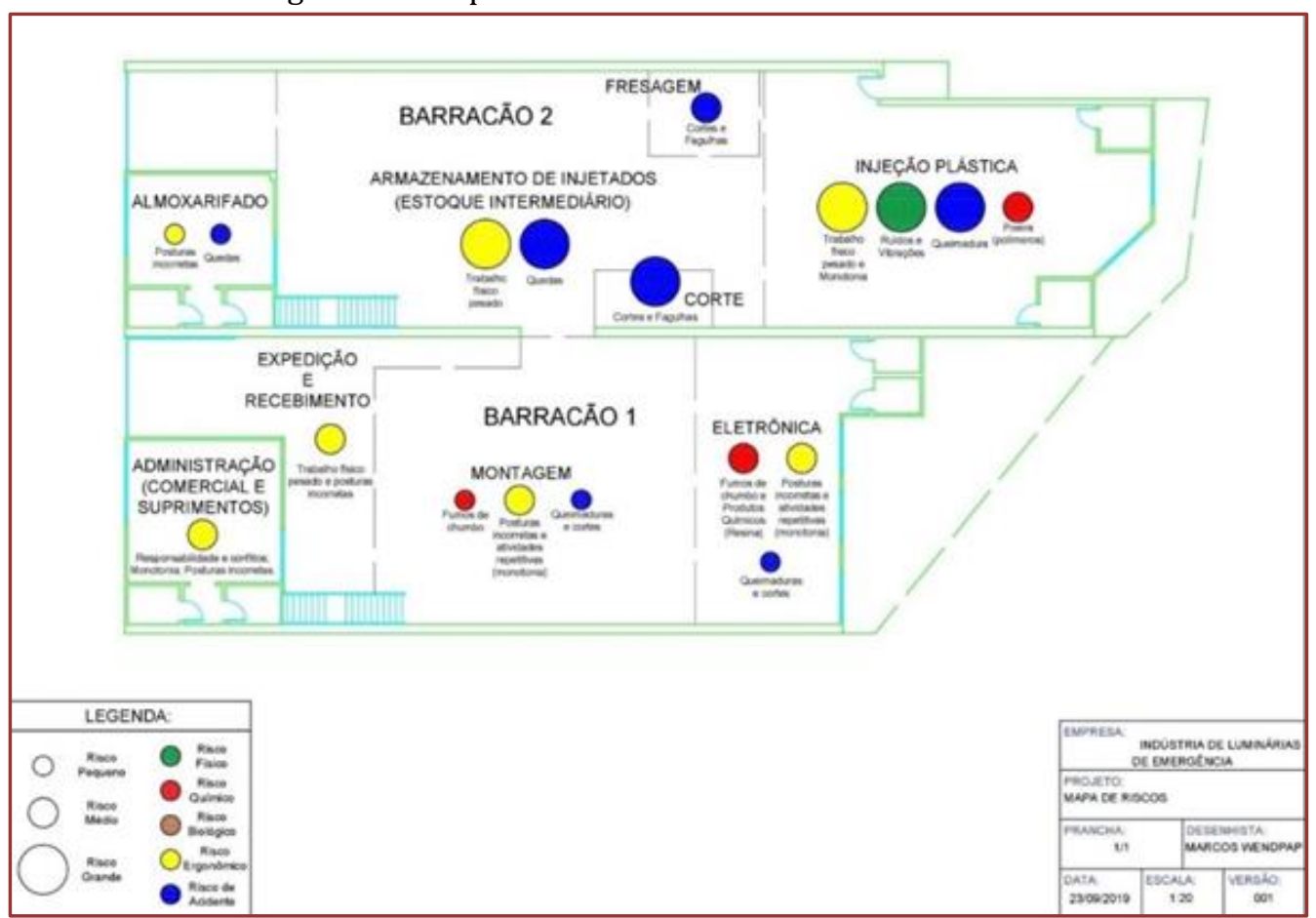

Fonte: Os autores, 2019

Em seguida, buscou-se associar os riscos identificados e não passíveis de eliminação aos EPIs adequados. Nessa etapa criou-se uma lista de EPIs relacionando-os com cada atividade de risco desenvolvida na empresa, exibida no Quadro 1. Com os EPIs definidos, foi realizada a aquisição dos faltantes. Ressalta-se 
que a empresa já possuía boa parte dos equipamentos de proteção listados, mas não exigia o uso pelos colaboradores.

Quadro 1 - EPIs necessários

\begin{tabular}{|c|c|c|c|c|}
\hline EPI NECESSARIO & $\begin{array}{l}\text { AGENTE } \\
\text { CAUSADOR }\end{array}$ & C.A & $\begin{array}{l}\text { ATIVIDADES } \\
\text { DE USO } \\
\text { NECESSÁRIO }\end{array}$ & IMAGEM \\
\hline $\begin{array}{l}\text { Oculos para proteçào } \\
\text { dos oilhos contra } \\
\text { impactos de particulas } \\
\text { volantes }\end{array}$ & $\begin{array}{l}\text { Pós plásticos e } \\
\text { de metais }\end{array}$ & 19625 & $\begin{array}{l}\text { Atividades de } \\
\text { corte com serra, } \\
\text { fresagem e } \\
\text { retifica. }\end{array}$ & \\
\hline $\begin{array}{l}\text { Oculos para proteçào } \\
\text { dos olhos contra } \\
\text { luminosidade intensa }\end{array}$ & $\begin{array}{l}\text { LED's SMD } \\
\text { presentes nOs } \\
\text { produtos } \\
\text { acabados }\end{array}$ & 20030 & $\begin{array}{l}\text { Atrvidades de } \\
\text { teste de } \\
\text { funcionamento } \\
\text { dos P. A. }\end{array}$ & \\
\hline $\begin{array}{l}\text { Protetor auditivo } \\
\text { circum-auricular para } \\
\text { proteçlo do sistema } \\
\text { auditivo contra niveis } \\
\text { de pressảo sonora } \\
\text { superiores ao } \\
\text { estabelecido na NR. } \\
15 \text {, Anexo } n^{\circ}, 1 \text { e2. }\end{array}$ & $\begin{array}{l}\text { Ruidos de } \\
\text { maquinase } \\
\text { equipamentos }\end{array}$ & 14235 & $\begin{array}{l}\text { Atividade de } \\
\text { corte com serra, } \\
\text { trituraçăo e } \\
\text { fresagem. }\end{array}$ & \\
\hline $\begin{array}{l}\text { Peça semilacial } \\
\text { filtrante (PFF2) para } \\
\text { protechlo das vias } \\
\text { respiratonias contra } \\
\text { poeiras, nevoas e } \\
\text { fumos. }\end{array}$ & $\begin{array}{l}\text { Fumos de } \\
\text { chumbo e } \\
\text { resquicios de } \\
\text { polimeros. }\end{array}$ & 38509 & $\begin{array}{l}\text { Ativivades de } \\
\text { solda, de corte } \\
\text { com serra, } \\
\text { fresagem e } \\
\text { rotifica. }\end{array}$ & \\
\hline $\begin{array}{l}\text { Luva para proteçào } \\
\text { das mâos contra } \\
\text { agentes cortantes, } \\
\text { perfurantes, abrasivos } \\
\text { e escoriantes }\end{array}$ & $\begin{array}{l}\text { Laminas de } \\
\text { estiletes, calor } \\
\text { das pecas } \\
\text { injetadas, } \\
\text { brocas, } \\
\text { ferramentas } \\
\text { cortantes. }\end{array}$ & 32034 & $\begin{array}{l}\text { Atividades de } \\
\text { rebarbaçẩo, } \\
\text { furaçato, corte e } \\
\text { injeçăo. }\end{array}$ & \\
\hline
\end{tabular}

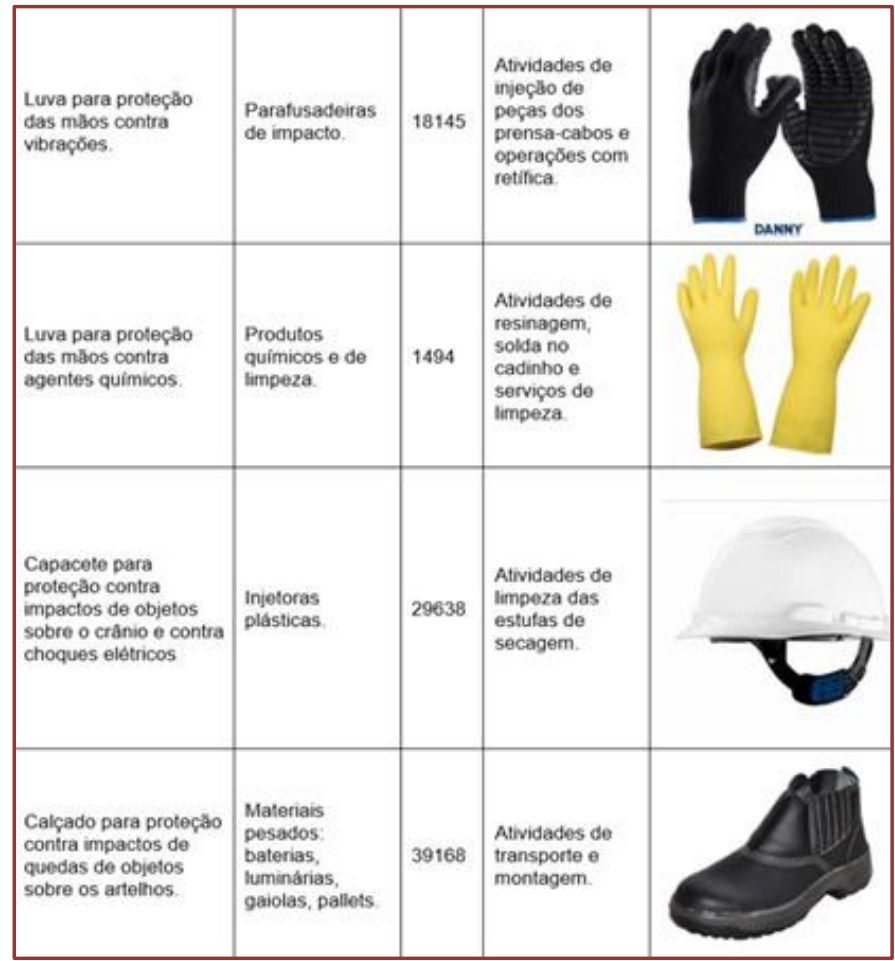

Fonte Os autores, 2019 
Após sanadas as obrigações do empregador, passou-se às responsabilidades dos empregados. 0 fornecimento dos EPIs e a ciência dos colaboradores quanto ao uso foram documentados em fichas de entrega de EPIs adequados às atividades desenvolvidas por cada colaborador.

\section{CONSIDERAÇÕES FINAIS}

A análise ergonômica física do ambiente de trabalho promoveu diversas melhorias no processo produtivo. Em várias operações os riscos ergonômicos existentes foram minimizados, como com a eliminação de ferramentas manuais que ofereciam riscos, a troca de assento inadequado dos colaboradores por assento ergonômico e a aquisição de um assento especial para o colaborador com sobrepeso. Da mesma forma, eliminou-se riscos iminentes de acidentes, como por exemplo com a aquisição de carrinhos para transporte, adequação dos moldes de injeção para eliminação da atividade de furação e aquisição de uma plataforma multiuso para a realização das atividades em altura. Várias outras adequações, neste trabalho não relatadas, foram sugeridas à empresa, de modo que $\overline{\bar{z}}_{\overline{\mathrm{a}}}$ se implantadas à curto e médio prazo, também trarão ganhos significativos de bem-estar aos colaboradores e redução de falhas operacionais.

Além de seu objetivo principal, a análise ergonômica promoveu diversos outros benefícios como: a correta definição do fluxo produtivo, eliminação de atividades de transporte morosas, perigosas e desnecessárias, desobstrução dos postos de trabalho, facilidade de localização de materiais e ferramentas e a subtração de atividades irrelevantes e inseguras, o que produziu aumentos consideráveis de produtividade e tornou o processo mais fluido.

\section{REFERÊNCIAS}

[1] ASSOCIAÇÃO BRASILEIRA DE ERGONOMIA (ABERGO). O que é ergonomia. 2000. Disponível em: http://www.abergo.org.br/internas.php?pg=o_que_e_ergonomia Acesso em: 17 maio 2019.

[2] BRASIL. Ministério Público do Trabalho (MPT). Observatório de segurança e saúde no trabalho. Brasília, 2020. Disponível em: https://smartlabbr.org/sst Acesso em: 03 maio 2020.

[3] CORRÊA, Vanderlei Moraes; BOLETTI, Rosane Rosner. Ergonomia: fundamentos e aplicações. Porto Alegre: Bookman, 2015.

[4] COSTA, Denise da Conceição da. Atenção à saúde nas pequenas e médias empresas de São José dos Campos: estudos de caso. 2007. 179 f. Dissertação (Mestrado) - Curso de Engenharia de Produção, Universidade Federal de São Carlos, São Carlos, 2007. Disponível em: https://repositorio.ufscar.br/handle/ufscar/3556. Acesso em: 03 maio 2020.

[5] EUROPEAN AGENCY FOR SAFETY AND HEALTH AT WORK (EU-OSHA). Occupational safety and health in micro and small enterprises. Disponível em: https://osha.europa.eu/pt/themes/safety-and-health-micro-and-smallenterprises Acesso em: 03 maio 2020.

[6] FERNANDES, Andressa de Souza. et al. Utilização do gráfico homem máquina para melhoria da produção: um estudo de caso em uma fábrica de pastéis. In: ENEGEP - Encontro Nacional de Engenharia de Produção, 39., 2019, Santos. Anais (on-line). Santos: ABEPRO, $2019 . \quad$ Disponível em: http://www.abepro.org.br/biblioteca/TN_STO_297_1677_38144.pdf Acesso em: 03 maio 2020.

[7] FERREIRA, Ivanilda Agustinho. et al. Análise de risco do trabalho: um estudo de caso envolvendo um operador de torno CNC. In: ENEGEP - Encontro Nacional de Engenharia de Produção, 37., 2017, Joinville. Anais (online). Joinville: ABEPRO, 2017. Disponível em: http://www.abepro.org.br/biblioteca/TN_STO_241_399_34802.pdf Acesso em: 03 maio 2020.

[8] FRANCISCO, Vanessa Cristina. Implantação do Gerenciamento da Rotina em uma indústria moveleira. 2018. 75 f. TCC (Graduação) - Curso de Engenharia de Produção, Pontifícia Universidade Católica do Paraná, Toledo, 2018.

[9] FUNDAÇÃO JORGE DUPRAT FIGUEIREDO DE SEGURANÇA E MEDICINA DO TRABALHO (FUNDACENTRO). Pontos de Verificação Ergonômicas: Soluções práticas e de fácil aplicação para melhorar a segurança, a saúde e as condições de trabalho. 2.ed. São Paulo, 2018.

[10] GINANI, Thalis Paulino. et al. Segurança do trabalho: perfil das empresas de pequeno porte da construção civil em Angicos/RN. In: ENEGEP - Encontro Nacional de Engenharia de Produção, 37., 2017, Joinville. Anais (on-line). Joinville: ABEPRO, 2017. Disponível em: http://www.abepro.org.br/biblioteca/TN_STP_241_398_33218.pdf Acesso em: 03 maio 2020.

[11] INTERNATIONAL ERGONOMICS ASSOCIATION. Definition and Domains of Ergonomics: Definition. 2000. Disponível em: https://www.iea.cc/whats/index.html. Acesso em: 17 maio 2019.

[12] MACIEL, Laura Lehn. et al. Fabricação e montagem de móveis: uma análise ergonômica da organização do trabalho. In: SEPROSUL - Semana de Engenharia de Produção Sul-Americana, 10., 2010, Santiago, Chile. Anais (on- 
line). Curitiba: UFPR, 2010. Disponível em: http://www.producao.ufrgs.br/arquivos/disciplinas/385_seprosul_x.pdf Acesso em: 03 maio 2020.

[13] MÁSCULO, Francisco Soares; VIDAL, Mario Cesar. Ergonomia: trabalho adequado e eficiente. Rio de Janeiro: Elsevier, 2011. 


\section{Capítulo 3}

\section{Estudo preliminar sobre desconforto ergonômico em um curso de graduação em Engenharia de Produção}

\section{Glicia Maria Barbosa}

Larissa Beatriz Fonseca Tavares

Hebert Roberto da Silva

Resumo: 0 aprendizado do aluno é influenciado por diversos fatores, tanto interno como externo, o mobiliário escolar, local onde o estudante passa horas sentado. Cadeira e prancheta adequada podem proporcionar maior absorção de conhecimento por parte do aluno, do mesmo modo que o mobiliário inadequado, aquela que causa dores no corpo, provoca incômodo e diminui a vontade de permanecer na aula, prejudicando toda a dinâmica do ensino e aprendizagem. Para que isso não ocorra é necessário haver análise antropométrica e adaptação ergonômica conforme a população de usuários. 0 presente artigo teve por objetivo realizar uma pesquisa com os alunos do curso de Engenharia de Produção de uma Universidade Federal para constatar se existe algum incômodo causado pelo mobiliário utilizado durante as aulas. Foram aplicados questionários com o objetivo de expor os problemas corporais decorrentes do mobiliário da sala de aula e relatar se os incômodos existiam antes ou após ingressar na universidade, e se os desconfortos causados pelo mesmo podem influenciar no aprendizado. Os resultados obtidos mostraram que o mobiliário utilizado causa algum incomodo em todos os participantes, e pouco mais de $64 \%$ dos alunos relataram desconforto corporais causados pela carteira após ingressar na universidade. Com isso, algumas medidas foram propostas para adequação e melhoria do mobiliário universitário da sala estudada.

Palavras-chave: Ergonomia; Antropometria; Conforto do Mobiliário: Alunos 


\section{INTRODUÇÃO}

Segundo Miranda, Pereira e Rissetti (2016), diversos fatores podem influenciar na aprendizagem, sendo um deles o espaço escolar, mais especificamente, a sala de aula. Alguns estudos já comprovaram que condições desfavoráveis de conforto ambiental são causa de mau desempenho dos alunos.

Instituições de ensino com infraestrutura e mobiliário adequado proporcionam uma sensação de bemestar, não somente para o estudante, mas para os professores também, abrindo espaço para oportunidades de aprendizado e a possibilidade do desenvolvimento intelectual, social e profissional. Portanto, é importante considerar a relevância que os impactos da infraestrutura e do mobiliário escolar causam no processo de desenvolvimento de ensino e aprendizagem.

Um dos métodos utilizados para tratar de fatores que estão relacionados a ambientes, estruturas ou hábitos diários que envolvem o ser humano e seus espaços, é a ergonomia. Esses fatores podem influenciar tanto a qualidade de vida quanto no aparecimento de comprometimentos posturais, e nessa perspectiva de qualidade de vida, um dos nortes da ergonomia é a postura.

A ergonomia pode dar diversas contribuições para melhorar as condições de trabalho, visto que, ela estuda a adaptação de todas as situações em que ocorrem o relacionamento entre o ser humano e uma atividade produtiva de bens ou serviços, visando preservar a saúde e o bem-estar do trabalhador (IIDA; GUIMARÃES, 2016).

0 artigo trata-se da análise ergonômica dos alunos do quinto período do curso de Engenharia de Produção da Universidade Federal de Uberlândia, campos Ituiutaba-MG. Têm como principal objetivo diagnosticar constrangimentos corporais causados pelo mobiliário da sala de aula e identificar se os incômodos existiam antes ou após ingressar na universidade.

\section{REFERENCIAL TEÓRICO}

Apresenta um embasamento da literatura sobre o tema e traçam paralelos com pesquisas relacionadas que apoiam e cercam o assunto abordado, possibilitando fundamentar, agregar a devida consistência e nortear o estudo.

\subsection{ERGONOMIA}

Segundo Silva (2018), a ergonomia pode ser entendida como sendo um estudo da interação entre o homem e a forma com que ele realiza seu trabalho, com o objetivo de prevenir os acidentes, corrigir os erros e diminuir os riscos, garantindo o conforto, saúde e segurança do trabalhador.

Conforme Associação Brasileira de Ergonomia (ABERGO), os domínios de especialização da ergonomia são: a ergonomia física que tem uma ligação com a anatomia humana, antropometria, fisiologia e biomecânica relacionada à atividade física; A ergonomia cognitiva que faz menção aos procedimentos mentais, como percepção, memória, raciocínio e resposta motora a medida que causem um efeito nas interações entre os seres humanos e quaisquer outros elementos de um sistema; E a ergonomia organizacional que se refere ao melhoramento dos sistemas sociotécnicos, estruturas organizacionais, políticas e de processos.

A aplicação da ergonomia nos postos de trabalho deve ser feita conforme a atividade desenvolvida, sendo necessário que o profissional analise e se preocupe em obter as informações necessárias de todos os aspectos da atividade humana e de todo campo de ação. É importante ressaltar que a melhoria da eficiência no trabalho não se restringe apenas ao âmbito individual, pois a preservação da saúde dos trabalhadores possui impactos positivos no campo coletivo (MARIA et al., 2019). Essas aplicações possuem classificações que são feitas de acordo com a ocasião, como por exemplo a ergonomia de correção e a ergonomia de participação.

Segundo Iida e Guimarães (2016), a ergonomia de correção é aplicada em situações que já existem para solucionar problemas que refletem na segurança, fadiga excessiva, doenças do trabalhador ou que afetem na quantidade e qualidade da produção. Geralmente já se sabe quais são os problemas a resolver, porém muitas vezes a solução não é totalmente satisfatória. Certas mudanças podem ser fáceis de melhorar, como por exemplo, mudança de postura, aumento da iluminação, colocação de dispositivos de segurança, porém outras não são tão fáceis assim, como a redução de carga mental ou de ruído (SANTOS; FERNANDES; LIMA, 2018). 
A ergonomia de participação busca a solução de problemas ergonômicos envolvendo o próprio operador no caso de um posto de trabalho, ou até mesmo um consumidor, no caso de um produto de consumo, pois os usuários possuem um conhecimento maior em relação aos detalhes que podem passar despercebidos do analista ou projetista (IIDA; GUIMARÃES, 2016). Segundo Merino (2019), nesta forma de contribuição ergonômica, a participação dos usuários diretamente ligados à situação problema é importante pois possui um maior detalhamento da situação, para que as soluções estejam alinhadas às necessidades reais do sistema.

\subsection{PESQUISA EM ERGONOMIA}

Existem duas formas de realizar pesquisa em ergonomia, sendo elas em laboratório ou no próprio campo. A pesquisa de campo serve para analisar o desempenho do projeto na sua condição real de uso, sendo indicada para detectar certos aspectos não previstos no projeto, como por exemplo, os usos não formais do produto ou sistema que os próprios projetistas não tinham presumido (IIDA; GUIMARÃES, 2016).

Segundo Alyrio (2009), é necessário definir quais as técnicas de coleta de dados mais adequado à natureza do tema e as estratégias que serão utilizadas para registro e análise, a pesquisa de campo poderá ser classificada como de abordagem predominantemente quantitativa ou qualitativa, de acordo com as técnicas de coleta, análise e interpretação dos dados.

Uma das técnicas utilizadas para a coleta de dados são os questionários escritos que podem ser abertos ou fechados. Segundo Iida e Guimarães (2016), os questionários abertos são bem semelhantes a entrevistas e demandam bastante tempo para análise, já os fechados apresentam opções para respostas e são fáceis de processar, porém existe ainda a possibilidade de combinar os dois tipos, complementando as questões fechadas com algumas abertas ao final do questionário.

Iida e Guimarães (2016), apresentam as principais etapas para elaboração do questionário, sendo a primeira, realizar um planejamento onde se define os objetivos, prazos e recursos disponíveis, em seguida define-se a amostragem, ou seja, público-alvo, tamanho da amostra e os procedimentos de amostragem, depois vem a construção do questionário, com a definição e ordem das perguntas, layout e o processamento das respostas, após a finalização do questionário é necessário fazer um teste de avaliação, onde o pesquisador vai a campo e aplica os questionários para algumas pessoas e se necessário realiza correções e ajuste das questões, a última etapa consiste no questionário formulado, com a definição das questões e desenho do layout.

\subsection{ANTROPOMETRIA}

A antropometria, juntamente com a ergonomia, trata de minimizar os efeitos do esforço do trabalho perante o trabalhador. De acordo com BATALHA; MEJIA (2016), a Antropometria é o estudo das medidas do corpo humano. Vários fatores são considerados para realizar esse estudo, como por exemplo, sexo, etnia, idade e saúde, mas, como a indústria considera pouco lucrativa a construção de objetos sob medida, foi estabelecido um padrão antropométrico que atenda a maior parte da população.

Segundo Iida (2016), quando uma máquina ou equipamento é projetada para atender a maioria da população de homens norte-americanos, ela também consegue satisfazer um grande número de homens alemães, mas, não a mesma comodidade para homens sul-americanos ou europeus e, muito menos, para mulheres de qualquer etnia. Com isso, podemos dizer que é necessário um estudo antropométrico antes da projeção de qualquer equipamento característico de um grupo de trabalhador ou usuários em específico. A Figura 1 representa um estudo feito com o objetivo de comprovar a diferença corporal entre homens de algumas localidades geográficas distintas. 
Figura 1 - Dados das proporções corporais de algumas etnias

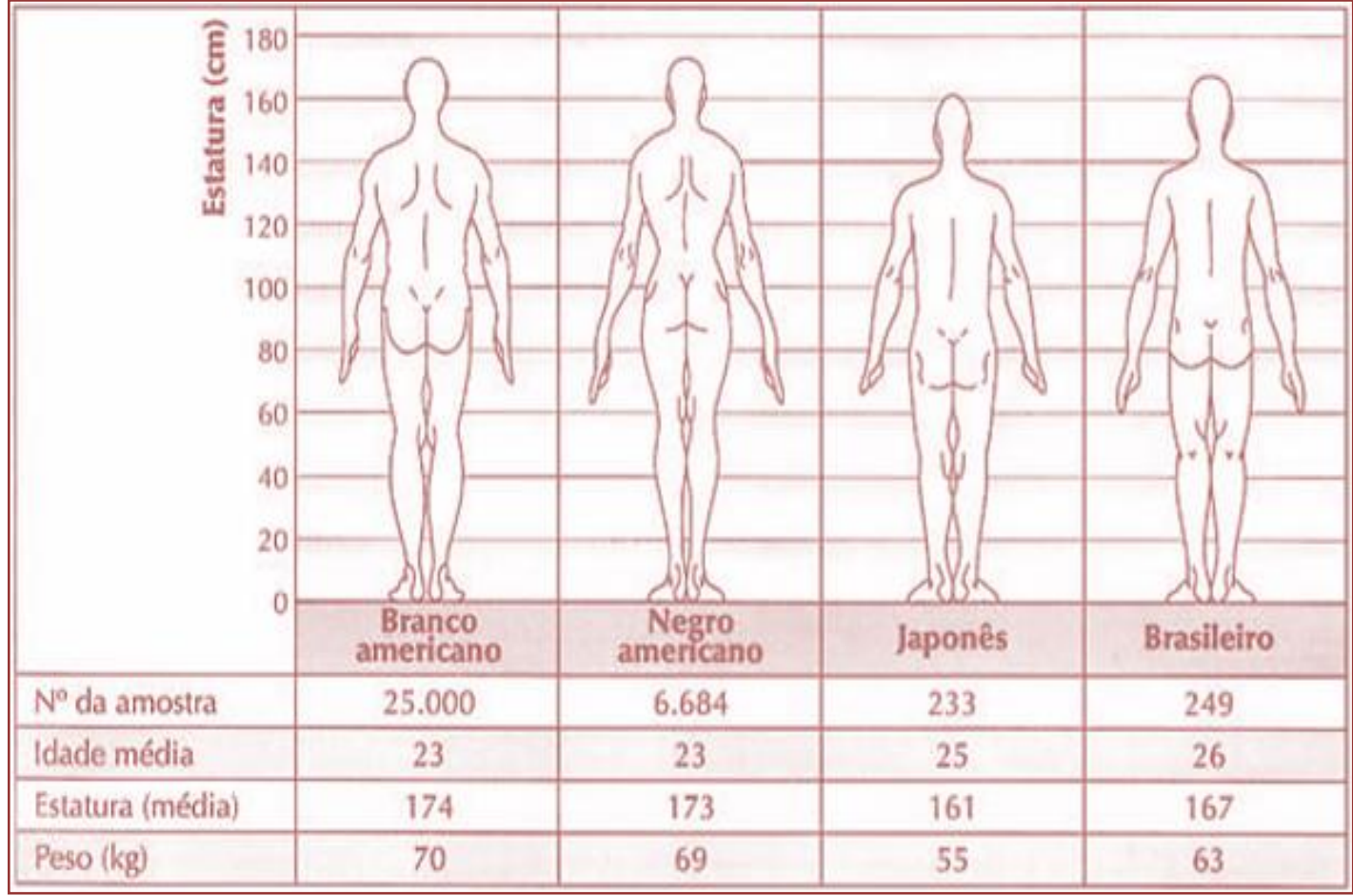

Fonte: Iida, 2016, p. 194

A antropometria, juntamente, com a biomecânica estuda com relevância os movimentos feitos em cada posto de trabalho e a extensão exercida em sua atividade. A biomecânica objetiva a análise postural e suas consequências, está dividida em trabalho estático e dinâmico (MARIA et al., 2019). 0 trabalho estático é caracterizado pelo pouco ou nenhum movimento do corpo, suas medições são feitas através de pontos pré-estabelecidos, já o dinâmico, pela presença do movimento e suas medições são feitas observando o alcance dos membros corporais (WACHOWICZ, 2013).

De acordo com Couto (1995), quando o ser humano se posiciona sentado, de forma incorreta, os discos intervertebrais da coluna lombar sofrem pressão e isso pode gerar uma degradação dos mesmos, acarretando dores ou até mesmo doenças. Para que o corpo não tenha problemas causados pela postura sentado é necessário que os móveis utilizados estejam com as medidas padrões e possuam material adequado, como por exemplo, a angulação feita entre o tronco e as coxas e o assento ser estofado (OLIVEIRA, 2006).

\section{METODOLOGIA}

No presente artigo o tipo de pesquisa empregado foi descritivo e pesquisa de campo, de natureza aplicada com abordagem quali-quantitativa, visto que o objetivo da mesma é descrever as particularidades de um grupo, expondo os problemas corporais causados pelo mobiliário da sala de aula e relatar se os incômodos existiam antes ou após ingressar na universidade.

Neste sentido, foi elaborado dois questionários, sendo um deles composto por perguntas objetivas e discursivas, que permitiram ter dados referentes ao caráter individual e em relação ao assento utilizado pelo aluno durante as aulas. No segundo os alunos responderam a um questionário contendo apenas questões objetivas quanto ao(s) local(is) que sentem desconforto no corpo, referidos antes e/ou após ingressarem na universidade e, para isso, usou-se como modelo o Questionário Nórdico de Sintomas Osteomusculares com adaptações para a presente situação.

O Questionário Nórdico de Sintomas Osteomusculares foi desenvolvido com a intenção de simplificar e padronizar a identificação de sintomas osteomusculares de um documento para outro, sendo um ótimo instrumento de diagnóstico do ambiente ou do posto de trabalho (PINHEIRO; TRÓCCOLI; CARVALHO, 2002). 
Os questionários foram aplicados em uma amostra de 28 alunos do quinto período de Engenharia de Produção da Universidade Federal de Uberlândia no segundo semestre de 2019, com a documentação de consentimento devidamente assinada para manuseio das informações coletadas. Os dados foram tabulados em um software estatístico e extraído as informações relevantes aos questionamentos.

\section{RESULTADOS E DISCUSSÕES}

Este tópico, apresenta os resultados obtidos dos estudos realizados a partir dos questionários aplicados em sala de aula.

\subsection{DADOS OBTIDOS COM A PESQUISA}

A partir da análise dos questionários foi possível identificar que a idade média dos participantes é de 21 a 25 anos, sendo 53,6\% do sexo masculino. Constatou-se também que o peso médio é de 70,76 quilogramas e a altura média é de 1,72 metros.

Um dos levantamentos feitos foi sobre o conforto da cadeira na qual 57,1\% dos alunos disseram que a mesma não é confortável. Em relação à altura, 75\% dos participantes consideraram confortável, 7,1\% muito confortável e 17,9\% pouco confortável. Quando perguntado sobre o conforto do assento da cadeira, $53,6 \%$ consideraram confortável e o restante, $46,4 \%$ pouco confortável. Sobre o encosto, 78,6\% o considera pouco confortável, 17,9\% confortável e 3,6\% pouco confortável. Também foi perguntado sobre a prancheta fixa, utilizada como apoio durante as aulas, sendo que 10,7\% disseram ser muito confortável, $50 \%$ confortável e 39,3\% pouco confortável.

A segurança da cadeira também foi uma questão levantada e grande parte dos participantes, 89,3\%, a considera segura. No que diz respeito a flexibilidade, a maioria considera a cadeira pouco flexível a movimentos, o que não a caracteriza como adequada a todos os corpos. Com relação ao desconforto causado pela cadeira, a Figura 2 apresenta em qual momento os alunos sentiam algum desconforto. A partir desses dados é possível observar que antes mesmo do início da segunda aula a maioria dos alunos sentem algum tipo de desconforto causado pela mobília utilizada.

Figura 2 - Tempo que os alunos sentem desconforto durante o uso da cadeira

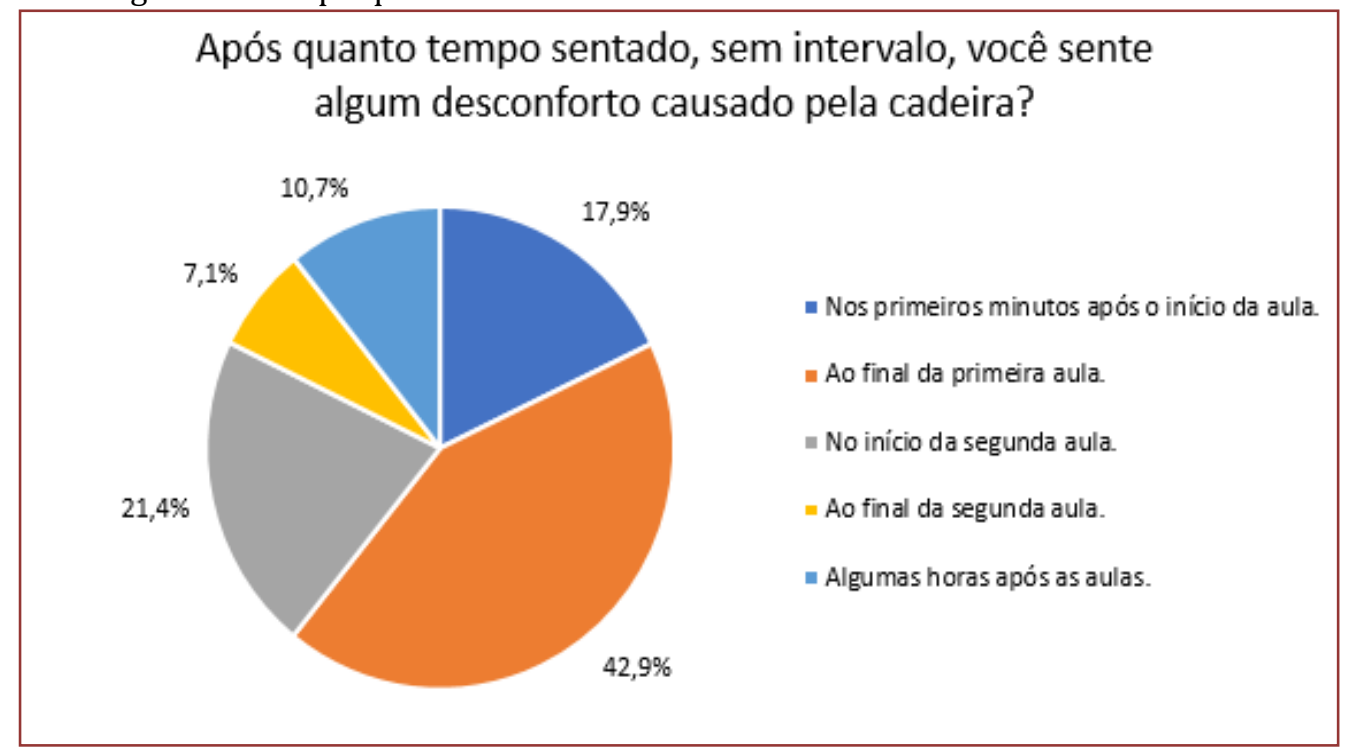

Fonte: Autoria própria

Alguns itens presentes no mobiliário foram questionados em relação a importância, sendo eles, assento com regulagem de altura e de inclinação, assento com estofado e encosto com regulação de altura e inclinação. De acordo com as porcentagens da Tabela 1, é possível verificar que para a maioria dos estudantes, todos os quesitos são muito importantes. Também foi questionado se a cadeira escolar pode influenciar no desempenho educacional e na eficiência da aprendizagem, e 96,4\% dos alunos concordam com essa afirmação. 
Tabela 1 - Porcentagem de relevância para os estudantes

\begin{tabular}{|l|c|c|c|}
\hline & Muito Importante & Importante & Nada Importante \\
\hline Assento com regulagem de altura & $64,3 \%$ & $32,1 \%$ & $3,6 \%$ \\
\hline Assento com regulagem de inclinação & $50,0 \%$ & $42,9 \%$ & $7,1 \%$ \\
\hline Encosto com estofado & $53,6 \%$ & $28,6 \%$ & $17,9 \%$ \\
\hline Encosto com regulagem de altura & $57,1 \%$ & $35,7 \%$ & $7,1 \%$ \\
\hline
\end{tabular}

Fonte: Autoria própria

A aplicação do Questionário Nórdico tem como intenção saber se os discentes apresentavam algum tipo de dor antes ou após ingressarem na universidade e em quais regiões essas dores aconteceram. Do total de 28 participantes, 19 apresentaram um histórico de problemas corporais antes de ingressar na universidade, sendo elas, em uma ou mais partes do corpo. As regiões mais citadas pelos questionados foram coluna lombar e dorsal, como apresentado na Tabela 2.

Tabela 2 - Partes do corpo com problemas antes de ingressar na universidade

\begin{tabular}{|l|c|c|}
\multicolumn{1}{c|}{ Partes do corpo } & \multicolumn{2}{c|}{ Frequência de pessoas } \\
& Com algum problema & Sem problema \\
\hline Pescoço & 4 & 24 \\
\hline Ombros & 6 & 22 \\
\hline Cotovelos & 0 & 28 \\
\hline Punhos e mãos & 5 & 23 \\
\hline Coluna dorsal & 12 & 16 \\
\hline Coluna lombar & 11 & 17 \\
\hline Quadril ou coxas & 1 & 27 \\
\hline Joelhos & 4 & 24 \\
\hline Tornozelo ou pés & 0 & 28 \\
\hline
\end{tabular}

Fonte: Autoria própria

Para mensurar o quanto o problema que ocorreu antes do ingresso na universidade afetou o estudante, foi questionado sobre a procura à um profissional de saúde, como por exemplo, fisioterapeuta ou médico, os quais poderiam ajudar o paciente a minimizar ou tratar as dores e, até mesmo, investigar as causas. No total, $35,7 \%$ de pessoas procuraram algum tipo de ajuda e as causas mais frequentes foi problemas na coluna dorsal e lombar, como indicado na Tabela 3.

Tabela 3 - Quantidade de pessoas que procuraram um profissional de saúde antes de ingressar na universidade

\begin{tabular}{|c|c|c|c|}
\hline \multirow[b]{2}{*}{ Partes do corpo } & \multicolumn{2}{|c|}{ Frequência de pessoas } & \multirow[b]{2}{*}{ Total } \\
\hline & $\begin{array}{l}\text { Procuraram ajuda } \\
\text { de um profissional }\end{array}$ & $\begin{array}{l}\text { Não procuraram ajuda } \\
\text { de um profissional }\end{array}$ & \\
\hline Pescoço & 2 & 2 & 4 \\
\hline Ombros & 3 & 3 & 6 \\
\hline Cotovelos & 0 & 0 & 0 \\
\hline Punhos e mãos & 2 & 3 & 5 \\
\hline Coluna dorsal & 8 & 4 & 12 \\
\hline Coluna lombar & 6 & 6 & 11 \\
\hline Quadril ou coxas & 0 & 1 & 1 \\
\hline Joelhos & 2 & 2 & 4 \\
\hline Tornozelo ou pés & 0 & 0 & 0 \\
\hline
\end{tabular}

Também foi analisado os problemas corporais dos participantes após o ingresso na universidade, como identificado na Tabela 4, sendo que 18 alunos apresentaram algum tipo de incômodo, sendo elas, em uma ou mais partes do corpo. 
Tabela 4 - Partes do corpo com problemas após o ingresso na universidade

\begin{tabular}{|c|c|c|}
\hline \multirow{2}{*}{ Partes do corpo } & \multicolumn{2}{|c|}{ Frequência de pessoas } \\
\hline & Com algum problema & Sem problema \\
\hline Pescoço & 8 & 20 \\
\hline Ombros & 5 & 23 \\
\hline Cotovelos & 0 & 28 \\
\hline Punhos e mãos & 4 & 24 \\
\hline Coluna dorsal & 14 & 14 \\
\hline Coluna lombar & 15 & 13 \\
\hline Quadril ou coxas & 0 & 28 \\
\hline Joelhos & 4 & 24 \\
\hline Tornozelo ou pés & 0 & 28 \\
\hline
\end{tabular}

Fonte: Autoria própria

De acordo com a Tabela 5, dos 28 alunos, apenas 6 procuraram algum profissional de saúde após ingressar na universidade por causa dos incômodos sentidos.

Tabela 5 - Quantidade de alunos que procuraram um profissional de saúde após o ingresso universidade

\begin{tabular}{|c|c|c|c|}
\hline \multirow[b]{2}{*}{ Partes do corpo } & \multicolumn{2}{|c|}{ Frequência de pessoas } & \multirow[b]{2}{*}{ Total } \\
\hline & $\begin{array}{c}\text { Procuraram ajuda de um } \\
\text { profissional }\end{array}$ & $\begin{array}{l}\text { Não procuraram ajuda de um } \\
\text { profissional }\end{array}$ & \\
\hline Pescoço & 3 & 5 & 8 \\
\hline Ombros & 0 & 5 & 5 \\
\hline Cotovelos & 0 & 0 & 0 \\
\hline Punhos e mãos & 1 & 3 & 4 \\
\hline Coluna dorsal & 4 & 10 & 14 \\
\hline Coluna lombar & 5 & 10 & 15 \\
\hline Quadril ou coxas & 0 & 0 & 0 \\
\hline Joelhos & 1 & 3 & 4 \\
\hline Tornozelo ou pés & 0 & 0 & 0 \\
\hline
\end{tabular}

Fonte: Autoria própria

O ajuste da mobília é um dos fatores que pode amenizar os danos que ela causa aos alunos, como por exemplo, flexibilidade de altura da cadeira e da prancheta ou estofamento do assento, são alguns simples ajustes que contribuiriam para o maior conforto do estudante. Alguns desses arranjos poderiam agregar, no mínimo, $80 \%$ de valor ao produto, o que implica em um alto custo da mobília adequada.

\section{CONCLUSÃO}

A partir da análise ergonômica dos alunos do quinto período de Engenharia de Produção, foi possível perceber que o mobiliário da sala de aula causa algum incômodo em todos os participantes, e pouco mais de $64 \%$ dos alunos relataram problemas corporais causados pela carteira após ingressar na universidade. 0 ideal seria proporcionar aos estudantes carteiras com alturas reguláveis ou carteiras com diferentes dimensões, pois, um mobiliário adequado traria benefícios significativos, visto que 96,4\% dos participantes da pesquisa relataram que a carteira pode influenciar no desempenho educacional e na eficiência da aprendizagem.

\section{REFERÊNCIAS}

[1] (ABERGO) Associação Brasileira de Ergonomia. 0 que é Ergonomia. Disponível em: <http://www.abergo.org.br/internas.php?pg=o_que_e_ergonomia>. Acesso em: 20 de dez. de 2019.

[2] ALYRIO. R. D. Métodos e técnicas de pesquisa em administração. volume único / Rio de Janeiro: Fundação CECIERJ, 2009. PDF. 281 p.

[3] BATALHA, P. R.; MEJIA, D. P. M. A importância da antropometria para a ergonomia. Pós-graduação em Ergonomia. $\quad$ Editor: $\quad$ Faculdade $\quad$ Biocursos, $2016 . \quad$ Disponível 
<https://portalbiocursos.com.br/ohs/data/docs/182/79-A_importYncia_da_antropometria_para_a_ergonomia.pdf>. Acesso em: 17 de mar. de 2020.

[4] COUTO, H.A. Ergonomia aplicada ao trabalho: manual técnico da máquina humana. volume único / Belo Horizonte: Ergo, 1995. PDF. 353p.

[5] IILDA. I; GUIMARÃES. L. B. M. Ergonomia: projeto e produção. 3. Ed. São Paulo: Blucher, 2016. PDF. 850 p.

[6] MARIA. L. H; SANTANA. P. V; FREITAS. D. R; GOMES. V. M. C; BARBOSA. L. C. M. Análise ergonômica do setor operacional e administrativo de um posto de trabalho da Polícia militar. In: XXXIX ENCONTRO NACIONAL DE ENGENHARIA DE PRODUCAO (ENEGEP 2019). Anais... Santos, SP: ABEPRO, 2019. Disponível em: <http://www.abepro.org.br/biblioteca/TN_STP_000_1677_37858.pdf>. Acesso em: 30 de mar. de 2020.

[7] MERINO. E. A. D; SILVA. L; CUNHA. J. M; SILVA. I. F; MERINO. G. S. A. D. Avaliação Ergonômica por meio da Eletromiografia de Superfície: Estudo de Caso na Indústria Automotiva. Revista GEPROS. Gestão da Produção, Operações e Sistemas, [S.l], v. 14, n. 5, p. $239 \quad$ - 261, 2019. Disponível em: <https://www.researchgate.net/profile/Lincoln_Silva6/publication/337266036_Ergonomic_Evaluation_by_Surface_E lectromyography_Case_Study_in_The_Automotive_Industry/links/5dcdf0dfa6fdcc7e1381aaee/Ergonomic-Evaluationby-Surface-Electromyography-Case-Study-in-The-Automotive-Industry.pdf $>$. Acesso em: 31 de mar. de 2020.

[8] MIRANDA. P. V; PEREIRA. A. R; RISSETTI. G. A Influência do ambiente escolar no processo de aprendizagem de escolas técnicas. In: VI Seminário Nacional de Pesquisa em Educação, 2016. Anais... Universidade de Santa Cruz: Seminário Nacional de Pesquisa em Educação, 2016 . Disponível em: <https://online.unisc.br/acadnet/anais/index.php/sepedu/article/view/14918/3649>. Acesso em: 07 de abr. de 2020.

[9] OLIVEIRA, J.M. Análise Ergonômica do Mobiliário Escolar Visando a Definição de Critérios. Pós-graduação em Ciência Florestal. Viçosa: Universidade Federal de Viçosa, 2006. Disponível em: <https://www.locus.ufv.br/bitstream/handle/123456789/3125/texto\%20completo.pdf?sequence=1\&isAllowed=y>. Acesso em: 31 mar. 2020.

[10] PINHEIRO. F. A; TRÓCCOLI. B. T; CARVAlHO. C. V. Validação do Questionário Nórdico de Sintomas Osteomusculares como medida de morbidade. Revista Saúde Pública [online], São Paulo, vol. 36, n. 3, p.307-312, jun. 2002. Disponível em: <http://www.scielo.br/pdf/rsp/v36n3/10492.pdf>. Acesso em: 07 de abr. de 2020.

[11] SANTOS, M.; FERNANDES, A. C.; LIMA, A. R. Avaliação ergonômica de estações de trabalho informatizadas. In: SIMPÓSIO DE ENGENHARIA DE PRODUÇÃO DE SERGIPE, 10., 2018, São Cristóvão, SE. Anais... São Cristóvão, SE, 2018. p. 359 - 373. Disponível em: < http://ri.ufs.br/jspui/handle/riufs/10420> Acesso em: 30 de mar. de 2020.

[12] SILVA, C. B. Ergonomia. Trabalho de Conclusão de Curso - Plano de Ensino. Editor: Faculdades IDAAM, 2018. Disponível em: <http://repositorio.idaam.edu.br/jspui/handle/prefix/101>. Acesso em: 17 de mar. de 2020.

[13] WACHOWICZ, M. Ergonomia, Saúde e Segurança do Trabalho. Curitiba: Biblioteca do Instituto Federal de Educação, Ciência $\quad$ e $\quad$ Tecnologia, $2013 . \quad$ Disponível $\quad$ em: http://proedu.rnp.br/bitstream/handle/123456789/1357/Ergonomia\%2C\%20Saude\%20e\%20Seguranca\%20do\%2 0Trabalhado.pdf?sequence=1\&isAllowed=y>. Acesso em: 30 de mar. De 2020. 


\section{Capítulo 4}

Estudo de caso para previsão dos resíduos industriais na produção de catalisadores para a área do petróleo

\section{Marcello Montillo Provenza \\ Marco Antonio Gaya de Figueiredo \\ Paula Martins de Souza}

Resumo: A sustentabilidade ambiental é objeto de estudo há algum tempo por parte de pesquisadores de diversas áreas do conhecimento. 0 objetivo desse artigo foi prever 0 volume de resíduos gerados para atender o mercado consumidor de catalisador. Foram considerados dados gerados entre janeiro de 2005 e maio de 2016 para produção de catalisadores e entre janeiro de 2010 e maio de 2016 para tonelada de resíduo. A previsão da série temporal foi feita através dos modelos médias móveis e alisamento exponencial. A eficácia dos modelos foi testada através de duas medidas: o erro quadrado médio e o erro percentual médio absoluto. Os resultados apontaram que o modelo médias móveis obteve os melhores resultados.

Palavras-chave: Produção de catalisadores; Gestão ambiental; Série temporal; Resíduos industriais. 


\section{INTRODUÇÃO}

Após a ocorrência de diversos acidentes na indústria com consequências negativas para o meio ambiente, houve a criação de legislações ambientais que regulamentam o setor. Isso impulsionou a indústria a investir na gestão ambiental de forma preventiva (DE MARTINI \& GUSMÃO, 2009).

As organizações passaram a ter sua própria política ambiental e a adotar ferramentas de gerenciamento nessa área (MAZZI et al., 2016). A questão ambiental se tornou estratégica porque possui relação direta com a imagem da empresa perante o público, seu desempenho financeiro e sua competitividade (OLIVEIRA, SERRA \& SALGADO, 2010).

Uma vez que, segundo o estatístico e professor universitário William Edwards Deming, não se pode gerenciar o que não se mede, o monitoramento contínuo seja da qualidade dos produtos acabados como dos efluentes industriais é fundamental para o sucesso do programa de gestão ambiental. A partir dos indicadores é possível identificar e corrigir desvios, analisar suas causas e sugerir propostas de melhoria (CAMPOS \& MELO, 2008). Ao observar séries históricas é possível ter uma visão analítica do estado do ambiente, o que contribui como base para a tomada de decisão (EEA, 2014).

Dentro desse cenário, a pesquisa científica possui fundamental importância para a indústria com a realização de estudos que avaliem os indicadores e critérios adotados, as metodologias de priorização dos mesmos e os resultados da sua aplicação na gestão ambiental.

Com base nisso, o presente trabalho tem como objetivo principal propor uma metodologia de análise e previsão de parâmetros possíveis para previsão da geração dos resíduos em função da capacidade de produção de catalisadores de uma indústria. Para isto, serão utilizados os modelos médias móveis e de alisamento exponencial, que tem ampla usabilidade e são de fácil compreensão.

\section{A EMPRESA E OS DADOS}

A empresa selecionada para a elaboração do estudo de caso é uma indústria produtora de insumos para refino de petróleo que possui destaque no seu ramo de atuação, sendo a única fornecedora na América Latina. Sua unidade está localizada em um Distrito Industrial do estado do Rio de Janeiro desde a década de 80 , sendo a maior indústria química do distrito e a terceira maior empresa do polo se avaliado o impacto ambiental. A companhia possui cerca de 500 colaboradores, entre efetivos e terceirizados, e sua produção média de 34.000 t/ano atende ao mercado interno e externo.

Assim, a missão da companhia é fornecer insumos para o refino de petróleo para as indústrias químicas e petroquímicas. Sua visão é ser uma empresa diversificada, líder no mercado sul americano na sua área, estabelecendo-se de forma rentável, competitiva e socialmente responsável. Seus valores são responsabilidade pelo bem comum, responsabilidade pelo todo, comprometimento, disciplina, confiança, trabalho em equipe, fazer acontecer, inovação e excelência. Por questão de sigilo contratual, não será divulgada a razão social da empresa, seu tipo de produto ou qualquer fluxograma de processo.

A indústria destaca-se pela obtenção das certificações ISO 9001 - Sistema de Gestão da Qualidade, ISO14001 - Sistema de Gestão Ambiental e OHSAS 18001 - Sistema de Gestão da Segurança e Saúde Ocupacional, pela conquista de prêmios e por diversas iniciativas de remediação e minimização de riscos na área socioambiental.

A gestão ambiental da empresa analisa indicadores específicos de processo. Há também um índice que avalia a adequação dos indicadores ambientais à legislação, porém ele é binário (sim ou não). Todavia, uma vez que a indústria se adequa à todas as legislações ambientais vigentes, esse índice se torna constante com valor igual a $100 \%$.

A empresa estudada foi escolhida não só pela sua relevância na área em que atua, como também pela preocupação com a área ambiental e disponibilidade em ceder seus dados de processo e participar da pesquisa.

Basicamente as matérias primas alimentam a área de preparo da suspensão de alumina e a área de preparo da Zeólita. Tanto a suspensão de Zeólita como a de Alumina alimentam a área de preparo de catalisador Bruto. Na sequência a suspensão alimenta o sistema de Secagem por Spray Drier. 
O material sólido sofre um processo de Lavagem sendo submetido a um posterior processo de secagem por Flash, sendo obtido o produto final que é transferido para a área de estocagem.

Em termos de monitoramento, a empresa, por ser certificada nas normas ISO 9000 e 1400, tem o registro periódico das perdas identificadas nas emissões atmosféricas, nos efluentes aquosos e nos parques de armazenamento.

A série histórica sobre a produção de catalisadores é compreendida entre janeiro de 2005 e maio de 2016, e a tonelada de resíduo e o percentual de perda entre janeiro de 2010 e maio de 2016. Para realização deste trabalho, foram utilizados os softwares Excel e $\mathrm{R}$, tendo em vista a aplicabilidade operacional de cada um.

\section{METODOLOGIA}

Séries temporais são agrupamentos observados sobre uma variável coletadas sequencialmente no decorrer do tempo e registrados em períodos constantes. Portanto, pode- se expressar que uma série temporal é a realização característica de um processo probabilístico (BOX et al., 2015). Algumas etapas devem ser efetuadas para analisar uma previsão temporal: inicialmente, avalia-se graficamente a série, podendo ser levantadas algumas hipóteses. Através de testes estatísticos, verifica-se se a série possui estacionariedade e sazonalidade para, assim, realizar o ajustamento dos modelos. Para avaliação e comparação entre os métodos, tem-se as medidas de erro de previsão.

O coeficiente de Spearman é um teste não paramétrico baseado na correlação de postos. Os dados são analisados em pares que são postos ou que podem ser convertidos em posto, deste modo, mede a intensidade da relação entre variáveis ordinais (usa, em vez do valor observado, apenas a ordem das observações). Este teste pode ser usado para detectar algumas relações que não são lineares (SIEGEL \& CASTELLAN, 1988).

o teste de Kruskal-Wallis, assim como o coeficiente de Spearman, é um teste não paramétrico, porém, o procedimento é bem diferente, pois a ideia é analisar um conjunto de grupos dentro da série, que no caso deste estudo são os meses. 0 procedimento inicial é ordenar do conjunto de valores da variável, onde cada uma das observações irá receber um posto correspondente. Depois, deve-se somar os postos de cada mês (grupo) e calcular a estatística de teste, na qual pode ser aproximada pela distribuição Qui-Quadrado (SIEGEL \& CASTELLAN, 1988).

Segundo Morettin e Toloi (2006), uma grande classe de métodos de previsão, que tentam tratar as causas de flutuações em séries de tempo, é a dos Métodos de Alisamento (também conhecidos como Métodos de Suavização). Essas técnicas são usadas para se obter o padrão básico da série assumindo que os valores extremos são representados pela aleatoriedade. Deste modo, os modelos utilizados neste trabalho foram: Médias Móveis, Alisamento Exponencial Simples, Alisamento Exponencial Linear de Brown, Alisamento Exponencial de Holt, Alisamento Exponencial Sazonal de Holt-Winters. Todas as previsões foram feitas um passo à frente.

É muito importante monitorar os erros de previsões periódicas quando executadas, e esses erros devem estar em limites aceitáveis, pois revela a decisão se representa um bom ajuste dos dados. Há varias métricas de previsão para aferir se um modelo é bom ou não, das quais envolvem valores absolutos ou percentuais. As utilizadas neste estudo foram o Erro Quadrático Médio (EQM) e o Erro Médio Percentual Absoluto (EMPA).

\section{RESULTADOS}

Para verificação de possíveis erros humanos, tais como digitação, a série da produção de catalisadores foi agregada em um único gráfico juntamente com o volume do consumo de água da empresa. Deste modo, caso as séries se comportem de maneiras parecidas, pode-se deduzir que não houve alguma interferência externa nos dados. Sendo assim, a Figura 1 representa a produção de catalisadores e o consumo de água no período compreendido entre janeiro de 2005 e abril de 2016. Como os valores das duas séries são discrepantes, o gráfico apresenta dois eixos: o eixo da esquerda representa os valores da produção de catalisadores e o eixo da direita o volume do consumo de água. 
FIGURA 1 - Produção de catalisadores e consumo de água.

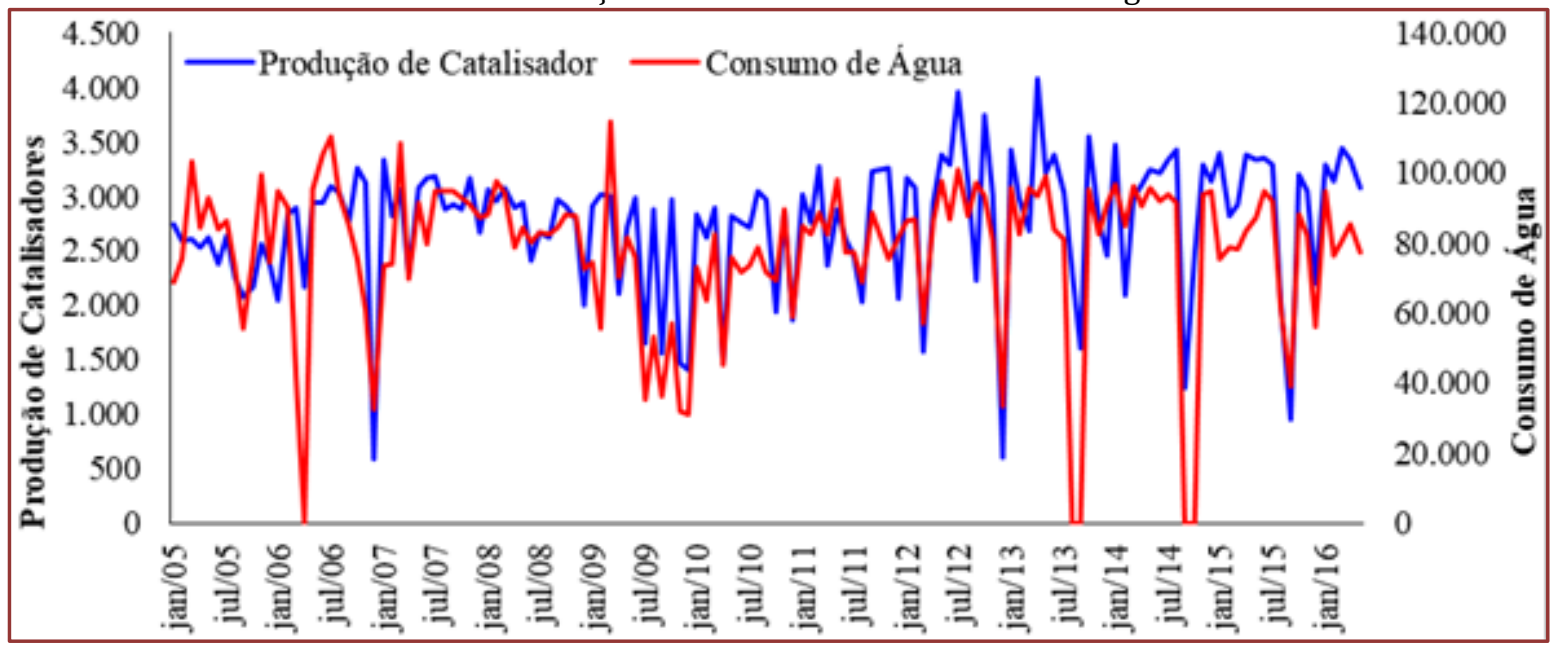

A Figura 2 revela a produção de catalisadores entre janeiro de 2005 e abril de 2016 e a produção de tonelada de resíduo entre janeiro de 2010 e abril de 2016. Como os valores das duas séries são discrepantes, assim como no anterior, este gráfico também apresenta dois eixos: o eixo da esquerda representa os valores da produção de catalisadores e o eixo da direita a produção de tonelada de resíduo.

FIGURA 2 - Produção de catalisadores e tonelada de resíduo.

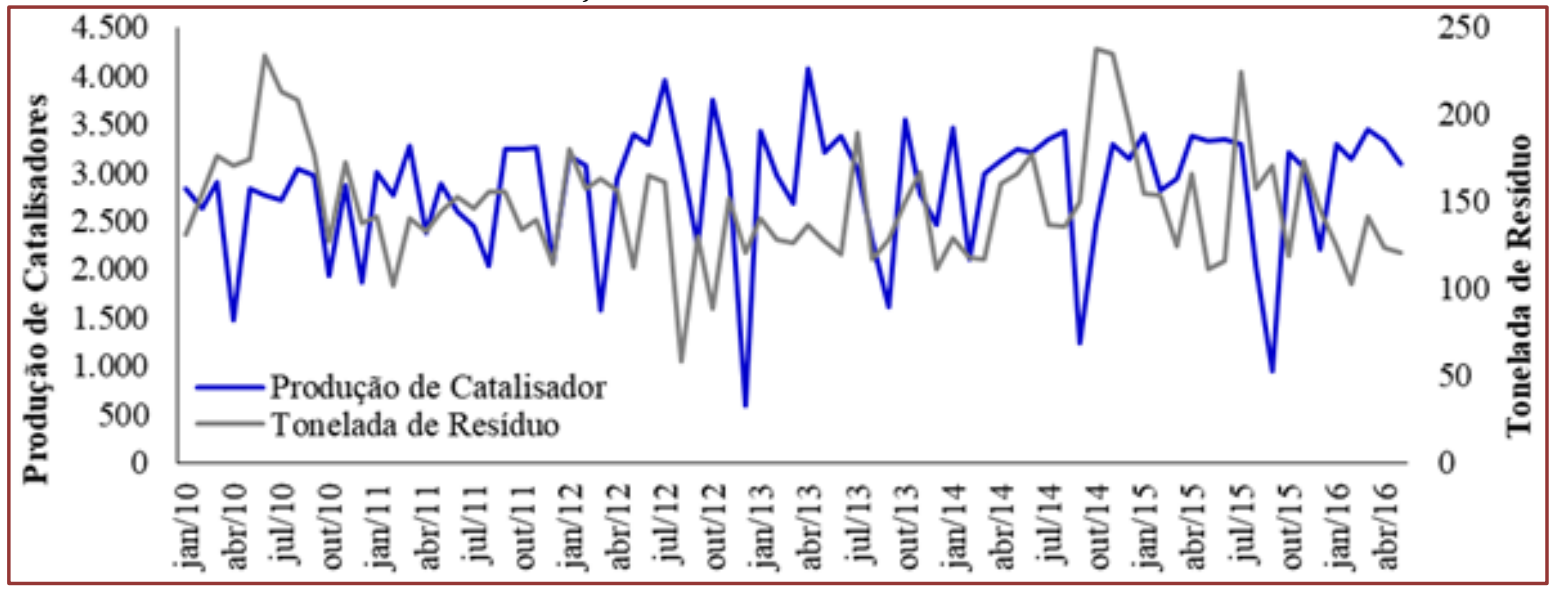

Na Figura 3 tem-se o percentual de perda da fábrica, ou seja, são os resíduos divididos pela produção de catalisadores. A linha vermelha representa a média da perda ao longo do período (5,75\%), as duas linhas pontilhadas acima os valores em relação a mais um e dois desvios-padrões em relação à média e a linha pontilhada abaixo menos um desvio-padrão em relação à média. Percebe-se que, por três vezes, o percentual de perda ficou dois desvios acima da média. 
FIGURA 3 - Percentual de perda da fábrica.

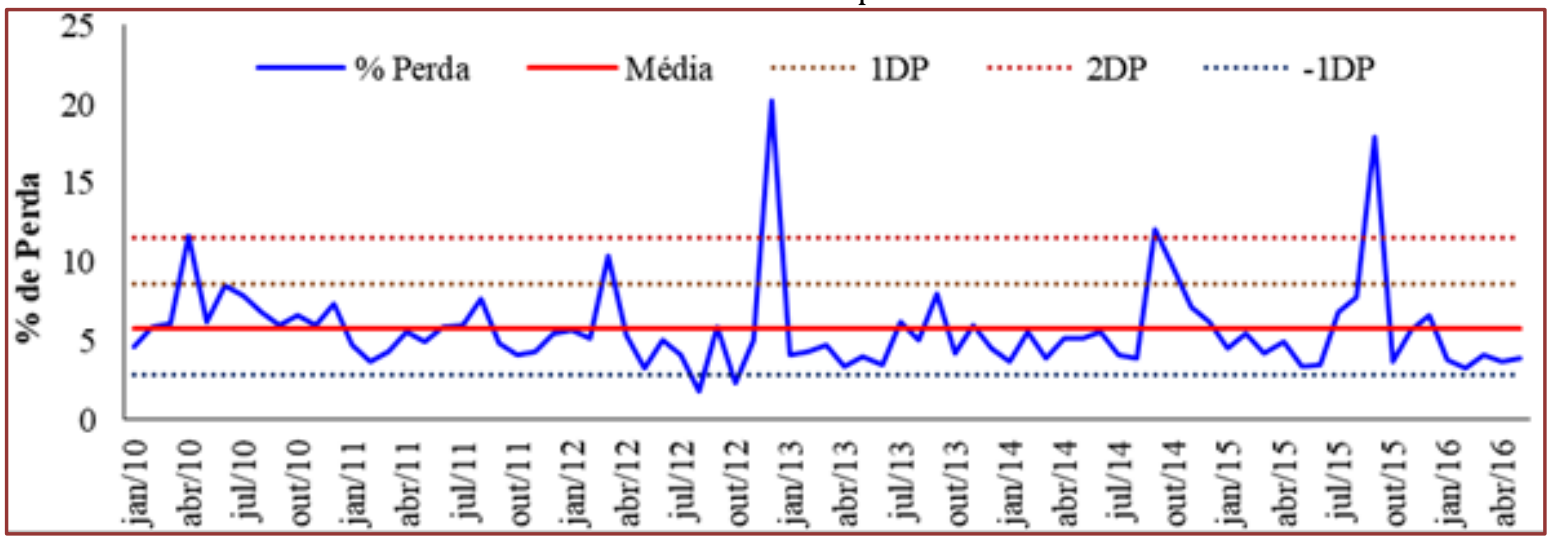

A produção de catalisadores mostra uma leve inclinação (tendência) positiva, o qual pode ser comprovado pelo coeficiente de Spearman, calculado no valor de 0,33. Como o coeficiente é positivo, pode-se dizer que a série não é estacionária, portanto, a produção tende a aumentar ao longo do período analisado. Para tonelada de resíduo e percentual de perda da fábrica os coeficientes foram, respectivamente, $-0,18$ e -0,27, obtendo-se assim que essas séries são estacionárias (Tabela 1).

TABELA 1 - Coeficiente de Correlação de Spearman.

\begin{tabular}{|c|c|c|}
\hline Série Temporal & Valor de $\rho$ & Conclusão \\
\hline Produção de Catalisadores & 0,33 & Não Estacionária \\
\hline Tonelada de Resíduo & $-0,18$ & Estacionária \\
\hline \% Perda & $-0,27$ & Estacionária \\
\hline
\end{tabular}

Em relação a sazonalidade, de acordo com o teste de Kruskal-Wallis (Tabela 2), o p- valor obtido de 0,003 revela que, para produção de catalisadores, rejeita-se a hipótese nula de não existência de sazonalidade. Em relação a tonelada de resíduo e percentual de perda da fábrica (p-valores iguais a, respectivamente, 0,208 e 0,089) não se rejeita a hipótese nula.

TABELA 2 - Teste de Kruskal-Wallis.

\begin{tabular}{|l|c|c|c|}
\multicolumn{1}{c}{ Estatística } & $\begin{array}{c}\text { Produção de } \\
\text { Catalisadores }\end{array}$ & Tonelada de Resíduo & $\%$ de Perda \\
\hline Valor calculado & 28,3 & 14,5 & 17,7 \\
\hline Qui-quadrado tabelado & 19,7 & 19,7 & 19,7 \\
\hline Graus de liberdade & 11 & 11 & 11 \\
\hline Nível de significância & $5 \%$ & $5 \%$ & $5 \%$ \\
\hline p-valor & 0,003 & 0,208 & 0,089 \\
\hline Conclusão & Sazonal & Não Sazonal & Não Sazonal \\
\hline
\end{tabular}

O cálculo das constantes de suavização não possuem fórmulas, e deste modo, o método utilizado devem ser as que reduzem as medidas métricas de previsão. Segundo Morettin e Tolói (2006), se a ideia é minimizar a variância, aconselha-se o EQM, já o EMPA é adequado para comparação de duas ou mais séries diferentes. A Tabela 3 apresenta o valores calculados através do EQM e do EMPA: 
TABELA 3 - Valor das constantes de alisamento de cada modelo em suas métricas de previsão.

\begin{tabular}{|c|c|c|c|c|c|c|c|}
\hline \multirow{2}{*}{ Série Temnoral } & \multirow{2}{*}{ Modelos } & \multicolumn{3}{|c|}{ EQM } & \multicolumn{3}{|c|}{ EMPA } \\
\hline & & $\alpha$ & $\vec{\beta}$ & $\gamma$ & $\alpha$ & $\beta$ & $\gamma$ \\
\hline \multirow{4}{*}{$\begin{array}{l}\text { Produção de } \\
\text { Catalisadores }\end{array}$} & $\mathrm{AES}$ & 0,02 & - & - & 0,01 & - & - \\
\hline & AELB & 0,01 & - & - & 0,01 & - & - \\
\hline & $\mathrm{AEH}$ & 0,11 & 0,30 & - & 0,11 & 0,32 & - \\
\hline & AESHW & 0,11 & 0,05 & 0,32 & 0,11 & 0,05 & 0,32 \\
\hline \multirow{4}{*}{$\begin{array}{c}\text { Tonelada de } \\
\text { Resíduo }\end{array}$} & $\mathrm{AES}$ & 0,34 & - & - & 0,01 & - & - \\
\hline & AELB & 0,14 & - & - & 0,00 & - & - \\
\hline & $\mathrm{AEH}$ & 0,56 & 0,13 & - & 0,57 & 0,11 & - \\
\hline & AESHW & 0,22 & 0,01 & 0,01 & 0,22 & 0,01 & 0,01 \\
\hline \multirow{4}{*}{$\%$ de Perda } & AES & 0,03 & - & - & 0,01 & - & - \\
\hline & AEL B & 0,01 & - & - & 0,01 & - & - \\
\hline & $\mathrm{AEH}$ & 0,05 & 0,01 & - & 0,61 & 0,11 & - \\
\hline & AESHW & 0,05 & 0,09 & 0,06 & 0,05 & 0,09 & 0,06 \\
\hline
\end{tabular}

De maneira a avaliar qual modelo melhor se ajustou aos dados, a Tabela 4 mostra os valores calculados das métricas de previsão. 0 método das Médias Móveis apresentou os melhores resultados para as três séries temporais.

TABELA 4 - Resultado das avaliações das previsões pelas métricas de previsão.

\begin{tabular}{|c|c|c|c|}
\hline Série Temporal & Modelos & EQM & EMPA (\%) \\
\hline \multirow{5}{*}{ Produção de Catalisadores } & $\mathrm{MM}$ & 184.996 & 14,67 \\
\hline & AES & 351.699 & 24,11 \\
\hline & AELB & 373.128 & 24,17 \\
\hline & $\mathrm{AEH}$ & 374.161 & 26,26 \\
\hline & $\mathrm{AESHW}$ & 440.201 & 22,14 \\
\hline \multirow{5}{*}{ Tonelada de Resíduo } & MM & 364 & 10,5 \\
\hline & $\mathrm{AES}$ & 1.076 & 17,8 \\
\hline & AELB & 1.159 & 17,9 \\
\hline & $\mathrm{AEH}$ & 1.317 & 19,8 \\
\hline & $\mathrm{AESHW}$ & 1.051 & 18,2 \\
\hline \multirow{5}{*}{$\%$ de Perda } & $\mathrm{MM}$ & 4 & 20,7 \\
\hline & $\mathrm{AES}$ & 9 & 28,5 \\
\hline & AEL B & 9 & 30,7 \\
\hline & $\mathrm{AEH}$ & 9 & 40,1 \\
\hline & AESHW & 10 & 35,6 \\
\hline
\end{tabular}

Os gráficos a seguir exibem a comparação dos valores reais observados e as previsões obtidas para as médias móveis, visto que este modelo apresentou os melhores resultados. A Figura 4 apresenta a comparação para a produção de catalisadores; a Figura 5 a comparação para tonelada de resíduo; e a Figura 6 para o percentual de perda da fábrica. As três séries foram calculadas em dois períodos. 
FIGURA 3 - Valores observados x médias móveis - produção de catalisadores.

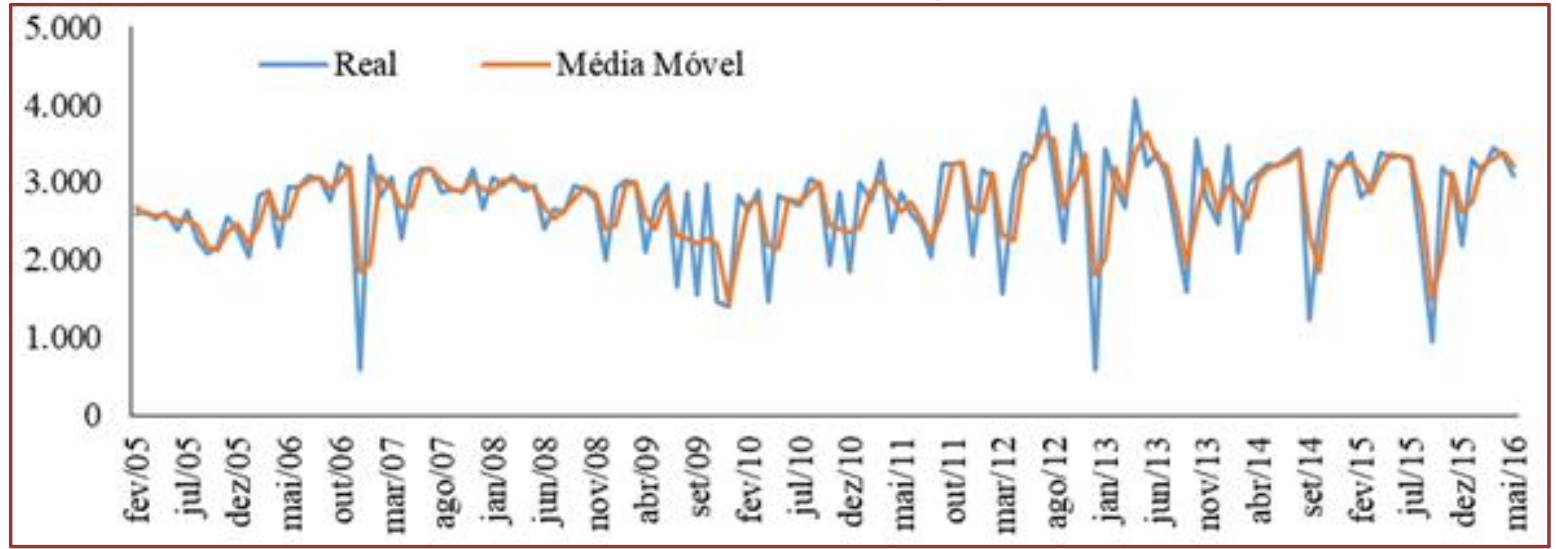

FIGURA 4 - Valores observados x médias móveis - tonelada de resíduo.

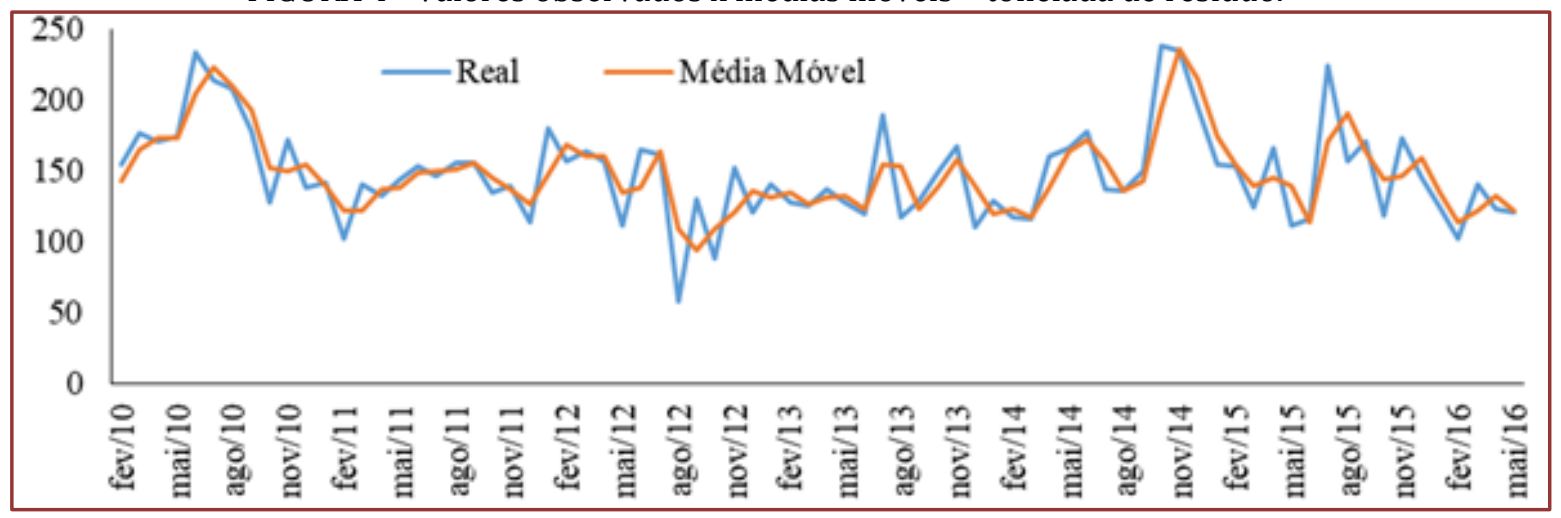

FIGURA 5 - Valores observados x médias móveis - percentual de perda.

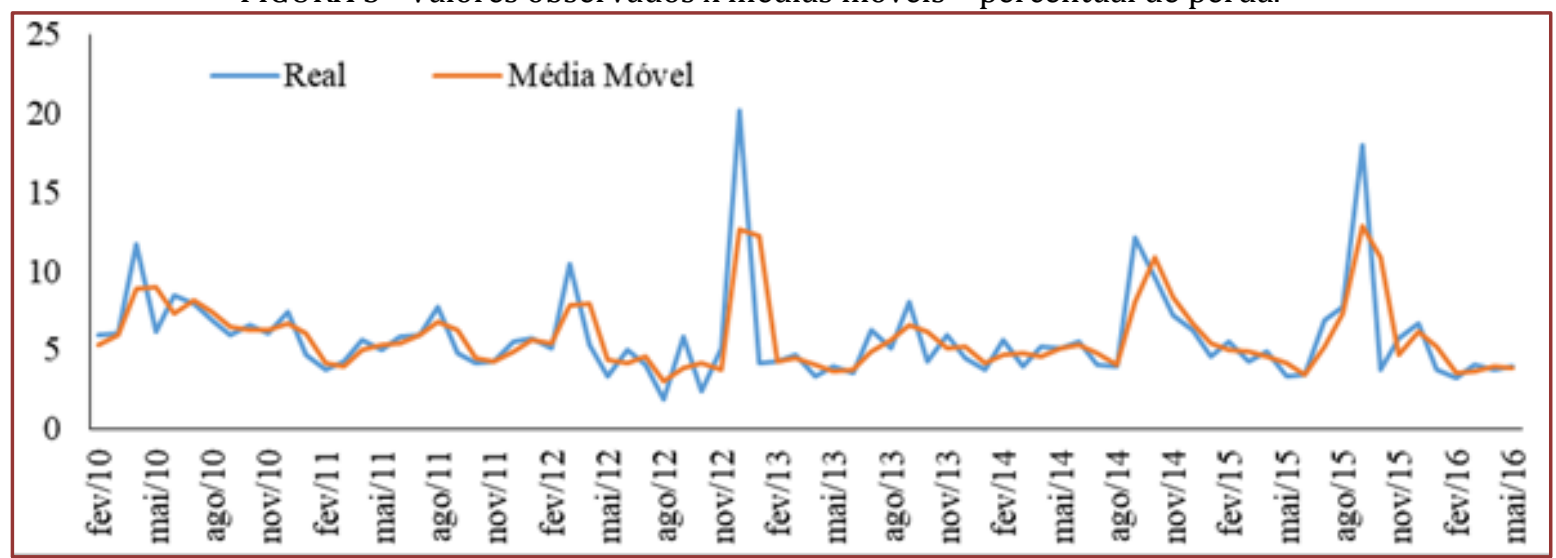

\section{CONSIDERAÇÕES FINAIS}

0 gerenciamento ambiental envolve três áreas: poluição do meio ambiente, conservação de recursos (reciclagem e reuso) e saúde e segurança das pessoas (FIGUEIREDO, 1996 apud WEIBE, 1994). Em determinados processos produtivos, existe este monitoramento ambiental, onde a capacidade de produção pode ser associada a uma série de outros parâmetros. Uma indústria que produz catalisadores gera diversos efluentes industriais que estão ligados diretamente a poluição do meio ambiente. 
No âmbito dos meios de produção de qualquer empresa, o objetivo primordial é sempre o lucro, mas ainda assim, nas últimas décadas, devido a diversos acidentes catastróficos como o desastre de Bhopal (1984), a explosão da Deepwater Horizon (2010), os acidentes nucleares de Chernobyl (1986) e Fukushima (2011), entre outros, o trato com as questões ambientais tem ganho cada vez mais força, não só pelas intervenções do Estado, mas também em grande parte pelo interesse público-social na busca de informações sobre os métodos de produção (a sociedade acabou adotando um pensamento cético a respeito das indústrias). Em consequência, os órgãos responsáveis pela fiscalização e controle ambiental sofrem pressão para adotar regulamentações mais rigorosas (SOUZA, 2017).

Por fim, para produção de catalisadores, tonelada de resíduo e percentual de perda foram utilizados testes não paramétricos e modelos de médias móveis e alisamento em séries temporais. A série temporal de catalisadores apresentou tendência e variação sazonal, revelando ser mais complexa do que algumas outras. Ainda assim, o modelo que melhor se ajustou para as três séries foi o das médias móveis, que na prática tem uma aplicação mais fácil do que os outros, mostrando que mesmo métodos mais simples podem também obter resultados bastantes satisfatórios.

\section{REFERÊNCIAS}

[1] BOX, G. E. P.; JENKINS, G. M.; REINSEL, G. C.; LJUNG, G. M.. Time series analysis: forecasting and control. John Wiley \& Sons, 2015.

[2] CAMPOS, L. M.; MELO, D. A. Indicadores de desempenho dos Sistemas de Gestão Ambiental (SGA): uma pesquisa teórica. Produção, [S.l.], p. 540-555, set. 2008.

[3] EEA, European Environment Agency. Digest of EEA indicators. 2014. Disponível em: http://www.eea.europa.eu/publications/digest-of-eea-indicators-2014. Acesso em: 21/11/2019.

[4] GUSMÃO, A. C. F.; DE MARTINI, L. C. Gestão ambiental na indústria. Rio de Janeiro: SMS Digital, 2009. FIGUEIREDO, M. A. G. de. 0 uso de indicadores ambientais no acompanhamento de sistemas de gerenciamento ambiental. Production, v. 6, n. 1, p. 33-44, 1996.

[5] MAZZI, A.; TONIOLO, S.; MASON, M.; AGUIARI, F.; SCIPIONI, A. What are the benefits and difficulties in adopting an environmental management system? The opinion of Italian organizations. Journal of Cleaner Production, 2016.

[6] MORETTIN, P. A.; TOLÓI, C. M. de C. Análise de séries temporais. In: Análise de séries temporais. 2006. OLIVEIRA, O. J.; SERRA, J. R.; SALGADO, M. H. Does ISO 14001 work in Brazil? Journal of Cleaner Production, p. 1797-1806, 2010.

[7] SIEGEL, S.; CASTELLAN, N. J. Nonparametric Statistics for the Behavioral Sciences. New York, 6. 1988.

[8] SOUZA, P. M. de. Proposição de um índice de meio ambiente por meio de uma ferramenta de tomada de decisão multicritério: estudo de caso em uma indústria produtora de insumos para refino de petróleo. Dissertação. Programa de Pós-graduação em Engenharia Química. Universidade do Estado do Rio de Janeiro (UERJ), Rio de Janeiro, 2017. 


\section{Capítulo 5}

\section{Avaliação de desempenho da sustentabilidade em uma organização do setor de cosméticos}

\section{Filipe Brito Lima de Macedo}

\section{Gilson Brito Alves Lima}

Luiz Paulo Marques Assumpção Resinente

\section{Thiago Gomes Brito Lima}

Resumo: 0 tema sustentabilidade ganha cada vez mais destaque na sociedade e no meio corporativo, passou a ser adotado como estratégia organizacional. Essa crescente preocupação com o tema tem levado as organizações ao constante aprimoramento do seu desempenho sustentável e divulgação às distintas partes interessadas. Os relatórios anuais de desempenho organizacional são atualmente a ferramenta para esta divulgação. Neste sentido, o objetivo desta pesquisa foi avaliar o desempenho da sustentabilidade em uma empresa multinacional do setor de cosméticos, sob a ótica dos resultados econômico, ambiental e social, inseridos no conceito Triple Bottom Line (TBL). Como abordagem metodológica, realizou-se uma pesquisa exploratória, de base quali-quantitativa, a partir de dados coletados nos cinco últimos relatórios anuais da organização. A modelagem dos dados foi efetuada com apoio da técnica de similaridade por solução ideal para análise e interpretação dos resultados. Os resultados obtidos permitiram um diagnóstico sistêmico sobre os eixos econômico, ambiental e social da organização e demonstraram a evolução e o comportamento destes indicadores no sentido do desenvolvimento sustentável. Este capítulo foi elaborado a partir da versão de um artigo preliminar, publicado pelos mesmos autores.

Palavras-chave: Avaliação de Desempenho; Sustentabilidade; Triple Bottom Line; Relatório Anual Integrado. 


\section{INTRODUÇÃO}

Atualmente, a sociedade enfrenta um crescente aumento da preocupação com o tema sustentabilidade. Mudanças climáticas, escassez de recursos, desastres naturais, inovações tecnológicas, dentre outros fatores, nos levam a imaginar e reimaginar, enquanto sociedade, como serão os próximos anos. A globalização e a tecnologia da informação possibilitaram maior conscientização da sociedade sobre temas diversificados, e assim o é com o tema sustentabilidade.

Nesta mesma realidade de conscientização e preocupação com a sustentabilidade, as organizações desenvolvem cada vez mais mecanismos para divulgar e informar seu desempenho, agora não só financeiro, mas também social e ambiental, à todas as partes interessadas (sociedade, acionistas, trabalhadores, órgãos reguladores e outros.).

Segundo Barbosa (2007), o conceito de sustentabilidade foi definido para as disciplinas de Economia Ambiental e Ética Empresarial, posteriormente outros pesquisadores buscaram uma concepção associando à forma como as empresas desempenhavam seu papel perante a sociedade como fator importante para obter resultados nas áreas financeira, social e ambiental (Triple Bottom Line). Os autores Van Marrewijk e Werre (2003), afirmam que as empresas deveriam criar sua própria estratégia de sustentabilidade, entendendo que cada organização deve estabelecer seu posicionamento de acordo com suas especificidades, sua estratégia, valores, princípios e o ambiente de mercado no qual está inserida.

Em 2013, o International Integrated Reporting Council (IIRC) criou uma estrutura conceitual para relatório integrado, que tem sido, desde então, o referencial para as organizações elaborarem seu relatório de desempenho. Entretanto, cada stakeholder de uma organização pode ter uma opinião diferente sobre a importância dos aspectos econômico, ambiental e social, conforme seus próprios interesses, conceitos, valores e experiências.

Neste sentido, um processo de análise envolvendo múltiplos aspectos e critérios, como os apresentados nos relatórios integrados, é importante para reduzir subjetividades e vieses durante uma avaliação. Como alternativa de solução, os métodos de avaliação multicritérios possibilitam a modelagem de problemas onde a subjetividade e ambiguidade possam estar presentes.

Dentro desse contexto, o objetivo desta pesquisa é avaliar o desempenho da sustentabilidade em uma organização multinacional do setor de cosméticos, analisando os resultados econômico, ambiental e social de seus últimos cinco relatórios anuais (2014 à 2018). A avaliação foi feita com a aplicação da Técnica de Similaridade por Solução Ideal, proposto por Hwang e Yoon em 1981, conforme apresentado por Wu et. al. (2009). 0 método em questão foi aplicado considerando o potencial de ordenação, por preferências prédefinidas, dos resultados obtidos pelos eixos econômico, social e ambiental, de interesse do estudo.

Este capítulo foi elaborado a partir da versão de um artigo preliminar, publicado pelos mesmos autores (MACEDO; LIMA; RESINENTE; LIMA, 2020). 0 artigo em pauta desenvolve-se em cinco capítulos. Este primeiro introduz e contextualiza o estudo, o segundo apresenta o referencial teórico, o terceiro apresenta a metodologia utilizada, o quarto as análises e discussão dos resultados, e o quinto e último capítulo, a conclusão.

\section{A SUSTENTABILIDADE ORGANIZACIONAL}

Sustentabilidade está intimamente relacionada ao termo desenvolvimento sustentável. De acordo com o relatório "Nosso Futuro Comum" da comissão de Brundtland, desenvolvimento sustentável pode ser entendido como o desenvolvimento capaz de suprir as necessidades da geração atual, sem comprometer a capacidade das futuras gerações também atenderem suas necessidades (BRUNDTLAND, 1987). A partir dessa definição, entende-se que o termo sustentabilidade expressa uma relação duradoura e equilibrada entre o desenvolvimento econômico, social e preservação ambiental.

De acordo com Porter e Kramer (2006), o princípio da sustentabilidade nas empresas aparece frequentemente citando o Triple Bottom Line, que consiste na busca da continuidade no mercado e no crescimento da organização a partir de sua viabilidade econômica, além da coexistência harmônica com o meio ambiente e sociedade. A sustentabilidade se converte em um princípio fundamental da gestão inteligente, que será difícil de ser ignorado (SAVITZ; WEBER, 2006). 
0 Triple Bottom Line, modelo criado por John Elkington nos anos 1990, tinha como objetivo fazer com que as organizações focassem, além da busca pelo lucro, as dimensões social e ambiental, traduzida pela fórmula dos 3P "People, Planet and Profit". Elkington (1997) relata que o modelo é amparado no conceito sobre a prosperidade econômica, a qualidade ambiental e a justiça social e passou a ganhar um espaço importante no meio acadêmico e fazer parte das estratégias empresariais como inovação e geração de valor.

A Declaração de Johanesburgo em 2002, na Cúpula Mundial sobre o Desenvolvimento Sustentável, estabeleceu que o desenvolvimento sustentável se baseia em três pilares: desenvolvimento econômico, desenvolvimento social e proteção ambiental. Tal conceito corrobora com o Triple Bottom Line de Elkington.

Eccles et al. (2001), explicam que a construção de um sistema estratégico de mensuração é mais do que a simples coleta de dados não financeiros, devendo apresentar equilíbrio e integração, com um desenho que permita destacar fatores críticos de sucesso.

Os indicadores estratégicos das organizações, ou seja, aqueles que agregam valor ao negócio, são registrados e comunicados aos stakeholders através de relatórios anuais integrados.

\subsection{RELATÓRIO ANUAL INTEGRADO}

Empresas de todo o mundo têm adotado relatórios que conciliam dados financeiros com os aspectos socioambientais e com suas práticas de gestão e governança. 0 tema sustentabilidade corporativa ganha cada vez mais status de vantagem competitiva (BM\&FBOVESPA, 2010).

Atualmente a sustentabilidade nos negócios é encarada não como uma iniciativa ambiental, mas sim como uma estratégia empresarial que gera valor a partir da busca de melhores resultados sociais e ambientais. As organizações estão procurando inserir o tripé da sustentabilidade na estratégia e gestão de seus negócios, e novos modelos de negócios surgem visando o equilíbrio entre o capital natural e o humano como desenvolvimento inclusivo com tecnologias limpas (BM\&FBOVESPA, 2010).

De acordo com Benites e Polo (2013), o relatório de sustentabilidades é a principal ferramenta de comunicação do desempenho social, ambiental e econômico das empresas. 0 modelo de relatório da Global Reporting Initiative (GRI) é atualmente o mais completo e mundialmente difundido e tem como objetivo medir e certificar as empresas com parâmetros que vão além da questão da transparência e da boa governança corporativa. O GRI inclui os indicadores econômico, ambiental, social / trabalho, direitos humanos, sociedade, e responsabilidade pelo produto.

Os padrões de relatórios de sustentabilidade da Global Reporting Initiative (GRI), são os mais adotados padrões globais de relatórios de sustentabilidade. De acordo com a pesquisa KPMG de relatórios de responsabilidade corporativa 2017, 93\% das 250 maiores corporações do mundo relatam seu desempenho em sustentabilidade.

Os autores Eccles e Krzus (2011), no entanto, relatam que muitos sistemas de apresentação de relatórios financeiros e de sustentabilidade não fornecem as informações necessárias para os novos desafios dentro de um ambiente complexo.

Diante deste cenário, as organizações International Integrated Reporting Council (IIRC), International Accounting Standards Board (IASB) e o Global Reporting Initiative (GRI), discutiram a necessidade de se estabelecer uma estrutura de governança e as diretrizes para um modelo de relatório adequado ao mercado. Em 2013, o International Integrated Reporting Council (IIRC), conselho internacional formado por reguladores, investidores, empresas, normatizadores, profissionais do setor contábil e ONGs, estabeleceu as diretrizes para elaboração de um Relatório Integrado.

\section{PROCEDIMENTOS METODOLÓGIICOS}

A pesquisa utilizou como fonte de coleta de dados os relatórios anuais de 2014, 2015, 2016, 2017 e 2018 da organização objeto do estudo, especificamente as informações e indicadores das esferas econômica, social e ambiental (Triple Bottom Line).

Para análise e modelagem dos dados foram utilizados 9 indicadores da organização, separados em 3 indicadores da esfera econômica, 3 indicadores da esfera ambiental e 3 indicadores da esfera social. 
Para modelagem dos dados foi utilizada a técnica de tomada de decisão para ordenamento das preferências por similaridade pela solução ideal (da lingua inglesa, Technique for Order Preference by Similarity to Ideal Solution). O uso da técnica objetivou a avaliação do desempenho das alternativas através do ordenamento dos critérios de decisão, representados pelos eixos economico, social e ambiental, onde, de acordo com essa técnica, a melhor alternativa seria aquela que é a mais próxima da solução ideal positiva e a mais distante da solução ideal negativa.

\subsection{A TÉCNICA DE SIMILARIDADE POR SOLUÇÃO IDEAL}

De acordo com Hwang et al. (1993), a técnica para ordenamento de preferência por similaridade pela solução ideal foi desenvolvida por Hwang e Yoon (1981), visando solucionar um problema de tomada de decisão com múltiplos atributos. A técnica associa o princípio do compromisso em que a alternativa escolhida deve ser a de menor distância da Solução Ideal Positiva (SIP) e a de maior distância da Solução Ideal Negativa (SIN).

A melhor alternativa é aquela mais próxima da solução ideal positiva e a mais distante da solução ideal negativa (Ertugrul \& Karakasoglu, 2007). A solução ideal positiva é uma solução que maximiza os critérios de benefício e minimiza os critérios de custo. Já a solução ideal negativa maximiza os critérios de custo e minimiza os critérios de benefício.

Conforme Wu et al. (2009), a técnica TOPSIS busca comparar as alternativas com a solução ideal positiva (PIS - Positive Ideal Solution) e a solução ideal negativa (NIS - Negative Ideal Solution).

O método TOPSIS pode ser aplicado a partir dos seguintes passos (HWANG; YOON,1981; LIMA JUNIOR; CARPINETTI, 2015):

Passo 1: Estruturar a matriz de decisão e vetor de pesos conforme a equação 1, onde $\mathrm{d}_{\mathrm{ij}}$ representa a pontuação da alternativa i $\left(\mathrm{A}_{\mathrm{i}}\right)$ no critério j $\left(\mathrm{C}_{1}\right)$.

\begin{tabular}{|c|c|c|c|c|}
\hline \multicolumn{5}{|c|}{ Equação 1} \\
\hline & $\mathrm{C}_{1}$ & $\mathrm{C}_{2}$ &..$\quad C_{j}$ & $\begin{array}{ll}. . & \mathrm{C}_{\mathrm{m}}\end{array}$ \\
\hline $\mathrm{A}_{1}$ & $d_{11}$ & $d_{12}$ &..$\quad d_{1 j}$ &..$\quad \mathrm{~d}_{\mathrm{Im}}$ \\
\hline : & : & : & : & : \\
\hline $\mathrm{D}=\mathrm{A}_{\mathrm{i}}$ & $\mathrm{d}_{\mathrm{il}}$ & $\mathrm{d}_{\mathrm{i} 2}$ &..$\quad d_{i j}$ &..$\quad \mathrm{~d}_{\mathrm{im}}$ \\
\hline : & : & : & : & : \\
\hline$A_{n}$ & $\mathrm{~d}_{\mathrm{nl}}$ & $d_{n 2}$ &..$d_{n j}$ & $d_{n m}$ \\
\hline
\end{tabular}

Passo 2: Ponderar e normalizar a matriz de decisão usando a equação 2, onde dij são os elementos da matriz de decisão e wj representa os critérios.

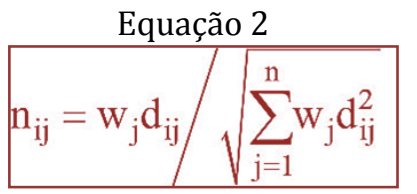

Passo 3: Obter as soluções ideais positiva (PIS, A+) e negativa (NIS, A-) de acordo com as equações 3 e 4, respectivamente. Nessas equações, nj+ representa a melhor pontuação alcançada pelas alternativas no critério j e nj-representa a pior pontuação das alternativas neste mesmo critério. 
Equação 3

$$
\begin{gathered}
\mathrm{A}^{+}=\left\{{ }_{\mathrm{j}}^{\text {MAX } \mathrm{n}_{\mathrm{ij}} \mid \mathrm{j}}=1,2, . ., \mathrm{m}\right\}=\left\{\mathrm{n}_{\mathrm{l}}^{+}, . ., \mathrm{n}_{\mathrm{j}}^{+}, . ., \mathrm{d}_{\mathrm{m}}^{+}\right\} \\
\text {Equação } 4
\end{gathered}
$$

\begin{tabular}{|c|c|c|c|}
\hline & $\mathrm{MIN}_{\mathrm{j}} \mathrm{n}_{\mathrm{ij}}$ & $\mathrm{j}=1,2, . ., \mathrm{m}$ & $\mathrm{n}_{1}^{-}, . ., \mathrm{n}_{\mathrm{j}}^{-}, \ldots, \mathrm{n}_{\mathrm{m}}^{-}$ \\
\hline
\end{tabular}

Passo 4: Calcular a distância (Di+) entre os elementos da matriz de decisão ponderada e normalizada, e a solução ideal positiva, usando a equação 5. Similarmente, calcular a distância (Di-) entre os elementos da matriz de decisão e a solução ideal negativa por meio da equação 6.

$$
\begin{array}{|c|}
\text { Equação } 5 \\
\mathrm{D}_{\mathrm{i}}^{+}=\sqrt{\sum_{\mathrm{i}=1}^{\mathrm{n}}\left(\mathrm{n}_{\mathrm{ij}}-\mathrm{n}_{\mathrm{j}}^{+}\right)^{2}}
\end{array}
$$

Equação 6

$$
\mathrm{D}_{\mathrm{i}}^{-}=\sqrt{\sum_{\mathrm{i}=1}^{\mathrm{n}}\left(\mathrm{n}_{\mathrm{ij}}-\mathrm{n}_{\mathrm{j}}^{-}\right)^{2}}
$$

Passo 5: Por último, usando a equação 7, deve-se calcular o coeficiente de aproximação (CCi ou $\left.\mathrm{RC}_{\mathrm{i}}\right)$ de cada alternativa e ordenar o resultado de forma decrescente. Quanto mais próximo de 1 for o valor de CCi, melhor é o desempenho da alternativa.

Equação 7

$$
\mathrm{CC}_{\mathrm{i}}=\mathrm{D}_{\mathrm{i}}^{-} /\left(\mathrm{D}_{\mathrm{i}}^{+}+\mathrm{D}_{\mathrm{i}}^{-}\right)
$$

\section{AVALIAÇÃO DE DESEMPENHO DA SUSTENTABILIDADE ORGANIZACIONAL}

0 presente estudo foi realizado em uma organização do setor de cosméticos, de reconhecidas ações sustentáveis em seus produtos, processos e serviços. A empresa conta com uma força de trabalho de mais de 6 mil colaboradores próprios, além de outro grande número de profissionais, de relacionamento indireto.

Os Relatórios anuais integrados da organização reuniram as principais práticas, resultados e desafios da empresa ao longo dos últimos cinco anos. Verificou-se que o conteúdo foi construído seguindo as metodologias da Global Reporting Initiative (GRI) e do International Integrated Reporting Council (IIRC), integrando informações financeiras e socioambientais. 
A avaliação do desempenho da sustentabilidade é detalhada no tópico 4.1 a seguir.

\subsection{ANÁLISE E DISCUSSÃO DOS RESULTADOS}

A primeira etapa da avaliação consistiu em relacionar as dimensões da sustentabilidade objeto de análise, os critérios utilizados, os indicadores avaliados com as respectivas unidades de medida, e por fim, o impacto do indicador (positivo ou negativo). Estes dados são apresentados na tabela 1.

Tabela 1 - Critérios e Indicadores.

\begin{tabular}{|c|c|c|c|c|}
\hline $\begin{array}{c}\text { Triple } \\
\text { Bottom } \\
\text { Line }\end{array}$ & CRITÉRIOS & INDICADORES AVALIADOS & $\begin{array}{l}\text { UNIDADES DE } \\
\text { MEDIDAS }\end{array}$ & $\begin{array}{l}\text { IMPACTO DO } \\
\text { INDICADOR }\end{array}$ \\
\hline \multirow{3}{*}{ Econômica } & $\begin{array}{c}\text { Econômico } \\
\text { I }\end{array}$ & Receita Líquida Consolidada & $\mathrm{R}$ \$ milhões & Positivo \\
\hline & $\begin{array}{l}\text { Econômico } \\
\text { II }\end{array}$ & $\begin{array}{l}\text { Investimentos nas comunidades de entorno das } \\
\text { unidades da Empresa }\end{array}$ & $\mathrm{R} \$$ mil & Positivo \\
\hline & $\begin{array}{c}\text { Econômico } \\
\text { III }\end{array}$ & Valor econômico distribuído aos colaboradores & $\mathrm{R} \$$ milhões & Positivo \\
\hline \multirow{3}{*}{ Social } & Social I & Número de colaboradores & $\begin{array}{l}\text { Número de } \\
\text { pessoas }\end{array}$ & Positivo \\
\hline & Social II & $\begin{array}{l}\text { Média anual de horas de treinamento por } \\
\text { colaborador }\end{array}$ & horas/colaborador & Positivo \\
\hline & Social III & $\begin{array}{l}\text { Famílias beneficiadas nas comunidades } \\
\text { fornecedoras }\end{array}$ & $\begin{array}{l}\text { Número de } \\
\text { pessoas }\end{array}$ & Positivo \\
\hline \multirow{3}{*}{ Ambiental } & $\begin{array}{l}\text { Ambiental } \\
\text { I }\end{array}$ & Emissões GEE na cadeia de valor & $\mathrm{tCO} 2 \mathrm{e}$ & Negativo \\
\hline & $\begin{array}{l}\text { Ambiental } \\
\text { II }\end{array}$ & Consumo de água & $\begin{array}{l}\text { Litro/unidade } \\
\text { produzida }\end{array}$ & Negativo \\
\hline & $\begin{array}{l}\text { Ambiental } \\
\text { III }\end{array}$ & $\begin{array}{l}\text { \% Material reciclado pós-consumo em } \\
\text { embalagem de produto acabado }\end{array}$ & Percentagem & Positivo \\
\hline
\end{tabular}

Fonte: elaborada pelos autores.

A partir do mapeamento dos indicadores e critérios acima, a segunda etapa da análise consistiu em elaborar a matriz de decisão, apresentada na tabela 2 abaixo, que é composta pelos anos avaliados (alternativas), nas linhas, e os critérios, nas colunas.

Tabela 2 - Matriz de decisão.

\begin{tabular}{|c|c|c|c|c|c|c|c|c|c|}
\multicolumn{3}{c|}{ Critérios Econômico } & \multicolumn{5}{c|}{ Critérios Ambientais } \\
ANO & Econômico I & $\begin{array}{c}\text { Econômic } \\
\text { o II }\end{array}$ & Econômico III & $\begin{array}{c}\text { Socia } \\
\text { II }\end{array}$ & $\begin{array}{c}\text { Socia } \\
\text { I II }\end{array}$ & $\begin{array}{c}\text { Socia } \\
\text { I III }\end{array}$ & $\begin{array}{c}\text { Ambiental } \\
\text { I }\end{array}$ & $\begin{array}{c}\text { Ambient } \\
\text { a II }\end{array}$ & $\begin{array}{c}\text { Ambient } \\
\text { I III }\end{array}$ \\
\hline 2018 & 13.397 .420 .000 & 1.032 .000 & 2.813 .000 .000 & 6.635 & 29 & 4.636 & 333.183 & 0,52 & 5,40 \\
\hline 2017 & 9.857 .420 .000 & 1.127 .000 & 1.836 .000 .000 & 6.311 & 27 & 4.294 & 308.048 & 0,53 & 4,60 \\
\hline 2016 & 7.912 .700 .000 & 910.000 & 1.327 .000 .000 & 6.397 & 38 & 2.841 & 303.424 & 0,53 & 4,30 \\
\hline 2015 & 7.899 .000 .000 & 933.000 & 1.245 .000 .000 & 6.591 & 51 & 2.251 & 321.267 & 0,49 & 2,90 \\
\hline 2014 & 7.408 .400 .000 & 965.000 & 1.075 .000 .000 & 6.591 & 77 & 3.121 & 332.326 & 0,45 & 1,20 \\
\hline
\end{tabular}

Fonte: elaborada pelos autores. 
Como os critérios expostos possuem unidades de medidas distintas, a terceira etapa consistiu em normalizar os dados dessa matriz de decisão. A normalização dos dados coloca a matriz em uma base adimensional, possibilitando a comparação entre os vários critérios. A tabela 3, abaixo, apresenta a matriz normalizada.

Tabela 3 - Matriz normalizada.

\begin{tabular}{|c|c|c|c|c|c|c|c|c|c|}
\hline \multirow[b]{2}{*}{ ANO } & \multicolumn{3}{|c|}{ Critérios Econômicos } & \multicolumn{3}{|c|}{ Critérios Sociais } & \multicolumn{3}{|c|}{ Critérios Ambientais } \\
\hline & $\begin{array}{c}\text { Econômico } \\
\text { I }\end{array}$ & $\begin{array}{l}\text { Econômico } \\
\text { II }\end{array}$ & $\begin{array}{l}\text { Econômico } \\
\text { III }\end{array}$ & Social I & $\begin{array}{l}\text { Social } \\
\text { II }\end{array}$ & $\begin{array}{l}\text { Social } \\
\text { III }\end{array}$ & $\begin{array}{c}\text { Ambiental } \\
\text { I }\end{array}$ & $\begin{array}{l}\text { Ambiental } \\
\text { II }\end{array}$ & $\begin{array}{c}\text { Ambiental } \\
\text { III }\end{array}$ \\
\hline 2018 & 0,0697 & 0,0515 & 0,0788 & 0,0507 & 0,03 & 0,065 & 0,0518 & 0,0512 & 0,0677 \\
\hline 2017 & 0,0513 & 0,0562 & 0,0514 & 0,0482 & 0,0279 & 0,0602 & 0,0479 & 0,0522 & 0,0576 \\
\hline 2016 & 0,0411 & 0,0454 & 0,0372 & 0,0489 & 0,0393 & 0,0398 & 0,0471 & 0,0522 & 0,0539 \\
\hline 2015 & 0,0411 & 0,0465 & 0,0349 & 0,0503 & 0,0527 & 0,0316 & 0,0499 & 0,0482 & 0,0363 \\
\hline 2014 & 0,0385 & 0,0481 & 0,0301 & 0,0503 & 0,0796 & 0,0438 & 0,0516 & 0,0443 & 0,0150 \\
\hline
\end{tabular}

Fonte: elaborada pelos autores.

A quarta etapa consiste na ponderação dos dados da matriz normalizada, de acordo com o peso definido para cada critério, conforme a atribuição de valor do profissional especialista ou do grupo decisório. Para este estudo, foram atribuídos pesos igualitários aos critérios. Sendo assim, a matriz ponderada não sofre alterações, permanecendo a mesma que a apresentada na Tabela 3 - Matriz normalizada.

A quinta etapa da análise consistiu na definição da solução ideal positiva (PIS) e na solução ideal negativa (NIS) para identificar o desempenho dos critérios, conforme apresentado na tabela 4, abaixo.

Tabela 4 - Valores PIS e NIS por critério.

\begin{tabular}{|c|c|c|c|c|c|c|c|c|c|}
\hline Valores & \multicolumn{3}{|c|}{ Critérios Econômicos } & \multicolumn{3}{|c|}{ Critérios Sociais } & \multicolumn{3}{|c|}{ Critérios Ambientais } \\
\hline $\begin{array}{l}\text { (PIS e } \\
\text { NIS) }\end{array}$ & $\begin{array}{c}\text { Econômico } \\
\text { I }\end{array}$ & $\begin{array}{l}\text { Econômico } \\
\text { II }\end{array}$ & $\begin{array}{c}\text { Econômico } \\
\text { III }\end{array}$ & $\begin{array}{l}\text { Social } \\
\text { I }\end{array}$ & $\begin{array}{l}\text { Social } \\
\text { II }\end{array}$ & $\begin{array}{l}\text { Social } \\
\text { III }\end{array}$ & $\begin{array}{c}\text { Ambiental } \\
\text { I }\end{array}$ & $\begin{array}{l}\text { Ambiental } \\
\text { II }\end{array}$ & $\begin{array}{c}\text { Ambiental } \\
\text { III }\end{array}$ \\
\hline PIS & 0,0697 & 0,0562 & 0,0788 & 0,0507 & 0,0796 & 0,065 & 0,0471 & 0,0443 & 0,0677 \\
\hline NIS & 0,0385 & 0,0454 & 0,0301 & 0,0482 & 0,0279 & 0,0316 & 0,0518 & 0,0522 & 0,0150 \\
\hline
\end{tabular}

Fonte: elaborada pelos autores.

Para os critérios com impactos positivos para a organização, quanto maior o resultado do PIS, melhor. Para os critérios com impactos negativos para a organização, quanto menor o resultado do NIS, melhor. Da tabela 4 acima, os critérios Ambiental I e Ambiental II, representam impactos negativos para a organização e devem ser minimizados. Todos os demais critérios representam impactos positivos para a organização e devem ser maximizados.

A sexta e última etapa, consistiu em calcular as distâncias euclidianas entre os valores da tabela 3 e os valores PIS (representado por D+) e NIS (representado por D-), o coeficiente de aproximação (RCi) de cada ano avaliado e classifica-los em ordem decrescente, conforme apresentado na tabela 5, abaixo.

Tabela 5 - Distâncias euclidianas, coeficiente e classificação.

\begin{tabular}{|c|c|c|c|c|}
\multirow{2}{*}{ ANO } & $\begin{array}{c}\text { Distâncias Euclidianas } \\
\text { D+ }\end{array}$ & D- & Coeficiente (RCi) & Classificação \\
\hline 2018 & 0,0505 & 0,0853 & 0,6278 & $1^{\text {o }}$ \\
\hline 2017 & 0,0629 & 0,0582 & 0,4806 & $2^{\text {o }}$ \\
\hline 2016 & 0,0719 & 0,0422 & 0,3699 & $4^{\text {o }}$ \\
\hline 2015 & 0,0754 & 0,0335 & 0,3078 & 5 o \\
\hline 2014 & 0,0815 & 0,0538 & 0,3977 & $3^{\text {o }}$ \\
\hline
\end{tabular}


Segundo Lima Junior e Carpinetti (2015), as melhores alternativas são aquelas que possuem o desempenho global próximo à 1. Neste sentido, o ano de 2018 obteve o melhor desempenho global, com coeficiente 0,6278 , ocupando o primeiro lugar na classificação.

A partir da aplicação do método TOPSIS e dos resultados obtidos, elaborou-se o gráfico 1 abaixo, demonstrando a evolução e a comparação do desempenho da empresa em cada um dos critérios econômico, ambiental e social, separadamente, conforme o tripé da sustentabilidade.

Gráfico 1: Comparação do desempenho anual por critério.

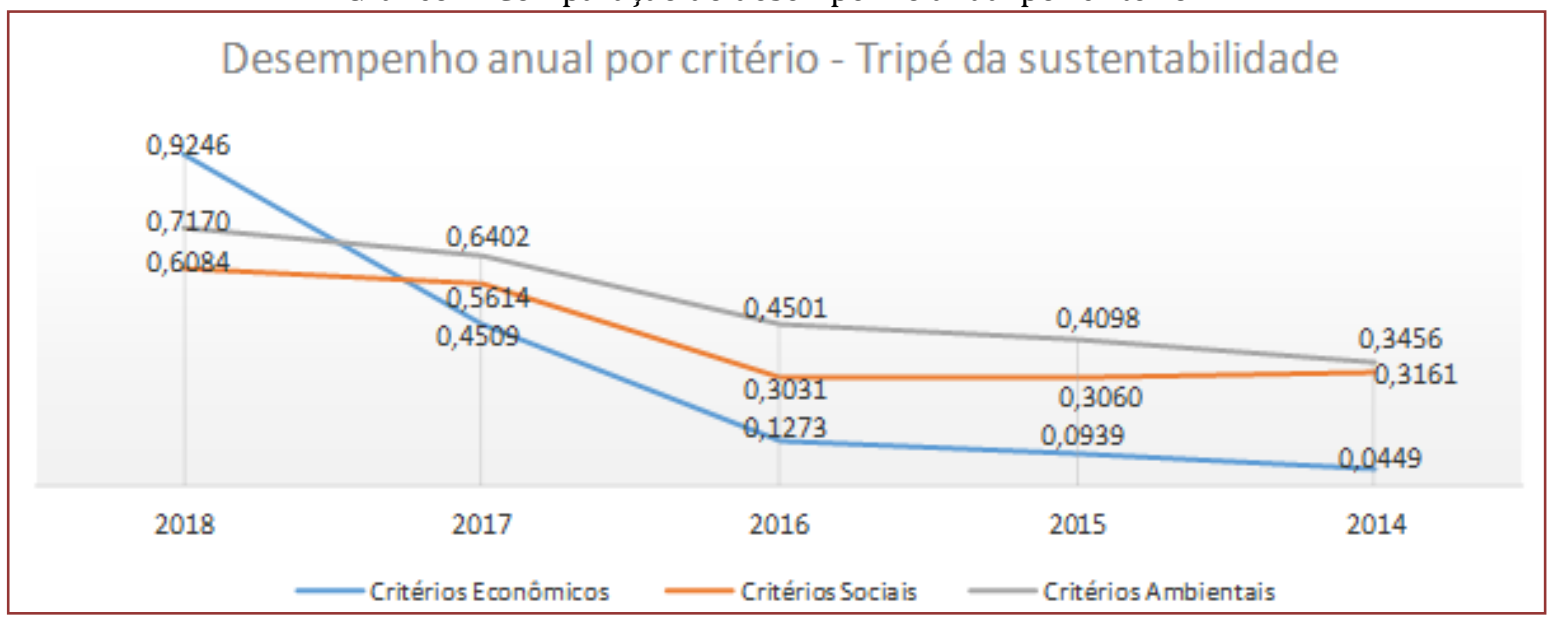

Ao analisar o comportamento das três esferas da sustentabilidade isoladamente, observa-se que o critério ambiental obteve o melhor desempenho no período de 2014 à 2017, seguido do critério social e, por último, o critério econômico. Já em 2018, último ano da análise, o critério econômico obteve melhor desempenho sobre os demais.

Para análise final, elaborou-se o gráfico 2 abaixo, demonstrando o comportamento do desempenho da organização com os três critérios da sustentabilidade integrados.

Gráfico 2: Avaliação do desempenho da sustentabilidade na organização.

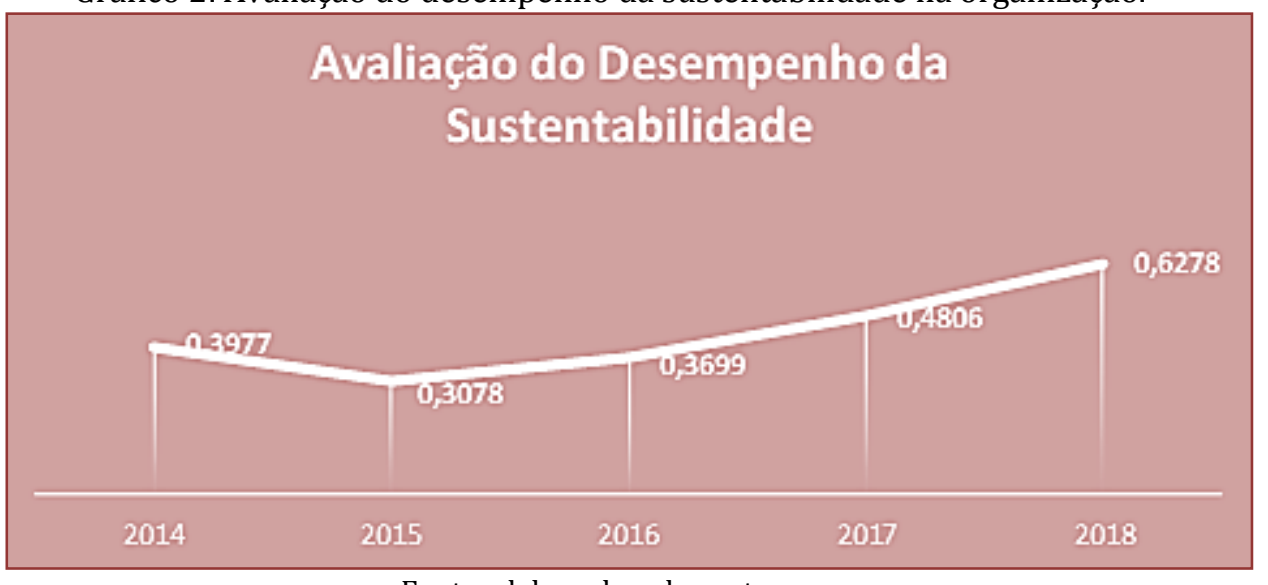

Fonte: elaborada pelos autores.

Ao analisar o gráfico acima, nota-se que a organização apresentou um declínio no desempenho de 2014 à 2016, e que este foi motivado pelos resultados da média anual de horas de treinamento por colaborador (critério social II) e o número de famílias beneficiadas nas comunidades fornecedoras da organização (critério social III). No entanto, nos últimos quatro anos analisados, a organização apresenta uma evolução positiva contínua em seu desempenho geral. 


\section{CONSIDERAÇÕES FINAIS}

A partir da aplicação da técnica proposta foi possível avaliar o desempenho da sustentabilidade da organização, sob a ótica do conceito Triple Bottom Line, atingindo o objetivo proposto neste artigo.

A técnica TOPSIS mostrou-se aderente ao estudo e propósito, possibilitando a ordenação e classificação dos cinco anos avaliados, conforme o desempenho obtido nos critérios da sustentabilidade: econômico, ambiental e social.

O diagnóstico realizado possibilitou analisar o comportamento das três esferas da sustentabilidade separadamente, observando-se que ao longo dos quatro primeiros anos o critério ambiental obteve o melhor desempenho no tripé da sustentabilidade, seguido do critério social e, por último, mas não menos importante, o critério econômico.

Os resultados obtidos possibilitaram evidenciar, ainda, que os critérios econômico e ambiental da organização, apresentam evolução positiva contínua nos cinco anos da análise, demonstrando crescimento equilibrado nas esferas do Triple Bottom Line. 0 comportamento dos indicadores demonstra que a organização está no caminho do desenvolvimento sustentável, e corroboram com o reconhecimento público de que a mesma possui uma forte vertente socioambiental na condução do negócio.

\section{REFERÊNCIAS}

[1] BARBOSA, Paulo Roberto. Arcoverde. Índice de sustentabilidade empresarial da bolsa de valores de São Paulo (ISE-BOVESPA): exame da adequação como referência para aperfeiçoamento da gestão sustentável das empresas e para formação de carteiras de investimento orientadas por princípios de sustentabilidade corporativa. Dissertação de Mestrado - Universidade Federal do Rio de Janeiro, Rio de Janeiro, 2007.

[2] BRUNDTLAND, G. H. et al. Our common future: Report of the World Commission on Environment and Development. New York, 1987.

[3] BM\&FBOVESPA. Novo Valor: Sustentabilidade nas empresas como começar, quem envolver e o que priorizar. São Paulo, 2010.

[4] ECCLES, R. G.; KRZUS, M. P. (2011). Relatório Único: divulgação integrada para uma estratégia sustentável. São Paulo: Saint Paul Editora.

[5] ELKINGTON, J (1997). Cannibals with forks: the triple bottom line of 21st century business, Oxford, Capstone.

[6] ERTUGRUL, I_., \& KARAKASOGLU, N. (2007), Performance evaluation of Turkish cement firms with fuzzy analytic hierarchy process and TOPSIS methods. Expert Systems with Applications. doi:10.1016/j.eswa.2007.10.014.

[7] GRI - GLOBAL REPORTING INITIATIVE. Acesso em: 02/11/2019, https://www.globalreporting.org/Information/about-gri/Pages/default.aspx

[8] HWANG, C.L., LAI, Y.J., LIU, T.Y. A new approach for multiple objective decision making. Computers Ops Res. Vol. 20,No. 8,pp. 889-899. 1993.

[9] HWANG, C. L., YOON, K., Multiple Attribute Decision Making: Methods and Applications. Springer, Heidelberg (1981).

[10] IIRC - INTERNATIONAL INTEGRATED REPORTING COUNCIL. Acesso em: 02/11/2019, https://integratedreporting.org/

[11] LIMA JUNIOR, F. R.; CARPINETTI, L. C. R. Uma comparação entre os métodos TOPSIS e Fuzzy-TOPSIS no apoio à tomada de decisão multicritério para seleção de fornecedores. Gestão \& Produção, v. 22, n. 1, p. 17-34, 2015.

[12] LLL Benites, EF Polo. A Sustentabilidade como ferramenta estratégica empresarial: Governança corporativa e aplicação do Triple Bottom Line na Masisa - Rev. Adm. UFSM, Santa Maria, v. 6, Edição Especial, p. 195-210, mai, 2013.

[13] MACEDO, F.B.L; LIMA, G.B.A; RESINENTE, L.P.M.A; LIMA, T.G.B; Avaliação de desempenho da sustentabilidade em uma organização do setor de cosméticos. XXVII SIMPÓSIO DE ENGENHARIA DE PRODUÇÃO (SIMPEP), 2020.

[14] PORTER, M; KRAMER, M. Strategy and Society: The Link Between Competitive Advantage and Corporate Social Responsibility. HBR Spotlight, Harvard Business Review .December 2006. 
[15] RELATÓRIO Anual Natura (2014-2018). Disponível em: https://www.natura.com.br/relatorio-anual. Acesso em: 20 out. 2019 .

[16] SAVITZ, A. W.; WEBER, K. The triple bottom line: how today's best-run companies are achieving economic, social, and environmental success - and how you can too. San Francisco: Wiley \& Sons, 2006.

[17] VAN MARREWIJK, M.; WERRE, M. Multiple levels of corporate sustainability. Journal of Business Ethics, v.44, p.107-119, 2003.

[18] WU, H. Y. et al. A Fuzzy MCDM Approach for Evaluating Banking Performance Based on Balanced Scorecard. Expert Systems with Applications 36(6): 10135-47, 2009. 


\section{Capítulo 6}

A importância da economia circular nos sistemas de produção - Um estudo de caso da Kalundborg Symbiosis

\section{Rayssa Gabrielle da Silva Soares \\ Ronniery Ilario Pereira \\ Gerson Luiz de Abreu Henriques \\ Sara Monaliza Sousa Nogueira \\ Ercilia de Stefano}

Resumo: Devido a finitude dos recursos naturais, uma nova metodologia no sistema de produção deve ser adotada, de modo a melhor aproveitar os recursos naturais e os resíduos geerados por esses sistemas. A economia circular mostra-se como uma alternativa viável para resolver esse problema, pois assemelha-se ao processo natural dos recursos, em que os mesmos são reutilizadas como matéria prima em diferentes ciclos biológicos. Essa metodologia passou a ser adotadas pelo setor industrial como modo de reduzir os gastos com energia, recursos e melhora da imagem da empresa em relação aos consumidores. Por meio de um estudo de caso, avaliou-se a importancia, vantagens e desvantagens dessa nova metodologia de produção. 0 complexo industrial de kalundborg foi pioneiro na implementação da metodologia de economia circular, tendo obtido redução de gastos com energia e matérias primas nos processos de produção das empresas pertencentes ao parque industrial, além de importante parceria com o setor público, havendo ganho também para a comunidade local.

Palavras-chave: kalundborg, Economia Circular, Parque Industrial. 


\section{INTRODUÇÃO}

A crescente escassez de recursos de produção é um dos indicativos que modelos lineares de negócios estão chegando cada vez mais perto de seu limite (MACARTHUR, 2013), e que a forma tradicional pode inviabilizar a continuação de sua operação. Faz-se necessário a conciliação entre empreendimentos e sustentabilidade, com pensamento a longo prazo, onde a visão deve ser sistêmica e inovadora, onde o equilíbrio entre qualidade de vida no planeta e economia devem ser alcançados.

A economia circular se configura como um caminho para o equilíbrio, onde associa o crescimento econômico a um ciclo de desenvolvimento positivo contínuo, que preserva e aprimora o capital natural, otimiza a produção de recursos e minimiza riscos sistêmicos, com a administração dos estoques finitos de matéria prima e fluxos renováveis (CE100 BRASIL, 2017).

STAHEL (2016) compara a economia linear a um rio, transformando os recursos naturais e materiais de base em produtos à venda, através de uma série de etapas de aumento dee valor agregado. No ponto de venda, a propriedade e a responsabilidade por riscos e resíduos são repassadas ao comprador, que passa a ser o novo proprietário e usuário do produto. A economia linear é eficiente para superar a escassez, onde as empresas ganham dinheiro comercializando grandes volumes de mercadorias. Já a economia circular, ainda de acordo com o autor, é como um lago no qual o reprocessamento de bens e materiais geram empregos e economizam energia, reduzindo o consumo e o desperdício de recursos. Projetar produtos para reutilização precisa ser incorporado e adotado pelas empresas (STAHEL, 2016).

0 objetivo deste estudo é realizar uma análise do modelo de economia circular, apresentar alguns exemplos de aplicabilidade da Ecologia e Simbiose Industrial, que vêm potencializando a metodologia, e também destacar como os Parques Industriais Ecológicos contribuem para o avanço e sucesso da Economia Circular. O presente artigo foi produzido com base em estudos teóricos descritivos, por meio de pesquisas bibliográficas.

\section{REVISÃO BIBLIOGRÁFICA}

\subsection{ECONOMIA CIRCULAR}

A economia mundial tem se baseado no modelo linear de negócios, criado logo após a revolução industrial, focado em extrair, transformar, produzir, utilizar e descartar (BRAUNGART; MCDONOUGH; BOLLINGER, 2007; MACARTHUR, 2013). Caso o atual modelo de negócios prevaleça, projeções indicam o aumento do já existente desbalanceamento nos níveis de produção e consumo, dada a finitude dos recursos naturais (SIMONIS, 2013), podendo levar a falência do sistema de produção em um futuro próximo.

De acordo com esse sistema, os produtos são confeccionados de tal maneira que podem ser considerados descartáveis. Tal comportamento adotado por parte dos consumidores, de descartar produtos ao fim de sua vida útil ou até o surgimento do primeiro sinal de mau funcionamento, se deve também ao estímulo gerado pelo setor de produção de bens e serviços, que estimula este tipo de comportamento no consumidor (LABOISSIÈRE, 2015).

Os dados revelam que, em 2018, foram geradas no Brasil 79 milhões de toneladas de resíduos sólidos urbanos (RSU), um aumento de pouco menos de 1\% em relação ao ano anterior. Desse montante, 92\% (72,7 milhões) foi coletado. Por um lado, isso significa uma alta de 1,66\% em comparação a 2017: ou seja, a coleta aumentou num ritmo um pouco maior que a geração. Por outro, evidencia que 6,3 milhões de toneladas de resíduos não foram recolhidas junto aos locais de geração. A destinação adequada em aterros sanitários recebeu 59,5\% dos resíduos sólidos urbanos coletados: 43,3 milhões de toneladas, um pequeno avanço em relação ao cenário do ano anterior. 0 restante $(40,5 \%)$ foi despejado em locais inadequados por 3.001 municípios, de um total de 5.570 no Brasil. Ou seja, 29,5 milhões de toneladas de RSU acabaram indo para lixões ou aterros controlados, que não contam com um conjunto de sistemas e medidas necessários para proteger a saúde das pessoas e o meio ambiente contra danos e degradações (ABRELPE, 2019).

De acordo com (BONCIU, 2014), até 2010, o planeta Terra precisava de um ano e meio para produzir e absorver o que é consumido como matéria-prima e eliminado como lixo em um ano. Ainda, de acordo com as estimativas das Nações Unidas, se as tendências atuais continuarem, até 2030 a humanidade precisaria de duas Terras para funcionar e em 2050, três planetas seriam necessários para atender a demanda de consumo e descarte da sociedade (ORGANIZAÇÃO DAS NAÇÕES UNIDAS BRASIL, 2016). 
Nessa tentativa de se assemelhar à natureza, o setor produtivo deve desenvolver ciclos de materiais e cascatas de energia, tendo como base a utilização de recursos naturais renováveis, bem como a utilização de resíduos e subprodutos, de maneira que tudo seja aproveitado, reduzindo ou até eliminando a geração de resíduos (LEITÃO, 2015).

Neste contexto de produção linear e de níveis elevados de descarte de produtos, surge a economia circular como uma proposta de solução e inovação, porém com dificuldades e barreiras para sua implementação. A economia circular, apresentada pela Fundação Ellen MacArthur com muita profundidade, tem como finalidade construir uma nova economia, que seja restauradora e regeneradora, e um novo modelo industrial que seja responsável por restaurar seus produtos e recuperá-los de forma circular em suas atividades (ELLEN MACARTHUR FOUNDATION, 2012). Importante destacar que o uso substitui o consumo.

A economia circular é centrada no ciclo de desenvolvimento contínuo que preserva e aprimora o capital natural, otimiza a produção de recursos e minimiza riscos sistêmicos, administrando estoques finitos e fluxos renováveis, oferecendo diversos mecanismos de criação de valor dissociados do consumo de recursos finitos. 0 consumo só ocorre em ciclos biológicos efetivos. Os recursos se regeneram no ciclo biológico ou são recuperados e restaurados no ciclo técnico. No ciclo biológico, os processos naturais da vida regeneram materiais, através da intervenção humana ou sem ela. No ciclo técnico, desde que haja energia suficiente, a intervenção humana recupera materiais e recria a ordem em um tempo determinado (MACARTHUR, 2017).

O Brasil paulatinamente insere-se na economia circular, onde oportunidades já identificadas no setor industrial são exploradas, como novos modelos de negócios, design, recuperação dos materiais, além da economia informal existente. Entre elas pode-se citar o potencial do setor eletroeletrônico, com a recuperação dos materiais e novos serviços; da construção civil, com a redução da quantidade de resíduos gerados; têxtil, com novos materiais e cadeias cíclicas de valor; e plástico, com grandes oportunidades de redução e recuperação, além de novos materiais (CE100 BRASIL, 2017; ELLEN MACARTHUR FOUNDATION, 2016).

Sendo assim, empresas com visão de longo prazo, com foco na inovação e na geração de valor, como apregoado pela Economia Circular, apresentam melhor desempenho econômico que as demais. Tais benefícios representam, em média, ganhos de 36\%, com receita 47\% superior e lucro $81 \%$ maior (BARTON; MANYIKA; WILLIAMSON, 2017).

\subsection{PARQUE INDUSTRIAL}

Parque Industrial e/ou Parque Empresarial é definido como um terreno desenvolvido e subdividido em lotes de acordo com um plano abrangente, com provisões para estradas, transporte e serviços públicos, para uso de um grupo de industrias (CARLOS MAGARINOS, 1998).

Todavia, esse termo pode ser dividido em duas categorias, a depender do porte das empresas que o compõem. No caso das empresas serem de grande porte, com sistemas de produção robustos, como por exemplo uma indústria petroquímica, o parque empresarial classifica-se como parque industrial. No caso de indústrias de pequeno porte, como empresas de serviços por exemplo, o parque classifica-se como industrial misto (LAMBERT; BOONS, 2002).

\subsubsection{PARQUE INDUSTRIAL ECOLÓGICO}

Parque Industrial Ecológico consiste em uma comunidade de indústrias que operam como um ecossistema industrial, buscando o fechamento do ciclo de materiais, a otimização do uso da água e da energia, a cooperação entre as indústrias e o desenvolvimento de parcerias entre elas e a comunidade, viabilizando ganhos de produtividade, o aumento de lucros devido à redução de gastos com transporte, aquisição de matéria prima substituída por resíduos e sua disposição, assim como a diminuição dos impactos ao meio ambiente e à saúde da comunidade, visto que a quantidade de resíduos dispostos no ambiente é reduzida (FRAGOMENI, 2005). 
STARLANDER (2003) define os parques industriais em dois tipos: Colocalizados e Virtuais. A proximidade física entre as indústrias pertencente aos Parques Industriais Ecológico colocalizados facilita o desenvolvimento de sinergias entre elas, permitindo assim, uma maior integração e cooperação entre os atores envolvidos. Já no caso dos Parques Industriais Ecológicos Virtuais, suas integrações não dependem unicamente da proximidade física, mas também da utilização da informática e logística, que proporcionam um maior número de possibilidades de interações entre as diferentes empresas.

\subsection{ECOLOGIA INDUSTRIAL}

Em virtude da ampliação dos debates sobre meio ambiente, emergiu o termo desenvolvimento sustentável, que é definido pela Comissão Mundial para o Meio Ambiente e Desenvolvimento como aquele que atende "às necessidades do presente sem comprometer a capacidade das gerações futuras de suprir suas necessidades" (SESSION, 1987).

Diante deste cenário, houve o surgimento de inúmeros conceitos que visavam atingir o desenvolvimento sustentável, conciliando ganhos econômicos, ambientais e sociais, culminando no final da década de 80, no surgimento do conceito de Ecologia Industrial (EI) (GIBBS; DEUTZ, 2005).

A EI surge com princípios bem definidos ligados à integração de atividades produtivas e reciclagem de recursos. Seus modelos e metas apontam para um modo de organização da economia segundo os princípios de defesa do meio ambiente e exploração sustentável dos recursos naturais (COSTA, 2002).

Os princípios da EI, e mais especificamente a redução da poluição através do intercâmbio de rejeitos entre diferentes atividades, historicamente tem sido aplicada em algumas iniciativas: "Iniciativa de Pesquisa em Emissão Zero (ZERI)", “Complexo Industrial Ecologicamente Balanceado", "Parque Industrial Ecológico" ou "Parque Eco-Industrial (PEI)" (TAVARES, 1999).

\subsection{SIMBIOSE INDUSTRIAL}

A Simbiose Industrial (SI) é um importante instrumento da EI na minimização dos rejeitos. LOWE (1997) define cinco princípios da EI, e destaca a analogia entre Ecologia Industrial e Simbiose Industrial, afirmando que a primeira representa um campo de estudo e pesquisa, e a segunda uma possível maneira de utilizar os princípios daquela.

O autor CHERTOW (2000) classifica SI como o envolvimento de indústrias tradicionalmente separadas em uma abordagem coletiva para a vantagem competitiva envolvendo intercâmbio físico de materiais, energia, água e subprodutos. Contudo, o sucesso dessa atividade torna-se dependente da capacidade de cooperação, integração e sinergias entre as empresas. Nesse sentido, os parques industriais são localidades propícias, devido à proximidade existente entre empresas, para a manifestação concreta do conceito de simbiose industrial.

DOMENECH (2011) explica que SI tem emergido como um corpo de estruturas de intercâmbio para avançar para um sistema industrial mais ecoeficiente através do estabelecimento de uma rede colaborativa de intercâmbio de conhecimento, materiais e energia entre diferentes unidades organizacionais.

USÓN VALERO (2012) citam vantagens para desenvolver a SI, sendo estas: diminuir a pressão institucional, acesso a recursos críticos, poupar custos e eficiência, aprendizagem inter organizacional, economia com subprodutos, poder ou controle sobre outros recursos, fatores para rede de Simbiose Industrial, coordenação e parcerias; inquilinos âncora e campeões na formação; comunicação e confiança e responsabilidade ambiental.

Por outro lado, desvantagens também podem ser diagnosticadas, como: despadronização quanto à classificação do subproduto; desestímulo ao intercâmbio de subproduto devido à matéria-prima ser subsidiada pelo governo; falta de ações do governo para incentivar o intercâmbio do subproduto, em vez de destiná-lo a aterros industriais; distância entre os parceiros, que tende a elevar o custo do transporte do subproduto; reaproveitamento, que pode passar a imagem de qualidade inferior (TANIMOTO, 2004). 


\subsection{INICIATIVAS NO BRASIL}

Especificamente no Brasil, não foram encontrados registros na literatura sobre a existência de Parques Industriais Ecológicos. Já foram observadas iniciativas no Rio de Janeiro, que não prosperou (FRAGOMENI, 2005; MAGRINI; VEIGA, 2018).

Por outro lado, em termos de SI, constatam-se ações desse gênero no Polo Petroquímico de Camaçari, na Bahia (TANIMOTO, 2004), e por meio do Programa Brasileiro de Simbiose Industrial (PBSI) (FIEMG, 2013).

O PBSI é apresentado como uma versão do National Industrial Symbiosis Programme (NISP), originário do Reino Unido e promovido pela Federação das Indústrias do Estado de Minas Gerais (FIEMG), pela Federação das Indústrias do Estado de Alagoas (FIEA) e pela Federação das Indústrias do Estado do Rio Grande do Sul (FIERGS). É direcionado a empresas de diversos setores e tamanhos e visa estabelecer interações lucrativas por meio de recursos (humanos, resíduos materiais, água, energia, logística, compartilhamento de ativos, tecnologia e perícia) que estão disponíveis, mas que ainda sejam subutilizados. O PBSI é divulgado como sendo capaz de diminuir os custos, de proporcionar novos negócios com mercados alternativos e também de construir uma marca ambientalmente responsável, "o que, nos dias de hoje, pode ser um grande diferencial competitivo" (FIEMG, 2013).

Para a seleção do mix de indústrias, CHERTOW (2000) sugere alguns critérios: (1) seleção de indústria âncora, (2) realização de balanço de massa e energia (input outputs analysis) da indústria âncora (3) a partir da identificação de possíveis tipologias industriais para realizar sinergias com a âncora, (4) para cada possibilidade considerada realizar balanço de massa e energia (input outputs analysis), (5) verificar a viabilidade técnica, econômica e ambiental da realização das sinergias identificadas, (6) seleção final do mix de indústrias.

De qualquer maneira, mesmo na presença de uma solução técnica viável não se pode garantir que um projeto de SI terá progresso na sua execução. Em muitos casos, as políticas ambientais do governo, a confiança e a comunicação entre as indústrias, as práticas de gestão específicas dentro das indústrias e outras barreiras não técnicas tornam-se um obstáculo significativo para o reconhecimento e desenvolvimento de uma sinergia potencial (BRAND; BRUIJN, 1999).

\section{ESTUDO DE CASO}

Um exemplo de economia circular e simbiose industrial colocalizada é o parque industrial ecológico de Kalundborg, na Dinamarca, reconhecido pelo caso bem-sucedido desse modelo, em que as companhias realizam o intercâmbio de materiais e energia para serem usados como insumo, formando um ciclo fechado de produção, como mostra a FIGURA 1 (KALUNDBORG SYMBIOSIS, 2020a).

Como já foi apresentado, o modelo de economia linear, take-make-use-dispor, tem sido o modelo dominante de produção. Entretanto, esse modelo causa impactos negativos no planeta e com isso, se faz necessário a criação e utilização de um novo modelo, o modelo de economia circular. Na Kalundborg Symbiosis, o modelo de economia circular é implementado ao tornar os resíduos de uma empresa a matéria prima para outra. Dessa maneira, o descarte de material é praticamente nulo. 
Figura 1 - Esquema do Parque Industrial Kalundborg Symbiosis.

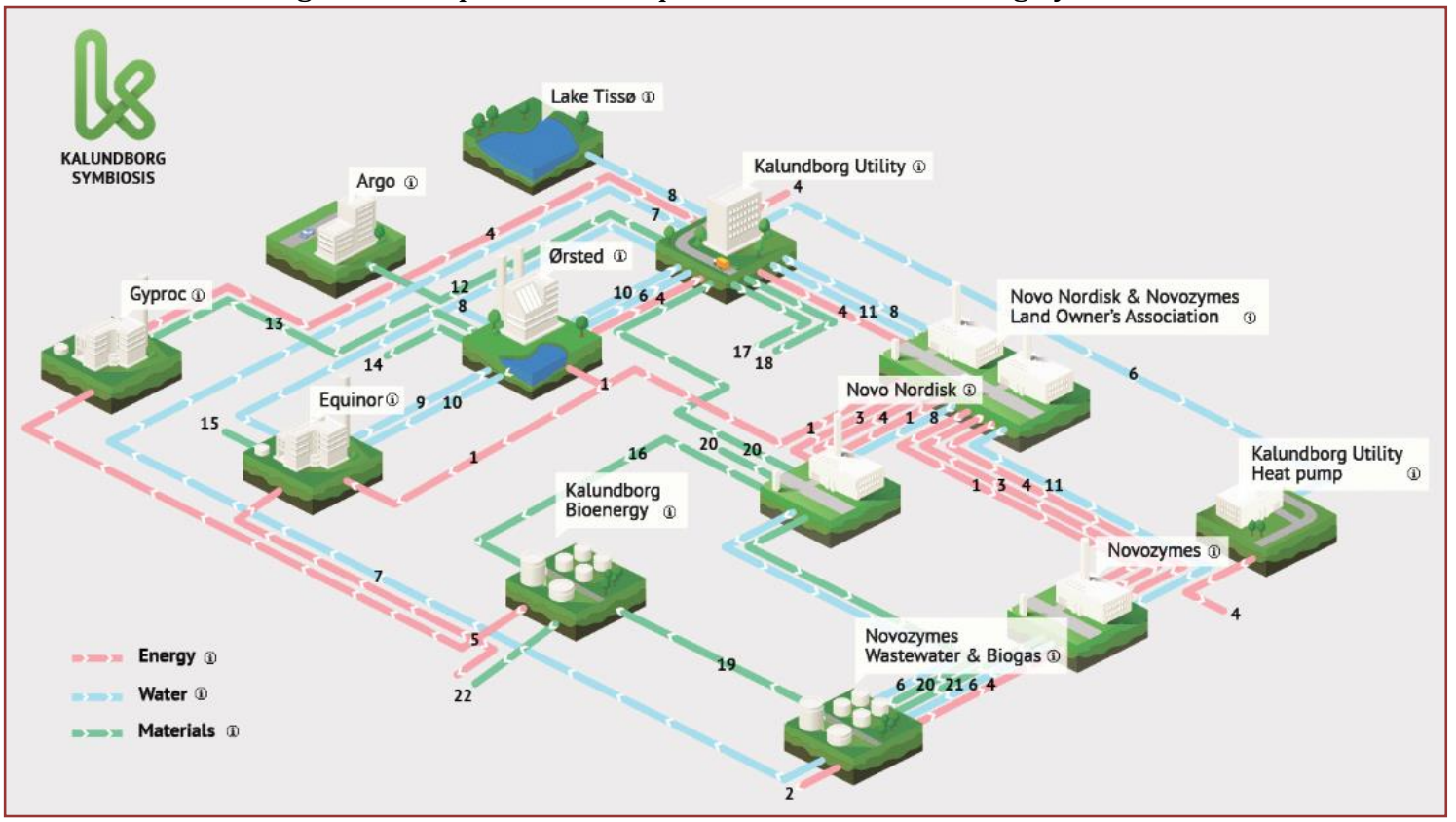

Fonte: (KALUNDBORG SYMBIOSIS, 2020a)

Para entender melhor como estão distribuídas as empresas apresentadas anteriormente na FIGURA 1, segue a foto da planta industrial na FIGURA 2.

Figura 2 - Foto da planta industrial de Kalundborg Symbiosis.

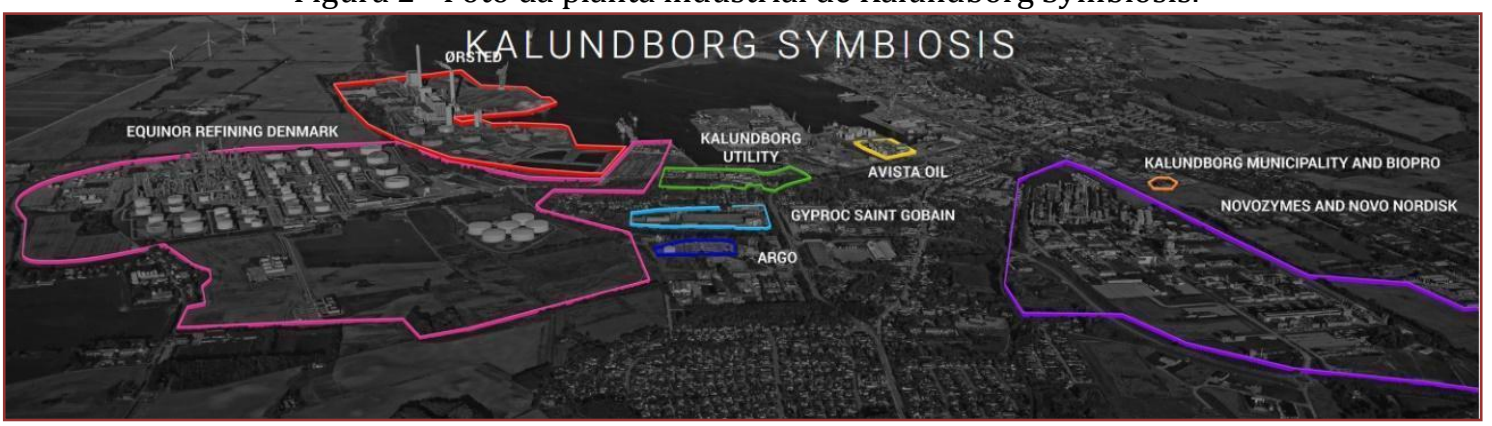

Fonte: Kalunborg Symbiosis, 2020.

A história desse complexo inicia-se em 1961, com o objetivo de atender o abastecimento de água da região. Entretanto, passou a ser considerado como simbiose industrial apenas em 1989 devido a filosofia adotada pelos dirigentes do complexo, working together is just smart business, que viam na sua nova metodologia uma forma de aumentar os lucros. Desde sua fundação em 1961, o complexo passou por diversas transformações, tendo casos de sucesso e fracassos de empreendimentos, quando estes não obtinham o retorno almejado. Tendo sempre em vista o lucro, a Kalundborg mostrou que os objetivos corporativos podem ser conciliados com a proteção ambiental. Com isso que foi abordado até o momento em mente, a Kalundborg Symbiosis almeja alcançar até o ano de 2025, um modelo totalmente circular de economia por meio de colaborações entre as empresas parceiras baseado em confiança, confidencialidade, abertura, igualdade e cooperação (ELLEN MACARTHUR FOUNDATION, 2017).

A Kalundborg conta atualmente com 25 diferentes fluxos de matéria e energia entre as empresas que compõem o complexo, como visto na FIGURA 1.

Em dados numéricos, o complexo industrial de Kalundborg obteve redução considerável de resíduos associado a um lucro decorrente disso, como pode ser visto na auditoria realizada pela Life Cycle Assessment (LCA). 
Foi verificado que tanto as empresas do complexo, como a prefeitura da cidade no qual se situa o complexo, obtiveram redução de gastos na ordem de milhões de euros anualmente, 24 milhões de euros economizados pelas empresas do complexo, ao reutilizar matéria prima e energia, e 14 milhões de euros por parte da prefeitura, ao utilizar o sistema de tratamento de água do parque industrial (DANIELSSON; MØLLER; RANDERS, 2018)

Entre os diversos empreendimentos presentes na Kalundborg, destaca-se a Usina Asnæs, que ao mudar seu combustível, de carvão para a biomassa produzida nas estações de tratamento de efluentes, reduziu as emissões de $\mathrm{CO}_{2}$ em 800 mil toneladas (ENERGY, 2017).

Apesar das reduções na emissão de gases do efeito estufa e redução de gastos ao se adotar uma otimização dos processos de produção por parte da Kalundborg Symbiosis, o processo de produção da empresa em si ainda não poderia ser considerado de economia circular.

Com isso, em 2018, um novo projeto para a melhoria da eficiência do processo de produção foi apresentado, o que tornaria o sistema de produção da empresa um modelo circular, otimizando ainda mais o processo de produção, reduzindo a emissão de $\mathrm{CO}_{2}$ e gastos com o processo de produção (KALUNDBORG SYMBIOSIS, 2020b).

Pode-se notar, que a Kalundborg é um Parque Industrial Ecológico que se tornou referência mundial no conceito de economia circular, ao mostrar de forma prática como esse modelo de produção pode ser lucrativo.

Este estudo menciona o Parque Industrial Ecológico Kalundborg, situado na Dinamarca. Todavia, levou-se a discussão de possíveis vantagens e desvantagens que a aplicação de um modelo deste pode gerar e quais são as barreiras enfrentadas, mencionando o modelo de Simbiose Industrial no Polo Petroquímico de Camaçari, situado na Bahia.

\section{CONCLUSÃO}

A partir da revisão bibliográfica podemos destacar que práticas que rodeiam a Economia Circular, Ecologia Industrial, Parque Ecológico Industrial e Simbioses Industriais podem potencializar ganhos nas esferas econômicas, sociais e ambientais. Vale ressaltar que não existe uma regra para implementação de um Parque Ecológico Industrial, onde cada um tem sua particularidade e planejamento. Contudo, o mesmo é fortemente influenciado pela participação da comunidade e instituições governamentais, desde a escolha do local até estabelecer padrões ambientais que deverão ser seguidos.

Os benefícios econômicos e a maximização de lucros previstos às indústrias se devem a melhoria de sua imagem no mercado, aumento de sua diversidade de consumidores diante de seu acesso a outras camadas do mercado, aumento da receita devido a venda de resíduos (subprodutos), redução do passivo ambiental, entre outros. $O$ governo é motivado a participar do PIE, pois este garante maior cumprimento da legislação ambiental, aumento da base tributária e diminuição de danos ao meio ambiente gerados por processos industriais.

\section{REFERÊNCIAS}

[1] ABRELPE. Panorama Dos Sólidos. Panorama dos Resíduos Sólidos no Brasil 2018/2019, p. 68, 2019.

[2] BARTON, D.; MANYIKA, J.; WILLIAMSON, S. K. Finally, Proof That Managing for the Long Term Pays Off. Harvard Business Review Digital Articles, p. 2-8, 2017.

[3] BONCIU, F. The European economy: From a linear to a circular economy. Romanian Journal of European Affairs, v. 14, n. 4, p. 78-91, 2014.

[4] BRAND, E.; BRUIJN, T. DE. Shared responsibility at the regional level: the building of sustainable industrial estates. European Environment, v. 9, n. 6, p. 221-231, 1 nov. 1999.

[5] BRAUNGART, M.; MCDONOUGH, W.; BOLLINGER, A. Cradle-to-cradle design: creating healthy emissions - a strategy for eco-effective product and system design. Journal of Cleaner Production, v. 15, n. 13-14, p. 1337-1348, 2007.

[6] CARLOS MAGARINOS. Annual report 1997. [s.l: s.n.]. Disponível em: <https://www.unido.org/resources/publications/flagship-publications/annual-report/annual-report-1997>. Acesso em: 27 jun. 2020. 
[7] CE100 BRASIL. UMA ECONOMIA CIRCULAR NO BRASIL: Uma abordagem exploratória inicial. Disponível em: <https://www.ellenmacarthurfoundation.org/assets/downloads/Uma-Economia-Circular-no-Brasil_Apêndice-deEstudos-de-Caso.pdf>. Acesso em: 29 maio. 2020.

[8] CHERTOW, M. R. Industrial symbiosis: Literature and taxonomy. Annual Review of Energy and the Environment, v. 25, n. June, p. 313-337, 2000

[9] COSTA, M. M. DA. Princípios de Ecologia Industrial Aplicados à Sustentabilidade Ambiental e aos Sistemas de Produção de aço. Tese submetida ao corpo docente da Coordenação dos Programas de Pós-Graduação Em Engenharia da Universidade Federal do Rio de Janeiro como parte dos requisitos necessários para a obtenção do grau de doutor em ciências em Planejamento Energético, p. 257, 2002.

[10] DANIELSSON, S. E.; MØLLER, P.; RANDERS, L. Modelling $\mathrm{CO}_{2}$ savings and economic benefits for the Kalundborg Symbiosis. [s.l: s.n.].

[11] DOMENECH, T.; DAVIES, M. Structure and morphology of industrial symbiosis networks: The case of Kalundborg. Procedia - Social and Behavioral Sciences. Anais...Elsevier Ltd, 1 jan. 2011

[12] ELLEN MACARTHUR FOUNDATION. The New Plastics Economy: Rethinking the future of plastics. Ellen MacArthur Foundation, n. January, p. 120, 2016.

[13] ELLEN MACARTHUR FOUNDATION. Effective industrial symbiosis. Disponível em: <https://www.ellenmacarthurfoundation.org/case-studies/effective-industrial-symbiosis>. Acesso em: 27 jun. 2020.

[14] ENERGY, D. One of the Largest Power Stations in Denmark Can Phase Out Coal. Disponível em: <https://stateofgreen.com/en/partners/state-of-green/news/one-of-the-largest-power-stations-in-denmark-canphase-out-coal/>. Acesso em: 27 jun. 2020.

[15] FIEMG. Programa Brasileiro de Simbiose Industrial. Federação das Indústrias do Estado de Minas Gerais (FIEMG). Belo Horizonte/MG. Disponível em: <http://www.fiemg.org.br/Default.aspx?tabid=13193>. Acesso em: 30 maio. 2013.

[16] FRAGOMENI, A. L. M. Parques Industriais Ecológicos como Instrumento de Planejamento e Gestão Ambiental Cooperativa. [s.l: s.n.].

[17] GIBBS, D.; DEUTZ, P. Implementing industrial ecology? Planning for eco-industrial parks in the USA. Geoforum, v. 36, n. 4, p. 452-464, 1 jul. 2005.

[18] KALUNDBORG SYMBIOSIS. Systems make it possible, people make it happen | Kalundborg Symbiose -. Disponível em: <http://www.symbiosis.dk/en/systems-make-it-possible-people-make-it-happen/>. Acesso em: 29 maio. 2020a.

[19] KALUNDBORG SYMBIOSIS. Systems make it possible, people make it happen | Kalundborg Symbiose -. Disponível em: <http://www.symbiosis.dk/en/systems-make-it-possible-people-make-it-happen/>. Acesso em: 27 jun. 2020b.

[20] LABOISSIÈRE, J. A Economia Circular Aplicada No Brasil: uma Análise a Partir dos Instrumentos Legais Existentes Para a Logística ReversaXI Congresso Nacional de Excelência em Gestão, 2015.

[21] LAMBERT, A. J. D.; BOONS, F. A. Eco-industrial parks: Stimulating sustainable development in mixed industrial parks. Technovation, v. 22, n. 8, p. 471-484, 1 ago. 2002.

[22] LEITÃO, A. Economia circular: uma nova filosofia de gestão para o séc. XXI. Circular economy: a new management philosophy for the XXI st century. Portuguese Journal of Finance, Management and Accounting, v. 1, n. 2, p. 23, 2015.

[23] LOWE, E. A.; MORAN, S. R.; WARREN, J. L. (VIAF)269673085. Discovering industrial ecology : an executive briefing and sourcebook. [s.l.] Columbus (Ohio) : Battelle press, 1997.

[24] MACARTHUR, E. Towards the Circular Economy: Opportunities for the consumer goods sector. Ellen MacArthur Foundation, p. 1-112, 2013.

[25] MACARTHUR, E. What is a Circular Economy? | Ellen MacArthur FoundationEllen Macarthur Foundation, 2017. Disponível em: <https://www.ellenmacarthurfoundation.org/circular-economy/concept>. Acesso em: 29 maio. 2020

[26] MAGRINI, A.; VEIGA, L. B. E. Ecologia industrial: desafios na perspectiva da economia circular. [s.l: s.n.].

[27] ORGANIZAÇÃO DAS NAÇÕES UNIDAS BRASIL. Banco Mundial: serão necessários 3 planetas para manter atual estilo de vida da humanidade. Disponível em: <https://nacoesunidas.org/banco-mundial-serao-necessarios-3planetas-para-manter-atual-estilo-de-vida-da-humanidade/>. Acesso em: 28 maio. 2020.

[28] SESSION, S. W. World commission on environment and development. Our Common Future; WCED, Ed.; Oxford University Press: Oxford, UK, 1987. 
[29] SIMONIS, U. E. Decoupling natural resource use and environmental impacts from economic growth. [s.l: s.n.].

v. 40

[30] STAHEL, W. R. The circular economyNatureNature Publishing Group, , 23 mar. 2016. Disponível em: <http://www.nature.com/news/the-circular-economy-1.19594>. Acesso em: 27 jun. 2020

[31] STARLANDER, J.-E. Industrial Symbiosis: A Closer Look on Organisational Factors A study based on the Industrial Symbiosis project in Landskrona, Sweden[Publisher information missing], , 2003. Disponível em: $<$ https://portal.research.lu.se/portal/en/publications/industrial-symbiosis-a-closer-look-on-organisational-factorsa-study-based-on-the-industrial-symbiosis-project-in-landskrona-sweden(eb635d5a-46cc-4d1f-be75167f35269566).html>. Acesso em: 27 jun. 2020

[32] TANimoto, A. H. Proposta de simbiose industrial para minimizar os resíduos sólidos no Pólo Petroquímico de Camaçari. Universidade Federal da Bahia, 2004.

[33] TAVARES, L. Administração Moderna da Manutenção. Rio de Janeiro: [s.n.].

[34] THE ELLEN MACARTHUR FOUNDATION. Towards a Circular Economy - Economic and Business Rationale for an Accelerated Transition. Greener Management International, p. 97, 2012.

[35] USÓN, S.; VALERO, A.; AGUDELO, A. Thermoeconomics and Industrial Symbiosis. Effect of by-product integration in cost assessment. Energy, v. 45, n. 1, p. 43-51, 1 set. 2012. 


\section{Capítulo 7}

Barreiras e desafios para a implantação da Indústria 4.0 - Revisão de Literatura

\section{Davi Teixeira Pinheiro}

José Artur Soares de Almeida Filho

Victor Igor Barros Farias

Resumo: A indústria 4.0 é um projeto do governo alemão com foco na digitalização e virtualização das empresas alemãs. Ela é baseada no sistema Ciber-Físico e para alguns autores é considerada como a $4^{a}$ Revolução Industrial. Este trabalho tem como objetivo realizar uma revisão de literatura sobre as barreiras, desafios e requisitos para adoção de tecnologias para a implantação da Indústria 4.0. Sendo assim, realizou-se um levantamento de trabalhos publicados em journals e conferências disponíveis no bancos de dados das plataformas Science Direct, Scopus e Web of Science e utilizou-se dos software start, mendeley e excel para extrair, organizar e ordenar as informações e dados. Inicialmente foram identificados 531 trabalhos de 18.724 encontrados nas plataformas, e ao final selecionados 40 trabalhos. Assim, foram identificados 303 barreiras, desafios e requisitos para adoção que foram ordenadas em 7 categorias e explicadas cada uma. As barreiras, desafios e requisitos de adoção encontrados demonstram o quanto as empresas enfrentam dificuldades para adotar os conceitos da Indústria 4.0 no dia-a-dia.

Palavras-chave: Indústria 4.0; Barreiras; Desafios; Implantação, Revisão de literatura. 


\section{INTRODUÇÃO}

A história da humanidade é marcada por períodos de grandes inovações que trazem um avanço significativo para a vida e desenvolvimento das sociedades. Durante o século XVIII, alguns avanços tecnológicos importantes levaram a classificar o período como uma Revolução Industrial, a partir daí, o mundo passaria por outras revoluções que mudaram a forma produtiva vigente. 0 advento da máquina a vapor e outras tecnologias revolucionárias que substituíram os diversos processos de manufatura durante 1760 e 1860, marcam a chamada 1ำ Revolução Industrial, ou o que podemos chamar como a fase da Indústria 1.0. Partindo de 1860 até 1900, acontecimentos como o desenvolvimento da eletricidade, o conceito de linha de montagem e produção em larga escala marcam a fase da Indústria 2.0, posteriormente o advento de máquinas automatizadas, aparelhos eletrônicos e o início da internet consagram a fase da Indústria 3.0. Atualmente o mundo engatinha na chamada Indústria 4.0, que traz o conceito de sistemas Ciber-Físicos, a união entre máquinas e redes inteligentes, a produção descentralizada e comandada virtualmente, processos que revolucionam a forma fabril atual. Algumas indústrias ainda são relutantes com a adoção de certas tecnologias ou não possuem recursos para adotálos. Com o intuito de averiguar e identificar tais empecilhos, foi realizado essa revisão bibliográfica para apontar as barreiras, desafios e requisitos para adoção que outros autores recolheram através de pesquisas ao redor do mundo. Isso reflete pontos de melhorias que a tecnologia precisa resolver ou problemas internos necessários a serem sanados para a entrada das indústrias nessa nova revolução.

Este trabalho consiste em 5 capítulos. 0 primeiro apresenta a introdução, um problema e a justificativa para esse trabalho. 0 segundo capítulo oferece um embasamento aos assuntos tratados neste trabalho. 0 terceiro capítulo descreve metodologia, as ferramentas usadas para seleção dos trabalhos e como os tópicos de interesse foram classificados para serem apresentados. 0 quarto capítulo mostra os resultados e o quinto conclui com as considerações sobre os resultados obtidos.

\section{REFERENCIAL TEÓRICO}

\subsection{CONSIDERAÇÕES GERAIS}

Indústria 4.0 é um programa de inovação estratégico adotado pelo governo alemão em 2011. Segundo Sishi e Telukdarie (2017, p.1), também pode ser descrita como uma extensão das 3 revoluções industriais anteriores). Sendo o seu principal objetivo a integração de processos produtivos utilizando tecnologias da informação (Nowotarski e Paslawski, 2017) . A base tecnológica desse conceito é a aplicação de sistemas ciber físicos e as tecnologias associadas a estes sistemas (Internet das coisas, Big Data, inteligência artificial).

A Indústria 4.0 tem como dois de seus princípios fundamentais a integração:

a) Horizontal: Refere-se a digitalização, integração e troca de dados entre toda a cadeia de valor, desde o fornecedor até o consumidor final.

b) Vertical: Refere-se a digitalização, integração e troca de dados entre todos os níveis de produção dentro da empresa.

Lom, Pribyl, Svitek (2016, p.1) citam mais 6 princípios que constituem o conceito de Indústria 4.0:

a) Interoperabilidade: Capacidade de conexão e comunicação entre os sistemas ciberfísicos, humanos e fábricas através da Internet das Coisas.

b) Virtualização: Uma cópia virtual da fábrica é criada, permitindo que o sistema ciber físico monitore todos os processos físicos através de sensores espalhados pela planta.

c) Descentralização: A capacidade do sistema ciber físico de tomar decisões por conta própria, baseado na demanda e necessidades de produção em tempo real.

d) Capacidade de operação em tempo real: Coletar e analisar dados de forma instantânea, permitindo tomada de decisão em tempo real.

e) Orientação a serviços: Os serviços de empresas, sistemas e humanos estão disponíveis e podem ser utilizados por outros participantes, tanto internamente quanto fora da empresa.

f) Modularização: Adaptação das fábricas de acorda com a demanda, substituindo ou expandindo módulos individuais, oferecendo maior flexibilidade para alterar as tarefas das máquinas. 
Recentemente, o tema Indústria 4.0 tem recebido muita atenção, devido ao potencial que a aplicação dos seus princípios e tecnologias tem de elevar a eficiência produtiva das fábricas. Dito isto, faz-se necessário caracterizar as barreiras e desafios enfrentados pelas fábricas na adoção da Indústria 4.0, com o intuito de melhorar o entendimento sobre as dificuldades, ajudando na aplicação das tecnologias e princípios da quarta revolução industrial.

\section{MATERIAIS}

\subsection{MATERIAIS}

Esta pesquisa utiliza-se das bases de trabalhos disponíveis nos portais: Science Direct; Scopus; e Web of Science, publicados em journal e conferências a partir do ano 2000, e dos softwares State of the Art through Systematic Review (StArt), Mendeley e Microsoft Excel para análise e apresentação dos resultados.

O StArt é um gerenciador de revisão sistemática de literatura desenvolvido pelo Laboratório de Pesquisa em Engenharia de Software (LaPES) da Universidade Federal de São Carlos (UFSCAR).

O Mendeley é um gerenciador de referências desenvolvido pela Elsevier e utilizados por pesquisadores e profissionais da academia para organizar os trabalhos acadêmicos.

E o Microsoft Excel é um sistema de planilhas eletrônicas desenvolvidas pela Microsoft Corporation utilizadas pelos profissionais das áreas de finanças, administração, contabilidade e engenharia.

\subsection{MÉTODO}

Para a execução desta pesquisa a utilizou combinação de vários métodos apresentados por Vitorino Filho et al. (2013), Cândido, Barreto e Barros Neto (2014), Petter et al. (2014) e Bouncken et al. (2015). Sendo estabelecido em quatro etapas caracterização do estudo, coleta de dados, análise dos dados e resultados conforme a Figura 1.

A primeira etapa é a caracterização do estudo e nela acontecem seis atividades. A primeira é a definição do tema que tem a Indústria 4.0 como foco que foram traduzidas para a string: "Fourth industrial revolution" OR "Industry 4.0" OR "4th industrial revolution" OR "Industrie 4.0" utilizada para realizar a busca nos bancos de dados das plataformas de busca.

As plataformas de buscas foram definidas de acordo com a qualidade e tamanho da base disponível. Utilizando como critério de seleção para a extração dos trabalhos dos bancos de dados o tipo de trabalho, publicados em conferências e journals em qualquer ano. E por fim, os softwares de análise foram selecionados de acordo com a necessidade para a realização deste trabalho e escolha foi pelo StArt, Mendeley e Excel.

Na coleta de dados, a segunda etapa, ocorreram duas atividades. A primeira foi a identificação dos estudos que consistiu em realizar a busca dos trabalhos utilizando a string determinada na etapa anterior e aplicando os filtros disponíveis em cada plataforma quanto ao tipo de trabalho e ao ano de publicação. Assim foram obtidas as seguintes quantidades de trabalhos 5.776 no Science Direct, 8.075 no Scopus e 4.873 no Web of Science, totalizando 18.724.

Em seguida, realizou-se a extração dos metadados de cada trabalho. Esse processo se deu pela seleção dos trabalhos encontrados e exportando em arquivos de texto de extensão bibtex (*.bib) as informações como título, resumo, palavras chaves, nome dos autores, ano de publicações dentre outros dados, o que não inclui o conteúdo do trabalho. 
FIGURA 1 - Etapas do estudo bibliométrico

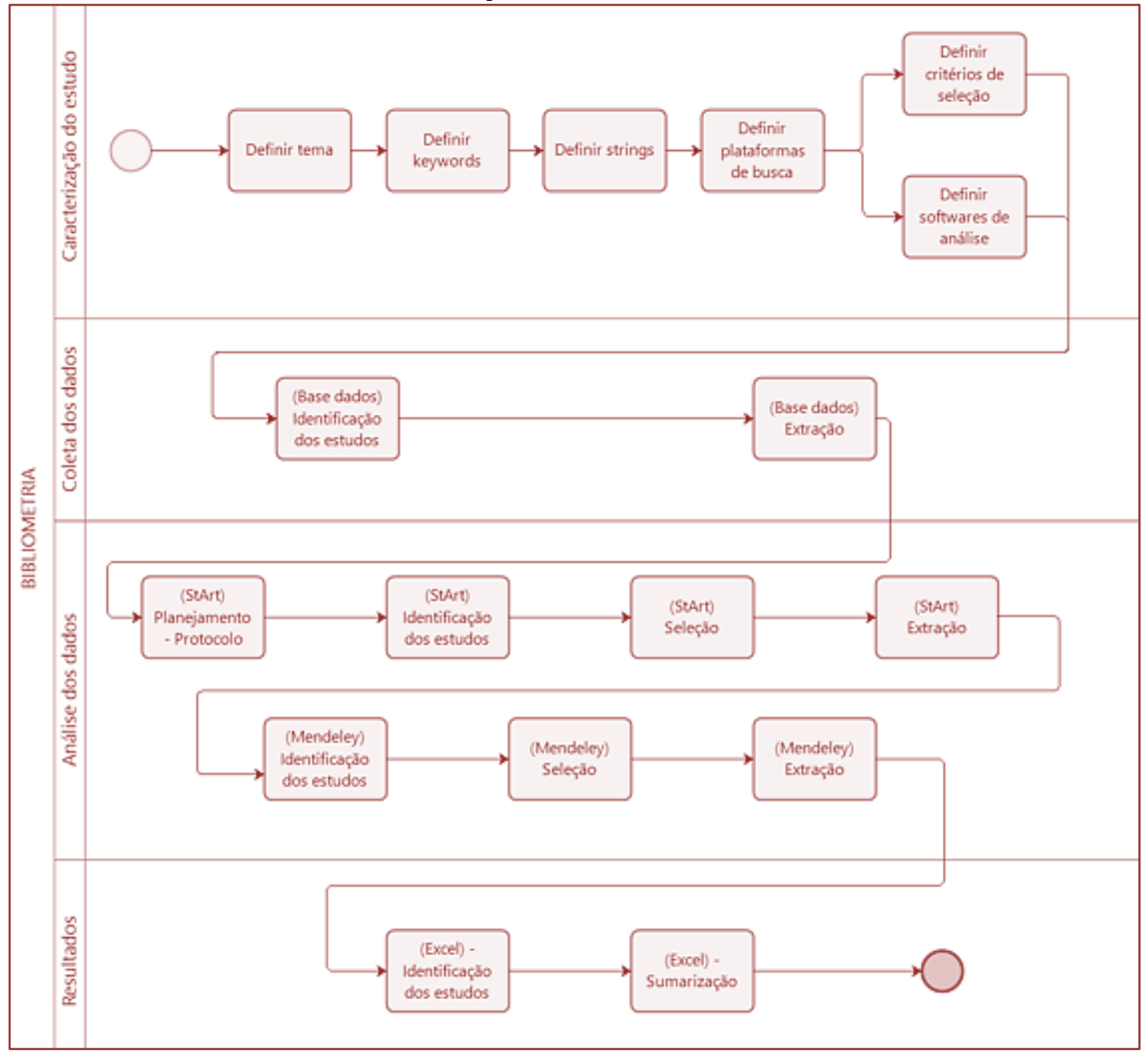

Fonte: Autor

Já na etapa de análise de dados, utilizou-se dois softwares o StArt e o Mendeley dividido em sete atividades. A primeira se deu com o planejamento, isto é, com o preenchimento do protocolo estabelecido pelo StArt, onde foi indicado o problema, os objetivos do trabalho, as fontes dos dados, e as keywords e sinônimos (Quadro 1) que foram utilizadas como critérios de classificação dos trabalhos por meio de escores conforme o Quadro 2, onde foram atribuídos valores maiores que 0 a 531 trabalhos.

QUADRO 1 - Lista de Keywords e sinônimos

\begin{tabular}{|c|}
\hline Keywords e sinônimos \\
\hline Adopt \\
\hline Barrier \\
\hline Challenge \\
\hline Implantation \\
\hline Model \\
\hline Opportunities \\
\hline
\end{tabular}

Fonte: Adaptado do software StArt (2020)

QUADRO 2 - Método de cálculo do valor dos escores.

\begin{tabular}{|l|c|}
\hline \multicolumn{1}{|c|}{ Keyword encontrado em: } & Pontos \\
\hline Título & 5 \\
\hline Resumo & 3 \\
\hline Keywords & 2 \\
\hline
\end{tabular}


Na segunda atividade, de identificação dos estudos, realizou-se a importação dos metadados obtidos nos bancos de dados por meio dos arquivos de texto (*.bib) e foi observado a duplicidade dos trabalhos. Em seguida, na terça atividade foram aplicados os critérios de inclusão e exclusão dos artigos pelos scores obtidos por cada trabalho conforme o Quadro 3, pela leitura do título foram identificados 207 trabalhos e com a leitura do resumo 40 trabalhos foram selecionados.

\begin{tabular}{l} 
QUADRO 3 - Critérios de seleção de estudos: inclusão e exclusão \\
\begin{tabular}{|l|l|} 
Critério \\
\hline Inclusão & (I) Industry 4.0 + Barrier or Challenge or Adoption \\
\hline Exclusão & (E) Out of topic \\
\hline Exclusão & (E) Score $=0$ \\
\hline Exclusão & (E) Duplicated \\
\hline Exclusão & (E) Article data unavailable \\
\hline Exclusão & (E) Article file unavailable \\
\hline
\end{tabular} \\
\hline
\end{tabular}

Na quarta atividade, e última utilizando o StArt, vem a extração dos trabalhos. Nesta etapa foi realizado o download na extensão ( ${ }^{*}$.pdf) dos 40 trabalhos e realizado a leitura completa. Após este momento foram selecionados 40 trabalhos que estão diretamente ligados ao tema e exportados ao Mendeley para as próximas atividades desta etapa.

A quinta etapa é identificação dos estudos no Mendeley. Nela os arquivos dos trabalhos na extensão (*.pdf) foram importados e inseridos no software. Em seguida, foram verificados os detalhes dos documentos, isto é, os metadados como título, autor, local e ano de publicação, resumos, palavras-chaves, Digital Object Identifier (DOI) e Uniform Resource Locator (URL) de onde encontra-se disponível o arquivo na rede mundial de computadores, Internet.

Por fim, é realizada a sexta e sétima atividade desta etapa, que consiste em identificação dos estudos e seleção utilizando o Mendeley. A primeira parte foram selecionados os trabalhos que além atender aos objetivos do trabalho quanto ao seu conteúdo, também apresentam conformidade quanto aos critérios dos detalhes do documento verificado na atividade anterior. E na última etapa, os dados, isto é, os detalhes de cada trabalho, foram exportados para na extensão ( $*$.xml) para a sumarização utilizando o Microsoft Excel.

Encerrando esta seção, temos a última etapa com duas atividades: a identificação dos estudos e sumarização, ambas utilizando o Excel. No primeiro momento, foi o arquivo originado do Mendeley e este aberto no formato de planilha, onde os metadados foram organizados em formato banco de dados. Em seguida deu-se a sumarização dessas informações de acordo com o objetivo proposto deste trabalho. As barreiras, desafios e requisitos para adoção foram coletadas dos artigos e foram classificadas em dois níveis.

O primeiro nível classificou as barreiras e desafios em:

a) Internos: Barreiras e desafios que dependem inteiramente da empresa, sendo esta responsável por resolvê-los, visando a adoção da tecnologia.

b) Externos: Barreiras e desafios que dependem de fatores externos, como incentivos estatais, formação de profissionais qualificados e cooperações entre vários setores do mercado, não sendo a empresa capaz de sanar tais problemas sozinha.

No segundo nível foram classificados em:

a) Tecnológicos: Relacionados a segurança de dados, maturidade tecnológica, incompatibilidade, interoperabilidade, etc.

b) Educacionais: Relacionados à qualificação profissional, informação quanto aos benefícios e funcionamento das tecnologias, mentalidade dos gestores.

c) Organizacionais: Relacionados à cultura da empresa, sistema de gestão adotado, hierarquia da empresa e interação entre os seus diferentes níveis, falta de padrões ou detalhes sobre o processo industrial.

d) Sociais: Relacionados à desemprego, desigualdade, redução salarial e preocupações éticas. 
e) Financeiros: Relacionados a custo de implementação, lucratividade, risco de investimento, custos operacionais.

f) Mercado: Referentes a interações de mercado como demanda, competição, regulamentação, interação entre indústrias.

\section{RESULTADOS E DISCUSSÕES}

Com os 40 artigos selecionados, separamos os 3 em tipos diferentes de foco, sendo artigos com foco em barreiras, artigos com foco em desafios, e artigos com foco na adoção de tecnologias para a fase da Indústria 4.0. Com a leitura desses artigos, eram extraídos tópicos apontados pelos autores que indicassem o foco do artigo em questão, com isso obtivemos 303 tópicos, todos eles com o objetivo em comum de apontar motivos determinantes para a adoção de tecnologia ou não, sendo 124 tópicos em adoção, 139 em barreiras e 40 em desafios. Os meios como os autores chegaram nos tópicos eram variados, alguns utilizam de questionários em que apontam hipóteses e averiguam a confiabilidade com pessoas das indústrias, outros faziam um levantamento de trabalhos semelhantes, dentre outros meios. 0 tipo de hipóteses ou tópicos variavam entre características das quais as empresas requisitavam que a tecnologia atendessem, como a compatibilidade, um sistema de segurança, modo operante pouco complexo ou características que influenciavam para não adoção como impossibilidade de adequar-se ao sistema existente, incerteza de efetividade, alto e esforço para coordenar.

Assim como variava a forma metodológica dos trabalhos, também era variado o tipo de indústria e o país de origem, tendo exemplares do ramo da indústria automobilística da indonésia, como também representantes do agronegócio brasileiro. Com isso esperava-se obter um apanhado global das dificuldades encontradas para evolução nos ramos industriais. Vale ressaltar que dentre os tópicos obtidos, não foram considerados sua relevância entre as amostras apontadas, visto que para esse trabalho, a intenção era apenas obter um apanhado geral, visto que a relevância de certos problemas pode variar dependendo da setor da indústria, do país ou da tecnologia que está sendo analisada, fatores como custo podem ser muito relevantes em pequenas empresas ou em países em desenvolvimento, e de pouca relevância em grandes empresas ou em países desenvolvidos.

Com os 303 tópicos extraídos dos trabalhos, foram classificados de acordo com o descrito no final da capítulo 3.2, e o resultado pode ser visto a seguir:

QUADRO 4 - Resultado quantitativo dos tópicos

\begin{tabular}{|c|c|c|c|}
\hline Classificação 1 & Internas & Externas & Total \\
\hline Tecnológica & 28 & 40 & 68 \\
\hline Educacional & 32 & 40 & 72 \\
\hline Financeira & 18 & 10 & 28 \\
\hline Social & 7 & 7 & 14 \\
\hline Organizacional & 56 & 2 & 58 \\
\hline Mercado & 13 & 44 & 57 \\
\hline Estrutural & 5 & 1 & 6 \\
\hline Total & 159 & 144 & 303 \\
\hline
\end{tabular}

Fonte: Autores 
FIGURA 1 - Resultado Percentual dos tópicos

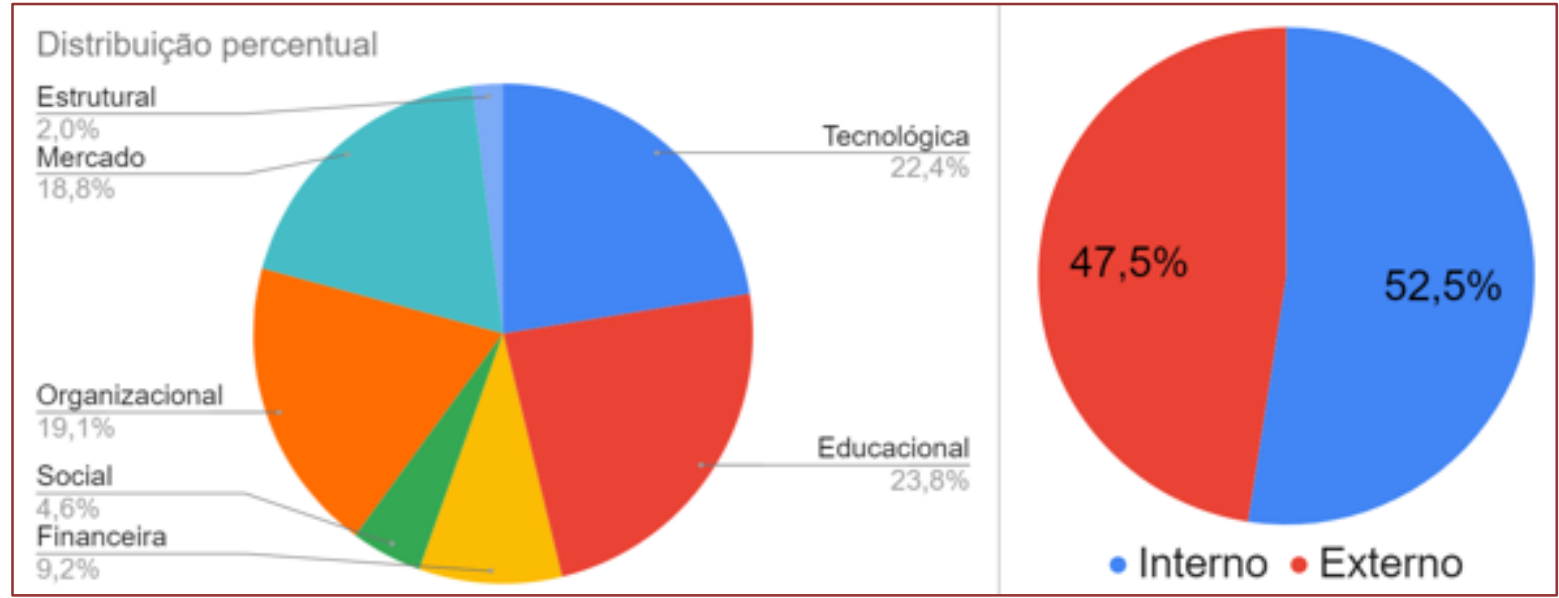

Fonte: Autores

FIGURA 2 - Resultado distribuído das categorias.

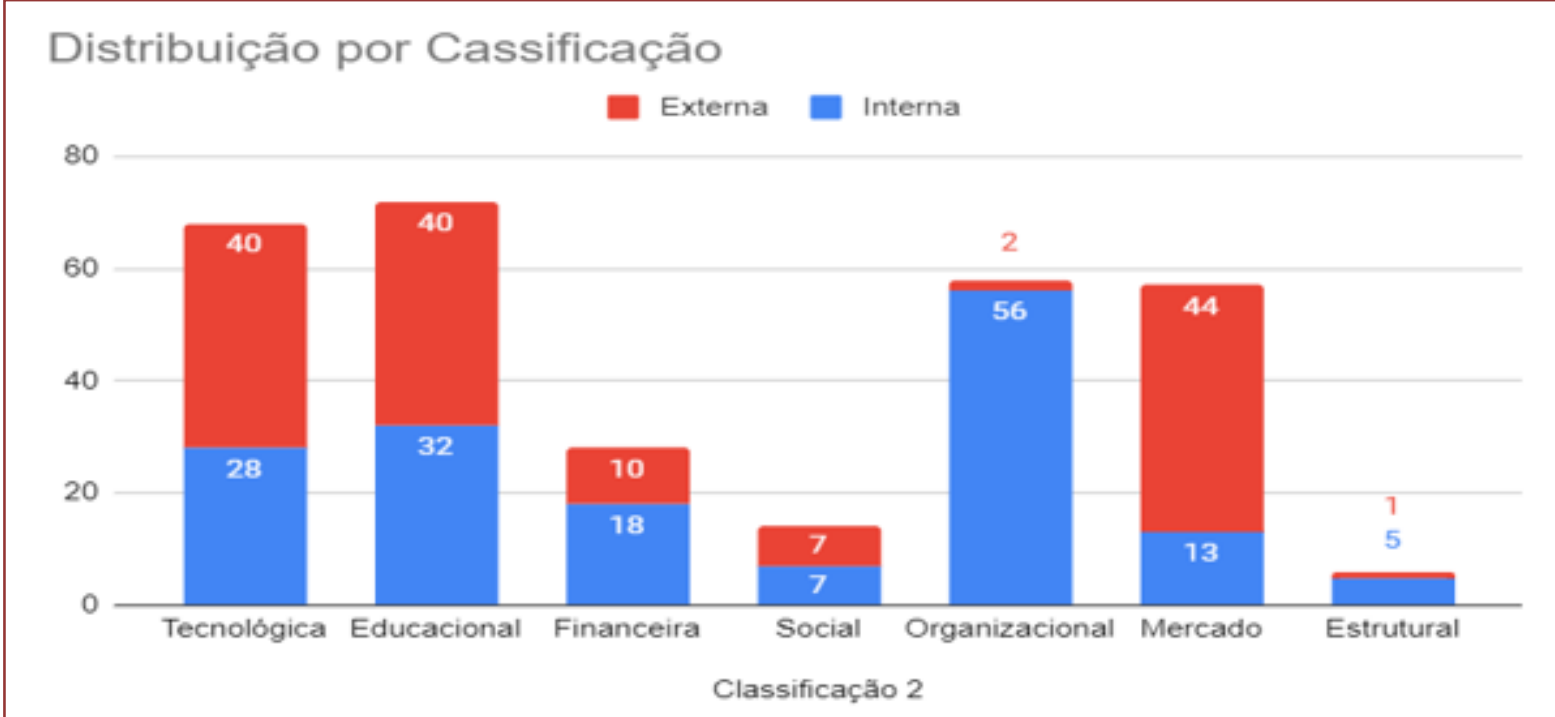

Fonte: Autores

\section{CONSIDERAÇ̃̃ES FINAIS}

Fatores Educacionais se mostraram os mais significantes, o que mostra baixa qualificação dos funcionários e uma falha nas empresas de tecnologia em informar e educar seus prospectos clientes, em segundo lugar ficou fatores tecnológicos, alguns apontados como incompatibilidade das novas tecnologias com a tecnologia existente nas fábricas, e também problemas com segurança, visto que um dos principais marcos da Indústria 4.0 está no fato de ter tudo em rede, o que abre brechas para ataques cibernéticos. Fatores financeiros não foram muitos apontados, pode-se concluir que se os resultados da tecnologia forem vantajosos e compatíveis, as empresas estão dispostas a pagar seus custos. Fatores sociais também foram poucos apontados, sinal de que problemas como a perda de empregos ou redução salarial não é levada em grande consideração.

Fatores tecnológicos, educacionais e de mercado tiveram maior classificação externa, visto que esses devem ser pontos no quais as empresas que oferecem a tecnologia deveriam sanar para conseguirem adoção de seus produtos nas indústrias. O maior apontamento entre os fatores interno está em organizacional, fatores como má eficiência da gestão ou não colaboração dos funcionários ainda barram o desenvolvimento industrial.

No geral, Fatores internos e externos se mantiveram equilibrados, visto que é necessário um esforço em conjunto de empresa e elementos externos para que haja a migração para Indústria 4.0. É possível ver dentre os tópicos retirados, que incentivos do governo ou leis que colaborassem para evolução eram apontados em mais de um artigo de diferentes países mostrando a necessidade de interação 
governo/indústria.

Os dados são considerados satisfatórios e como recomendação de trabalho futuro, sugere-se um método de averiguação, para identificar, dentre as classificações, qual mais impacta uma empresa em questão, a fim de poder traçar planos estratégicos mais eficazes.

\section{REFERÊNCIAS}

[1] SISHI, M.N.; TELUKDARIE, A. Implementation of industry 4.0 technologies in the mining industry: A case study. International Conference on Industrial Engineering and Engineering Management, 2017.

[2] NOWOTARSKI, P.; PASLAWSKI, J. Industry 4.0 Concept Introduction into Construction SMEs. IOP Conference Series: Materials Science and Engineering, 2017.

[3] LOM, M.; PRIBYL, O.; SVITEK, M. Industry 4.0 as a part of smart cities. Smart Cities Symposium, Prague, 2016.

[4] FILHO, V.A.V.; DA SILVA, E.M.; JÚNIOR, J.B.C.; PIRES, S.R.I. Identificação dos principais autores em coopetição. Revista Ibero-Americana de estratégia, 2013.

[5] CÂNDIDO, L.F.; BARRETO, J.M.L.; BARROS NETO, J.P. Análise da produção científica relacionada ao custeiometa (target costing) na construção civil nos últimos 5 anos (2009-2013). XV Encontro nacional de tecnologia do ambiente construído, 2014.

[6] PETTER, R.R.H.; RESENDE, L.M.; JÚNIOR, P.P.A.; HORST, D.J. Systematic review: an analysis model for measuring the coopetitive performance in horizontal cooperation networks mapping the critical success factors and their variables. The Annals of Regional Science, 2014.

[7] BOUNCKEN, R.B.; GAST, J.; KRAUS, S.; BOGERS, M. Coopetition: a systematic review, synthesis, and future research directions. Review of Managerial Science, 2015. 


\section{Capítulo 8}

\section{O impacto do uso da tecnologia da Indústria 4.0 sobre a sociedade: Resultados e transformações sociais}

\section{Fernanda Carlos da Fonseca \\ Sara Monaliza Sousa Nogueira}

\section{Ercilia de Stefano}

Resumo: A Indústria 4.0 levou a mudanças expressivas tanto no contexto organizacional quanto social. Os paradigmas desta nova era conduzem as fábricas a melhorias significativas com a eficiência e eficácia em sua produção. No entanto, a sociedade não apresenta, em sua totalidade, benefícios na aplicação destes modelos industriais. Com isso, o presente artigo objetiva abordar as principais transformações sociais, contemplando os seus desafios e seus benefícios para analisar os desdobramentos sobre a responsabilidade social no novo contexto industrial. A pesquisa de caráter exploratório, foi classificada de abordagem qualitativa e com procedimento bibliográfico. A partir de revisões bibliográficas, foi possível explorar os desafios sociais frente aos pilares da Indústria 4.0, em contrapartida, os mesmos são responsáveis por grandes melhoras sociais, como segurança no trabalho. Assim, permitiu-se realizar o levantamento das transformações, sejam benéficas ou maléficas, que essa nova era trouxe para a sociedade e assim fomentar estudos posteriores.

Palavras-chaves: Responsabilidade social, Indústria 4.0, Sociedade 5.0, Impacto Social. 


\section{INTRODUÇÃO}

Novas tecnologias que surgiram em meados do século passado, os computadores e softwares, complementado pelo advento da internet, trouxeram enormes transformações à sociedade como um todo. A habilidade das máquinas de substituírem a mão de obra humana com grande efetividade vem sendo um dos principais propulsores da atual revolução industrial.

Em 2011, frente às automações fabris, surge a chamada Indústria 4.0, que traz as chamadas smart factories (fábricas inteligentes), nas quais humanos e robôs trabalham cada vez mais próximos (WEISS et al., 2016), quando não são substituídos integralmente pelos autômatos.

Nesse novo contexto organizacional, a responsabilidade social representa uma forma de autoregulação corporativa que integra-se ao modelo de negócios existente, que no ambiente fabril envolve, principalmente, áreas como normas ambientais e trabalhistas (CHOI, 2017).

Desse modo, para o novo ambiente 4.0, é possível observar mudanças no que diz respeito à organização de trabalho. Segundo Santos et al. (2018) as organizações podem apoiar e incentivar a criatividade e habilidades dos trabalhadores, utilizando as máquinas para a realização de tarefas repetitivas ou de difícil posição corporal. As interfaces homem-máquina devem ser intuitivas para auxiliarem nas novas interações adaptadas às restrições de trabalho.

Dentre essas evidências, o presente artigo, através de uma pesquisa bibliográfica, objetiva abranger os impactos da Indústria 4.0 sobre a sociedade em geral, esclarecendo o rumo dessa indústria para a responsabilidade social, por meio das principais transformações sociais acerca da nova era industrial, com o propósito de elucidar a problemática social e seus impactos tanto positivos quanto negativos e acompanhar essas transformações em futuros estudos.

\section{REVISÃO BIBLIOGRÁFICA}

\subsection{INDÚSTRIA 4.0}

A Indústria 4.0, também conhecida como Manufatura Avançada, Indústria Avançada ou Internet Industrial das Coisas, está ligada a diversas áreas de estudo, e recentemente tem sido amplamente abordada em pesquisas. As pesquisas apresentam que, mudanças no cenário tecnológico, tem a capacidade de alterar a forma como as pessoas se relacionam, trabalham e vivem (ROBLEK; MESKO; KRAPEZ, 2016).

A Quarta Revolução Industrial é a primeira revolução a levar em consideração o conhecimento antes de se tornar concreta a sua aplicação (HERMANN et. al., 2015).

Considera-se que o setor 4.0 representa um novo estágio industrial, em que a integração dos processos de fabricação vertical e horizontal e a conectividade do produto ajuda as empresas a alcançarem um maior desempenho produtivo e econômico, de acordo com Dalenogare et al. (2018). Nessa pesquisa foi levantada que algumas indústrias brasileiras já adotam diferentes tecnologias citadas como pilares da Indústria 4.0.

O relatório da Boston Consulting Group (BCG, 2019) sugere nove principais pilares da Indústria 4.0, que define como base para novas transformações produtivas e para o crescimento coorporativo, sendo eles descritos na figura 1 a seguir. 
Figura 1- Pilares da indústria 4.0

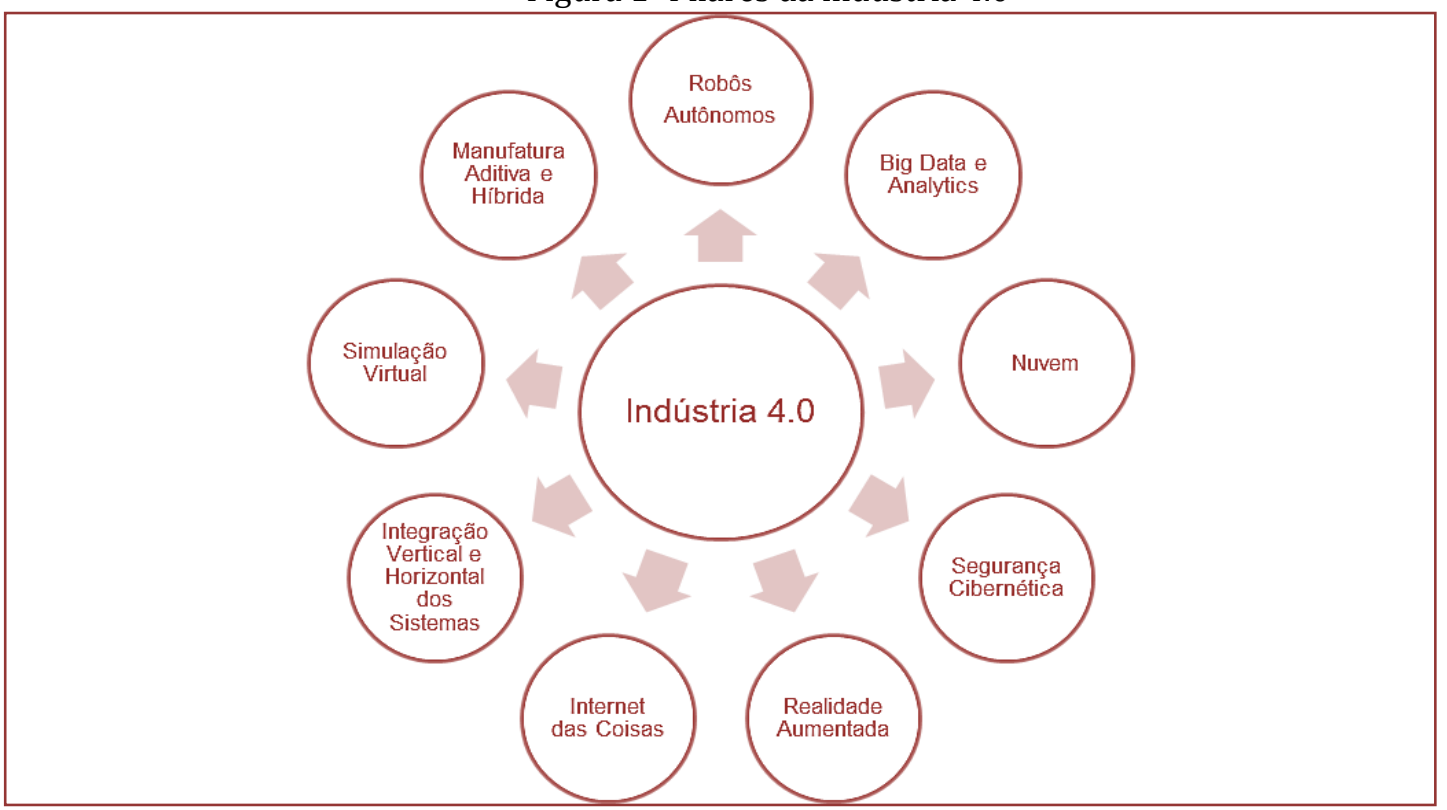

Fonte: Adaptado de Boston Consulting Group (BCG, 2019)

Os Robôs Autônomos são conhecidos como máquinas inteligentes que desempenham funções com parcial ou total independência do controle humano. Os robôs mais sofisticados apresentam uma ampla gama de funções, de adaptabilidade às situações adversas, bem como raciocínio artificial que pode ser capaz de alcançar níveis bastante complexos, por exemplo, robôs autônomos para a pulverização de pesticidas em estufas (SAMMONS et al., 2005), para mapear ambientes fechados (HEINEN, 2012), ambientes aquáticos (JANUSZ et al. 2015), no chão de fábrica de indústrias automotivas (SOBREIRA et al., 2020).

Já a Manufatura Aditiva é considerada uma das principais tecnologias revolucionárias da Indústria 4.0, e representa uma mudança na confecção de produtos, já que ela é capaz de produzir objetos de geometria complexa sem a necessidade de se criar ferramentas específicas para tal, através da impressão 3D (BCG, 2019). Essas máquinas de manufatura aditiva, conhecidas como flexíveis não têm, no entanto, detalhamentos acerca da flexibilidade inserida no gerenciamento de operações (EYERS et. al., 2018).

O uso de Simulação Virtual é feito por meio de sistemas específicos que integram dados e produzem análises sobre determinados problemas, podendo intervir e solucioná-los. 0 sucesso da simulação é dependente da estrutura dos dados utilizados, sendo estes de boa qualidade e quantidade ideais para que a haja a efetividade (BCG, 2019).

A Integração na Indústria 4.0 está relacionado a maneira como o sistema se relaciona. De acordo com (PÉREZ-LARA, et. al., 2018), o crescimento industrial e tecnológico, obtidos por meio dos novos sistemas organizacionais na Indústria 4.0, levou a transformações e adaptações das novas formas de gestão empresariais, considerando os sistemas verticais e horizontais, sendo o primeiro referido ao sistema de tecnologia de informação e à cadeia de fornecimento e valor, já o segundo, mostra os componentes internos a níveis hierárquicos, representando os sistemas de TI e abrangendo os vários níveis dentro de determinadas indústrias.

A Internet das Coisas (Internet of Things - IoT), o pilar mais conhecido da Indústria 4.0, visa conectar diversos dispositivos a qualquer hora e qualquer lugar independente de quem os utilize. Essa nova era, em que as realidades convergem, é capaz de gerar e compartilhar informações a um serviço de nuvem (cloud), como também, criar ambientes inteligentes (BOBOC, CEBUC, 2019).

Ainda de acordo os autores, ela descreve um ambiente em que as máquinas são ligadas através da internet, que possibilita ter informações dos equipamentos conectados em tempo real, podendo apresentar soluções automatizadas para problemas identificados, bem como reportar a centrais para que a intervenção humana ocorra, trazendo agilidade e melhoria dos processos, além de melhorar os benefícios sociais, técnicos e econômicos. 
Para Santos et al.(2018), os sistemas ciber-físicos podem se auto organizar, monitorar processos e criar cópias virtuais do mundo real. Já a internet das coisas conecta máquinas, objetos e pessoas em tempo real.

A Computação em Nuvem (cloud computing) se tornou um assunto importante e popular na área de tecnologia de rede e tem papel fundamental, pois permite armazenar, trocar e gerir as informações recebidas dos sistemas ciber físicos e dos dispositivos IoT, e possibilita que os processos produtivos e negócios agregem valor para as organizações, online, ininterruptamente (HUANG, 2016).

Com o impulso direcionado às tecnologias da IoT e da internet, os dados tornam-se cada vez mais acessíveis e inseridos no contexto das empresas, resultando, assim, no Big Data, sendo outro importante pilar na Indústria 4.0 (ZHONG, et. al., 2017).

Constituído pelo conjunto de grande volume de dados e, possuindo uma análise eficiente (Big Data Analytics), constitui uma importante ferramenta para auxiliar na tomada de decisões, seja no âmbito estratégico, tático ou operacional, que garante a otimização do tempo, de recursos, flexibilidade, dentre outros pontos positivos, a melhoria na análise de dados que é apresentar (BCG, 2019).

O processamento de Big Data industrial está na formatação de dados, redução de dimensionalidade, avaliação das atividades, entre outros pontos. De modo geral, o Big Data possui características conhecidas como " $5 \mathrm{~V}$ ", isto é, volume, velocidade, variedade, veracidade e o valor (YAN, et. al.,2017).

Segundo Jayavardhana et al.(2013), os recursos de computação e armazenamento, banco de dados, sensores e pessoas precisam estabelecer relações de integração uma com as outras para serem efetivos de fato.

De acordo, ainda, com o Boston Consulting Group (2019), os recursos computacionais que fazem o grande diferencial na Indústria 4.0 trazem consigo um alto risco de vulnerabilidade na segurança dos dados. Falhas de segurança podem expor as informações, comprometer o correto funcionamento de equipamentos e serviços, trazendo riscos não só para as empresas, mas também para empregados e usuários.

Surge assim a Segurança Cibernética, que se refere aos sistemas que interagem entre dispositivos para resolver determinados problemas existentes no mundo real, dessa forma, os sistemas ciber-físicos se tornam, atualmente, um dos principais alvos dos hackers e quaisquer danos submetidos a eles pode trazer grandes perdas (AL-MHIQANI, et al., 2018).

O último pilar, a Realidade Aumentada, auxilia na resolução de problemas produtivos, com a simulação de tarefas e de cenários a partir da sobreposição da realidade virtual, como também, oferece uma grande capacidade em aplicações industriais e educacionais (KIRNER, TORI, 2017).

\subsection{RESPONSABILIDADE SOCIAL}

Melo e Brenand (2004) destacam que uma empresa com responsabilidade social é aquela que respeita seus compromissos com seus empregados, acionistas e parceiros, como também exerce uma gestão ética, transparente e responsável de seus negócios.

Para Eberhardt-Toth (2017) é necessário que haja o levantamento dos integrantes do conselho de Responsabilidade Social Corporativa (RSC) para que assim possa impactar positivamente no desempenho social corporativo. 0 estudo feito por ele, mostrou evidências de que esse desempenho mais elevado acontece em empresas onde o comitê RSC apresenta características, tais como: maior proporção de conselheiros independentes, não associados ao diretor executivo, maior idade média dos conselheiros, presidência e tamanho menor.

Já a pesquisa feita por Shaukat e Trojanowski (2016) baseou-se em administração e governança corporativa para desenvolver um modelo teórico que explicite a relação do conselho administrativo, com a responsabilidade social corporativa de uma empresa, com a responsabilidade ambiental e com o desempenho social. Conforme obtidos os resultados da pesquisa, conclui-se que quanto maior a orientação de responsabilidade social do conselho (medido pela variedade de gênero, experiência econômica e a sua independência), é maior a proatividade e abrangência da estratégia de responsabilidade social da empresa, assim como é a sua responsabilidade ambiental e social. 
Não obstante, Sena (2018) levantou exemplos de falta de RSC, a seguir citados: o uso incorreto dos atuais conceitos associados aos novos desafios tecnológicos e novas áreas de atividade administrado pela Indústria 4.0, e o abuso cometido a eles que se expõem a críticas, às vezes até a condenação social. Com isso, estudos descrevem que há problemas éticos e de responsabilidade social que atinge, também, a cocriação em organizações, isto é, acometem às práticas que buscam a inovação por meio de engajamento e da participação de pessoas.

Vale destacar que em 2004 o Brasil adotou uma norma elaborada pelo Instituto Nacional de Metrologia, Qualidade e Tecnologia - INMETRO denominada: Responsabilidade Social - Sistema de gestão Requisitos, que criou o Programa Brasileiro de Certificação em Responsabilidade Social, onde simultaneamente o país liderou o Grupo de Trabalho da ISO (International Organization for Standardization) sobre o mesmo tema. Em 2012 foi publicada a segunda versão da norma (ABNT NBR 16001:2012).

Ela traz como definição de Responsabilidade Social:

"Responsabilidade de uma organização pelos impactos de suas decisões e atividades na sociedade e no meio ambiente, por meio de um comportamento ético e transparente que:

- Contribua para o desenvolvimento sustentável, inclusive a saúde e o bem estar da sociedade;

leve em consideração as expectativas das partes interessadas;

- Esteja em conformidade com a legislação aplicável e seja consistente com as normas internacionais de comportamento, e

- Esteja integrada em toda a organização e seja praticada em suas relações."

Ainda de acordo com a norma, ela é aplicável a todos os tipos e portes de organizações (pequenas, médias e grandes) e de todos os setores (governo, ONG's e empresas privadas); é uma norma de sistema de gestão e deve estar integrada por toda a estrutura organizacional; faz-se necessário o comprometimento de todos, especialmente da alta direção; e, finalmente, estabelece os requisitos mínimos de gestão com responsabilidade social, seguindo as premissas: responsabilização (accoutability) a transparência; comportamento ético; respeito pelos interesses das partes interessadas; o atendimento aos requisitos legais e outros requisitos subscritos pela organização; o respeito às normas internacionais de comportamento; o respeito aos direitos humanos e a promoção do desenvolvimento sustentável.

Infelizmente a ISO 26000 é de caráter voluntário não obrigatório, e não se caracteriza como legislação, pois a norma não estabelece requisitos a serem cumpridos, traz apenas recomendações, através de elementos que podem ser incorporados aos sistemas de gestão já existentes, sugerindo formas de integrar a Renponsabilidade Social às atividades usuais da organização.

\section{PROCEDIMENTOS METODOLÓGICOS}

O método científico, segundo Marconi e Lakatos (2003), é a junção das atividades sistemáticas e racionais, que, com maior segurança e economia, estabelecem o objetivo-conhecimento válido e verdadeiro, de forma a descobrir os erros e avaliar as discussões.

A pesquisa em questão segue a proposta de Gil (2008), que subdivide o estudo em seus objetivos e procedimentos técnicos. Quanto aos objetivos, é de caráter exploratório com abordagem qualitativa, pois procura oferecer informações e orientar estudos posteriores e contribue para um novo olhar acerca dos rumos da nova era industrial. Sendo assim, visa abordar a temática da responsabilidade social, suas transformações no novo contexto da Indústria 4.0 e explorar essa relação.

Ademais, a pesquisa é classificada como pesquisa bibliográfica sendo constituída por bases em materiais já existentes, com o uso de bancos de dados para a busca de livros e artigos científicos (GIL, 2008). Utilizou também como suporte, sites para corroborar questões atuais.

0 universo pesquisado foi a Indústria 4.0, com sua fundamentação referente à abordagem da responsabilidade social, dessa forma, utilizou-se variados bancos de dados de literatura para incrementar a revisão de literatura e estruturar os resultados obtidos, como base Scopus, Capes e Google Acadêmico, por intermédio de artigos de publicações tanto nacional quanto internacional, com o uso de palavraschaves para facilitar e direcionar a pesquisa. 
Sendo assim, chegou-se aos resultados sobre o tema em questão, para validação do objetivo de responder a principal questão referente à responsabilidade social, no que tange às transformações, em meio à Indústria 4.0 e auxiliar em estudos posteriores.

\section{RESULTADOS E DISCUSSÕES}

\subsection{IMPACTO DA INDÚSTRIA 4.0 NA SOCIEDADE}

O impacto da indústria 4.0 sobre a população é controverso e polêmico principalmente na questão de geração de emprego e na renda, sendo que o perfil do trabalhador mudou nesta nova era (ROBLEK; MESKO; KRAPEZ, 2016).

Os mais recentes estudos acerca dos impactos dessa revolução apontam para uma mudança totalitária sobre a empregabilidade, de acordo com Stojanova et. al. (2019), o número de empregos e ocupações que exigem apenas habilidades baixas diminui constantemente, levantado, assim, a questão sobre o futuro dos empregos.

Para Tessarini e Saltorato (2018) foram identificados quatro impactos provocados pela Indústria 4.0 na organização de trabalho, dentre eles o aumento do desemprego tecnológico, causado pelo uso excessivo de tecnologias. Entretanto, tem-se algumas mudanças que visam a novas oportunidades de emprego, com novas técnicas e especialização. Os novos trabalhadores aptos a competirem com essas máquinas devem ter dentre suas competências a criatividade, a flexibilidade, a inovação e a visão empreendedora.

O conceito Triple Bottom Line proposto por Elkington (1994), comumente chamado de tripé da sustentabilidade, considera três vertentes: econômico, ambiental e social, e nesse sentido, a indústria 4.0 considera um crescimento positivo nesses três aspectos.

Para Carbeck (2016), o pilar social será beneficiado na pela utilização da automação nos setores de Mineração e Industrial, eliminando atividades de repetição de algumas etapas na produção.

Através desta perspectiva, será necessário o aumento na qualificação dos profissionais, com ênfase àqueles ligados à tecnologia, uma das interfaces da Quarta Revolução Industrial.

Os outros dois pilares ganharam resultados positivos em algumas performances como diminuição de resíduos, e aumento de produtividade e lucratividade em decorrência dessa redução e otimização. Com isso, como menciona Buhr (2015), "é imprescindível que olhemos com mais atenção para esse aspecto, para que seja possível identificar onde estão os riscos, mas também as oportunidades para o progresso e a inovação social".

Nesse sentido, no atual contexto de pandemia do COVID 19, é previsto que cerca de 25 milhões de empregos sejam perdidos em todo o mundo como resultado desse cenário segundo a Organização Internacional do Trabalho (OIT, 2020). Com isso, em meio à pandemia, Normas Internacionais do Trabalho fornecem respostas políticas que se concentram em medidas de proteção à saúde dos trabalhadores, principalmente, por bases na responsabilidade social.

Para isso, enquanto o cenário se estabelece com trabalhadores em suas casas para maior proteção, empresas estão flexibilizando suas atividades, permitindo o uso do home office, ou seja, trabalhar em suas próprias casas (ROSSI, 2020), esta relação de trabalho, pautada pela Indústria 4.0.

A informatização na Industria Avançada possibilita trazer soluções possíveis para alguns problemas, como por exemplo, na mobilidade urbana, agricultura, saúde e energia, de acordo com a Confederação Nacional Industrial (CNI, 2016). Ela se caracteriza pelo controle da produção a partir da comunicação das máquinas via internet, com a criação dos sistemas cibernéticos e viabilizado pela inteligência artificial.

É de suma importância as possibilidades de transformação que a Quarta Revolução Industrial trouxe para a área da saúde. Seja no monitoramento, automação e na análise que os novos modelos tecnológicos acometem, a redução no número de acidentes poderá ser feita e a otimização dos processos. A inteligência artificial é a mais promissora no que tange à melhoria nos aspectos hospitalares, com a precisão nos resultados de testes, a criação de novos tratamentos, medicina preventiva bem como a gestão de recursos na unidade de atendimento (DE PAULA, 2018). 
De outro modo, a questão da empregabilidade é um assunto muito debatido de acordo com WEF (2016). 0 Fórum Econômico Mundial fala sobre a polaridade que existe entre a ideia de empregos ilimitados e a de substituição da mão-de-obra, consequentemente, a perda desses trabalhos. Para Carvalho (2018), a "otimização exigirá do profissional, habilidade com o mundo digital. Ele precisará ser multidisciplinar, saber conceitos de matemática, tecnologia da informação e robótica".

Nesse contexto, a internet das coisas também facilitará a comunicação dos funcionários à empresa, isso porque será possível realizar o cumprimento das tarefas nas próprias residências (home office). Outrossim, a qualificação dos trabalhadores ocorrerá dentro das fábricas, em primeira instância, sendo necessário capacitá-los em seus postos de trabalho (CARVALHO, 2018), motivando autonomia e autogestão, modificações agregam valor para a sociedade.

De acordo com Scavarda et al, 2019, a lógica em torno de temas relacionados à sustentabilidade e indústria 4.0 estabelece uma relação da responsabilidade corporativa com a sociedade. Com base na pesquisa realizada pelo autor envolvendo recursos humanos, conceito de sustentabilidade, indústria 4.0, responsabilidade corporativa, obteve-se como resultado possíveis propostas, com destaque a responsabilidade social corporativa e indústria 4.0, com enfoque na geração de jovens, pois estão mais familiarizados com a tecnologia.

\section{CONCLUSÕES}

A partir das pesquisas bibliográficas aqui apresentadas, é possível realizar algumas análises e conclusões. Do ponto de vista empresarial, o advento da Indústria 4.0 é muito positivo, pois aumenta a produtividade, reduz retrabalho, desperdício, aumenta a qualidade do produto final, reduz riscos de processos por acidentes de trabalho, onde atividades perigosas e/ou insalubres poderão ser realizadas por robôs, enfim, uma gama de possibilidades de aumento da lucratividade e da responsabilidade social.

Sendo assim, é possível observar o caráter social proporcionado pela nova era industrial, dessa maneira as contribuições que as empresas devem prestar aos trabalhadores é mais evidente na Indústria 4.0, como por exemplo a qualificação de seus funcionários para seus novos postos de trabalho e a redução dos riscos em acidente de trabalho.

Contudo, como ponto negativo para a indústria é o investimento inicial em tecnologia e automação, fato esse que tem deixado o Brasil ainda mais defasado quanto à modernização industrial.

Já do ponto de vista do trabalhador, infelizmente verifica-se a redução de postos de trabalho, com destaque para os menos qualificados. Far-se-ão necessárias políticas sociais para inclusão, como cursos voltados à tecnologia e operação de robôs, visando a aumentar a empregabilidade da mão-de-obra. Como ponto positivo da indústria 4.0 para o trabalhador, é o aumento da segurança nos postos de trabalho, como acima mencionado.

Ademais, por meio da responsabilidade social, um funcionário que esteja com alguma dificuldade de acesso físico ao seu posto de trabalho, poderá, dependendo de sua função na empresa, cumprir suas atividades via internet, flexibilizando assim a forma de lidar com suas obrigações e sua vida social, e melhorando a qualidade de seus serviços.

Portanto, pode-se observar que a sociedade é afetada diretamente pelas novas tecnologias advindas da Indústria 4.0, benéfica e maleficamente. É preciso, pois, tornar os trabalhadores aptos para a nova realidade e ratificar a responsabilidade social nas empresas conforme as tecnologias vão se inovando. Para isso, mostra-se interessante essa abordagem, sendo essencial acompanhar essas transformações em estudos futuros, envolvendo empresas e sociedade, assim sendo, levantar todos os desafios que as acompanham frente ao rumo dessa indústria e aos avanços tecnológicos. 


\section{REFERÊNCIAS}

[1] ASSOCIAÇÃO BRASILEIRA DE NORMAS TÉCNICAS. NBR 16001: Responsabilidade social - Sistema de gestão Requisitos. Rio de Janeiro: ABNT, 2012.

[2] AL-MHIQANI, M., et al. Cyber-security incidents: a review cases in cyber-physical systems. International Journal of Advanced Computer Science and Applications. 9(1), pp. 499-508, 2018.

[3] BOBOC, D. I., CEBUC, S. C. Internet of Things (IoT). Database Systems Journal, vol. X/2019, 2019.

[4] BOSTON CONSULTING GROUP. Embracing Industry 4.0 and Rediscovering Growth, 2019. Disponível em: <https://www.bcg.com/pt-br/capabilities/operations/embracing-industry-4.0-rediscovering-growth.aspx>. Acesso em: 20 mai. 2019.

[5] BUHR, D. Social Innovation Policy for Industry 4.0. Friedrich-Ebert-Stiftung, Division for Social and Economic Policies, 2015. Disponível em: <http://library.fes.de/pdf-files/wiso/11479.pdf > Acesso em 10 abr. 2019.

[6] CARBECK, J. Revista Valor Econômico. Conferência Ethos, 2016.

[7] CARVALHO, D. Revolução em Curso. Correio Braziliense, 2018. Disponível em: <https://www.correiobraziliense.com.br/educacaoprofissional/profissional/>. Acesso em: 01 mai. 2019.

[8] CHOI, J. The Future of Jobs and the Fourth Industrial Revolution: business as usual for unusual business, 2017. Disponível em: <http://blogs.worldbank.org/psd/future-jobs-and-fourth-industrial-revolution-business-usualunusual-business>. Acesso em 27 de mar. 2020.

[9] CONFEDERAÇÃO NACIONAL INDUSTRIAL. Desafios para Indústria 4.0 no Brasil, 2016. Disponível em: <https://bucket-gw-cni-static-cms-si.s3.amazonaws.com/media/filer_public/d6/cb/d6cbfbba-4d7e-43a0-978486365061a366/desafios_para_industria_40_no_brasil.pdf>. Acesso em: 03 abr. 2019.

[10] DALENOGARE, L. S., et al. A contribuição esperada das tecnologias da indústria 4.0 para o desempenho industrial. International Journal of Production Economics, 2018. pp. 383-394.

[11] DE PAULA, C. Inteligência Artificial na Indústria da Saúde: risco ou oportunidade? Healthcare Management, 2018. Disponível em: <https://hcm.grupomidia.com/com-o-tema-inteligencia-artificial-na-industria-da-saude-riscoou-oportunidade-7o-cimes-traz-debate-sobre-a-importancia-da-inovacao-no-setor/>. Acesso em 10 de jun. 2019.

[12] EBERHARDT-TOTH, E. Who Should Be on a Board Corporate Social Responsibility Committee? Journal of Cleaner Production, 2017, Vol.140, pp. 1926-1935.

[13] ELKINGTON, J. Towards the Sustainable Corporation: win-win-win business strategies for sustainable development. California Management Review, v.36, n.2, p.90-100, 1994.

[14] EYERS, D.R., et al. The flexibility of industrial additive manufacturing systems. International Journal of Operations \& Production Management, Vol. 38 No. 12, pp. 2313-2343, 2018. https://doi.org/10.1108/IJOPM-042016-0200.

[15] GIL, A. C. Métodos e Técnicas de Pesquisa Social. 6. ed. São Paulo: Atlas, 2008.

[16] HEINEN, F. J. Sistema de controle híbrido para robôs móveis autônomos. Dissertação de mestrado submetida no Programa de Pós-Graduação em Computação Aplicada da Universidade do Vale do Rio do Sinos, 2012. Disponivel em: http://www.repositorio.jesuita.org.br/handle/UNISINOS/2198 Acesso em: 08/07/2020.

[17] HERMANN, M., PENTEK, T., OTTO, B. Desing Principles for Industrie 4.0 Scenarios: a literatue review, Working Paper, 2015.

[18] HUANG, J.Y. Patent portfolio analysis of the cloud computing industry. Journal of Engineering and Technology Management. V. 39, 2016, Pages 45-64

[19] INSTITUTO NACIONAL DE METROLOGIA QUALIDADE E TECNOLOGIA - INMETRO (2004). Disponível em: http://www.inmetro.gov.br/ qualidade/responsabilidade_social/contextualizacao.asp. Acesso em 27 de mar. 2020.

[20] JANUSZ, W., MIELIMAKA, R., NIEZABITOWSKI, M., ORWAT, J., SIKORA, P. Surface monitoring of water basins based on use of autonomous flying robots. 20th International Conference on Methods and Models in Automation and Robotics, MMAR 2015, 7283905, pp. 376-381, 2015.

[21] JAYAVARDHANA, G., et.al. Internet of Things (IoT): A vision, architectural elements, and future directions. Future Generation Computer Systems, 2013, vol. 29, pp. 1645-1660.

[22] KIRNER, C., TORI, R. Fundamentos de Realidade Aumentada. 2017. (Ed.). Fundamentos e Tecnologia de Realidade Virtual e Aumentada.

[23] MARCONI, M., LAKATOS, E. M. Fundamentos De Metodologia Científica. São Paulo: Atlas, 2003.

[24] MELO NETO, F. P. BRENAND, J. M. Empresas Socialmente Sustentáveis: o novo desafio da gestão moderna. Rio de Janeiro: Qualitymark, 2004. 
[25] ORGANIZAÇÃO INTERNATIONAL DO TRABALHO (2020). Disponível em: <https://www.ilo.org/brasilia/noticias/WCMS_738780/lang--pt/index.htm>. Acesso em 20 de abr. 2020.

[26] PÉREZ-LARA, M., et. al. Vertical and horizontal integration systems in industry 4.0. Wireless Networks, 2018.

[27] ROBLEK, V., MESKO, M., KRAPEZ, A. A Complex View of Industry 4.0. SAGE Open, v. 6, n. 2, p. 1-11, 2016.

[28] ROSSI, C. Coronavírus e o Futuro do Trabalho: o depois é agora, 2020. Disponível em: < https://www.meioemensagem.com.br/home/opiniao/2020/03/18/coronavirus-e-o-futuro-do-trabalho-o-depois-eagora.html>. Acesso em 20 de abr. 2020.

[29] SAMMONS, P.J., FURUKAWA, T., BULGIN, A. Autonomous pesticide spraying robot for use in a greenhouse. Proceedings of the 2005 Australasian Conference on Robotics and Automation, ACRA, 2005.

[30] SANTOS, B. P., et al. Indústria 4.0: desafios e oportunidades. Revista Produção e Desenvolvimento, 2018, Vol.4.316.

[31] SCAVARDA, A. et al. Uma Análise da Responsabilidade Social Corporativa e da Indústria 4.0, com foco na geração de jovens: uma estrutura sustentável de gestão de recursos humanos. Revista Sustentabilidade, 2019, 11 (18).

[32] SENA, N. A Digitalização e a Sustentabilidade Trazem um Novo Conceito: a sustentabilidade 4.0. Consumidor Moderno, São $\quad$ Paulo. $\quad$ Nov. $2018 . \quad$ Disponível <https://www.consumidormoderno.com.br/2018/10/03/digitalizacao-a-sustentabilidade-em-um-novo-conceitosustentabilidade-4-0/>. Acesso em: 17 de mai. 2019.

[33] SHAUKAT, A., QIU, Y., TROJANOWSKI, G. Board Attributes, Corporate Social Responsibility Strategy, and Corporate Environmental and Social Performance. Journal of Business Ethics, 2016, Vol.135 (3), pp.569-585.

[34] SOBREIRA, H., et al. Autonomous Robot Navigation for Automotive Assembly Task: An Industry Use-Case. In book: Robot 2019: Fourth Iberian Robotics Conference, pp.645-656 (2020). Doi 10.1007/978-3-030-35990-4_52.

[35] STOJAnOVA, H., LIETAVCOVA, B., RAGUZ, I. V. The Dependence of Unemployment of the Senior Workforce upon Explanatory Variables in the European Union in the Context of Industry 4.0. Social Sciences, 2019, 8(1), 29.

[36] TESSARINI, G., SALTORATO, P. Impactos da Indústria 4.0 na Organização do Trabalho: uma Revisão Sistemática da Literatura. Revista Produção Online. Florianópolis, SC, v. 18, n. 2, p. 743-769, 2018.

[37] WEISS, A., et al. First Application of Robot Teaching in na Existing Industry 4.0 Environmemte: does it really work? Societies, v.6, n. 3, p. 20, 2016.

[38] WORD ECONOMIC FORUM. The future of jobs: employment, skills and workforce strategy for the fourth industrial revolution. Report. Genebra, 2016. Disponível em: < http://reports.weforum.org/future-of-jobs-2016/ > Acesso em 05 mai. 2019.

[39] YAN, J., et al. Big Data Industrial em um Ambiente Indústria 4.0: desafios, Esquemas e Aplicações para Manutenção Preditiva. IEEE Access, vol. 5, pp. 23484-23491, 2017, doi: 10.1109 / ACCESS.2017.2765544.

[40] ZHONG, R. Y., et. al. Intelligent Manufacturing in the Context of Industry 4.0: A Review. Engineering, 2017, 3(5): $616-630$. 


\section{Capítulo 9}

Reflexões sobre o potencial socioeconômico de uma Associação de Catadores em Nova Era/MG

\section{Jean Carlos Machado Alves \\ João Pedro de Almeida Oliveira}

Resumo: Os catadores de materiais recicláveis compõem uma das classes de trabalhadores que ainda sofrem com os efeitos do capitalismo, sendo alvos de estigmas e preconceitos. esses sujeitos encontram nas associações uma alternativa para melhores condições de vida e trabalho, além da inclusão social. Assim, o presente artigo teve por objetivo "analisar os potenciais sociais e econômicos de uma associação de catadores de materiais recicláveis em minas gerais". Foram realizados pesquisa documental e bibliográfica, visita in-loco, contatos com lideranças e apoiadores da associação e coleta de dados. Foi possível verificar uma dependência da associação em relação ao poder público, esse que, por muitas vezes, se apresenta de forma impositiva no cumprimento de metas aos associados. Observou-se também que com o apoio de colaboradores a associação potencializa suas causas sociais e ambientais, buscando a valorização do catador e o respeito ao meio ambiente.

Palavras-chave: Catadores de materiais recicláveis; economia solidária; gestão ambiental.

0 presente artigo foi apresentado no XXVII SIMPEP/2020 e a pesquisa tem o apoio da Pró-Reitoria de Pesquisa, PósGraduação e Inovação da Universidade Federal de Ouro Preto. 


\section{INTRODUÇÃO}

Nos últimos tempos, com a constante mecanização e informatização dos processos de trabalho junto à ressignificação da acumulação do capital, impostos pelo mercado capitalista, grande parte dos trabalhadores tiveram seus meios tradicionais de renda perdidos, gerando situações de vulnerabilidade social. Como efeito, essa mesma parcela passou a ocupar os espaços urbanos e deles retirar seu próprio sustento, muitas vezes utilizando o que para alguns já não teria mais funcionalidade ou utilidade (ALVES, 2018).

Nesse cenário, Sousa, Pereira e Calbino (2019) e Alves (2018), apontam o surgimento de uma nova classe de trabalhadores, os quais passaram a utilizar do "lixo" como uma alternativa para suprir suas necessidades, configurando-se como catadores de materiais recicláveis. Logo, para esses trabalhadores, o material reciclável recolhido não se restringe apenas em uma mercadoria que se troca por dinheiro, mas se estende na garantia de continuidade da vida.

Mesmo com um papel fundamental no que tange a sustentabilidade dos espaços urbanos, uma vez que influenciam diretamente na redução dos resíduos sólidos nesses ambientes, além dos inúmeros benefícios da reciclagem, a figura do catador é perenemente estigmatizada pela sociedade, que por sua vez não lhe oferece oportunidades de inclusão (VASCONCELOS; GUIMARÃES; ZANETI, 2018).

Como forma de superar os vários desafios, os catadores têm buscado se organizar através de associações e cooperativas que se baseiam da filosofia da chamada Economia Solidária. Essa que tem auxiliado esses trabalhadores na busca pela expressividade de suas ações, visto que tem por propósito a ressignificação das condições de vida e trabalho, além de ser um meio para a realização de outros objetivos, sejam eles sociais, culturais, ambientais e políticos.

Dentre as várias conquistas dos catadores, tem-se a Lei 12.305/2010 referente à Política Nacional de Resíduos Sólidos (PNRS), a qual dentre algumas inovações "exige que todos os atores envolvidos nos processos tanto de produção quanto de consumo, quanto à própria administração pública em suas diferentes escalas (municipal, estadual e federal), participem de tal enfrentamento", ou seja, todos os atores são responsáveis pela redução, gestão e destinação dos resíduos (ALVES e VELOSO, 2018, p. 234).

Assim, vários municípios iniciaram o processo de finalização dos lixões para implantação da coleta seletiva, priorizando os catadores neste processo. Ainda há muito a ser feito e desafios a serem superados, principalmente, no que tange as relações entre poder público e os catadores no processo de reconhecimento do potencial desses profissionais, mas também de suas limitações em vários níveis.

Em uma realidade mais específica na cidade de Nova Era, em Minas Gerais, há uma associação de catadores aqui denominada de $\mathrm{ACNE}^{1}$, essa que tem como objetivo a geração e ocupação de renda através do "lixo", realizando coletas seletivas em alguns bairros e organizações da cidade e, atualmente, é composta por 16 associados.

A ACNE desenvolve algumas estratégias de parcerias ou intenções de articulações e alianças, porém tímidas. De maneira desorganizada, a associação apresenta esforços, mobilização, e até mesmo articulação entre entidades (pública e privada). Além disso, tem enfrentado problemas tais como: contradições internas e dificuldades vividas por injunções de setores políticos, públicos e privados que interferem em sua performance e, consequentemente, tem-se uma baixa produtividade econômica e social.

Assim, o presente trabalho tem por objetivo analisar elementos que indiquem potenciais sociais e econômicos da ACNE de forma a contribuir com o fortalecimento de ações de gestão socioambiental e sustentável da associação e do município de Nova Era.

\section{REFERENCIAL TEÓRICO}

0 grande marco da globalização econômica, termo pelo qual descreve a atual conjuntura do sistema capitalista, possibilitou a ampla difusão da informação e a introdução de novas tecnologias no mercado. Entretanto, articula-se por moldes competitivos e caracteriza-se como grande propulsor das desigualdades sociais, em razão do favorecimento às classes e ideologias dominantes com a centralização do capital e as diversas formas de exploração aos trabalhadores nos meios de produção (POCHMANN, 2018).

\footnotetext{
${ }^{1}$ Com o objetivo de preservar o nome da organização utilizou-se um nome fantasia.
} 
Os modelos adotados nos processos de produção do capital, até então baseados na produção em massa com ampla utilização da força de trabalho, foram logo substituídos por um sistema de produção flexível (CARMO, 2015). Com o novo modelo produtivo, grande parte das indústrias não mais prezava pela quantidade de produto, serviço ou de trabalho, focando cada vez mais na eficácia, além disso, gera-se uma percepção de um novo perfil de trabalhador, caracterizado pela mão de obra qualificada e multifuncional.

Como efeito, a reestruturação produtiva do capital acarretou na precarização das condições de trabalho, a exclusão do mercado formal, o desemprego estrutural, a pobreza e o aprofundamento das desigualdades sociais (STAMPA; LOLE, 2018), uma vez que as exigências de qualificação e multifuncionalidade passaram a ser imprescindíveis dentro dessas organizações, culminando na desvalorização da força de trabalho e, consequentemente, na exclusão de uma grande parcela de trabalhadores do processo.

Druck (2018), também ressalta os drásticos efeitos do capitalismo sobre esses trabalhadores, ressaltandose o individualismo, a competição entre as forças de trabalho e a divisão de classes, além da instabilidade daqueles que permaneceram nos processos produtivos sob a ameaça de terem seus empregos perdidos. Logo, eram necessárias alternativas que, de certa forma, auxiliassem esses trabalhadores na busca de melhores condições de vida e trabalho.

Nesse contexto, em repostas às desigualdades econômicas e sociais, a Economia Solidária surge como alternativa ao sistema econômico vigente, inicialmente com a proposta de sanar o desemprego, a pobreza e a exclusão social, buscando reduzir os desequilíbrios socioeconômicos. Tal movimento se apresenta como um novo sistema econômico, o qual tem como base essencial para o seu desenvolvimento a propriedade coletiva, o direito à liberdade individual, a cooperação, a solidariedade e a igualdade entre seus praticantes (SINGER, 2002).

Oliveira (2019), ainda destaca que a Economia Solidária está vinculada às necessidades da classe trabalhadora diante da crise capitalista e tem como principal objetivo a geração de trabalho, renda e a inclusão social, além do desenvolvimento de ações coletivas, que por sua vez buscam a valorização humana acima de qualquer propósito material. Desta maneira, o movimento solidário surge como possibilidade de amenizar os estragos provenientes da ideologia capitalista com a ressignificação das condições de vida e trabalho.

No Brasil, o movimento ganhou expressividade ao longo dos anos de 1990, sendo reconhecido por seu caráter associativo e suas práticas de cooperação e autogestão (GAIGER, 2013). Logo, as associações e cooperativas populares, designadas como Empreendimentos Econômicos Solidários (EES), ganharam espaço como alternativa na geração de trabalho e renda, visando os interesses dos associados e cooperados.

Lima, Araújo e Rodrigues (2011), apontam que os EES são constituídos pelos próprios trabalhadores excluídos dos sistemas de produção no modelo capitalista, além daqueles que não se enquadram de acordo com as exigências do mercado, seja pela qualificação, faixa etária, escolaridade e gênero. Além disso, os autores enfatizam os diversos setores de atuação dos EES, dentre eles, a coleta seletiva e a reciclagem, responsáveis por garantir a inclusão social dos catadores de materiais recicláveis.

Os catadores de materiais recicláveis, por sua vez, compõem um grupo de trabalhadores marcados pelos efeitos do capitalismo. Com a grande crise na oferta dos postos de trabalho, esses sujeitos perderam seus meios tradicionais de renda, sendo submetidos a encontrarem nos espaços urbanos outros recursos que suprissem suas necessidades. Assim, os catadores configuram-se uma nova classe de trabalhadores que passou a utilizar do que é descartado pela sociedade como a própria garantia de sobrevivência (SOUSA; PEREIRA; CALBINO, 2019; ALVES, 2018).

Esses trabalhadores são importantes agentes ambientais, visto sua efetiva atuação na sustentabilidade dos espaços urbanos com a redução dos resíduos sólidos nesses ambientes, além de ser o principal elo na cadeia produtiva da reciclagem. Entretanto, a classe do catador é desassistida, tão pouco reconhecida pela sociedade, tornando-se alvo de estigmas, preconceitos e são vítimas da própria exclusão social (ALVES, 2018; VASCONCELOS; GUIMARÃES; ZANETI, 2018).

Por trabalharem com que é descartado por aqueles considerados "incluídos", esses profissionais vivem sob o estigma da sujeira, uma vez que estão em contato direto com o lixo, percebendo-se também como parte desse descarte (TEIXEIRA, 2015; ARANTES; BORGES, 2013). Ademais, os catadores de materiais recicláveis vivenciam diversos desafios em sua rotina laboral que vão desde as condições insalubres de trabalho até o desamparo dos órgãos governamentais quanto às políticas públicas de proteção e garantia da qualidade de vida que favoreçam esses sujeitos (ALVES, 2018). 
Alves et. al (2020), ainda enfatizam que os catadores são submetidos a uma "injustiça cognitiva", proveniente do sistema capitalista, tendendo a notá-los como inferiores e isentos de qualquer conhecimento formal ou técnico.

Em contrapartida, diante de todos os estigmas e adversidades do dia a dia, esses trabalhadores não medem esforços para garantir sua dignidade e cidadania em meio a uma sociedade que não lhes oferecem oportunidades de inclusão, além de resistirem na busca de seus direitos e reconhecimento social. Prova dessa resistência é o Movimento Nacional dos Catadores de Materiais Recicláveis (MNCR) que, desde sua consolidação, em 2001, busca a valorização da categoria do catador, lutando pela participação direta e efetiva da classe de forma a mudar os estigmas abrindo caminhos para a inclusão social (MNCR, 2020).

Além disso, no que tange a luta e resistência desses profissionais quanto aos seus direitos também podemos citar o reconhecimento da profissão do catador pelo Ministério do Trabalho e Emprego através da Classificação Brasileira de Ocupações, em 2002, e a Política Nacional dos Resíduos Sólidos (PNRS), em 2010. Essa, que prevê a eliminação dos lixões e da disposição inadequada dos resíduos sólidos no país, além do incentivo na criação de associações e cooperativas de catadores, estabelecendo estratégias para reintegração desses indivíduos (ALVES e VELOSO, 2018).

Nesse sentido, as associações e cooperativas de catadores buscam enfrentar a exclusão social, tornando-se instrumento de reinserção, transformando o "lixo" em dignidade para esses sujeitos e desempenhando um importante papel no que tange o fortalecimento das práticas de gestão socioambiental e sustentabilidade. Essa que Sabedot e Neto (2017), enfatizam a grande contribuição dos catadores, uma vez que o retorno dos resíduos sólidos recicláveis para as indústrias interfere diretamente na redução do extrativismo de novas matérias-primas, ressaltando-se a responsabilidade com o meio ambiente e, principalmente, a melhoria da qualidade de vida desses profissionais.

Entretanto, Arantes e Borges (2013), apontam que a figura do catador ainda permanece vinculada a ideia de miséria, tendo em vista o seu contato direto com o lixo. Mesmo com o reconhecimento legal da profissão, os catadores carecem de necessidades, encontrando-se ainda em situações de vulnerabilidade social. Logo, torna-se necessário investigar a fundo sobre esses profissionais, além do impacto sobre esses sujeitos, buscando respostas e alternativas que possam garantir sua proteção e a garantia da qualidade de vida.

\section{PROCEDIMENTOS METODOLÓGICOS}

Inicialmente, buscou-se realizar uma pesquisa documental e bibliográfica, através de livros, revistas, dissertações, teses e artigos científicos, referente aos catadores de materiais recicláveis, investigando sobre a realidade desses sujeitos e suas diversas formas de organização, a fim de analisar pensamentos e reflexões de estudiosos acerca do estudo, relacionando-os com a experiência da ACNE. Ademais, foram pesquisados temas como capitalismo, economia solidária e empreendimentos econômicos solidários para um amplo embasamento da atual vivência dos catadores.

No que diz respeito à coleta de dados, em um primeiro momento, foram realizados contatos com a equipe do Laboratório de Extensão Incubadora de Empreendimentos Sociais e Solidários da Universidade Federal de Ouro Preto, a qual iniciou o processo de assessoria sociotécnica junto a associação em novembro de 2019. Assim, facilitou o contato inicial com a liderança da associação e os associados na sequência foi realizada uma visita in-loco. No decorrer dos primeiros passos da pesquisa de campo iniciou-se o processo de pandemia e quarentena, restringindo as visitas in-loco e os contatos são realizados por telefone ou outros meios digitais. Estão sendo realizados contatos com o representante do Departamento de Meio Ambiente da Prefeitura Municipal de Nova Era com o intuito de coletar informações sobre os resíduos sólidos recolhidos no município e sobre os que são comercializados pela ACNE. A partir das informações iniciais, estão sendo mapeados a cadeia produtiva da associação e realizando novos contatos com os atores envolvidos.

\section{CONTEXTUALIZAÇÃo DA ACNE E ANÁLISE DE DADOS}

A presente pesquisa ainda se encontra em desenvolvimento, mas são perceptíveis algumas ações, dados, iniciativas, mobilizações, limitações, avanços e possibilidades, as quais serão apresentadas e refletidas.

A ACNE, objeto desse estudo, está localizada na cidade de Nova Era, em Minas Gerais, distanciando-se 142 $\mathrm{km}$ a leste da capital mineira, Belo Horizonte. O município, segundo estimativas do IBGE (2019), ocupa 
uma área territorial de 361,926 $\mathrm{km}^{2}$ e comporta uma população de 17.578 habitantes, sendo que, aproximadamente, 15.420 estão situados no perímetro urbano da cidade. Quanto à economia, Nova Era destaca-se no setor terciário na área de prestação de serviços, maior fonte de renda geradora do PIB novaerense atualmente. Com média salarial mensal de 2,2 salários mínimos, o município soma 411 unidades locais e 405 empresas atuantes, responsáveis pela ocupação de 4.622 pessoas, sendo que 4.090 encontram-se assalariadas.

Com este contexto socioeconômico, começa-se uma reflexão sobre a geração de resíduos dessa realidade. Segundo dados da Abrelpe (2019), a região Sudeste, além de mais populosa, é também a maior geradora de resíduos. Em 2018, os 1.668 municípios da região geraram juntos em média um total de 108.063 toneladas/dia de resíduos sólidos urbanos, sendo que cada habitante produziu em média 1,232 kg de resíduos por dia. 0 município de Nova Era, por sua vez, de acordo com os dados disponibilizados pela Prefeitura Municipal da cidade, tendo como base os resíduos que vão para o aterro e os resíduos recolhidos pela ACNE no ano de 2019, teve uma geração média total de 7,33 toneladas/dia e com base na sua população houve uma geração per capita em média de $0,475 \mathrm{~kg} /$ dia por população urbana.

E com base nesta realidade de Nova Era, a temática de resíduos e dentre várias organizações que influenciam na dinâmica dos municípios tem-se a ACNE, uma associação de catadores de materiais recicláveis que através do processo de catação e triagem de materiais recicláveis vê no "lixo" um mecanismo para geração de trabalho e renda para 16 associados. Fundada em 2010, a associação realiza as atividades de catação, triagem e comercialização dos resíduos sólidos recicláveis do município. Através de um convênio com a Prefeitura Municipal de Nova Era, o qual consiste na disponibilização de um caminhão, a ACNE também realiza a coleta seletiva em alguns bairros da cidade, mas não há uma coleta seletiva consolidada no município.

No que se refere ao perfil dos catadores que compõem a associação, observou-se a superioridade numérica das mulheres, somando-se 12 em relação ao total de associados, acompanhadas por 4 homens. Quanto à escolaridade, percebe-se que a maioria dos associados possuem baixos níveis de formação escolar formal, visto que 12 dos associados possuem ensino fundamental incompleto, 2 possuem ensino médio incompleto e os outros 2 afirmam ter ensino médio completo.

De acordo com dados disponibilizados pela prefeitura, tendo como base o ano de 2019, com o fornecimento do caminhão foram destinadas, em média, 22 toneladas/mês para associação. Além disso, também em 2019, através de empresas privadas de limpeza urbana, foram destinadas, em média, 201 toneladas/mês para o aterro. Considerando que o município não possui uma coleta seletiva implantada em toda cidade, percebe-se que parte dos resíduos que vão para o aterro ainda podem ter uma quantidade considerável de materiais recicláveis que poderiam ser melhor direcionados para a ACNE. 0 que poderia proporcionar um aumento de renda para a associação, auxiliando no aumento do tempo de vida do aterro, além de uma possível redução dos gastos da prefeitura, uma vez que a mesma paga pela quantidade de resíduos recolhidos e destinados ao aterro.

Atualmente, a associação conta com o apoio de um grupo de colaboradores, constituído por alguns moradores da cidade e representantes da prefeitura, com o intuito de amparar as necessidades da organização. Além disso, em 2019, o Laboratório de Extensão Incubadora de Empreendimentos Sociais e Solidários da Universidade Federal de Ouro Preto (Incop), iniciou o processo de assessoria sociotécnica junto a associação, o qual permanece até o presente momento.

Esse grupo de colaboradores tem um perfil diversificado com profissionais de várias áreas e formações que lutam e defendem a questão ambiental como também acreditam na ACNE. Porém, observa-se que há falhas de comunicação entre esses atores e a associação como também uma limitação de conhecimento sobre a realidade dos catadores o que às vezes geram conflitos e dependência desses profissionais junto ao grupo de voluntários.

A prefeitura, com a perspectiva de melhorar o ambiente da cidade, tenta cumprir as exigências ambientais, principalmente, referente ao PNRS assim apoia a associação, cedendo o espaço onde a ACNE é responsável pelas despesas de água e luz. No convênio entre o município e a associação, essa tem que atender a uma quantidade mínima de resíduos por mês para receber um repasse de um valor que ainda não é suficiente para atender as demandas e necessidades dos catadores. Observa-se uma dependência da ACNE em relação ao poder público, o qual nem sempre tem um diálogo saudável, muitas vezes impondo determinadas metas ou mudanças de estratégias organizacionais sem construir as propostas junto com os catadores, gerando alguns conflitos e problemas de nível organizacional. 
No que tange às ações da Incop, essa através da assessoria sociotécnica vem desenvolvendo ações e estratégias de conhecimento e caracterização do grupo buscando conhecer a realidade específica dos catadores de Nova Era. De novembro de 2019 até início de 2020, foram realizadas visitas semanais e quinzenais, onde foram desenvolvidas ações de caracterização e iniciada ações visando a organização, amadurecimento da gestão, emancipação e capacitação dos catadores. Observou-se a necessidade de trabalhar também com o grupo de voluntários, esse que é da cidade, como forma de unir forças. Com o início da pandemia as visitas presenciais foram suspensas, mas a incubadora continua suas atividades remotamente realizando reuniões virtuais com os voluntários e utilizando de recursos da tecnologia da informação e comunicação para realizar reuniões e manter contato com os catadores.

\section{CONSIDERAÇÕES FINAIS}

Com o objetivo de encontrar potenciais sociais e econômicos da ACNE, percebe-se uma grande dependência da associação em relação ao poder público através da prefeitura, essa que se apresenta, na maioria das vezes, com imposições no cumprimento de determinadas metas. Em contrapartida, a associação ganha forças em sua causa social com o apoio do grupo de colaboradores a que, mesmo apresentando algumas lacunas a serem trabalhadas, não mede esforços para amparar a ACNE em suas necessidades. Destaca-se também o papel da Incop, que por sua vez, também movida pelos princípios da Economia Solidária, busca, através da assessoria sociotécnica, o fortalecimento e emancipação da organização, além da valorização da classe do catador.

Desta maneira, observa-se que a relação desses atores, sejam do setor público, privado ou civil, com a ACNE há níveis diferentes de conhecimento e percepções sobre a realidade do catador e da própria associação. Alguns veem demonstram atitudes, ações e pensamentos mais assistencialistas e reforçando um estigma dos catadores como, por exemplo, da incapacidade de gestão, decisão, princípios, dentre outros. Outros atores já interagem de forma a trabalhar a emancipação, empoderamento e valorização do catador através de ações que envolvam esses profissionais visando sua autonomia e reconhecimento da sua importância.

Quanto aos potenciais econômicos, nota-se que a associação cumpre seu papel no que tange a capacidade de gerar trabalho e renda para seus associados. Entretanto, ressalta-se a necessidade de uma aliança que seja mais equitativa entre o poder público e os catadores, principalmente na implantação da coleta seletiva em todo município, o que poderia aumentar os rendimentos da associação e, consequentemente, de seus associados. Tal possibilidade também poderia auxiliar nas práticas de gestão socioambiental, uma vez que a associação receberia uma maior quantidade de resíduos sólidos recicláveis e o aterro teria seu tempo de vida útil prolongado, podendo influenciar na diminuição da poluição dos solos, da água e do ar, redução da extração dos recursos naturais, melhor limpeza da cidade e dentre outros vários benefícios.

Ressalta-se também o perfil dos catadores na associação com a predominância das mulheres e de associados com baixa escolaridade, o que reforça a possibilidade da marginalização ou exclusão de algumas características ou perfis exigidos pelo mercado capitalista.

Por fim, percebe-se que ainda há muito que ser trabalhado com a associação e os demais atores que englobam seu campo de ação. É possível também ressaltar que apesar de todas as dificuldades, a ACNE apresenta-se como uma base de sustentação para esses trabalhadores que buscam na associação, além de um meio de geração de trabalho, renda e inclusão social, a resistência por sua dignidade.

\section{REFERÊNCIAS}

[1] ASSOCIAÇÃO BRASILEIRA DE EMPRESAS DE LIMPEZA PÚBLICA E RESÍDUOS ESPECIAIS - Abrelpe. Panorama dos Resíduos Sólidos no Brasil - 2018/2019. São Paulo, 2019.

[2] ALVES, J. C. M.; VELOSO, L. H. M.; ANDRADE; E. P.; SILVA, A. M.; Economia Solidária e a dimensão cognitiva da experiência dos catadores. In.: Interações, Campo Grande, MS, v. 21, n. 1, p. 125-140, jan./mar. 2020. Disponível em: https://doi.org/10.20435/inter.v21i1.2199. Acesso em: abril 2020.

[3] ALVES, J. C. M. Análise da sustentabilidade social de redes solidárias de catadores de materiais recicláveis: um estudo de caso da Rede Catavales. Tese (Doutorado) Programa de Pós-Graduação em Sistemas de Gestão Sustentáveis, Universidade Federal Fluminense, Niterói, 2018.

[4] ___ VELOSO, L.H.M. A Política Nacional de Resíduos Sólidos e a "Catação" de Lixo: Uma Relação Sinérgica? In.: O Social em Questão. Ano 21, n. 40 - jan.-abr./2018. 
[5] ARANTES, B. O.; BORGES, L. O. Catadores de materiais recicláveis: cadeia produtiva e precariedade. In.: Arquivos Brasileiros de Psicologia, Rio de Janeiro, v. 65, n. 3, p. 319-337, nov. 2013.

[6] CARMO, R. G.; Acumulação flexível: do local ao global, do obsoleto ao moderno. In: Revista HISTEDBR On-line, Campinas, v. 15, no 61, p. 219-236, mar. 2015.

[7] DRUCK, G. A metamorfose das classes sociais no capitalismo contemporâneo: algumas reflexões, In: Em Pauta, Rio de Janeiro, v. 16, n. 41, p. 68-92, jun. 2018. Disponível em: https://doi.org/10.12957/rep.2018.36685. Acesso em: jun. 2020.

[8] GAIGER, L. I. A economia solidária e a revitalização do paradigma cooperativo. In.: Revista Brasileira de Ciências Sociais, São Paulo, v. 28, n. 82, p. 212-27, jun. 2013.

[9] INSTITUTO BRASILEIRO DE GEOGRAFIA E ESTATÍSTICA - IBGE. Nova Era. Disponível em: https://cidades.ibge.gov.br/brasil/mg/nova-era/panorama. Acesso em: jun. 2020

[10] LIMA, J. C.; ARAÚJO; A. M. C.; RODRIGUES, C. C. P. Empreendimentos urbanos de economia solidária: alternativa de emprego ou política de inserção social? In.: Sociologia \& Antropologia, Rio de Janeiro, v. 1, n. 2, p. 119146, abril 2011.

[11] MNCR. Sobre o Movimento Nacional dos Catadores de Materiais Recicláveis. 2020. Disponível em: http://www.mncr.org.br/sobre-o-mncr. Acesso em: abril 2020.

[12] OLIVEIRA, E. D. Responsabilidade social empresarial, empreendedorismo social e economia solidária: similitudes, ambivalências e possíveis conexões. In.: Revista Observatório, Palmas, v. 5, n. 5, p. 697-750, ago. 2019. Disponível em: https://doi.org/10.20873/uft.2447-4266.2019v5n5p697. Acesso em: jun. 2020.

[13] POCHMANN, M. Desestabilização do trabalho. In.: Saúde em Debate, Rio de Janeiro, v. 42, n. 3, p. 67-77, nov. 2018. Disponível em: https://doi.org/10.1590/0103-11042018s306. Acesso em: jun. 2020.

[14] SABEDOT, S.; NETO, T. J. P. Desempenho ambiental dos catadores de materiais recicláveis em Esteio (RS). In: Eng. Sanit. Ambient., Rio de Janeiro, v. 22, n. 1, p. 103-109, jan./fev. 2017. Disponível em: https://doi.org/10.1590/s1413-41522016155686. Acesso em: maio 2020.

[15] SINGER, Paul. Introdução à Economia Solidária. São Paulo: Perseu Abramo, 2002.

[16] STAMPA, I.; LOLE, A.; Trabalho e precarização social no capitalismo contemporâneo: dilemas e resistência do movimento organizado de trabalhadores. In: Revista de Políticas Públicas, São Luís, v. 22, p. 277-304, maio 2018. Disponível em: https://www.redalyc.org/articulo.oa?id=321158844012. Acesso em jun. 2020.

[17] SOUSA, R. R.; PEREIRA, R. D.; CALBINO, D. Memórias do lixo: luta e resistência nas trajetórias de catadores de materiais recicláveis da Asmare. In.: Read: Revista Eletrônica de Administração, Porto Alegre, v. 25, n. 3, p. 233-246, set/dez. 2019. Disponível em: http://dx.doi.org/10.1590/1413-2311.250.92258. Acesso em: abril 2020.

[18] TEIXEIRA, K. M. D. Trabalho e perspectivas na percepção de catadores de materiais recicláveis. In.: Psicologia \& Sociedade, v. 27, n. 1, pg. 98-105, 2015.

[19] VASCONCELOS, J. P. R.; GUIMARÃES, S. M. F.; ZANETI I. C. B. B. Condições de vida de catadores de resíduos sólidos recicláveis: revisão integrativa da literatura. In.: Sustentabilidade em Debate, Brasília, v. 9, n. 1, p. 187-197, abr. 2018. Disponível em: https://doi.org/10.18472/SustDeb.v9n1.2018.25439. Acesso em: maio 2020. 


\section{Capítulo 10}

Explorando conexões para a formação de inovadores em ambientes multiculturais

\section{Stephanie Felix Amaral}

Emmanuel Paiva de Andrade

João Paulo Ferreira Martins

Walber Santos de Assis

Neide Lucia de Oliveira Almeida

Resumo: Se o mundo pós-pandemia do COVID-19 não será o mesmo que conhecemos até aqui, a formação de pessoas para a inovação continua merecendo atenção e esforços, tanto da academia quanto do mundo das organizações. 0 presente estudo verifica de que maneira programas de formação de inovadores consolidam e/ou fazem avançar as chamadas "competências de descoberta" (Dyer et al. 2012) entre estudantes de diferentes nacionalidades, inscritos em um programa de intercâmbio em Business de uma universidade holandesa. A pesquisa tem um caráter exploratório, utiliza o delineamento do estudo de caso, replica analiticamente pesquisa realizada com estudantes de engenharia de produção de universidade brasileira, entrevistando dez estudantes da universidade holandesa e dois consultores de uma empresa brasileira líder em consultoria de gestão. Os resultados obtidos são cotejados com as entrevistas dos consultores, mostrando convergência entre o framework de Dyer et al. (2012) e as expectativas das empresas de consultoria em relação a sua demanda de talentos. 0 trabalho foi publicado como working paper no XXIV Simpósio de Engenharia de Produção da UNESP-SP e atualizado para a presente coletânea de textos sobre gestão e formação de gestores.

Palavras-chave: Formação de inovadores; Ambientes multiculturais; Gestão do conhecimento. 


\section{INTRODUÇÃO}

O conhecimento tem sido objeto de estudos e pesquisas tanto no meio acadêmico quanto no meio empresarial. No meio acadêmico, estudos sobre a natureza, a importância e a utilização do conhecimento já ocorrem há tempos, tendo sido incrementados desde a chamada Primeira Revolução Acadêmica, quando a pesquisa é internalizada como atividade central da universidade (ETZKOWITZ, 2003; SUBRAMANIAM, YOUNDT, 2005; XIE et al., 2016).

No mundo empresarial, o conhecimento adquire papel fundamental a partir dos anos 1990 com o surgimento da chamada "gestão do conhecimento". Tal surgimento coincide com a emergência de novas e aperfeiçoadas tecnologias de informação e comunicação (TICs). Na origem desses estudos, se destacam os trabalhos de Nonaka e Takeuchi (1997), Sveiby (1998), Stewart (2002) entre outros. Todos esses autores dialogam, simultaneamente, com o mundo da academia e o mundo das organizações.

Se a introdução da gestão do conhecimento nas organizações é impulsionada pelas TICs, a sua consolidação, no entanto, só acontece quando entra em cena a área de recursos humanos nas organizações. Neste momento, se percebe que identificar, desenvolver, adquirir e difundir conhecimento requer mais do que apenas tecnologia, exigindo, fundamentalmente, pessoas capacitadas. Nesse sentido, 0 papel da universidade, como formadora de recursos humanos de alto nível, volta a ter relevância, agora em outras dimensões (LÓPEZ-ORTEGA et al, 2016; XIE et al, 2016).

A presente pesquisa, tomando como referência estudos anteriores, replicou para um contexto internacional a pesquisa de Andrade et al (2015) desenvolvida com estudantes de engenharia da Universidade Federal Fluminense. No quadro internacional, foram entrevistados estudantes na área de Business em uma universidade holandesa, a fim de verificar a presença e desenvolvimento das chamadas competências de descoberta em estudantes estrangeiros inscritos em um programa de intercâmbio. Adicionalmente, a pesquisa comparou esse resultado com expectativas capturadas em entrevistas com profissionais de uma consultoria de gestão considerada entre as maiores do Brasil, a fim de identificar como as habilidades inovativas são vistas e reconhecidas no mercado e de que forma elas são apropriadas pela gestão do conhecimento nas empresas (ANDRADE et al, 2015; DYER, GREGERSEN E CHRISTENSEN, 2012).

Na próxima sessão será apresentada a literatura que embasou a presente pesquisa, seguida da metodologia utilizada para as análises necessárias. Na sessão quatro serão analisados os resultados obtidos para que, em seguida, sejam apresentas as considerações finais e as limitações da pesquisa.

\section{CONHECIMENTO, CULTURA E COOPERAÇÃO}

O contexto onde o conhecimento é produzido, difundido e utilizado é caracterizado pela presença de ao menos algum grau de colaboração. No caso do ambiente de P\&D, Bäcka e Kohtamäkia (2015) falam das fronteiras de cooperação, as quais são influenciadas pelo nível de confiança existente. Em sua pesquisa, os autores afirmam que o desenvolvimento de competências, facilitado pela confiança, habilita os processos de aprendizagem e a criação de conhecimento tácito entre os parceiros. Afirmam ainda que a competência e a experiência acumulada aperfeiçoam a própria eficiência do relacionamento entre estes (MICHELINO et al, 2015; FEDOCE et al, 2015).

Outro fator que pode impactar a performance da produção de conhecimento, particularmente no caso da P\&D, é a estrutura de redes de cooperação, cujos modelos e formas podem assumir diversos atributos. Guan et al (2016) estudaram a eficiência da P\&D em nível de países, utilizando a análise envoltória de dados (DEA) e a análise de redes sociais (ARS). Como resultado, observaram que a estrutura de redes sociais não só influencia diretamente publicações científicas em nível nacional, mas também concluíram que quanto maior os indicadores encontrados pela ARS, maior a eficiência do sistema P\&D (BENITOBILBAO et al., 2015; SCHOTT et al., 2016; ASSIS et al., 2016).

A geração de conhecimento também pode ser notavelmente desenvolvida quando se consideram diferentes culturas, e portanto, diferentes perspectivas e domínios sobre os conteúdos. Nesse contexto, é possível verificar os vestígios da cultura, o que Gibson e Gibbs (2006) denominaram de "o conjunto de valores associados à eficácia social, compartilhada por um grupo identificável". Hofstede (1993) também defende a imagem de grupo como o centro da cultura a respeito da programação coletiva de mentes. Para Schein (2001), isso recai sobre a expressão "taken for granted", o que significa que por vezes os costumes são tão intrínsecos aos indivíduos, que acabam se tornando não questionáveis e/ou invisíveis.

Nesse aspecto as redes de cooperação podem ser motivadas e provocadas pelo convívio múltiplo e diverso 
dos indivíduos. Kaasa et al (2013) defendem que os valores compartilhados, as crenças e os comportamentos atuam como protagonistas no progresso de um meio inovador. Adicionalmente, Vale et al (2008) percebem que criar, complementar e associar diferentes elementos também representam o cerne na inovação. Amabile (1997) complementa afirmando que a criatividade pode ser percebida em um individuo pela observação de três componentes: expertise, habilidades criativas e motivação para tarefas.

Em trabalho recente, Andrade et al (2015), seguindo a pesquisa de Dyer et al (2012), estudam a agregação de competências que conduzem a capacidade inovadora de estudantes de engenharia de produção da Universidade Federal Fluminense. Esse trabalho tomou por base a medição das chamadas "competências de descoberta", entre ingressantes da universidade e o seu grau entre concluintes do mesmo curso.

Tais "competências de descoberta", propostas por Dyer et al (2012), consistem em cinco competências de duas naturezas distintas. A primeira delas de natureza cognitiva - resumida na facilidade de associar coisas, fatos, eventos e fenômenos -, e as outras quatro de natureza tipicamente comportamentais, que se refletem nos atos de observar, questionar, experimentar e formar redes de relacionamento.

A fim de compreender o que diferencia as pessoas comprovadamente inovadoras das outras, Dyer et al (2012) chegaram ao resultado anterior, através de uma pesquisa realizada com aproximadamente 500 executivos classificados como inovadores de primeira linha em nível mundial, e outros 500 bons executivos, não necessariamente inovadores. 0 objetivo era identificar o hiato nos padrões inovadores que faziam com que esses dois grupos fossem distintos. Dessa maneira, como produto dessa pesquisa, foi formulado uma espécie de DNA do inovador, um código "genético" que seria o responsável por essa capacidade de inovar dos inovadores.

Outra relação interessante encontrada nos profissionais inovadores, incluindo engenheiros e cientistas, foi o seu alinhamento com o compromisso organizacional. Perry, Hunter e Currall (2016), estudando comunidades de engenheiros e cientistas e adotando uma abordagem que investiga a dupla lealdade em contextos organizacionais, encontram uma forte correlação entre orientação para inovação e compromisso organizacional, principalmente entre os profissionais que percebiam a importância do seu papel e que trabalhavam em organizações de excelência. Dessa maneira, líderes de instituições de pesquisa multidisciplinares que estão atentos à complexidade da dinâmica entre compromisso organizacional/profissional e o seu papel, estão melhores equipados para gerenciar com eficiência os inovadores (PERRY et al, 2016).

Tanto as competências quanto as propensões das pessoas para o comprometimento organizacional, constituem o núcleo do que tem sido chamado de cultura da inovação. Para Souto (2015), a cultura da inovação tem o papel central na capacidade de inovação das organizações, bem como na sua competitividade. Segundo o autor, faz-se necessário utilizar-se ferramentas adaptadas às necessidades e idiossincrasias de cada organização para que se possa alcançar uma eficaz gestão da cultura de inovação com foco sobre as pessoas e suas competências.

As competências envolvidas na produção da inovação extrapolam as fronteiras da P\&D, estando presente nas atividades cotidianas dos trabalhadores dos diversos departamentos. Lee e Walsh (2016) afirmam que os trabalhadores obtêm experiência e conhecimento ao longo de toda a sua jornada de trabalho, seja na P\&D ou fora dela. Para eles, intuição, julgamento, criatividade fazem parte do conjunto de competências mobilizadas para responder aos desafios do trabalho, dependendo da natureza do conhecimento, ou seja, o seu nível de mobilidade/transferibilidade e o grau de implicação entre a ação e as suas consequências (LEE e WALSH, 2016). Além disso, para Subramaniam e Youndt (2005), os colaboradores com maior potencial costumam ser mais questionadores perante seu cotidiano com o objetivo de transformar o meio ao seu redor através de sua criatividade.

Toda essa dinâmica interna de mobilização e articulação de competências precisa entrar em relação com o ambiente externo afim de produzir inovação. Nesse cenário, a inovação no meio empresarial pode ter sua origem na criatividade organizacional. Segundo Woodman et al (1993), esta é mais conhecida pela criação de novos e melhores produtos e serviços por indivíduos num complexo sistema social. Contudo, para que os membros de uma instituição consigam se desenvolver ao seu máximo potencial e competências, contribuindo de forma significativa para o incremento inovador nas empresas, é preciso que esses se identifiquem com a cultura da organização local.

\section{METODOLOGIA}

O estudo corrente tem um caráter exploratório, utilizando como procedimentos técnicos a pesquisa bibliográfica, análise de documentos e observação de campo, tomando por base estudantes em uma 
instituição holandesa e consultores de uma renomada empresa de gestão brasileira.

0 método adotado para a busca dos resultados foi estudo de caso que, de acordo com Yin (2005) é caracterizado pelo estudo exaustivo e em profundidade de poucos objetos, de forma a permitir conhecimento amplo e específico dos mesmos, tarefa praticamente impossível mediante os outros delineamentos considerados. Para Stake (2000), esse método também se revela valioso para ampliar a experiência, e assim aumentar o entendimento e a convicção sobre um tema (GRAY, 2012).

A coleta de dados, foi realizada através de entrevistas em profundidade aplicadas a dez estudantes da universidade holandesa e, posteriormente, a dois profissionais de uma empresa de consultoria líder em gestão no Brasil. Para avaliar a presença das cinco competências de Dyer et al (2012) nos estudantes, tomou-se como base as questões utilizadas por Andrade et al (2015), adaptadas para as circunstâncias da pesquisa em contexto internacional e transformando-se o questionário de Andrade et al. (2015) em um roteiro de entrevista em profundidade.

\section{ANÁLISE DE RESULTADOS}

Embora não exista intenção e nem elementos válidos nos dados levantados para a análise estatística, utilizou-se valores de média apenas para situar diferenças de padrões tão somente nas próprias instâncias analisadas. Não há aqui nenhuma intenção de se generalizar para as culturas respectivas, muito embora tenha sido atraente a ideia de comparar os resultados obtidos com os achados mais consistentes de comportamentos culturais presentes em autores como Hofstede (1997), Schein (2001) e Fukuyama (1996).

Conforme mencionado anteriormente, foram realizadas entrevistas com estudantes de diferentes nacionalidades com o objetivo de identificar a presença e evolução de capacidades inovadoras em alunos estrangeiros. Assim, para cada uma das características em estudo foi proposta uma definição acompanhada de exemplos de fácil compreensão no momento do questionamento, para que eles entendessem, de uma forma mais consistente, o significado de cada uma das qualificações propostas em Dyer et al. (2012).

Para efeito da análise dos resultados, torna-se interessante apresentar as características mais relevantes de cada um dos entrevistados. Levando-as em consideração, é possível perceber e/ou até mesmo prever padrões nas respostas elaboradas e discutidas. Esse resultado dialoga com a caracterização de Hosftede (1993) a respeito da imagem de grupo, conceituada como a essência da cultura na programação coletiva das mentes. A implicação disso permite perceber os vestígios da cultura como "o conjunto de valores associados à eficácia social, compartilhada por um grupo identificável" (GIBSON E GIBBS, 2006).

Tabela 1 - Identificação dos participantes

\begin{tabular}{|c|c|c|c|c|c|c|}
\hline Estudante & Continente & Origem & Idade & Universidade & Graduação & Semestre \\
\hline E1 & Ásia & Indonésia & 22 & $\begin{array}{c}\text { Singapoure Management } \\
\text { University }\end{array}$ & $\begin{array}{l}\text { Administração } \\
\text { de Empresas }\end{array}$ & $7 / 8$ \\
\hline E2 & Ásia & Taiwan & 22 & $\begin{array}{c}\text { National Taiwan } \\
\text { University }\end{array}$ & Economia & $4 / 5$ \\
\hline E3 & Ásia & Cingapura & 24 & $\begin{array}{c}\text { Singapoure Management } \\
\text { University }\end{array}$ & Finanças & $7 / 8$ \\
\hline E4 & Europa & França & 24 & Neoma Business School & Finanças & $9 / 10$ \\
\hline E5 & Europa & Áustria & 22 & Innsbruck University & $\begin{array}{c}\text { Administração } \\
\text { Internacional e } \\
\text { Economia }\end{array}$ & $6 / 8$ \\
\hline E6 & Europa & Alemanha & 20 & Maastricht University & $\begin{array}{l}\text { Administração } \\
\text { Internacional }\end{array}$ & $3 / 6$ \\
\hline E7 & Europa & Alemanha & 20 & Maastricht University & $\begin{array}{l}\text { Administração } \\
\text { Internacional }\end{array}$ & $5 / 6$ \\
\hline E8 & Oceania & Austrália & 20 & $\begin{array}{l}\text { Queensland University of } \\
\text { Technology }\end{array}$ & $\begin{array}{l}\text { Economia e } \\
\text { Engenharia }\end{array}$ & $6 / 10$ \\
\hline E9 & $\begin{array}{l}\text { América do } \\
\text { Sul }\end{array}$ & Chile & 23 & $\begin{array}{l}\text { Universidad del } \\
\text { Desarrollo }\end{array}$ & $\begin{array}{c}\text { Engenharia } \\
\text { Comercial }\end{array}$ & $10 / 10$ \\
\hline E10 & $\begin{array}{l}\text { América do } \\
\text { Sul }\end{array}$ & Equador & 22 & $\begin{array}{c}\text { Universidad San Francisco } \\
\text { de Quito }\end{array}$ & $\begin{array}{l}\text { Administração } \\
\text { de Empresas }\end{array}$ & $6 / 8$ \\
\hline
\end{tabular}

Os participantes se atribuíram notas de um a cinco em cada uma das competências propostas por Dyer et 
al (2012), gerando médias que são ordenadas segundo o seguinte ranking: Networking (3,9), Observação $(3,7)$, Associação $(3,6)$, Experimentação $(3,5)$ e Questionamento $(3,1)$.

Esse padrão de resposta se torna mais interessante quando segregado por continente, que para Fukuyama (1992) concentram fatores convergentes, tais como igualdade social, religião e identidade nacional, gerando diferentes costumes entre povos. É possível observar esse resultado na Tabela 2 abaixo.

Tabela 2 - Auto avaliações dos participantes

\begin{tabular}{|c|c|c|c|c|c|c|c|}
\hline \multicolumn{3}{|c|}{ Origem } & \multicolumn{5}{|c|}{ Nota Capacidade Inovadora } \\
\hline Continente & Entrevistado & País & Associar & Questionar & Observar & Experimentar & Networking \\
\hline \multirow{3}{*}{ Ásia } & 1 & Indonésia & 4 & 3 & 3,5 & 4 & 4 \\
\hline & 2 & Taiwan & 4 & 1,5 & 3 & 2 & 2,5 \\
\hline & 3 & Cingapura & 4 & 3 & 3 & 2 & 3 \\
\hline \multirow{4}{*}{ Europa } & 4 & França & 4 & 3 & 4,5 & 4 & 4 \\
\hline & 5 & Áustria & 3,5 & 4,5 & 4 & 2 & 5 \\
\hline & 6 & Alemanha & 3 & 2 & 3 & 4 & 4 \\
\hline & 7 & Alemanha & 4 & 3 & 5 & 3 & 4 \\
\hline Oceania & 8 & Austrália & 3 & 4 & 3,5 & 3,5 & 4 \\
\hline \multirow{2}{*}{$\begin{array}{l}\text { América do } \\
\text { Sul }\end{array}$} & 9 & Chile & 3,5 & 4,5 & 3 & 3 & 4 \\
\hline & 10 & Equador & 3 & 2 & 4,5 & 4 & 4,5 \\
\hline \multicolumn{3}{|c|}{ Média Total } & 3,6 & 3,1 & 3,7 & 3,2 & 3,9 \\
\hline
\end{tabular}

Nos estudantes da Ásia, observamos elevada auto-atribuição da capacidade de associar e um certo recuo quando o assunto é questionar. Em sustentação ao primeiro efeito, os asiáticos entrevistados atribuíram importância ao fato de perceber o todo, e não apenas um campo de informações separadamente. Lee e Walsh (2016) exploram esse fenômeno lembrando que trabalhadores obtêm experiências e conhecimento em largo espectro, ao longo de toda a sua jornada de trabalho. Nas palavras de E2

Porque quando você aprende mais, você possui mais fontes de informação para levar em consideração.

$\mathrm{O}$ ato de questionar, por sua vez, vem envolto em um certo constrangimento quase unânime entre os participantes. Os três entrevistados, de alguma forma, mencionaram a indisposição de questionar diante de assuntos que não estão sob sua responsabilidade. Isso faz lembrar a ideia do "taken for granted" de Shein (2001), se referindo a premissas e crenças profundas de uma cultura, que informam a maneira como as pessoas veem a si próprias e ao seu ambiente.

Os estudantes da Europa apresentaram os resultados mais elevados no que se refere à presença e evolução das capacidades inovadoras. Não se esquecendo que, no caso da presente pesquisa, eles eram os anfitriões dos demais estudantes, percebe-se principalmente o reconhecimento da importância atribuída à troca de informações, especialmente em relação às culturas. Essa disposição, segundo eles, ajuda a enriquecer experiências de conhecimento, o que vai diretamente ao encontro da afirmação de Bäcka e Kohtamäkia (2015), para quem as fronteiras de cooperação são influenciadas pelo nível de confiança existente no grupo.

Em contraste, mais uma vez o questionamento foi a competência menos apreciada entre os estudantes. Porém esse comportamento, segundo os próprios, é situacional, ou seja, depende fundamentalmente da circunstância. Ainda assim, a grande maioria reconhece esse ponto como passível de ser mais desenvolvido para que se alcance melhores resultados, revelando que a cultura pode ser revelada pela oposição da vontade de alguém aos costumes do grupo ao qual esta pertence. Para E6:

Eu acho que realmente depende, porque a maioria das pessoas escolhem diretamente os caminhos mais fáceis, e eu me incluo nessa situação. Contudo, acho que, uma vez que eu tenho essa sensação, talvez isso pudesse ser diferente. Se eu começasse a questionar alguma coisa, talvez eu sempre questionaria mais e mais para aprofundar o conhecimento. Então acho que começar é a parte mais difícil. 
O estudante australiano entrevistado, por sua vez, se destacou principalmente por se distanciar dos padrões de resposta para a capacidade de questionamento. Ele revelou ser incisivo até que um conteúdo seja totalmente compreendido. Segundo suas próprias palavras:

Certamente eu faço muitas perguntas. Muitas vezes discordo das pessoas. Se não entendo o que eles estão querendo dizer, apenas questiono. Quero dizer que, se algo não faz sentido para mim, eu pergunto até entender a questão completamente.

Em referência às entrevistadas sul americanas, a capacidade de associar ainda é um potencial a ser desenvolvido. Mesmo com os valores que se auto-atribuíram não sendo elevados, elas ainda chamaram a atenção para a circunstância em que se encontram atualmente, vivendo a experiência do intercâmbio, onde o excesso de novidades constitui-se em um convite permanente para associações. A competência de networking recebeu, mais uma vez, alta avaliação por motivos semelhantes aos já mencionados.

Com relação à experimentação, E10 trouxe à tona uma espécie de receptividade ao novo, ao inesperado e ao desvio de caminhos, que tem semelhança com a maneira como Amabile (1997) trata das habilidades criativas, como uma oportunidade para o reconhecimento de novas perspectivas para a solução de problemas, métodos de pesquisa ou aprimoramento de novas alternativas. A estudante equatoriana expõe sua visão, dizendo

Eu faço o que vem à minha cabeça, não planejo muito as coisas. Gosto de seguir o fluxo e descobrir o que posso fazer. Por exemplo, não sou muito uma pessoa de mapas. Se tenho um em minhas mãos, me sinto estranha de não o seguir, mas eu só quero me perder nas ruas, andar, conhecer e conversar com pessoas. Perguntar o que eu devo fazer ou o que eles me recomentam para conhecer. Mesmo que eu entre na rua errada, está tudo bem.

A competência da observação se manteve no meio termo para quase todos os participantes. Em geral associada à curiosidade, os estudantes se auto classificaram como parcialmente observadores. Similarmente, suas repostas também tinham em comum a seletividade, no sentido de prestarem mais atenção às coisas que realmente os interessavam. É o que se pode observar no comentário de E4

Me considero muito observador, eu acho. Não costumo ser a pessoa que lidera discussões, eu gosto de estar "ao fundo". Sou mais do tipo que gosta de observar o que está acontecendo à minha volta... as pessoas, o ambiente. Consigo notar os pequenos detalhes.

Na sequencia da pesquisa, foram entrevistados gestores de empresa de consultoria no Brasil, a fim de cotejar aqueles resultados obtidos com os estudantes com as expectativas da empresa. Foram ouvidos na primeira etapa da pesquisa dois consultores - $\mathrm{C} 1$ e C2 -, entrevistados a partir de um roteiro que levava em consideração os resultados obtidos com os estudantes.

Ambos os consultores atribuíram uma forte importância às características em questão para as organizações, mostrando que o desenvolvimento, a identificação e propagação do conhecimento exige não apenas tecnologia, mas pessoas cada vez mais capacitadas (LÓPEZ-ORTEGA et al, 2016; XIE et al, 2016). Foi reconhecido, igualmente pelos dois, a centralidade da presença das referidas competências nos colaboradores de uma empresa. Segundo C1, em um mundo onde as empresas possuem muitas informações disponíveis, essas competências são cruciais para o aproveitamento do conhecimento que já existe na organização. Em suas palavras

A associação facilita buscar através de uma extensão grande dados, quais as informações são necessárias e extrair o que é mais importante para empresa. A observação e questionamento também são interessantes, uma vez que só através da observação você vai poder identificar onde estão as potenciais oportunidades de melhoria que a organização tem, tanto internamente quanto externamente.

O outro consultor também elaborou raciocínio semelhante. Ele ressaltou que as empresas precisam estar sempre evoluindo, atendendo constantemente a necessidade do mercado, destacando portanto a cultura da inovação como protagonista na capacidade de inovação das organizações (SOUTO, 2015). Para ele, isso significa observar, atender e até mesmo antecipar as tendências de usuários, ou seja, deve-se associar fatores onde se enxergue uma possibilidade. Esse pensamento está diretamente atrelado à criatividade organizacional, levando em consideração a aspiração pelo desenvolvimento de novos e melhores produtos 
(WOODMAN et al, 1993). De forma similar ele ressaltou que o mesmo acontece quando encontra-se um problema numa empresa. Primeiro observa-se o problema, associa-se o que está acontecendo e questionase se não há uma maneira melhor de fazer aquilo, o que acaba tornando a experimentação uma etapa também fundamental. 0 networking entra como uma troca de conhecimento e relacionamento que pode ajudar a levar uma ideia adiante.

Quando questionados sobre a procura dessas características nos candidatos, C1 e C2 afirmaram que geralmente isso é feito pela utilização de cases e se torna mais fácil por entrevista presencial. C2 ainda destacou que algumas grandes empresas e universidades verificam essas habilidades associadas à inovação por meio de testes que não possuem resposta única, são utilizadas questões que exigem do candidato uma resposta analítica com um poder anterior de associação e observação. Por instância, quando o recrutador pergunta qual o número de janelas que a cidade de São Paulo possui, seu objetivo primordial passa a ser observar a linha de raciocínio lógico e associação do candidato, compreendendo a observação de sua memória, proficiência técnica e talentos especiais. Dessa forma, a expertise - outra componente de criatividade - também passa a ser alvo de observação (AMABILE, 1997).

Aprofundando no campo da gestão do conhecimento, essa é vista como um instrumento de apoio aos colaboradores para obtenção e centralização de informações captadas e organizadas, ainda mais para empreses que vivem de conhecimento, como é o caso da consultoria. Para eles, a gestão do conhecimento facilita e amplia a produtividade dos projetos, em especial atualmente, quando as empresas clientes trabalham com um volume muito grande de dados e os problemas já não são mais tão simples. A organização que não entende o conhecimento como prioridade, encontra mais dificuldades para evoluir.

As chamadas competências de descoberta também foram reconhecidas como pertinentes e úteis à dinâmica da gestão do conhecimento. Para C1 isso acontece principalmente através do questionamento, onde o profissional, ao receber uma informação, deve associar se aquela vai ser útil ou não. Ele deve se questionar por exemplo se é possível fazer de forma diferente, se poderia ganhar velocidade ou ainda poupar uma etapa do processo. Essa resposta vem ao encontro da afirmação de Subramaniam e Youndt (2005) quando esses argumentam que colaboradores mais qualificados e preparados são mais propensos a questionar procedimentos comuns para modificar a esfera que o cerca. Adicionalmente, C2 enxerga que o conhecimento é, em parte gerado a partir dessas competências, e em parte é gerado pelo networking, quando as pessoas se conhecem e o compartilham entre si. Nas palavras de C2

Existe a parte do conhecimento que é gerado a partir dessas competências e existe a disponibilização do conhecimento pelo networking, ou seja, as pessoas se conhecem e podem compartilhar os conhecimentos gerados. Existe o networking formal que é estabelecido pela disponibilização do conhecimento, existe a experimentação de testar algo que funcionou antes em algum lugar quando aplica-se isso num momento diferente para ver se funciona. Ou seja, é a organização de todos esses cinco fatores que levam a GC a ter um material organizado, classificado e disponibilizado da maneira correta, que é o grande fim.

Nesse sentido, as entrevistas também confirmaram que a existência de mecanismos da gestão do conhecimento nas organizações aumenta as possibilidades de que o conhecimento não se perca. 0 resultado é um acesso mais rápido à informação por parte dos colaboradores e um consequente ganho de produtividade, velocidade e de acuracidade do que se está fazendo. Não há a necessidade de "reinventar a roda", perdendo tempo reelaborando raciocínios que já podem estar prontos. Para C1 isto é focar nos fins e ganhar velocidade nos meios para chegar aos próprios fins. Nesse sentido, tem-se como produto, a partir do processo de criação, complementação e associação, a inovação (VALE et al., 2008).

\section{CONCLUSÃO}

O dilema da inovação, mais do que nunca, está colocado para a humanidade nestes tempos de pandemia. Formar inovadores que compreendam como colocar a sustentabilidade acima dos ganhos de curto prazo, como alinhar os esforços públicos com os privados no sentido de minorar os sofrimentos da população e como aproveitar a diferença e a diversidade para produzir soluções que sejam mais facilmente apropriáveis por todos é o grande desafio das gerações atuais e futuras. Parte do trabalho replica esforço, ainda em andamento mas já com resultados parciais, de compreender de que maneira o ambiente acadêmico cria ou reforça a presença das chamadas competências de descoberta em seus estudantes.

Ao levar os procedimentos de análise desenvolvidos localmente para uma experiência internacional, em universidade holandesa, aproveitando o intercâmbio de estudante de graduação, o trabalho otimiza 
esforços e traz para a reflexão acadêmica a importância, não apenas dos programas de intercâmbio propriamente ditos, mas também do confronto das experiências de formação em toda a sua amplitude, envolvendo a dimensão da mobilidade como fator de intensificação na formação de inovadores. Ao cotejar os achados da pesquisa com as expectativas de consultores, a pesquisa revela que inovação de fato constitui-se em um eixo de integração universidade-indústria que pode e precisa ser mais explorado.

Como limitação, cumpre registrar que a pesquisa tem apenas caráter exploratório, fazendo emergir uma série de questões que precisam de aprofundamento, tanto empírico quanto teórico. 0 período de sua execução foi limitado à duração de um programa de intercâmbio que trazia em seu bojo outras responsabilidades para a pesquisadora além da pesquisa propriamente dita.

Como trabalhos futuros, alguns dos quais já em andamento, sugere-se o aprofundamento dos estudos junto às empresas, diversificando e ampliando as amostras, e examinando com mais profundidade os programas acadêmicos de formação de empreendedores e inovadores, cotejando-os com o olhar das competências de descobertas tomado como eixo de compreensão da formação de inovadores na presente pesquisa.

\section{AGRADECIMENTO}

Os autores agradecem à FAPERJ - Fundação de Amparo à Pesquisa do Estado do Rio de Janeiro pelo financiamento de parte da pesquisa que gerou o presente trabalho.

\section{REFERÊNCIAS}

[1] AMABILE, T. M. Motivating Creativity in organizations: on doing what you love and loving what you do. California Management Review, 1997.

[2] ANDRADE, E. P; VERBiCARo, C. G.; Alves, J. C. M.; SMOLEnTZOV, G. J.; FAZENDA, V. G. Formando engenheiros inovadores: competências de descoberta nos estudantes de engenharia de produção da UFF. In: SIMPÓSIO DE ENGENHARIA DE PRODUÇÃO, 22., 2015. Anais... Bauru: UNESP, 2015.

[3] ASSIS, W. S.; ANDRADE, E. P.; SILVA, A. M.; ALVES, J. C. M.; ROCHA, M. de M. Quem é e onde está o inovador nas organizações?. In: XIX SemeAd - Seminários de Administração. USP, novembro de 2016.

[4] BENITO-BILBAO, J.; SÁNCHEZ-FUENTE, F.; OTEGI-OLASO, J. R. Mapping the Connection between Knowledge Transfer and Firm Competitiveness: An Empirical Research in the Basque Country. Journal of Technology Management \& Innovation, v. 10, n. 4, p. 45-56, 2015. DOI: http://dx.doi.org/10.4067/S0718-27242015000400005

[5] DYER, J.; GREGERSEN, H.; CHRISTENSEN, C. M. DNA do Inovador: dominando as 5 habilidades dos inovadores de ruptura. São Paulo: HSM editora, 2012.

[6] ETZKOWITZ, H. Innovation in innovation: the triple helix of university-industry governmentrelations. Social Science Information, v. 42, n. 3, p. 293-337, 2003. DOI: doi: 10.1177/05390184030423002

[7] FEDOCE, R. S.; MORAES, R. de O.; PIQUEIRA, J. R C. Knowledge Management as a Competitive Advantage to the Brazilian MVAS Ecosystem. Journal of Technology Management \& Innovation, v. 10, n. 2, p. 1-8, 2015. DOI: http://dx.doi.org/10.4067/S0718-27242015000200001

[8] FUKUYAMA, F. O fim da História e o último homem. Rio de Janeiro: Rocco, 1992.

[9] GIBSON, C. B.; GIBBS, J. L. Unpacking the Concept of Virtuality: the effects of geographic dispersion, electronic dependence, dynamic structure, and national diversity on team innovation. Administrative Science Quarterly, v. 51, n. 3, p.451-495, 2006.

[10] GRAY, D. E. Pesquisa no mundo real. Porto Alegre: Penso, 2012.

[11] GUAN, J. C.; ZUO, K. R.; CHEN, K. H.; YAM, R. C.M. Does country-level R\&D efficiency benefit from the collaboration network structure? Research Policy, v. 45, n. 4, p. 770-784, Maio, 2016. DOI: doi: 10.1016/j.respol.2016.01.003

[12] KAASA, A.; VADI, M.; VARBLANE, U. European Social Survey as a Source of New Cultural Dimensions Estimates for Regions. International Journal of Cross Cultural Management, v. 13, n. 2, p.137-157, 2013.

[13] LEE, Y.-N.; WALSH, J. P. Inventing while you work: Knowledge, non-R\&D learning and innovation. Research Policy, v. 45, n. 1, p. 345-359, Fevereiro, 2016. DOI: doi: 10.1016/j.respol.2015.09.009

[14] LÓPEZ-ORTEGA, E.; CANALES-SANCHEZ, D.; BAUTISTA-GODINEZ, T.; MACIAS-HERRERA, S. Classification of micro, small and medium enterprises (M-SME) based on their available levels of knowledge. Technovation, v. 47, p. 59-69, Janeiro, 2016. DOI: doi:10.1016/j.technovation.2015.10.001

[15] HOFSTEDE, G. Cultural constraints in management theories. Academy of Management, Vol.7, No1, p.81-95, 
1993.

[16] MICHELINO, F.; CAMMARANO, A.; LAMBERTI, E.; CAPUTO, M. Knowledge Domains, Technological Strategies and Open Innovation. Journal of Technology Management \& Innovation, v. 10, n. 2, p. 50-78, 2015. DOI: http://dx.doi.org/10.4067/S0718-27242015000200005

[17] NONAKA, I.; TAKEUCHI, H. Criação do conhecimento na empresa. Rio de Janeiro: Campus, 1997.

[18] PERRY, S. J.; HUNTER, E. M.; CURRALL, S. C. Managing the innovators: Organizational and professional commitment among scientists and engineers. Research Policy, v. 45, n. 6, p. 1247-1262, Julho, 2016. DOI: doi: 10.1016/j.respol.2016.03.009

[19] SCHEIN,E. H. Guia de sobrevivência da cultura corporative. Rio de Janeiro: José Olympio, 2001.

[20] SOUTO, J. E. Gestión de una Cultura de Innovación Basada en las Personas. Journal of Technology Management \& Innovation, v. 10, n. 3, p. 60-65, 2015. DOI: http://dx.doi.org/10.4067/S0718-27242015000300007

[21] STAKE, R. E. The case study method in social inquiry. In: GOMM, R; HAMMERSLEY, M; FOSTER, P (eds). Case Study Method: Key Issues, Key Texts. London: Sage, 2000.

[22] STEWART, T. A. A riqueza do conhecimento: o capital intelectual e a nova organização. Rio de Janeiro: Campus, 2002.

[23] SUBRAMANIAM, M.; YOUNDT, M. A. The influence of Intellectual Capital on the Types of Innovative Capabilities. Academy of Management Journal, v. 48, n. 3, p. 450-463, 2005.

[24] SVEIBY, Karl Erik. A Nova Riqueza das Organizações. Rio de Janeiro: Campus, 1998.

[25] XIE, Z.; HALL, J.; MCCARTHY, I. P.; SKITMORE, M.; SHEN, L. Standardization efforts: The relationship between knowledge dimensions, search processes and innovation outcomes. Technovation, v. 48-49, p. 69-78, Fevereiro-Março, 2016. DOI: doi:10.1016/j.technovation.2015.12.002

[26] YIN, R.K. Estudo de caso. Planejamento e métodos. Porto Alegre: Bookman, 2005.

[27] WOODMAN, R., SAWYER, J;.GRIFFIN, R. Toward a theory of organizational creativity. Academy of Management Review, 18(2), p. 293-321, 1993. 


\section{Capítulo 11}

\section{Análise do Terminal de Passageiros do Aeroporto Internacional Tom Jobim por meio de uma simulação}

\section{Pedro Henrique Campos da Costa \\ Pedro da Matta e Andrade Basilio \\ Ana Carolina Cellular Massone}

Resumo: Em virtude do massivo número de passageiros que realizam diariamente voos no Aeroporto Internacional Tom Jobim, se fez necessário um estudo sobre a gestão de processos no aeroporto. Este estudo buscou dar enfoque aos problemas que podem ocorrer no processo de embarque dos passageiros, como filas exageradamente grandes ou demoradas. Este trabalho tem o objetivo de elaborar, por meio de simulação discreta, o processo de embarque dos passageiros. Para destacar os pontos que devem ser posteriormente melhorados, para isso será elaborada uma simulação no arena® simulation software da rockwell automation.

Palavras-chave: Gestão de processos; aeroporto; pesquisa operacional; simulação discreta. 


\section{INTRODUÇÃO}

O crescimento do setor aéreo mundial teve seu início na década de 70, com a desregulamentação do setor aéreo norte americano, que logo foi seguido pela Europa e pela América do Sul, nas décadas de 80 e 90 respectivamente (Pasin, 2003). Jesus (2005) fala que a expansão do setor aéreo também foi impulsionada pelo surgimento de diversos acordos comerciais de união entre empresas, inovando assim, na forma de cooperar. Com isto, era possível racionalizar recursos de produção, em especial o direito de operar determinadas rotas.

A aviação civil brasileira passou, nos últimos 20 anos, por um intenso processo de popularização, o que facilitou o acesso de diferentes pessoas as viagens aéreas. Muitos desses novos clientes, costumavam realizar suas viagens através de meios terrestres, e por conta da democratização das passagens aéreas, começaram a possuir o hábito de viajar de avião, o que aumentou expressivamente o tráfego de clientes nos aeroportos (OLIVEIRA; SALGADO, 2014).

No momento das viagens, é muito comum que os passageiros percam tempo procurando filas de check-in, com despacho de bagagens, em revistas policiais e com conferências de passagens. Por conta disso viu-se a necessidade de um estudo, com foco nos processos que um viajante deve enfrentar ao realizar uma viagem aérea.

Em seu princípio, a simulação começou a ser utilizada para encontrar falhas em sistemas existentes. No entanto, passou a ser usada também para prever falhas nos sistemas antes da implementação destes (De Landa, 2007). De acordo com Miyagi (2006), simulação é o nome dado à projeção de uma operação ou processo, a fim de descobrir os possíveis impactos gerados através de mudanças propostas no sistema original, sem a necessidade efetiva de realizá-las, sendo uma ótima ferramenta de auxílio ao processo decisório. Esta se trata de uma técnica experimental, que tem como base, um modelo computacional, onde os ambientes são reproduzidos e os sistemas são examinados de diferentes óticas. Analisando os cenários apresentados, escolhe-se as melhores soluções para os desafios (Garza-Reyes, 2010). Desta forma, a simulação auxilia os aeroportos em seu funcionamento.

É possível observar na literatura artigos que reforcem as ideias acerca de simulação apresentadas anteriormente, como em Vilella, Dávalos e Cavaco (2019), e em Formigoni (2017). Este último, também utilizou o software Arena para a criação do modelo, tal qual De Abreu (2018).

De acordo com informações do RIOgaleão (2019), no decorrer do ano de 2018, 15.035 .083 passageiros utilizaram o aeroporto para embarcar para suas viagens, sendo que desses 15 milhões, 4.505 .912 foi a quantidade de passageiros que tiveram destinos internacionais e 10.529.171 domésticos. Este grande fluxo acabou por gerar alguns problemas, como a organização dos passageiros desde o momento de sua chegada ao aeroporto até o seu embarque na aeronave. Com base nesta questão, este trabalho tem o objetivo de analisar, por meio da simulação, os processos pela ótica do passageiro. Criando um modelo que possibilite testes para futuras alterações no processo de embarque de passageiros.

Para organizar os processos, fez-se uso de ferramentas como fluxograma, a fim de estabelecer uma ordem cronológica e organizada de todas as atividades exercidas por um passageiro, momentos antes de sua viagem. Com a finalidade de simular o processo, este trabalho utilizou a Simulação Discreta, buscando a simulação mais próxima possível da realidade do Aeroporto Internacional Tom Jobim, o popular Aeroporto do RIOgaleão, no Rio de Janeiro.

Portanto este trabalho está dividido da seguinte forma. Na seção 2 estão as referências bibliográficas, onde é mostrado o cenário do setor aéreo no Brasil e no mundo, assim como brevemente explicada sua trajetória pela história. Ainda nesta seção, há uma rápida explicação sobre o uso da simulação e do software utilizado. A seção 3 refere-se a metodologia utilizada no artigo, mostrando as etapas para a sua construção. Logo depois, na seção 4, a simulação construída é abordada, assim como os dados para a execução dela. Os resultados obtidos se encontram na seção 5 , bem como a análise dos diferentes cenários propostos. Por fim, na seção 6 as considerações finais sobre o projeto são apresentadas.

\section{REFERÊNCIAS BIBLIOGRÁFICAS}

A partir da década de 90, uma grande quantidade de acordos comerciais, desde o code-sharing modalidade onde duas ou mais companhias aéreas compartilham o mesmo voo e os mesmos canais de venda - e até mesmo fusões começaram a surgir. Como tratado por De Souza Silveira (2007), nos anos 2000, as vendas de passagens aéreas foram fortemente impulsionadas pela utilização dos sistemas de reserva por computador (CRSs), re-nascimento dos programas de fidelidade, pelo advento da internet e o e-ticket. 
De acordo com Castro, Balassiano e Santo Jr. (2015) o transporte aéreo no Brasil teve um nítido crescimento entre 2003 e 2008, o que possibilitou ao consumidor presenciar uma queda considerável no preço médio por quilômetro voado neste período. Notou-se, no entanto, que o investimento não acompanhou tal aumento em questão de infraestrutura aeroportuária do país, o que gerou problemas periódicos aos passageiros e turistas em geral. Ainda mais quando levado em consideração que o Rio de Janeiro sediaria os Jogos Olímpicos de 2016 e o Aeroporto Internacional Antônio Carlos Jobim seria o principal portão de entrada de turistas nacionais e internacionais. Sendo assim, o RIOgaleão, com o objetivo de oferecer conforto e apresentar uma imagem positiva aos clientes, foi cedido à iniciativa privada em 2013 e, assim, investiu-se estrategicamente na melhoria dos seus produtos e serviços.

O Aeroporto Internacional Tom Jobim é o maior e mais movimentado aeroporto da cidade do Rio de Janeiro, tendo registrado no ano de 2018 o embarque de 15.035 .083 passageiros, segundo RIOgaleão (2019). Por conta da grande importância desse aeroporto para a cidade, este trabalho visou à criação de um modelo de simulação que represente todo o processo de embarque dos passageiros neste aeroporto, para que assim, seja possível prever consequências de alterações antes que estas sejam efetivamente realizadas.

No momento das viagens, é muito comum que os passageiros percam tempo procurando filas de check-in, com despacho de bagagens, em revistas policiais e com conferências de passagens. Buscando otimizar todo o processo de embarque de passageiros, viu-se a necessidade de um estudo, com foco nos processos que um viajante deve enfrentar ao realizar uma viagem aérea, e, para simular todo este processo foi utilizado o software Arena ${ }^{\circledR}$ Simulation da Rockwell Automation.

De acordo com Formigoni (2017), a simulação vem sendo cada vez mais utilizada nas empresas, por ser uma ferramenta que municia o tomador de decisões com informações e detalhes importantes que podem ser cruciais para o desempenho satisfatório de sistemas. Conforme De Abreu (2018), o Arena apresenta um ambiente gráfico integrado com vários recursos que possibilitam a modelagem de processos, desenhos e animações, os quais facilitam a leitura dos sistemas, assim como análises estatísticas e de resultados. A simulação por meio deste programa possibilita o refinamento de sistemas, para que estes, se adequem a algumas necessidades e restrições, apoiando assim, decisões estratégicas a serem tomadas pelos gestores.

No setor de transportes, a utilização do Arena permite que planejadores construam, testem e analisem os resultados de cenários fictícios, buscando encontrar os melhores desempenhos de suas atividades (De Abreu, 2018). No setor aéreo, a simulação vem sendo testada por parte dos aeroportos, com o intuito de melhorar a eficiência das operações mantendo a segurança de todo o processo (Formigoni, 2017).

\section{METODOLOGIA}

Para este trabalho, foi realizada uma revisão bibliográfica e pesquisa de dados, obtendo um modelo de simulação que possibilite analisar o terminal de passageiros no Aeroporto Internacional Tom Jobim.

Para isso, o primeiro passo foi buscar na literatura algumas abordagens sobre os aeroportos no mundo e no Brasil, dando ênfase no RIOgaleão. Após esta etapa, realizou-se uma busca bibliográfica focando em estudos sobre simulação e aplicação de simulação discreta, já que o trabalho tem o intuito de apresentar um modelo neste tipo de simulação.

Como etapa posterior, buscou-se os dados a serem utilizados no modelo, por meio de entrevistas no formulário do Google, contato por e-mail com o RIOgaleão, relatórios e na literatura. Tais dados foram trabalhados para melhor se ajustarem ao modelo em questão. Por fim, foi elaborado o modelo de simulação do embarque de passageiros e criado cenários para todo o processo.

\section{SIMULAÇÃO}

Para a realização da simulação, se fez necessário um levantamento de todos os processos que envolvem o embarque do passageiro na aeronave. 0 modelo de simulação do embarque de passageiros no Aeroporto Internacional Tom Jobim é caracterizado pelos seguintes processos, conforme Figura 1. 
FIGURA 1 - Fluxograma do embarque de passageiros internacional.

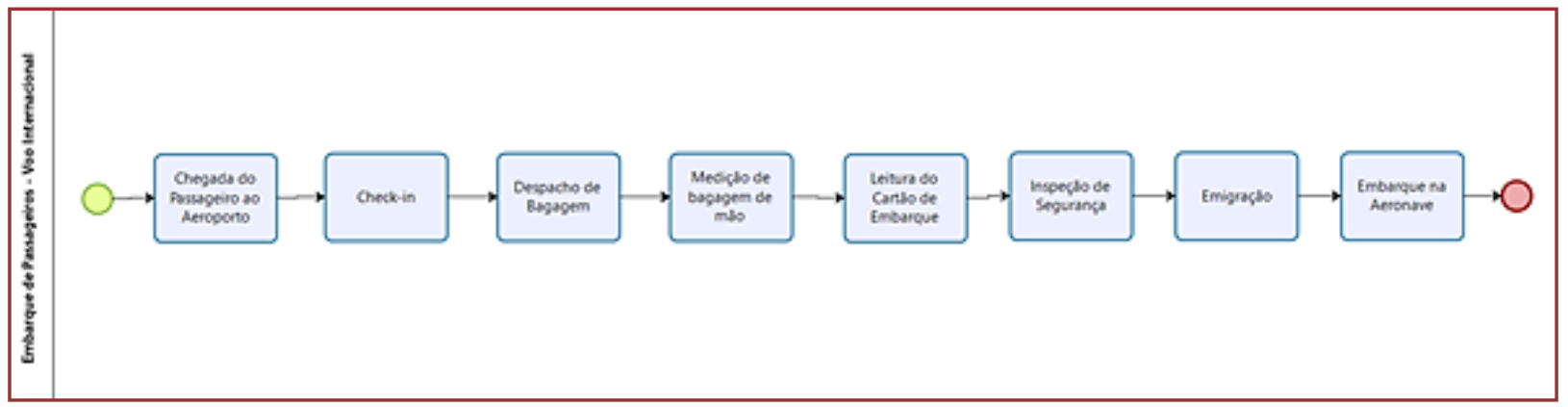

Fonte: Autor.

Portanto, foi realizada uma pesquisa com 15 entrevistados a fim de mensurar os tempos médios de cada processo envolvido no embarque de passageiros. Esta pesquisa está representada na Tabela 1. Os únicos processos em que não houve perguntas para o público são os de: "inspeção de segurança", "check-in balcão + despacho de bagagem" e "Leitura de cartão de embarque", uma vez que os dados referentes a estes dois primeiros processos foram repassados pelo próprio Aeroporto. 0 processo de "Leitura de cartão de embarque" foi estipulado em 0,15 minutos, dado que se trata de um processo automático.

TABELA 1 - Respostas - Formulário Google - Tempo gasto em processos de embarque RIOgaleão.

\begin{tabular}{|c|c|c|c|c|c|c|c|}
\hline \multirow[b]{2}{*}{$\begin{array}{l}\text { Tipo de } \\
\text { Check-in }\end{array}$} & \multirow[b]{2}{*}{ Tipo de voo } & \multicolumn{6}{|c|}{ Tempo gasto (em minutos) } \\
\hline & & Check-in & $\begin{array}{l}\text { Despacho de } \\
\text { bagagem - } \\
\text { Doméstico }\end{array}$ & $\begin{array}{l}\text { Despacho de } \\
\text { bagagem - } \\
\text { Internacional }\end{array}$ & $\begin{array}{c}\text { Medição de } \\
\text { bagagem de } \\
\text { mão }\end{array}$ & Emigração & Embarque \\
\hline Eletrônico & Doméstico & 3 & 1 & & 0,1 & & 0,6 \\
\hline Eletrônico & Doméstico & 1 & 4 & & 0,3 & & 0,4 \\
\hline Eletrônico & Doméstico & 4 & 4 & & 0,2 & & 0,4 \\
\hline Internet & Internacional & & & 5 & 0,4 & 1,3 & 1 \\
\hline Internet & Internacional & & & 4 & 0,1 & 1,3 & 0,2 \\
\hline Eletrônico & Doméstico & 2 & 2 & & 0,5 & & 0,6 \\
\hline Eletrônico & Internacional & 5 & & 3 & 0,5 & 1,5 & 0,2 \\
\hline Eletrônico & Doméstico & 1 & 2 & & 0,6 & & 0,6 \\
\hline Eletrônico & Doméstico & 4 & 3 & & 0,8 & & 0,2 \\
\hline Eletrônico & Internacional & 2 & & 3 & 0,4 & 0,8 & 0,4 \\
\hline Internet & Internacional & & & 3 & 0,8 & 0,9 & 0,4 \\
\hline Internet & Internacional & & & 4 & 0,8 & 1 & 0,2 \\
\hline Eletrônico & Doméstico & 2 & 3 & & 0,4 & & 0,2 \\
\hline Eletrônico & Internacional & 1 & & 2 & 0,7 & 1,3 & 0,2 \\
\hline Internet & Internacional & & & 2 & 0,9 & 1,1 & 0,4 \\
\hline \multicolumn{2}{|c|}{ Média } & 2,5 & 2,7 & 3,25 & 0,5 & 1,15 & 0,4 \\
\hline
\end{tabular}

Para a realização da simulação, deve-se considerar o tipo de voo que o passageiro irá realizar. Em voos domésticos, a média de passageiros é de 171, enquanto em voos internacionais é de 233. Baseado nos relatórios trimestrais de desempenho operacional do Aeroporto Internacional do Galeão - Rio de Janeiro (SGBL), foi elaborado o gráfico da Figura 2 que apresenta a chegada dos passageiros para os dois tipos de voos. 
FIGURA 2 - Gráfico - Antecedência de chegada para voo doméstico e internacional.

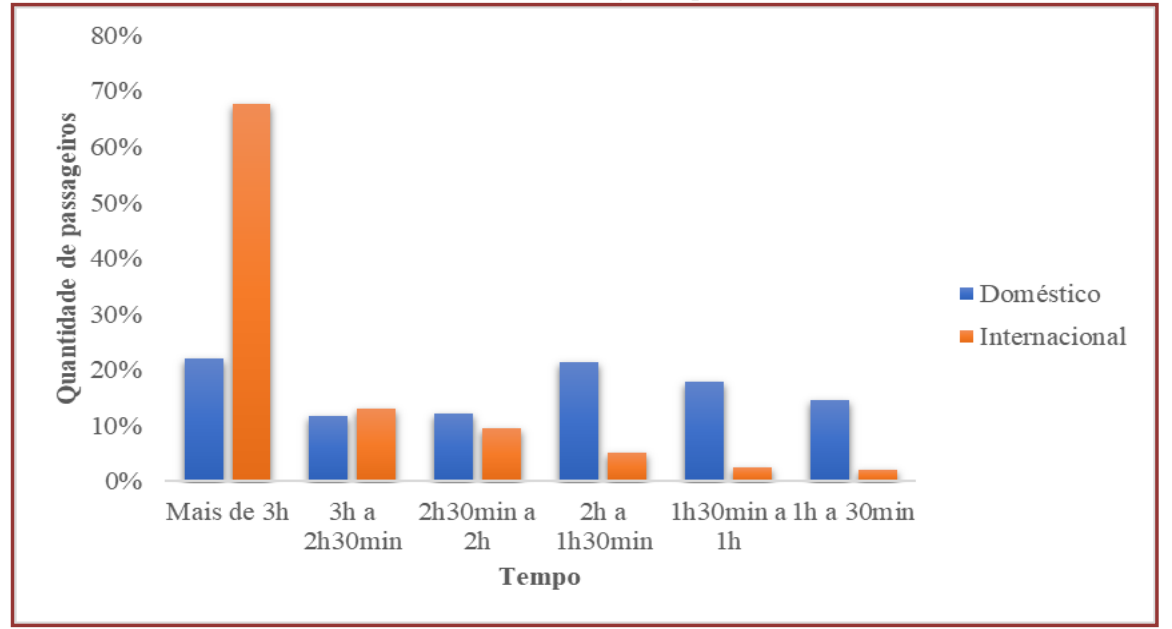

Fonte: Autor.

0 processo de check-in, possui três alternativas diferentes, que são: Check-in feito no balcão, check-in eletrônico e check-in pela internet. A distribuição da opção dos passageiros está representada na Figura 3.

FIGURA 3 - Gráfico - Formas de check-in.

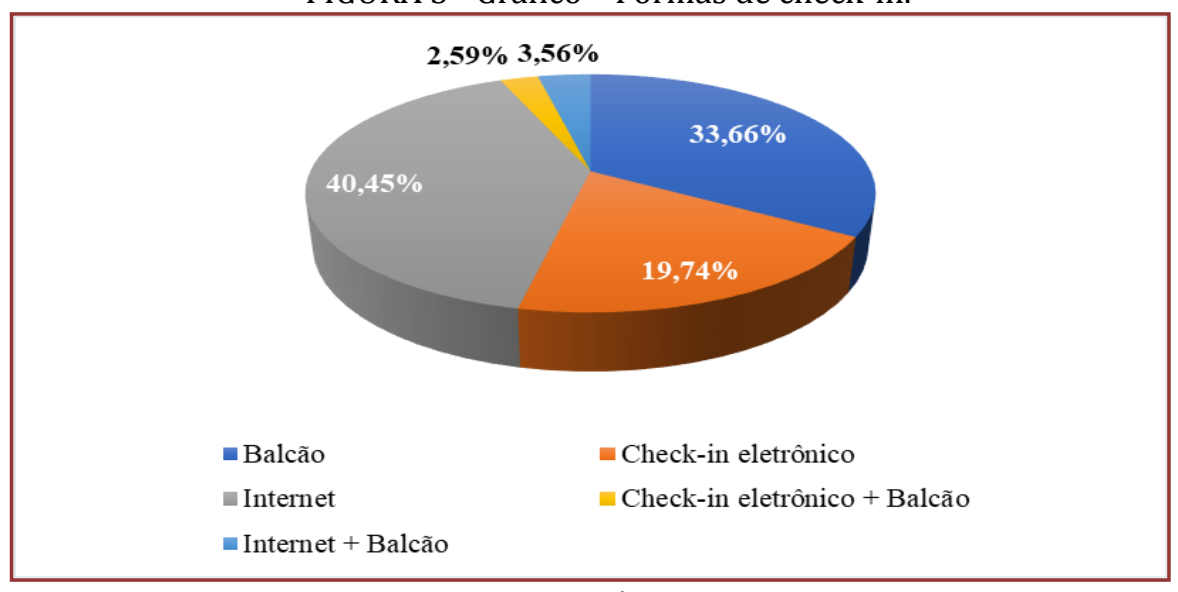

Fonte: Autor.

A Tabela 2 apresenta as informações gerais usadas na simulação. 0 check-in eletrônico é a média obtida nas entrevistas aos passageiros. 0 tempo de check-in balcão foi informado pelo RIOgaleão. Por fim, o tempo gasto no check-in na internet não foi utilizado na simulação, uma vez que o processo costuma ser feito anteriormente ao momento simulado.

TABELA 2 - Resumo de dados utilizados na simulação.

\begin{tabular}{|c|c|c|c|}
\hline \multirow{2}{*}{\multicolumn{2}{|c|}{ Processo }} & \multicolumn{2}{|c|}{ Tempos (min) } \\
\hline & & Doméstico & Internacional \\
\hline \multirow{3}{*}{ Check-in } & Internet & & \\
\hline & Eletrônico & 2,5 & 2,5 \\
\hline & $\begin{array}{c}\text { Balcão + Despacho de } \\
\text { bagagem }\end{array}$ & 4,9 & 5,5 \\
\hline \multicolumn{2}{|c|}{ Despacho de bagagem } & 2,7 & 3,25 \\
\hline \multicolumn{2}{|c|}{ Medição de bagagem de mão } & 0,5 & 0,5 \\
\hline \multicolumn{2}{|c|}{ Leitura de cartão de embarque } & 0,15 & 0,15 \\
\hline \multicolumn{2}{|c|}{ Inspeção de Segurança } & 2,7 & 2,6 \\
\hline \multicolumn{2}{|c|}{ Emigração } & & 2,6 \\
\hline \multicolumn{2}{|l|}{ Embarque } & 0,4 & 0,4 \\
\hline
\end{tabular}


A simulação começa com 6 diferentes chegadas, para que os clientes cheguem com a antecedência informada na figura 1. 0 campo "Aguardar 1" serve para que os passageiros não avancem pela simulação enquanto o check-in ainda se encontra fechado. Existe a decisão que define qual tipo de check-in o passageiro fará, podendo ser: internet, eletrônico ou balcão.

Após o check-in feito existe a decisão do processo de "Despachar bagagem", seguido pela "Medição de Bagagem de Mão", caso esta esteja dentro dos padrões, a simulação continua para a etapa da "Leitura de Cartão de Embarque", caso contrário, o passageiro é mais uma vez, encaminhado para o despacho de bagagem.

A próxima etapa é a inspeção de segurança, seguido pela emigração. Logo depois existe "Saída Área Emigração" e o "Chegada Área Embarque", que representa o deslocamento, estipulado em 10 minutos, entre a área da emigração e a setor de embarque.

Antes do processo de embarque, existe o "Aguardar 2", que é responsável por "segurar" os passageiros enquanto o processo "Embarque" se encontra fechado. Este último processo abre nos últimos 40 minutos em voos domésticos e 1 hora nos internacionais. Por fim, a "Entrada na Aeronave" encerra a simulação. Para realização da simulação foi utilizado o Software Arena. Tal software utiliza uma base de fluxograma de simples montagem. A Figura 4 mostra a simulação de um voo internacional. A diferença da simulação de voos domésticos, é que neste caso não há o processo de emigração.

FIGURA 4 - Simulação do embarque de voos internacionais.

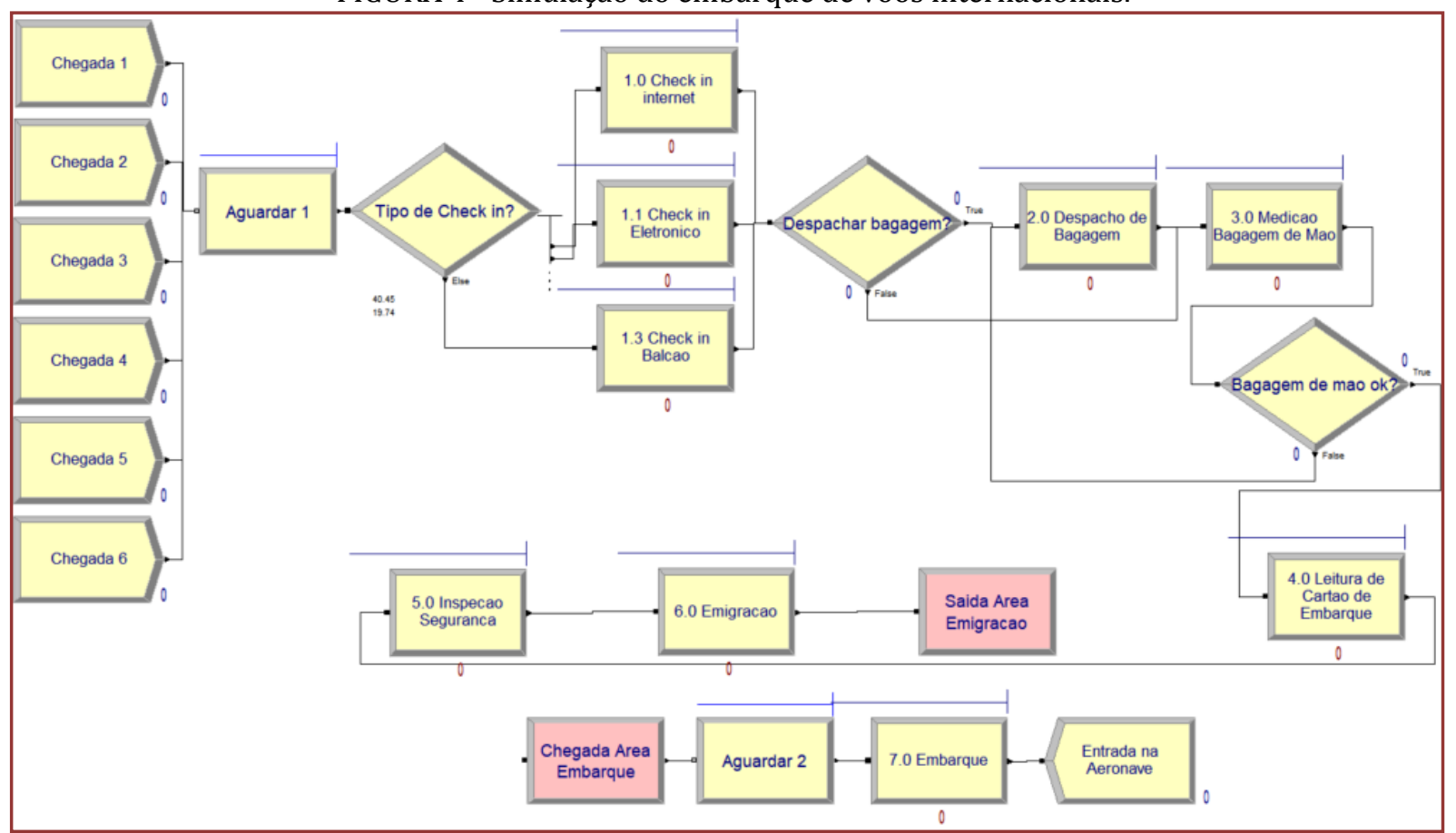

Fonte: Autor.

Foram realizadas 50 replicações dos modelos de simulação de voo doméstico e internacional em dois diferentes cenários. 0 primeiro é o cenário base, já o segundo se trata de um cenário com menos recursos disponíveis. Para ambos os tipos de voo, o tempo simulado foi de 3 horas e 30 minutos. Nenhum passageiro atrasado foi considerado para a simulação. A quantidade de recursos para cada simulação está representada na Tabela 3. 
TABELA 3 - Recursos utilizados nas simulações.

\begin{tabular}{|c|c|c|c|c|}
\hline \multirow{2}{*}{ Nome Recurso } & \multicolumn{2}{|c|}{ Doméstico } & \multicolumn{2}{|c|}{ Internacional } \\
\hline & Cenário 1 & Cenário 2 & Cenário 1 & Cenário 2 \\
\hline R_CheckinBalcao & 3 & 2 & 9 & 7 \\
\hline R_CheckinEletronico & 3 & 3 & 6 & 4 \\
\hline R_CheckinInternet & 1 & 1 & 1 & 1 \\
\hline R_DespBagagem & 2 & 2 & 8 & 6 \\
\hline R_Embarque & 2 & 2 & 3 & 3 \\
\hline R_InspecaoSeguranca & 3 & 2 & 7 & 5 \\
\hline R_LeitCartEmbarque & 2 & 2 & 3 & 3 \\
\hline R_MedicBagMao & 2 & 2 & 2 & 2 \\
\hline
\end{tabular}

Fonte: Autor.

\section{RESULTADOS COMPUTACIONAIS E DISCUSSÕES}

Neste tópico são apresentados os resultados mais importantes de ambos os cenários da simulação voos domésticos (Tabela 4).

TABELA 4 - Resultados da simulação do embarque de voos domésticos.

\begin{tabular}{|c|l|c|c|}
\hline \multicolumn{2}{|c}{ Passageiros Embarcados } & Cenário 1 & Cenário 2 \\
\hline \multirow{4}{*}{ Tempo Médio (min) } & Fila Embarque & 14,71 & 124 \\
\cline { 2 - 4 } & Fila Check-in Balcão & 4,99 & 8,36 \\
\cline { 2 - 4 } & Fila Inspeção de Segurança & 8,18 & 33,47 \\
\cline { 2 - 4 } & No Sistema & 99,69 & 119,47 \\
\hline \multirow{2}{*}{$\begin{array}{c}\text { Taxa de Utilização } \\
(\%)\end{array}$} & Check-in Balcão & 53,67 & 79,49 \\
\cline { 2 - 4 } & Inspeção de Segurança & 73,29 & 85,4 \\
\hline
\end{tabular}

Fonte: Autor.

Na simulação de voos domésticos, no cenário 1, todos os 171 passageiros conseguiram realizar o procedimento de embarque por completo dentro do tempo estabelecido de 3 horas e 30 minutos. Em geral, os clientes gastaram 99,69 minutos dentro do sistema, destes, apenas 7,18 minutos foram gastos em processos, enquanto 82,50 minutos foram gastos em filas e 10 minutos em deslocamentos.

A fila mais demorada foi a de embarque, com média de 14,71 minutos, e isso acontece porque esta etapa somente é liberada quando já existem vários passageiros prontos para entrar neste processo. A eficácia do modelo pode ser constatada ao comparar os tempos de fila mostrados na tabela 4 com os tempos de fila esperados, divulgados nos relatórios trimestrais de desempenho operacional do Aeroporto Internacional do Galeão do ano de 2018.

O segundo cenário da simulação de voos domésticos conta com uma diminuição de uma unidade nos recursos "Check-in balcão" e na "Inspeção de segurança". Esta diminuição gerou um salto no tempo médio gasto pelos clientes no sistema, passando para a nova média de 119,47 minutos. Esta pequena mudança na capacidade de recursos fez com que apenas 124 passageiros conseguissem embarcar no voo, ou seja, completar o sistema no tempo estipulado de 3 horas e 30 minutos.

Sendo assim, os tempos de fila nos processos que tiveram sua capacidade alteradas mais do que quadruplicaram. A fila nos processos de "Check-in balcão + despacho de bagagem" e "Inspeção de Segurança" saltaram para 21,57 minutos e 33,43 minutos, assim como as suas taxas de utilização, que passaram para $79,49 \%$ e $85,40 \%$.

A Tabela 5 mostra os resultados mais importantes de ambos os cenários da simulação voos internacionais. 
TABELA 5 - Resultados da simulação do embarque de voos internacionais.

\begin{tabular}{|c|l|c|c|}
\hline \multicolumn{2}{|c|}{ Passageiros Embarcados } & Cenário 1 & Cenário 2 \\
\hline \multirow{4}{*}{ Tempo Médio (min) } & Fila Embarque & 233 & 233 \\
\cline { 2 - 4 } & Fila Check-in Balcão & 14,63 & 13,75 \\
\cline { 2 - 4 } & Fila Inspeção de Segurança & 15,33 & 21,96 \\
\cline { 2 - 4 } & No Sistema & 9,72 & 18,65 \\
\hline \multirow{2}{*}{ Taxa de Utilização (\%) } & Check-in Balcão & 130,73 & 130,73 \\
\cline { 2 - 4 } & Inspeção de Segurança & 27,56 & 34,84 \\
\hline
\end{tabular}

Fonte: Autor.

No cenário 1 da simulação de voos internacionais, todos os 233 passageiros conseguem embarcar sem maiores problemas durante as 3 horas e 30 minutos simuladas. Nesta simulação, as filas mais demoradas são as que envolvem o processo de despachar bagagem, isto acontece porque, neste tipo de viagem, em média, todos os passageiros despacham bagagens, o que gera um acúmulo de pessoas no processo que possui um tempo considerável.

Por conta da grande quantidade de recursos empregados nesta simulação as taxas de utilização são, em geral, pequenas. Os recursos com as maiores taxas de utilização média neste cenário são a "Emigração" e "Inspeção de Segurança", com 42,53\% e 41,21\%, respectivamente. Este modelo de simulação se mostra condizente com a realidade, e isto pode ser constatado ao comparar os tempos de filas com aqueles tempos de fila divulgados nos relatórios trimestrais de desempenho operacional do Aeroporto Internacional do Galão no ano de 2018.

No segundo cenário da simulação de voos internacionais, foi proporcionado uma maior diminuição na quantidade de recursos disponíveis, tendo sido diminuído 2 unidades na capacidade do "Check-in balcão", "Check-in eletrônico", "Despacho de Bagagem" e "Inspeção de Segurança". Estes recursos foram escolhidos porque são considerados processos importantes dentro da simulação. No entanto, estas mudanças proporcionadas acabaram gerando um impacto pequeno, já que todos os 233 passageiros conseguiram embarcar dentro das 3 horas e 30 minutos disponíveis. Isto ocorreu, em grande parte, por conta da grande antecedência que a maior parte dos passageiros chega ao aeroporto, conforme Figura 2. Dessa forma, eles dispõem de mais tempo para realizar todo o processo de embarque.

Porém, não se pode dizer que as alterações neste cenário não tenham surtido efeito, já que o tempo médio de fila na "Inspeção de Segurança" praticamente dobrou, saltando de uma média de 9,72 minutos no cenário 1 para 18,65 minutos no cenário 2. A maior fila registrada foi no "Check-in balcão + despacho de bagagem", com média de 21,96 minutos. As taxas médias de utilização que mais cresceram neste segundo cenário foram as da "Inspeção de Segurança" e "Despacho de Bagagem", o que já era esperado, pois estes são processos de tempo consideráveis e que foram dois dos recursos que tiveram sua capacidade diminuída. Por outro lado, o "Check-in Eletrônico" ainda se mostrou subutilizado, isto se deve a rapidez e simplicidade deste processo.

\section{CONSIDERAÇÕES FINAIS}

A pesquisa operacional, por meio da simulação é extremamente indicada para analisar os problemas de logística que possam vir a ocorrer nos aeroportos, uma vez que é permitido se fazer diferentes testes, buscando uma melhor solução para resolver a problemática enfrentada.

Este trabalho visa oferecer um modelo capaz de analisar os processos de um terminal de passageiros, verificando todos os tempos de filas e processos de cada etapa que um viajante passa ao embarcar para uma viagem. A simulação proposta possui resultados coerentes com o real, e, portanto, poderia ser utilizada. Isto pode ser confirmado ao se comparar os primeiros cenários de cada simulação com os números de filas obtidos no Relatório de Desempenho Operacional do Aeroporto Internacional do Galeão - Rio de Janeiro (SBGL) do ano de 2018. Sendo assim, as simulações podem ser utilizadas para a realização de testes no aeroporto, evitando assim, prejuízos ao se colocar em prática determinadas alterações no modelo sem os testes necessários.

Tendo como base os resultados apresentados no capítulo 5, pode-se propor uma série de mudanças visando o melhor atendimento dos passageiros no processo de embarque de voos, desde a diminuição ou o aumento de atendentes em determinado processo, ou até mesmo em relação a disponibilidade de máquinas, como por exemplo a quantidade de totens de check-in eletrônico. 
A análise dos resultados da simulação possibilita ainda identificar gargalos do processo, assim como fornecer aos gestores do aeroporto uma melhor leitura das particularidades de cada tipo de voo.

\section{REFERÊNCIAS}

[1] CASTRO, Rafael; BALASSIANO, Ronaldo; SANTO JR, Respício A. Espírito. Aeroporto Internacional do Rio de Janeiro-Galeão e os jogos olímpicos de 2016: uma questão de branding?. 2015.

[2] DE ABREU, Victor Hugo Souza et al. Simulação aplicada a um terminal de passageiros: relação entre desistência de realização da viagem e frequência de atendimento aos usuários. Revista Uniabeu, v. 11, n. 29, p. 404$422,2018$.

[3] DE SOUZA SILVEIRA, Débora Machado. Análise dos benefícios das alianças internacionais entre empresas de transporte aéreo. 2007. Tese de Doutorado. UNIVERSIDADE FEDERAL DO RIO DE JANEIRO.

[4] FORMIGONI, Alexandre et al. Aplicação da simulação computacional no processo de check-in do aeroporto internacional de guarulhos. South American Development Society Journal, v. 1, n. 2, p. 20-32, 2017.

[5] GARZA-REYES, Jose Arturo et al. Overall equipment effectiveness (OEE) and process capability (PC) measures: a relationship analysis. International Journal of Quality \& Reliability Management, v. 27, n. 1, p. 48-62, 2010.

[6] JESUS, Claudiana Guedes de et al. Desregulamentação e trabalho na aviação comercial brasilera (1990-2002). 2005.

[7] MIYAGI, Paulo E. Introdução a simulação discreta. Escola Politécnica da Universidade de São Paulo. Departamento de Engenharia Mecatrônica e de Sistemas Mecânicos. São Paulo, 2006.

[8] OLIVEIRA, Alessandro; SALGADO, Lucia Helena. Popularização do transporte aéreo no Brasil: onde falta avançar nas políticas públicas. Regulação e Concorrência no Setor Aéreo no Brasil: Alternativas Possíveis. São Paulo: Singular, p. 297-318, 2014.

[9] PASIN, Jorge Antonio Bozoti; LACERDA, Sander Magalhães. A reestruturação do setor aéreo e as alternativas de política para a aviação comercial no Brasil. 2003.

[10] Relatório de Desempenho Operacional dos Aeroportos - Aeroporto Internacional do Galeão - Rio de Janeiro (SBGL), 2018 - Ministério da Infraestrutura. Disponível em: <http://transportes.gov.br/component/content/article/52-sistema-de-transportes/6636-pesquisa-satisfacao.html>. Acesso em 26 de out. 2019.

[11] VILLELA, Maria Giuliana Occhioni Martins; DÁVALOS, Ricardo Villarroel; CAVACO, Marco Antonio Martins. Modelagem e simulação do embarque de passageiros em terminais aeroportuários. 2019. 


\section{Capítulo 12}

Planejamento de sistemas de distribuição de energia elétrica por meio de uma metaheurística GRASP

\section{Fábio Seiti Hadano}

Gabriela Helena Bauab Shiguemoto

André Luís Shiguemoto

Resumo: Neste trabalho apresenta-se um estudo de planejamento de sistemas de distribuição de energia elétrica baseado na construção de novas rotas e no uso de diversos tipos de condutores. Esta tomada de decisão é feita através da meteheurística Greedy Randomized Adaptive Search Procedures (GRASP). Sua eficácia é avaliada mediante testes comparativos com outras metodologias através de um sistema de 23 barras presente na literatura, e durante estes testes, foram realizadas alterações no valor da variável alpha, a fim de mensurar seu impacto na qualidade das soluções propostas.

Palavras-chave: Sistemas elétricos de potência, Planejamento de sistemas de distribuição, Otimização. 


\section{INTRODUÇÃO}

Ter conhecimento de quanta potência cada subestação irá fornecer ao sistema de distribuição e qual o tipo de condutor será utilizado na construção de uma rota são algumas das decisões que os departamentos de planejamento de distribuidoras deparam-se constantemente durante o processo de elaboração da expansão de seus circuitos.

Com o aumento a cada ano da população mundial e o avanço da tecnologia em geral, as empresas de distribuição de energia têm que constantemente analisar casos e cenários com relação às previsões de demandas à serem atendidas para a população.

Desta forma, as técnicas de otimização têm extrema importância neste planejamento, pois são estas que fornecem o devido suporte para que se possam atender as crescentes demandas da população, mantendo níveis de qualidade, confiabilidade e custos competitivos.

Segundo o boletim trimestral divulgado pela Agência Nacional de Energia Elétrica (ANEEL), em março de 2019, representado pela Tabela 1, o número de unidades consumidoras tem sofrido um aumento constante de aproximadamente $3 \%$ a cada ano, juntamente com a receita de fornecimento de energia elétrica.

Tabela 1 - Receita e consumo - mercado cativo.

\begin{tabular}{|c|c|c|c|c|c|c|}
\hline & \multicolumn{2}{|c|}{$\begin{array}{c}\text { Consumo de energia } \\
\text { elétrica }\end{array}$} & \multicolumn{2}{|c|}{$\begin{array}{c}\text { Receita de fornecimento de energia } \\
\text { elétrica }\end{array}$} & \multicolumn{2}{|c|}{$\begin{array}{l}\text { Número de unidades } \\
\text { consumidoras }\end{array}$} \\
\hline & $\mathrm{MWh}$ & $\%$ Cresc & BRL & $\%$ Cresc & & $\%$ Cresc \\
\hline 2005 & $253.260 .853,86$ & & $61.426 .214 .861,28$ & & 56.836 .625 & \\
\hline 2006 & $252.107 .694,46$ & $-0,5$ & $64.706 .373 .433,80$ & 5,3 & 58.261 .836 & 2,5 \\
\hline 2007 & $263.215 .700,26$ & 4,4 & $68.122 .958 .570,12$ & 5,3 & 60.534 .375 & 3,9 \\
\hline 2008 & $278.592 .020,41$ & 5,8 & 68.838.701.970,26 & 1,1 & 63.088 .315 & 4,2 \\
\hline 2009 & $286.871 .823,71$ & 3,0 & $74.456 .147 .481,54$ & 8,2 & 65.450 .236 & 3,7 \\
\hline 2010 & $302.390 .369,72$ & 5,4 & $80.005 .116 .616,98$ & 7,5 & 67.627 .240 & 3,3 \\
\hline 2011 & $310.398 .063,14$ & 2,6 & $86.435 .093 .265,57$ & 8,0 & 70.130 .344 & 3,7 \\
\hline 2012 & $319.871 .062,06$ & 3,1 & $93.675 .397 .987,68$ & 8,4 & 72.245 .611 & 3,0 \\
\hline 2013 & $329.429 .678,77$ & 3,0 & 83.711.095.870,92 & $-10,6$ & 74.669 .108 & 3,4 \\
\hline 2014 & $345.223 .238,50$ & 4,8 & $95.368 .593 .165,50$ & 13,9 & 76.883 .226 & 3,0 \\
\hline 2015 & $342.346 .955,34$ & $-0,8$ & $133.555 .897 .959,26$ & 40,0 & 78.941 .194 & 2,7 \\
\hline 2016 & $330.109 .404,16$ & $-1,0$ & $138.660 .435 .548,96$ & 41,2 & 80.648 .668 & 2,5 \\
\hline 2017 & $313.257 .518,51$ & $-3,5$ & $131.917 .580 .892,75$ & 2,7 & 81.752 .588 & 2,2 \\
\hline 2018 & $312.597 .708,28$ & $-0,2$ & $147.906 .210 .284,60$ & 12,1 & 83.576 .144 & 2,2 \\
\hline 2019* & $82.899 .542,85$ & 6,1 & $40.617 .107 .007,50$ & 9,8 & 83.933 .980 & 1,7 \\
\hline
\end{tabular}

Fonte: Adaptado de Superintendência de Gestão Tarifária - SGT (ANEEL, 2019).

Devido a este crescimento constante, e levando em consideração que a cada ano, a preocupação com relação à alocação ótima de recursos financeiros aumenta, foi idealizado esse trabalho, visando criar um algoritmo robusto e com um alto grau de confiabilidade que disponibilize, de forma rápida, soluções próximas à otimalidade para o planejamento de sistemas de distribuição primária de energia elétrica.

Na literatura, há diversas propostas para solucionar este problema, dentre elas, métodos clássicos de otimização, como o branch-and-bound, presente em Paiva et al. (2005) e Oliveira (2010). Esta é uma técnica robusta e capaz de fornecer o resultado ótimo, porém, o desempenho computacional fica prejudicado, dependendo da complexidade do planejamento e da magnitude do sistema em questão.

Dentre as técnicas heurísticas, pode-se citar a aplicada em Ponnavaikko et al. (1987), na qual foi elaborado um algoritmo heurístico construtivo (AHC) que, através de uma função quadrática, aproxima as perdas de potência ativa do sistema, e em Oliveira (2010), onde um AHC com uma fase de melhoria local foi utilizado.

Atualmente, estão sendo realizados diversos estudos que adotam metaheurísticas para lidar com este tema, tais como o algoritmo genético presente em Miranda et al. (1994), a colônia de formigas utilizada por Gomez et al. (2004), o simulated annealing exibido em Nahman e Peric (2008) e a busca tabu mostrada em Koutsoukis et al. (2014). 
Para este trabalho, é utilizado a metaheurística GRASP (Greedy Randomized Adaptive Search Procedures) Resende (2003), muito utilizada para problemas de otimização combinatória. Este algoritmo é desenvolvido utilizando a ferramenta computacional MATrix LABoratory (MatLab ${ }^{\circledR}$ ) e, para testar sua eficácia, é utilizado um sistema presente na literatura para fins comparativos.

\section{FUNDAMENTAÇÃO TEÓRICA}

\subsection{SISTEMAS ELÉTRICOS DE POTÊNCIA}

Um sistema elétrico de potência (SEP) pode ser compreendido como um conjunto de instalações e equipamentos que tem como objetivo gerar, transmitir e fornecer energia elétrica dentro de um mercado competitivo de compra e venda de energia. Sua operação visa suprir o mercado consumidor com continuidade, qualidade e economia.

A geração é o setor responsável por converter alguma forma de energia como, por exemplo, a térmica ou eólica, em elétrica. No caso do Brasil, a maior parte da energia elétrica gerada provém das usinas hidrelétricas. Atualmente, este percentual está em torno de 65\%, segundo a Empresa de Pesquisa Energética (2018). Ademais, as usinas hidrelétricas fornecem eletricidade com tensões usuais na faixa de 13,8 até $24 \mathrm{kV}$, podendo surgir algumas variações devido a não existência de um padrão para as tensões destes, como na faixa de 18 à $24 \mathrm{kV}$ de acordo com Stevenson (1986). Uma melhor representação da oferta interna de energia elétrica está representada a seguir pela Figura 1.

Figura 1 - Oferta interna de energia elétrica por fonte

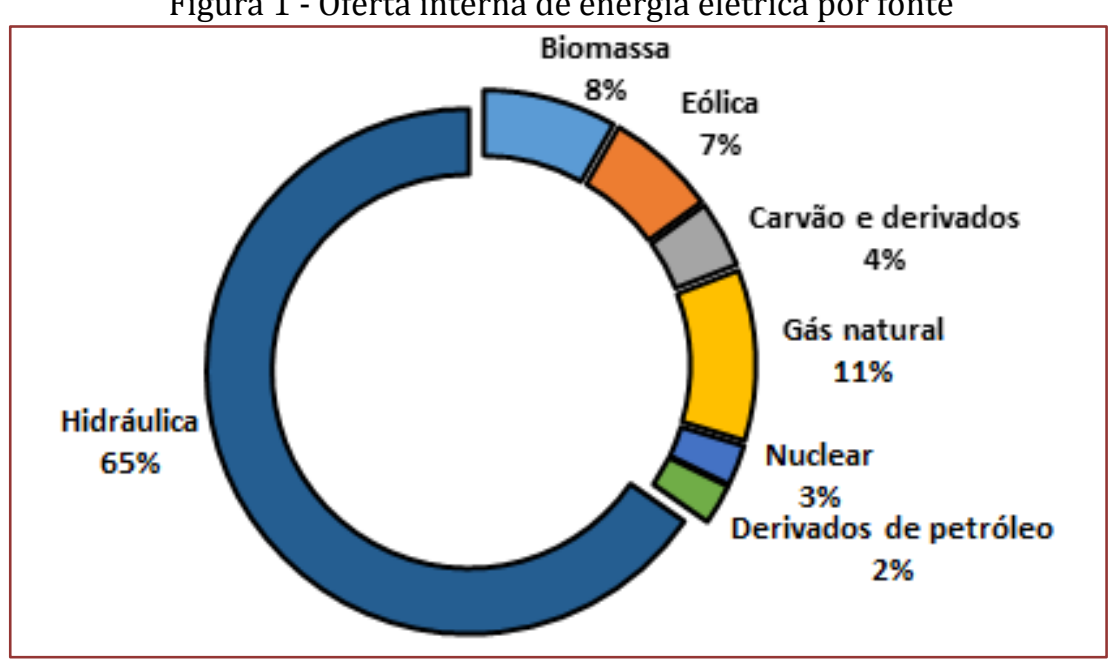

Fonte: Adaptado de Balanço Energético Nacional - BEN (2018, p. 16).

Esta energia gerada é transportada dos grandes centros de geração para os consumidores através de grandes linhas de transmissão, de até $750 \mathrm{kV}$. Para isto, utilizam-se transformadores que elevam estas tensões provenientes dos geradores das usinas. Este aumento é necessário para evitar perdas muito significativas durante este processo de transporte.

Por fim, ocorre o fornecimento aos consumidores, através de redes de distribuição. De acordo com ANEEL (2016), no documento intitulado "Procedimentos de Distribuição de Energia Elétrica no Sistema Elétrico Nacional" (PRODIST), módulo 2, estas podem ser classificadas como sendo de alta tensão de distribuição (AT), onde o valor eficaz da tensão entre as fases varia entre $69 \mathrm{kV}$ até $230 \mathrm{kV}$; média tensão de distribuição (MT), com valor eficaz da tensão entre as fases entre $1 \mathrm{kV}$ até $44 \mathrm{kV}$; baixa tensão de distribuição (BT): valor eficaz da tensão entre as fases inferior ou igual à $1 \mathrm{kV}$. 


\subsection{PLANEJAMENTO DE SISTEMAS DE DISTRIBUIÇÃO (PSD)}

Durante a elaboração de um plano de expansão de um determinado sistema de distribuição, são levados em consideração diversos fatores, que variam de acordo com os interesses de cada distribuidora. Segundo Sousa (2013) alguns aspectos a serem considerados são, por exemplo, de caráter técnico, em que um conjunto de medidas de planejamento visa melhorar a qualidade do serviço fornecido e a confiabilidade do sistema; econômico, com ações para reduzir os custos de investimento, operação e manutenção das redes; social, com escolhas efetuadas para reduzir, por exemplo, danos ambientais, que acarretariam uma melhor imagem da empresa para a sociedade.

A criação deste plano pode ser feita a partir de duas abordagens, uma estática e outra, dinâmica.

0 planejamento dinâmico busca atender diferentes níveis de demandas para um determinado período de tempo. Caso seja um planejamento com um horizonte longo, este período varia normalmente de 5 a 20 anos. Por outro lado, caso vise um período de curto prazo, o lapso de tempo varia de 1 a 4 anos.

Já a visão estática, os períodos de tempo não são levados em consideração, pois apenas a demanda de um determinado momento é considerada.

Com relação à parte econômica do planejamento, pode-se, ainda, subdividir este tópico dependendo dos objetivos da empresa que o realiza e quais pontos esta leva em consideração durante a fase de elaboração da expansão de um circuito.

Ainda de acordo com Sousa (2013), muitas distribuidoras dão ênfase em buscar o maior lucro possível, ou então à minimização dos custos de investimento e de manutenção do SEP em questão.

Outro fator que afeta diretamente a execução do planejamento diz respeito às variáveis que serão levadas em conta. As variáveis terão impacto direto na função objetivo estabelecida, modificando-se de acordo com o horizonte que o plano procurar atender e, normalmente, são dados financeiros, como o custo de instalação de novos equipamentos, a taxa de uso de equipamentos e as perdas no circuito.

\subsection{MODELO MATEMÁTICO}

Segundo Figueiredo et al. (2011), este é um problema de otimização combinatório que possui restrições tanto físicas como orçamentárias. Não há, ao certo, um modelo matemático universal para este problema, porém, de forma geral, pode-se estabelecer o modelo matemático como um planejamento que busca encontrar as melhores possibilidades viáveis com custos operacionais e de expansão reduzidos, que atendam ao aumento de demanda, mantendo um determinado nível de qualidade e confiabilidade.

Para este trabalho, será utilizado como base o modelo matemático presente em Oliveira (2010), onde a função objetivo é dada pela equação (1):

$$
\left.\min f=k_{l} \sum_{(i, j) \in \Omega_{l}} \sum_{a \in \Omega_{a}}\left(c_{i j, a} n_{i j, a} l_{i j}\right)+\delta_{l} \sum_{(i, j) \in \Omega_{l}} \sum_{a \in \Omega_{a}} g_{i j, a} \hat{n}_{i j, a}\left(V_{i}^{2}+V_{j}^{2}-2 V_{i} V_{j} \cos \theta_{i j}\right)\right)
$$

Esta equação representa todos os custos de investimento e operação do sistema baseado em BernalAgustín (1998), na qual o primeiro termo se refere aos custos de investimento para a construção de circuitos, onde $n_{i j, a}$ é uma variável binária de tomada de decisão, $c_{i j, a}$ representa o custo de uma rota que liga os pontos $i$ à $j$ fazendo uso de um condutor de tipo $a$, e $k_{l}$ como sendo a taxa de recuperação. 0 segundo termo representa os custos anuais referentes às perdas do circuito, onde $\delta_{l}$ se refere ao fator de perdas do sistema, $g_{i j, a}$ é a condutância da rota que liga os pontos $i$ à $j$ utilizando um condutor do tipo $a$, $\hat{n}_{i j, a}$ como sendo o número total de ramos que ligam os pontos $i$ à $j$ utilizando um condutor do tipo $a$ e $V_{i}$ e $V_{j}$ como sendo, respectivamente, as magnitudes de tensão presentes nos nós $i$ e $j$.

Já as equações (2) e (3) limitam os balanços de potência ativa e reativa no sistema, onde os elementos $P_{i}$ e $Q_{i}$ destas equações estão representados por (11) e (12): 


$$
\begin{aligned}
& P_{i}-P_{S_{i}}+P_{D_{i}}=0 \forall i \in \Omega_{b} \\
& Q_{i}-P_{S_{i}}+P_{D_{i}}=0 \forall i \in \Omega_{b}
\end{aligned}
$$

A equação (4) restringe a magnitude da tensão nos nós do SEP para que não haja a extrapolação dos limites pré-estabelecidos, enquanto a equação (5) trata da capacidade máxima de geração da subestação $i$ :

$$
\begin{gathered}
1-\frac{\Delta V}{100} \leq \frac{V_{i}}{V_{\text {nom }}} \leq 1+\frac{\Delta V}{100} \forall i \in \Omega_{b} \\
P_{S_{i}}^{2}+Q_{S_{i}}^{2} \leq\left(\bar{S}_{i}^{0}+m_{i} \bar{S}_{i}\right)^{2} \forall i \in \Omega_{b_{s}}
\end{gathered}
$$

Para que a potência ativa e reativa que circula pela rota $i j$ utilizando o tipo de condutor $a$ não ultrapasse os limites deste condutor, é modelada a equação (6), e para garantir que não haja a possibilidade de duplicidade entre os circuitos existentes é elaborada a equação (7):

$$
\begin{gathered}
P_{i j, a}^{2}+Q_{i j, a}^{2} \leq\left(\hat{n}_{i j, a} \bar{S}_{i j, a}\right)^{2} \forall(i j) \in \Omega_{f}, \forall a \in \Omega_{a} \\
\sum_{a \in \Omega_{a}} \hat{n}_{i j, a} \leq 1 \forall(i j) \in \Omega_{l}
\end{gathered}
$$

Neste modelo, a tomada de decisão da construção de uma nova rota para o sistema está representada pela equação (8), na qual estas tem natureza binária:

$$
n_{i j, a} \in[0,1] \forall(i j) \in \Omega_{l}, \forall a \in \Omega_{a}
$$

Visando garantir a radialidade do sistema, elabora-se a equação (9), onde com o auxílio das equações de balanço de carga (2) e (3), garantem que o resultado final será um sistema totalmente conectado e com topologia radial:

$$
\begin{gathered}
\sum_{(i j) \in \Omega_{l}} \sum_{a \in \Omega_{a}} \hat{n}_{i j, a}=n_{b}-n_{b_{s}} \\
\hat{n}_{i j, a}=n_{i j, a}^{0}+n_{i j, a} \forall(i j) \in \Omega_{l}, \forall a \in \Omega_{a} \\
P_{i}=V_{i} \sum_{j \in \Omega_{b}} V_{j}\left[G_{i j}\left(\hat{n}_{i j, a}\right) \cos \theta_{i j}+B_{i j}\left(\hat{n}_{i j, a}\right) \operatorname{sen} \theta_{i j}\right] \\
Q_{i}=V_{i} \sum_{j \in \Omega_{b}} V_{j}\left[G_{i j}\left(\hat{n}_{i j, a}\right) \operatorname{sen} \theta_{i j}-B_{i j}\left(\hat{n}_{i j, a}\right) \cos \theta_{i j}\right]
\end{gathered}
$$

\section{GRASP APLICADO AO PLANEJAMENTO DE SISTEMAS DE DISTRIBUIÇÃO}

Neste trabalho, desenvolveu-se um algoritmo GRASP com objetivo de realizar o planejamento de sistemas de distribuição de energia elétrica, propondo uma configuração através da criação de novas rotas para atender a demanda de energia ou, alternativamente, substituir uma linha já existente. 


\section{1. ÍNDICE DE SENSIBILIDADE}

0 índice de sensibilidade é um fator fundamental para o algoritmo que é responsável por indicar o quão essencial será a inclusão de um determinado elemento à solução final, escolhendo os melhores candidatos para compor a Lista de Candidatos Reduzida (LCR), Festa e Resende (2002).

Neste problema, algumas variáveis possuem elevado potencial para o índice de sensibilidade, como por exemplo, a demanda atendida por um determinado ramo, a influência que um componente irá causar no fluxo de potência do sistema ou, então, o custo/benefício obtido com a inclusão de um dado elemento. Circunscrevendo-nos a este trabalho, no qual o foco é a configuração de sistemas levando em conta as rotas que compõem a sua topologia, e não um planejamento integrado que contém a alocação de bancos de capacitores ou de reguladores de tensão determinou-se como índice de sensibilidade o comprimento das rotas.

Esta decisão foi tomada levando-se em consideração que seria muito mais interessante, do ponto de vista econômico, construir $n$ rotas que irão atender uma ramificação com múltiplas demandas do que se construir apenas uma rota que irá satisfazer um único ponto de demanda, pois ainda seria necessário a construção de outras rotas para atender o restante das demandas.

Visando calcular estes índices, estabeleceu-se a Equação (13):

$$
\text { Indice }_{i j}=\max (D)-D_{i j}
$$

em que $\max (D)$ é a maior distância entre todos os candidatos presentes na lista de candidatos (LC), e $D_{i j}$ é a distância do ramo que liga o nó $i$ ao $j$ em estudo. Ou seja, quanto menor for o valor de Indice $_{i j}$ menor é sua contribuição para o problema, uma vez em que se trata de um problema de minimização.

\subsection{FASE CONSTRUTIVA}

Após o cálculo dos índices de sensibilidade dos candidatos presentes na Lista de Candidatos - LC, é estabelecido um valor como referência para realizar a escolha dos candidatos para a LCR, sendo esta seleção realizada através da Equação (14):

$$
R e f=\max (\text { Indices })-\alpha \cdot \max (\text { Indices })-\min (\text { Indices })
$$

em que $\alpha$ varia entre [0,1].

Com Ref determinado, é criada então, a LCR, onde apenas os elementos que possuírem seus índices maiores que (14) irão compor esta nova lista. Esta seleção revela-se fundamental, pois exclui os candidatos que iriam gerar soluções de baixa qualidade.

Logo em seguida, de forma aleatória, é adicionado a cada iteração, um elemento pertencente à LCR na solução corrente, até que a condição de radialidade do sistema seja satisfeita. Esta condição diz respeito ao número de ramos de uma topologia radial, que é determinada pelo número de barras total do sistema menos um $(n-1)$.

Porém, não é qualquer candidato da LCR que pode ser adicionado à estrutura em construção, pois, ao longo das iterações da fase construtiva do algoritmo, alguns elementos, caso inseridos, podem criar ciclos na topologia, o que certamente acarretará a perda da identidade radial do problema.

Para contornar esta possibilidade de criar malhas na rede, foi aplicado um algoritmo de busca em profundidade (Depth-first search), onde a cada iteração da fase construtiva, os ramos da topologia eram testados para verificar se a condição de radialidade era mantida.

Após o término da fase construtiva, era realizado o cálculo do fluxo de potência do sistema através do método backward-forward sweep load flow, como visto em Teng (2014). 


\subsection{FASE DE MELHORIA}

Nesta etapa de melhoria do algoritmo, é realizada uma sistemática de busca local com vistas a refinar os resultados obtidos com a estrutura da fase anterior. Simula-se a troca de um ramo selecionado durante a fase construtiva do GRASP por um elemento remanescente da LCR, levando-se em consideração que nem todos os membros dela foram utilizados.

Estas trocas simples são realizadas até que ocorra uma melhora no resultado final. Quando se observa uma melhoria no valor, independente da magnitude, esta fase é finalizada, configurando um critério de parada de first-improving. Outra possibilidade seria realizar uma busca local completa, com o intuito de encontrar a melhor modificação possível, o que caracteriza um critério de parada de best-improving, Lourenço et al. (2002).

\section{TESTES E RESULTADOS}

O algoritmo GRASP proposto para resolver o PSD foi escrito na linguagem M, e as soluções para os problemas foram obtidos através do software MATLAB ${ }^{\circledR}$ (MATrix LABoratory) versão R2014a. Para todos os testes a seguir, foi utilizado um processador i7-4770 com uma velocidade de processamento de 3,40GHz, 8 GB de memória RAM e Windows ${ }^{\circledR} 10$ 64-bits como sistema operacional.

O sistema presente em Nahman e Peric (2008) constitui-se de uma rede de distribuição de $34,5 \mathrm{kV}$, alimentada por uma subestação de $10 \mathrm{MVA}$, composto por um total de 23 barras, sendo 21 delas de carga. Na Figura 2, segue um esquemático de todas as possíveis rotas que podem ser construídas neste problema. Neste experimento, considera-se apenas a construção de rotas, com um custo de perdas de energia equivalente a 0,005 US $\$ / \mathrm{kWh}$, fator de perdas igual à 0,35 , taxa de interesse de 0,1 , fator de potência médio de 0,9 e um horizonte de planejamento de 20 anos.

Figura 2: Possíveis rotas a serem criadas para o sistema de 23 barras.

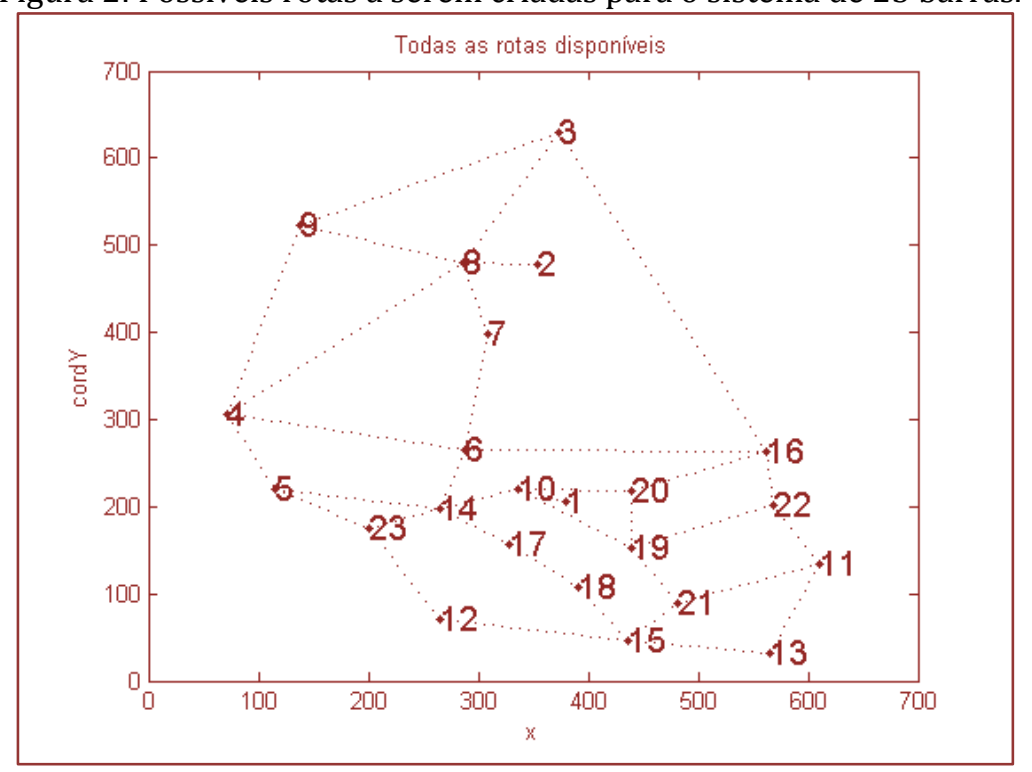

Fonte: 0 autor (2020).

Durante a primeira etapa do algoritmo, realiza-se o cálculo de todos os índices de sensibilidade dos ramos candidatos, utilizando a Equação (13), para gerar a LC.

Em seguida, são realizadas 3 execuções da rotina do algoritmo, cada uma com 10 rodadas de 50 iterações cada, alterando o valor de $\alpha$ para 1, 0,75 e 0,5 a fim de gerar uma LCR com diferentes dimensões, totalizando 500 iterações para cada valor de $\alpha$, onde foi adotado o método de first-improving como critério de parada na fase de melhoria.

Os resultados obtidos estão representados pela Tabela 2, onde se observa uma melhora considerável na qualidade das soluções obtidas ao passo em que se reduz o valor de $\alpha$. Neste algoritmo, esta variável tem extrema importância, uma vez que este determina a probabilidade de um candidato ser incluído na 
configuração final do problema. Quando se reduz o valor de $\alpha$, os critérios para um candidato compor a LCR ficam mais rigorosos, reduzindo desta forma a influência do caráter aleatório do algoritmo ao mesmo passo que as tornam menos variadas.

Tabela 2: Resultados obtidos para diferentes valores de $\alpha$.

\begin{tabular}{|c|c|c|c|c|c|}
\hline$\alpha$ & Rodada & Melhor saída (US\$) & Pior saída (US\$) & Média (US\$) & Tempo (s) \\
\hline \multirow{10}{*}{1} & 1 & $202.686,15$ & $393.390,91$ & $269.908,52$ & 26,08 \\
\hline & 2 & $190.480,36$ & $357.336,99$ & $267.531,09$ & 32,28 \\
\hline & 3 & $223.559,31$ & $409.725,40$ & $268.611,06$ & 30,25 \\
\hline & 4 & $209.437,39$ & $407.460,51$ & $270.576,74$ & 30,22 \\
\hline & 5 & $199.857,41$ & $440.923,07$ & $272.154,60$ & 33,95 \\
\hline & 6 & $195.793,64$ & $395.050,58$ & $265.733,69$ & 34,41 \\
\hline & 7 & $212.218,47$ & $351.431,78$ & $268.724,06$ & 37,38 \\
\hline & 8 & $209.260,83$ & $378.473,28$ & $263.629,70$ & 31,54 \\
\hline & 9 & $207.683,23$ & $423.616,98$ & $275.183,42$ & 32,16 \\
\hline & 10 & $220.540,59$ & $492.566,85$ & $287.598,83$ & 29,52 \\
\hline \multirow{10}{*}{0,75} & 1 & $190.825,03$ & $307.332,63$ & $238.704,39$ & 29,45 \\
\hline & 2 & $183.991,15$ & $307.092,19$ & $232.580,00$ & 26,12 \\
\hline & 3 & $185.217,43$ & $315.768,75$ & $236.278,17$ & 22,54 \\
\hline & 4 & $192.723,44$ & $311.181,29$ & $235.285,04$ & 22,76 \\
\hline & 5 & $201.058,04$ & $292.641,76$ & $238.570,09$ & 23,87 \\
\hline & 6 & $188.925,34$ & $325.210,34$ & $241.270,73$ & 23,64 \\
\hline & 7 & $192.712,18$ & $297.548,75$ & $232.933,10$ & 25,18 \\
\hline & 8 & $189.844,73$ & $326.406,94$ & $236.474,13$ & 27,84 \\
\hline & 9 & $194.580,41$ & $308.265,03$ & $243.502,12$ & 26,52 \\
\hline & 10 & $192.211,64$ & $310.398,63$ & $230.652,82$ & 23,85 \\
\hline \multirow{10}{*}{0,5} & 1 & $184.372,82$ & $285.184,80$ & $216.988,09$ & 22,44 \\
\hline & 2 & $184.881,89$ & $263.126,80$ & $213.682,24$ & 26,62 \\
\hline & 3 & $183.684,14$ & $257.080,38$ & $208.282,95$ & 26,60 \\
\hline & 4 & $176.431,27$ & $278.270,16$ & $217.704,75$ & 24,69 \\
\hline & 5 & $178.331,88$ & $297.545,95$ & $217.861,92$ & 25,15 \\
\hline & 6 & $175.962,22$ & $290.489,66$ & $218.536,94$ & 21,18 \\
\hline & 7 & $184.814,14$ & $262.256,89$ & $215.623,34$ & 19,26 \\
\hline & 8 & $181.854,68$ & $291.454,55$ & $211.627,69$ & 20,28 \\
\hline & 9 & $180.220,32$ & $292.900,50$ & $216.789,65$ & 22,33 \\
\hline & 10 & $183.064,83$ & $271.915,07$ & $219.774,77$ & 20,12 \\
\hline
\end{tabular}

Por fim, na Tabela 3, há um comparativo entre esta metodologia em relação à otimalidade presente na literatura e outras metaheurísticas. Em uma breve análise, o melhor custo de investimento total encontrado pelo GRASP desenvolvido neste trabalho foi de US\$175.962, utilizando o first-improving e $\alpha$ equivalente 0,5 , em um tempo computacional total de 228,67 segundos. Verifica-se que este resultado é $2,23 \%$ mais elevado que a otimalidade encontrada pelo algoritmo branch-and-bound proposto em Oliveira (2010), porém em um tempo computacional total 86,59\% menor.

Tabela 3: Comparativo entre os resultados dos métodos.

\begin{tabular}{|l|c|c|}
\hline \multicolumn{1}{|c|}{ Metodologia } & Custo total (US\$) & Tempo (s) \\
\hline Branch-and-bound (Oliveira, 2010) & 172.119 & $1.705,84$ \\
\hline AHC final (Oliveira, 2010) & 172.119 & 28,98 \\
\hline Colônia de formigas (Gomez et al., 2004) & 172.913 & - \\
\hline Simulated Annealing (Nahman e Peric, 2008) & 172.899 & 4.578 \\
\hline SA-MILP (Popovic et al., 2014) & 173.142 & 12,4 \\
\hline Busca Tabu (Koutsoukis et al., 2014) & 172.445 & 7,23 \\
\hline GRASP proposto & 175.962 & 21,18 \\
\hline
\end{tabular}




\section{CONSIDERAÇÕES FINAIS}

Este trabalho apresenta um algoritmo GRASP para elaborar a construção de rotas para sistemas de distribuição de energia elétrica e apontar quais fatores desta metaheurística possui influência direta nos resultados finais.

O GRASP, por ser uma metaheurística, não garante a otimalidade, principalmente com um número pequeno de iterações, pois como a iteração $n$ deste método não depende da $n-1$ ou muito menos da primeira iteração, a sequência de resultados apresentados pelo algoritmo é um tanto quanto "aleatória" quando comparado com outros métodos como o Algoritmo Genético ou a metaheurística de Colônia de Formigas onde há um refinamento dos resultados, e que a cada iteração constata-se uma melhoria na função objetivo do problema. Ela apresenta algumas vantagens quando comparada com outros métodos presentes na literatura como o branch-and-bound, proposto por Oliveira (2010), que apresentou um tempo computacional total de $1.705,84 \mathrm{~s}$ e a capacidade de operar de forma paralela, por exemplo.

Logo, para refinar os resultados obtidos e aumentar as chances de se ter uma solução de qualidade é fundamental aplicar um método de busca local de qualidade. Outra forma de refinar os resultados é tornando este método cada vez mais guloso, através da redução de $\alpha$, onde se identificou que a função objetivo do problema sofreu um aumento considerável quando $\alpha$ assumiu o valor 1 , mesmo mantendo os tempos computacionais muito próximos em relação aos demais testes.

\section{REFERÊNCIAS}

[1] AGÊNCIA NACIONAL DE ENERGIA ELÉTRICA - ANEEL. Informações gerenciais: Receita e consumo mercado cativo. 2015. 71 f. Disponível em: < http://www.aneel.gov.br/informacoes-gerenciais>. Acesso 20 de maio 2016.

[2] AGÊNCIA NACIONAL DE ENERGIA ELÉTRICA - ANEEL. Procedimentos de Distribuição de Energia Elétrica no Sistema Elétrico Nacional - PRODIST: Módulo 2 - Planejamento da Expansão do Sistema de Distribuição. Brasília: ANEEL, 2016.

[3] BERNAL-AGUSTÍN, J. L. Aplicación de algoritmos genéticos al diseño optimo de sistemas de distrubuición de energía eléctrica. Tese (doutorado em engenharia elétrica) - Departamento de Engenharia Elétrica, Universidad de Zaragoza, Espanha, janeiro 1998.

[4] EMPRESA DE PESQUISA ENERGÉTICA. Balanço Energético Nacional 2018: Ano base 2017. Rio de Janeiro: EPE, 2015.

[5] FESTA, P; RESENDE, M. G. C. GRASP: An annotated bibliography. Essays and surveys on metaheuristics, 325367, Kluwer Academic Publishers, 2002.

[6] FIGUEIREDO, R. M. V.; SILVA, P. H. G.; POSS, M. Uma mete-heurística GRASP para o problema de planejamento de expansão de redes de transmissão com redimensionamento. XLIII Simpósio Brasileiro de Pesquisa Operacional, agosto de 2011.

[7] GÓMEZ, J. F.; KHODR, H. M.; OLIVEIRA, P. M.; OCQUE, L.; YUSTA, J. M.; VILLASANA, R.; URDANETA, A. J. Ant colony system algorithm for the planning of primary distribution circuits. IEEE Transactions on Power Systems, 19(2):996-1004, maio 2004.

[8] KOUTSOUKIS, N. C.; GEORGILAKIS, P. S.; HATZIARGYRIOU, N. D. A Tabu Search Method for Distribution Network Planning Considering Distributed Generation and Uncertainties. IEEE Transactions on Power Systems, 2014.

[9] LOURENÇO, H.R.; MARTIN, O.C.; STUTZLE, T. Iterated Local Search. Handbook of Metaheuristics, 321-353. Kluwer, Boston, 2002.

[10] MIRANDA, V.; RANITO, J. V.; PROENÇA, L. M. Genetic algorithm in optimal multistage distribution network planning. IEEE Transactions on Power Systems, 9(4):1927-1933, novembro 1994.

[11] NAHMAN, J.M.; PERIC, D.M. Optimal planning of radial distribution networks by simulated annealing technique. IEEE Transactions on Power Systems, 23(2):790-795, maio 2008.

[12] OLIVEIRA, Marina L. de. Planejamento integrado da expansão de sistemas de distribuição de energia elétrica. 2010. 199 f. Tese (doutorado em engenharia elétrica) - Faculdade de Engenharia Elétrica e de Computação, Universidade Estadual de Campinas, Campinas, março 2010.

[13] PAIVA, P. C.; KHODR, H. M.; DOMÍNGUES-NAVARRO, J. A. D.; YUSTA, J. M.; URDANETA, A. J. Integral planning of primary-secondary distribution systems using mixed interger linear programming. IEEE Transactions on Power Systems, 20(2):1134-1143, maio 2005. 
[14] PONNAVAIKKO, M.; RAO, K.; VENKATA, S. Distribution system planning through a quadratic mixed integer programming approach. IEEE Trans. Power Deliv, 2(4), págs. 1157-1163, outubro de 1987.

[15] RUPA, J. A. M.; GANESH, S. Power Flow Analysis for Radial Distribution System Using Backward/Forward Sweep Method. International Journal of Electrical, Computer, Energetic, Electronic and Communication Engineering Vol:8, No:10, 2014, 1621-1625, World Academy of Science, Engineering and Technology.

[16] RESENDE, M.G.C.; RIBEIRO, C.C. Greedy randomized adaptive search procedures. Handbook of Metaheuristics, 219-249, Kluwer Academic Publishers, 2003.

[17] SOUSA, João de. Planejamento de sistemas de distribuição de energia elétrica através de um modelo de programação linear inteiro misto (plim). 2013. 114 f. Tese (doutorado em engenharia elétrica) - Faculdade de Engenharia de Ilha Solteira, Universidade Estadual Paulista, Ilha Solteira, 2013.

[18] STEVENSON JR., William D. Elementos de análise de sistemas de potência. 2. Ed. São Paulo: McGraw- Hill do Brasil, 1986.

[19] TENG, F. Implementation of a Voltage Sweep Power Flow Method and Comparison with Other Power Flow Techniques. Semester Thesis, Swiss Federal Institute of Technology Zurich, 2014. 


\section{Capítulo 13}

\section{Proposta de aplicação da Metodologia MASP para redução das perdas em estoque}

\section{Bruno Silva de Aguiar \\ Jonathan Gonçalves Figueiredo \\ Sophia Travesedo Cardoso}

Resumo: Atualmente, as organizações buscam mais agilidade em seus processos afim de atender o maior número de consumidores sem gerar desperdícios. Buscando promover um diferencial competitivo, o estudo propôs um projeto voltado para os softwares de gestão. Com o avanço da tecnologia, o gerenciamento de informações por meio da tecnologia traz um novo conceito de tomada de decisão. A capacidade de agir em diferentes contextos e segmentos, melhorar a comunicação, padronizar, controlar e monitorar a atividade em tempo real promover a integração entre os stakeholders, trazer rentabilidade para empresa e garantir a conformidade dos processos, proporciona o alinhamento dos conhecimentos técnicos com os gerenciais formando um ciclo de autoanalise. 0 presente trabalho adota a Metodologia MASP (análise e solução de problemas), descrevendo suas etapas, utilizando ferramentas de qualidade e de TI (tecnologia da informação) para desenvolver uma proposta que não só atenda aos padrões iso, mas também esteja inserida no contexto mercadológico e situacional da microbiologia industrial.

Palavras-chave: Softwares de Gestão; Qualidade; MASP (Análise e Solução de Problemas); TI (Tecnologia da Informação). 


\section{INTRODUÇÃO}

A Microbiologia industrial vem demonstrando seu potencial na obtenção de produtos ou na criação de processos de interesse comercial, ambiental e social. Esse setor apresenta um diferencial no quesito prevenção e controle permitindo a qualquer empresa resguardar a qualidade e segurança de seus produtos e evitar o impacto direto ao cliente (SBM, 2016). Essa constante exigência por redução de preços e melhoria na qualidade de produtos e serviços lançam as organizações a uma interminável luta por análise e melhoria em termos de eficiência e eficácia de seu modo de produção (SANTOS e BARROS,2007).

A utilização de ferramentas de qualidade integradas aos avanços tecnológicos do mercado caracteriza um destaque na competitividade. As normas ISO surgem então como um diferencial para quem as implementa pois apresentam melhorias significativas na produtividade, custos e mesmo no clima organizacional com responsabilidades e tarefas mais bem definidas e controladas. (FERREIRA, 2001). Com o foco das organizações no aperfeiçoamento de seus processos visando como resultados o aumento de flexibilidade, a redução de custos e lead time, consequentemente, obtém-se a melhoria da percepção sobre a qualidade e a confiabilidade no nível de serviço prestado a seus clientes e usuários (PERGHER et al. 2014).

Os problemas identificados dentro de empresas, geralmente, são oriundos da falta de transformação do conhecimento tácito em explicito. Procurando atender assim os preceitos da Qualidade Total, vinculando as informações prescritas nas normas reguladoras NBR/ISO, este estudo baseia-se na aplicação do MASP (Método de Análise e Solução de Problemas) que possui uma abordagem sistemática ao se referendar na produção enxuta (SOARES, 2014). Sendo o MASP uma das metodologias mais conhecidas no contexto industrial e que contribui com a melhoria dos fatores competitivos devido à busca permanente da eliminação das perdas. (FEITOSA et al. 2013).

Portanto, o objetivo deste trabalho está em apresentar, por meio de um estudo de caso, o desdobramento de uma proposta de melhoria ofertada a uma empresa de serviços industriais na área de Microbiologia de forma a garantir a produtividade e rentabilidade ao negócio. Utilizando o conjunto de normativas ISO para referendar a implantação da proposta no setor de estoque da organização.

\section{REFERENCIAL TEÓRICO}

De acordo com Bassi e Diniz (2017) as mudanças do mercado estão sendo rapidamente absorvidas. A visão holística de um sistema produtivo que integre áreas e processos a fim de obter o melhor desempenho está se tornando uma prerrogativa no mundo contemporâneo. Por isso a função produção é vital para a organização porque produz os bens e serviços que são a razão de sua existência, sendo responsável por satisfazer às solicitações dos consumidores. (SLACK; CHAMBERS; JOHNSTON, 2009)

Segundo Corrêa, Gianesi e Caon (2013) a gestão das operações proporciona um gerenciamento estratégico de recursos escassos visando atender os anseios de qualidade, tempo e custo dos clientes. De acordo Dantas (2015) os estoques representam um dos ativos mais importantes do capital circulante da maioria das empresas comerciais e industriais. Setor representado muitas vezes como válvula de controle para gestão de recursos ociosos (materiais, mercadorias ou produtos), detentores de valor econômico, esta área destina-se ao suprimento das necessidades da organização. (BALDAM et al. 2010)

Para Tubino (2000) quando as empresas priorizam o estoque é garantido a independência entras as etapas produtivas, permitindo a redução de lead times produtivos e a produção constante de lotes econômicos. No que tange ao controle de estoque a análise da função minimizadora dos custos totais investidos é importante, pois se permite avaliar os desperdícios e os desvios que possam prejudicar o capital de giro da corporação, pois se apresenta como um setor com grande influência na rentabilidade da empresa (BALLOU, 2007). 


\subsection{GESTÃO DE PROCESSOS}

A busca por melhoria contínua, tende a ser mais eficaz quando se consegue interligar todo o ambiente corporativo. Conforme Robles (2016) a inter-relação dos componentes logísticos com a gestão integrada propiciou maior flexibilidade e adaptação dos processos, além de mais agilidade na tomada de decisão e uma comunicação mais ativa. Pires (2007, p.128) afirma que tecnologias baseadas na Web estão se tornando fundamentais para execução de processos básicos de uma cadeia de suprimentos como a previsão da demanda (forecasting), o planejamento, a programação da produção (scheduling) e a execução de processos logísticos.

Segundo a NBR ISO 9000: 2015 o conceito de processo define-se como "o conjunto de atividades interrelacionadas ou interativas que transforma insumos (entradas) em produtos (saídas) no qual, geralmente, as saídas de um processo são as entradas de outro". Sabe-se que o processo de melhoria traz consigo importantes vertentes, hoje totalmente enraizadas, que são: a análise de valor, a eliminação de perdas, a padronização, a racionalização da força de trabalho, entre outros (SLACK, 2009).

De acordo com Soares (2014) quando nos inserimos no contexto da melhoria continua a ferramenta MASP (Método de Análise e Solução de Problemas) é ótima para análise de processos produtivos, e devido a sua grande eficácia é utilizada por vários gestores. Sua metodologia é composta de passos e sub passos, sendo possível: realizar análise de causas; determinar e planejar um conjunto ações de correção; verificar o resultado da solução; e realimentar o processo de melhoria e autoanálise.

\subsection{GESTÃO DA QUALIDADE}

Segundo a FNQ (Fundação Nacional da Qualidade) os sistemas de gestão são um conjunto de ações padronizadas, logicamente interrelacionadas que tem como objetivo gerenciar processos de uma organização e produzir resultados. Com a implementação de um sistema de gestão há possibilidade de otimizar processos e garantir benefícios aos consumidores e a organização enquanto promulga a melhoria contínua dos produtos e serviços. (ABNT, 2007).

As normas ISO estão diretamente ligadas a qualidade, porém a que tem um destaque maior nessa área é a série ISO 9000. Segundo Mello (2009) a série ISO 9000 apresenta métricas para que organizações possam implementar e operar de forma segura um sistema de gestão de qualidade e agregam valores indispensáveis para a implantação de melhoria contínua.

As normativas são produzidas através de consenso afim de estabelecer um padrão mundial de qualidade para produtos e serviços, podendo ser aderido e aplicado em qualquer empresa independente do seu tamanho (FERREIRA, 2001). A fim de estabelecer diretrizes para os gestores, assegurado o cumprimento de requisitos, o desenvolvimento de sistemas tecnológicos, em conformidade com as normas, conseguiu correlacionar as métricas de qualidade aos processos de software.

A ISO e a IEC (International Electrotechnical Commission) estabelecem como qualidade de software características totais que lhe conferem a capacidade de satisfazer as necessidades explicitas e implícitas do cliente. Na Tabela 1 são descritas as normas da família 9000, relacionadas ao sistema de gestão da qualidade, e normas IEC, voltadas a qualidade e desempenho de software: 
Tabela 1 - Normativas ISO e IEC

\begin{tabular}{|c|c|}
\hline Normas & Objetivo \\
\hline NBR ISO 9000: & Definir normas de gestão da qualidade e de garantia da qualidade; \\
\hline ISO/IEC/IEEE 9000-03: & $\begin{array}{l}\text { Define diretrizes para aplicação da ISO } 9001 \text { ao desenvolvimento, fornecimento e } \\
\text { manutenção de software. }\end{array}$ \\
\hline NBR ISO 9001: & $\begin{array}{l}\text { Define um modelo de garantia de qualidade em projeto, instalação, desenvolvimento, } \\
\text { produção e assistência técnica; }\end{array}$ \\
\hline ISO/TS 9002: & Define um modelo de qualidade em produção e instalação; \\
\hline ISO 9003: & Define um modelo para garantia da qualidade em inspeção e ensaios finais; \\
\hline NBR ISO 9004: & Voltado para gestão da qualidade e elementos do sistema da qualidade; \\
\hline ISO/IEC 25030: & $\begin{array}{l}\text { Norma que atua avaliando a qualidade e atributos do software, padronizando os aspectos } \\
\text { a serem avaliados e impactando diretamente no seu nível de desempenho. }\end{array}$ \\
\hline ISO/IEC/IEEE 12207: & $\begin{array}{l}\text { Esta é uma norma voltada para o ciclo de vida de software e estabelece uma estrutura } \\
\text { bem definida para atividades e tarefas. Para cada processo são propostas uma sequência } \\
\text { de atividades que variam de acordo com a complexidade dos projetos, cada atividade } \\
\text { corresponde a um conjunto de tarefas. Divididos em processos fundamentais, de apoio e } \\
\text { organizacionais. }\end{array}$ \\
\hline NBR ISO/IEC 29110: & $\begin{array}{l}\text { Esta norma é composta por } 5 \text { partes e tem como objetivo estabelecer regras para } \\
\text { aplicação e desenvolvimento de software, porem está restrita a VSE (Very Small Entity), } \\
\text { que são pequenas organizações com até } 25 \text { colaboradores envolvidos no } \\
\text { desenvolvimento do software. }\end{array}$ \\
\hline
\end{tabular}

Fonte: Autores 2020.

\section{METODOLOGIA}

0 presente estudo tem por objetivo analisar os dados coletados no ambiente operacional de uma empresa, situada no município do Rio de Janeiro, reduzindo as perdas ocorridas no setor de estoque e agregando valor ao processo ao introduzir a melhoria contínua a organização. Aplicando a metodologia MASP e compondo suas fases com base nas normas NBR/ISO/IEC e nas ferramentas de qualidade (brainstorming, diagrama Ishikawa, PDCA, FMEA etc.).

Os dados foram coletados através de múltiplas fontes e métodos de coleta distintos: observações diretas e indiretas de processos, entrevistas com os gestores e supervisores das operações, documentos e relatórios cedidos pela a empresa em estudo. Tendo como base a pesquisa bibliográfica, foram utilizados livros, artigos científicos, teses e dissertações para fundamentação teórica e o estudo de caso, que permite a investigação profunda de um ou mais objetos, de maneira que permita seu amplo e detalhado conhecimento de um fenômeno.

Sua classificação, quanto aos fins, configura-se como pesquisa explicativa e aplicada. Segundo Gil (2008) a pesquisa explicativa é aquela que se preocupa em identificar os fatores que determinam ou que contribuem para a ocorrência dos fenômenos. Considerando sua natureza, Prodanov e Freitas (2013), designam como pesquisa aplicada, pois gera conhecimentos para aplicação prática dirigidos à solução de problemas específicos, envolvendo verdades e interesses locais.

\section{ESTUDO DE CASO}

A empresa em questão possui como principal atividade fabricação de produtos para diagnóstico e controle de qualidade possuindo um portifólio extenso de produtos. Atuante no mercado laboratorial/hospitalar e no setor industrial (alimentos, bebidas, cosméticos e farmacêuticas) à indústria volta-se para o controle da qualidade com avaliação de risco microbiológico. A zona fabril onde a pesquisa foi realizada se situa no município do Rio de Janeiro/RJ. A fábrica utiliza processos de produção em massa e é responsável pelo maior percentual de fabricação dada a sua capacidade e seu armazenamento. Essa unidade contempla os principais setores investigados: a produção, o estoque, o armazém e o centro de distribuição. 


\subsection{IDENTIFICAÇÃO}

Nesta etapa avaliamos o foco do desgaste de operações, o setor de estoque. No qual foram identificadas as principais perdas de produtos: produção em excesso, obsolescência, transporte, processamento desnecessário e movimentação interna. Além disso foi encontrado uma imprecisão ou ausência de indicadores impactando assim na análise dos níveis de estoque, na comunicação e no fluxo de informações. Correlacionando as percepções de capacidade e padrão de consumo identificamos também o valor que a empresa deixou de faturar com essas perdas.

Para analisar a capacidade do estoque é preciso delimitar sua rotina, sua estrutura e seus indicadores buscando cobrir todos os parâmetros da cadeia de valor que geram imprecisão sobre sua atuação. Já para análise do padrão de consumo foram confortados os parâmetros do produto com a previsão da demanda. A fim de demonstrar o modelo de gestão adotado, bem como ressaltam as condições físicas existentes atualmente na unidade de armazenamento foram investigados: (1) o funcionamento autônomo do sistema; (2) a estrutura de armazenagem; (3) o fluxo de informações; (4) a administração do setup; (5) os indicadores de desempenho; (6) o ciclo do pedido; e (7) a comunicação entre os setores.

\subsection{OBSERVAÇÃO}

Averiguamos os setores que estão diretamente ligados com o estoque, setor de referência neste estudo, como: comercial, produção, armazém e distribuição. Obtendo uma visão ampla das operações e interações entre os setores que corroboram com a operação logística da empresa. Mediante a observação dos dados coletados e das informações colhidas com os colaboradores em entrevistas foi possível identificar uma repetição quanto as falhas nos setores investigados. podemos citar dentre elas: a comunicação entre setores, processos desnecessários, o controle do fluxo de materiais, a rastreabilidade do produto, o monitoramento do processo, treinamento de pessoal, desatualização do sistema, compartilhamento de informação limitada, entre outros.

\subsection{ANÁLISE}

As entrevistas tiveram como objetivo entender a percepção dos gestores e demais colaboradores as não conformidades encontradas, bem como compreender a rotina das operações e definir claramente as anomalias e suas respectivas causas, propondo assim ações de correção que poderão ser apresentadas através de tecnologias, mudanças organizacionais ou comportamentais. Por isso foi realizado uma análise do processo atual, através do fluxograma de operações que confrontado com o detalhamento de todas as atividades por setor, apresenta as falhas referentes a cada etapa do processo produtivo, demonstradas pelo Diagrama de Ishikawa.

\subsection{PLANO DE AÇÃO}

Procurando visualizar a causa raiz para à anomalia identificada, foi utilizada como método de análise o FEMEA (Failure Mode and Effect Analysis). 0 FMEA é um método utilizado para prevenir falhas e analisar os riscos de um processo, identificando os possíveis modos de falha ocorridos e descrevendo os possíveis efeitos e causas dessas falhas. Após definir, estabelece-se assim atos de correção correlatos que ajudariam não só a empresa a corrigir essas falhas como a impulsionar um processo de melhoria nos padrões ISO 9001.

Com isso, foi classificado os modos de falha e identificada o número de ocorrência, a severidade e o nível de detecção do sistema. Com o intuito de indicar o RPN (Risk Priority Number), ou seja, demonstrar a criticidade do modo de falha. Através dele é possível estabelecer o ponto de partida para melhoria de processos. Analisando as ações corretivas nota-se o intuito de eliminar os ruídos de comunicação e facilitar o tráfego de informação, consequentemente, evita-se o desperdício de tempo e material com o uso da tecnologia como sistema de apoio.

Como modelo de gerenciamento se propôs um software voltado para o monitoramento e controle do fluxo de materiais. Utilizando como interface o Sistema Kanban Eletrônico e no que diz respeito a usabilidade a simplicidade de um aplicativo (APP). A plataforma digital permite que se faça alterações e acompanhe em tempo real o andamento das atividades, através da interconexão das etapas pela rede. 
O Sistema Kanban, em resumo, é um método de programação e controle da produção, que utiliza cartões para sinalizar e orientar o processo produtivo. 0 sistema facilita a circulação de informações, gerando ambientes mais colaborativos e funcionais. Assim para cada lote gerado é atribuído um código de barras, identificado pelo sistema, que registra e controla as medições, em tempo real, encontrando o produto na linha fabril e identificando seu status em relação ao processo de fabricação.

0 aplicativo veio promover o dinamismo e a agilidade que o sistema pede, visto que notificará de pronto imediato quando ocorrer alguma anomalia que fuja dos parâmetros registrados. Com isso, é possível acompanhar, controlar e programar todo o processo de modo visual e direto através dos cartões kanban. Não está presente no escopo do projeto a atuação do supervisório a tomada de ações automáticas no que tange à correção de problemas.

\subsection{EXECUÇÃO}

O desenvolvimento do Sistema Kanban Eletrônico interface aplicativo visa facilitar todo o processo produtivo, tornando a equipe coesa, minimizando falhas e adotando técnicas que facilitem a compreensão. 0 aplicativo promoverá o gerenciamento ágil do estoque tendo como premissas: (1) o monitoramento de ativos; (2) o controle; (3) a armazenagem; (4) a rastreabilidade; (5) a comunicação; (6) o fluxo de informações.

O sistema foi pensado para que qualquer funcionário, cujo acesso seja permitido, possa usar do seu aparelho já que suas atribuições são de aplicativo. O APP necessita de algumas configurações mínimas para operar em um celular comum, para ser instalado e funcionar de forma correta, estes requisitos básicos são apresentados na Tabela 2, a seguir:

Tabela 2 - Requisitos Básicos do Sistema

\begin{tabular}{|l|l|}
\multicolumn{1}{c|}{ Requisitos } & \multicolumn{1}{c|}{ Descrição } \\
\hline Tamanho & varia de acordo com o dispositivo, mas em média de 90 MB; \\
\hline Classificação & acima de 18 anos; \\
\hline Plataforma & Android; IOS; \\
\hline Sistema & a partir do ANDROID ICE CREAM SANDWICH (4.0) \\
\hline Idioma & português \\
\hline Acesso & restrito aos funcionários da empresa. \\
\hline
\end{tabular}

Fonte: Autores 2020.

O sistema opera de duas formas diferentes conectado com a internet e offline. Pautada na ISO/IEC/IEEE 12207, a Tabela 3 apresenta a estrutura de funcionamento do sistema:

Tabela 3 - Estrutura de Funcionamento do Sistema

$$
\text { Online }
$$

Nesse modo a conexão se estabelece via internet possibilitando o acesso de todas as funcionalidades, bem como a visualização de informações em tempo real (coleta de dados e atualização dos dados). Offline

Esse modo contempla a exibição de dados nativos, cadastrados somente pelo gerente do projeto, interface simples e nenhuma interatividade. Tem- se a disponibilidade o histórico de informações armazenadas com possibilidade de emissão de gráficos e relatórios.

Fonte: Autores 2020.

Considerando a especificação do projeto baseadas nas definições do Sistema Kanban Eletrônico a ser implementado na área de armazenagem, viu-se as técnicas relacionadas ao sistema e algumas especificações básicas de estrutura. Através desses fatores estabeleceu- se as premissas do software, são eleas: Documentações de hardware/software; infraestrutura de rede; arquitetura do sistema; custo do projeto;

No que tange a arquitetura do sistema proposto foram desenvolvidos, levando-se em conta as necessidades do cliente, os critérios de aceitação. Segue abaixo, na Figura 1, as premissas adotadas na instalação do sistema de acordo com a ISO/IEC 25030: 
Figura 1 - Qualidade Interna e Externa do Produto.

\begin{tabular}{|c|c|c|c|c|c|}
\hline & & $\begin{array}{r}\text { QUAL } \\
\text { INTERNA }\end{array}$ & $\begin{array}{l}\text { ADE } \\
\text { XTERNA }\end{array}$ & & \\
\hline & & & 4 & & \\
\hline EFICIÊNCIA & MANUTENABILIDADE & FUNCIONALIDADE & USABILIDADE & PORTABILIDADE & CONFIABILIDADE \\
\hline $\begin{array}{l}\text { Conformidade; } \\
\text { Utilização de } \\
\text { recursos; } \\
\text { Comportamento } \\
\text { em relação ao } \\
\text { tempo; }\end{array}$ & $\begin{array}{l}\text { Analisabilidade; } \\
\text { Modificabilidade; } \\
\text { Estabilidade; } \\
\text { Testabilidade; } \\
\text { Comformidade; }\end{array}$ & $\begin{array}{l}\text { Adequação; } \\
\text { Acurácia; } \\
\text { Interoperabilidade; } \\
\text { Segurança de } \\
\text { acesso; } \\
\text { Comformidade; }\end{array}$ & \begin{tabular}{|l|} 
Inteligibilidade; \\
Apreensibilidade; \\
Operacionalidade; \\
Atratividade; \\
Conformidade;
\end{tabular} & $\begin{array}{l}\text { Adaptabilidade; } \\
\text { Capacidade } \\
\text { para ser } \\
\text { instalado; } \\
\text { Coexistência; } \\
\text { Capacidade } \\
\text { para substituir; } \\
\text { Conformidade; }\end{array}$ & $\begin{array}{l}\text { Maturidade; } \\
\text { Tolerância a } \\
\text { falhas; } \\
\text { Recuperabilidade; } \\
\text { Conformidade; }\end{array}$ \\
\hline
\end{tabular}

Fonte: Autores 2020.

Considerando a normativa NBR ISO/IEC 29110, define-se as configurações de hardware/software implementados para que o sistema e os equipamentos de medição e apoiopossam ser instalados na área de armazenagem. As especificações de desenvolvimento serão apresentadas nas Tabelas 3 e 4, a seguir:

Tabela 4 - Especificação de Hardware

\begin{tabular}{|l|l|}
\multicolumn{1}{c}{ Hardware } & tirar fotos e vídeos; \\
\hline Mâmera & gravar áudio; \\
\hline Fotos / Mídia / Arquivos & $\begin{array}{l}\text { modificar ou excluir o conteúdo do seu armazenamento USB; ler o conteúdo do seu } \\
\text { armazenamento USB; }\end{array}$ \\
\hline Armazenamento & $\begin{array}{l}\text { modificar ou excluir o conteúdo do seu armazenamento USB; ler o conteúdo do seu } \\
\text { armazenamento USB; histórico do aplicativo e do dispositivo; recuperar aplicativos em } \\
\text { execução; }\end{array}$ \\
\hline Telefone & $\begin{array}{l}\text { ligar diretamente para números de telefone; mandar SMS; lista de contatos; acesso a contas } \\
\text { de e-mail; }\end{array}$ \\
\hline Identidade & ID do dispositivo e informações da chamada; ler status e identidade do telefone; \\
\hline Local & $\begin{array}{l}\text { localização precisa (GPS e baseada em rede); localização aproximada (baseada na rede); } \\
\text { acessar comandos adicionais de provedores de localização; }\end{array}$ \\
\hline Conexões / Wi-Fi & $\begin{array}{l}\text { informações sobre a conexão Wi-Fi; ver conexões Wi-Fi; } \\
\text { conectar e desconectar do Wi-Fi; acesso total à rede; receber dados da Internet; receber } \\
\text { dados de outros programas; parear com dispositivos Bluetooth; }\end{array}$ \\
\hline
\end{tabular}

Fonte: Autores 2020.

Tabela 5 - Especificação de Software

\begin{tabular}{|l|c|l|}
\hline \multicolumn{1}{|c|}{ Software } & Especificação & \multicolumn{2}{c|}{ Descrição } \\
\hline Banco de dados & SQLite & $\begin{array}{l}\text { É um banco de dados que serve como implemento do SQL e } \\
\text { seu uso é comum para aplicativos moveis. }\end{array}$ \\
\hline Linguagem de desenvolvimento & Java & $\begin{array}{l}\text { Por rodar 350 tipos de linguagens alem de ser uma das } \\
\text { linguagens de programação mais utilizadas foi a selecionada } \\
\text { para o projeto. }\end{array}$ \\
\hline Linguagem de Marcação & XML & $\begin{array}{l}\text { O XML é uma linguagem de marcação que concede a } \\
\text { viabilidade de criação de documentos, com ele é possivel } \\
\text { definir estilos de telas para a aplicação. }\end{array}$ \\
\hline Plataforma para desenvolvimento & Android Studio & $\begin{array}{l}\text { Android studio oferece um espaço para desenvolvimento e } \\
\text { teste para Android }\end{array}$ \\
\hline Metodologia de desenvolvimento & RUP & $\begin{array}{l}\text { É uma feramenta que tem como objetivo guiar e grenciar o } \\
\text { processo de desenvolvemento do software. }\end{array}$ \\
\hline $\begin{array}{l}\text { Versão do Software de controle de } \\
\text { temperatura }\end{array}$ & MGE & $\begin{array}{l}\text { Um sistema de gestão voltado para refrigeração e climatização, } \\
\text { que permite monitorar, controlar a temperatura e analisar os } \\
\text { dados de desempenho do equipamento e transforma-lo em } \\
\text { graficos. }\end{array}$ \\
\hline
\end{tabular}


O custo aproximado para se desenvolver um aplicativo pode variar entre $\mathrm{R} \$ 15$ mil e $\mathrm{R} \$ 60$ mil, o custo aumenta de acordo com as especificações. Além da fase inicial de elaboração o aplicativo detém outros custos atrelados a ele, tais como: manutenção, evolução e hospedagem em um servidor. 0 custo desses serviços varia em torno de R\$ 500 mensais. Considerando a fase de concepção para criação de aplicativo temos os seguintes valores:

- 15 a 30 mil reais: aplicativos para apenas uma plataforma (stand alone), ou seja, será desenvolvido para IOS ou para Android ou para a WEB e assim vai.

- 30 a 60 mil reais: projetos multiplataformas e interativos com gerenciamento de demanda (servidor/ cliente) para proporcionar escalabilidade.

A seguir, na Tabela 6, serão descritos os valores orçamentarios para a instalação do aplicativo e sua estrutura referida dentro do setor.

Tabela 6 - Custo do projeto.

\begin{tabular}{|l|c|}
\hline \multicolumn{2}{|c|}{ Custo do projeto } \\
\hline Materiais auxiliares & $\mathrm{R} \$ 5.490,00$ \\
\hline Equipamento principal & $\mathrm{R} \$ 3.097,70$ \\
\hline Desenvolvimento do APP & $\mathrm{R} \$ 50.000,00$ \\
\hline Manutenção do APP (mensais) & $\mathrm{R} \$ 500,00$ \\
\hline \multicolumn{1}{|c|}{ TOTAL } & $\mathrm{R} \$ 59.087,40$ \\
\hline
\end{tabular}

Fonte: Autores 2020

\section{CONSIDERAÇÕES FINAIS}

O estudo realizado concluiu seu principal objetivo, encontrar a causa raiz do desgaste das operações através da metodologia MASP, e apresentou ações corretivas implementando dentro da organização um sistema de autoanalise. Apresentou também uma proposta de solução para a empresa em questão, através do desenvolvimento do Sistema Kanban Eletrônico interface aplicativo. 0 APP veio promover a interação entre os departamentos e o compartilhamento do conhecimento do processo com o auxílio da tecnologia de monitoramento em tempo real. Um sistema com metodologia ágil, leve e flexível que transforma dados em oportunidades de negócio promulgando a conectividade móvel.

Portanto a tecnologia, nesse caso, veio introduzir a melhoria contínua do processo e impulsionar a economia circular da empresa, visto que ao reduzir as perdas em estoques impele na diminuição do descarte de materiais biológicos. Promovendo assim o desenvolvimento sustentável e a ecologia industrial, enquanto fortalece a economia e o ciclo produtivo. Com as orientações das normas técnicas estabelecidas pela ISO/IEC, voltadas a qualidade de software e implementação dele, foi possível cobrir todos os parâmetros iniciais de estrutura e instalação dos softwares de gestão.

\section{REFERÊNCIAS}

[1] ASSOCIAÇÃO BRASILEIRA DE NORMAS TÉCNICAS. NBR 9000: Sistemas de gestão da qualidade Fundamentos e vocabulário - Apresentação. Rio de Janeiro: ABNT, 2015.

[2] ASSOCIAÇÃO BRASILEIRA DE NORMAS TÉCNICAS. ISO/IEC/IEEE 9000-3: Software engineering -- Guidelines for the application of ISO 9001:2015 to computer software - Elaboração. Rio de Janeiro: ISO, 2018.

[3] ASSOCIAÇÃO BRASILEIRA DE NORMAS TÉCNICAS. NBR 9001: Sistemas de gestão da qualidade - Requisitos Elaboração. Rio de Janeiro: ABNT, 2015.

[4] ASSOCIAÇÃO BRASILEIRA DE NORMAS TÉCNICAS. ISO/TS 9002: Quality management systems -- Guidelines for the application of ISO 9001:2015 - Elaboração. Rio de Janeiro: ISO, 2016.

[5] ASSOCIAÇÃO BRASILEIRA DE NORMAS TÉCNICAS. NBR 9004: Gestão da qualidade - Qualidade de uma organização - Orientação para alcançar o sucesso sustentado - Apresentação. Rio de Janeiro: ABNT, 2019.

[6] ASSOCIAÇÃO BRASILEIRA DE NORMAS TÉCNICAS. NBR ISO/IEC 25030: Engenharia de software - Requisitos e Avaliação da Qualidade de Produto de Software (SQuaRE) - Requisitos de qualidade - Apresentação. Rio de Janeiro: ABNT, 2008.

[7] ASSOCIAÇÃO BRASILEIRA DE NORMAS TÉCNICAS. ISO/IEC/IEEE 12207: Systems and software engineering -Software life cycle processes - Elaboração. Rio de Janeiro: ISO, 2017. 
[8] ASSOCIAÇÃO BRASILEIRA DE NORMAS TÉCNICAS. NBR ISO/IEC 29110: Engenharia de software e sistemas Perfis de ciclo de vida para micro-organizações (VSE) - Elaboração. Rio de Janeiro: ABNT, 2020.

[9] BALDAM, R.L.; DO VALE, R.A.B.; PEREIRA, H.R.M.; HILST, S.M.; DE ABREU, M.P.; SOBRAL, V.S. Gerenciamento de Processos

[10] de Negócio BPM - Business Process Management. 2ªEd. - São Paulo: Érica Ltda, 2010.

[11] BALLOU, R.H. Gerenciamento da Cadeia de Suprimentos: Planejamento, Organização e Logística Empresarial; Tradução Raul Rubenlch. 5 a Ed - Porto Alegre: Bookman, 2006.

[12] BASSI, E; DINIZ, M.A.S. Gerenciamento do processo produtivo por meio da melhoria contínua: estudo de caso em uma indústria têxtil; Disponível em: <http://www.simpep.feb.unesp.br/anais_simpep.php?e=12>; Acesso em: 05 mai. 2019

[13] CORREA, H. L.; GIANESI, I. G. N.; CAON, M. Planejamento, Programação e Controle da Produção. 5a Ed. São Paulo: Atlas, 2013.

[14] DANTAS, J. C. A. A importância do controle de estoque: estudo realizado em um supermercado na cidade de Caicó/RN; 1-57 f. Monografia (Bacharel em Ciências Contábeis) - Universidade Federal do Rio Grande do Norte, Rio Grande do Norte, 2015

[15] FEITOSA, P. P. B.; PONTES, H.L.J.; PEREIRA, N.S.; HERBSTER, J. B.; ALBERTIN, M. R.; Aplicação do Método de Análise e Solução

[16] de Problemas (MASP) para redução do índice de retorno de mercadoria de uma fábrica de embutidos; XXXIII Encontro Nacional de Engenharia de Produção: A Gestão dos Processos de Produção e as Parcerias Globais para o Desenvolvimento Sustentável dos Sistemas Produtivos; Salvador, BA, Brasil, 08 a 11 de outubro de 2019.

[17] FERREIRA, J. J. A. A série ISO 9000:2000. São Paulo: Fundação Vanzolini, 2001.

[18] FUNDAÇÃO NACIONAL DA QUALIDADE (FNQ). Sistemas de Gestão. Disponível em: <https://fnq.org.br/comunidade/modelo-post-e- book/> Acesso em: 03 mai. 2020.

[19] GIL, A. C. Como Elaborar Projeto de Pesquisa. 4aㅡ ed. São Paulo: Atlas, 2009.

[20] MELLO, C. H. P.; SILVA, C. E. S.; TURRIONE, J. B.; SOUZA, L. G. M. ISO 9001: 2008: Sistema de Gestão da Qualidade para

[21] operações de produção e serviços. São Paulo: Atlas, 2009.

[22] PERGHER, I.; SILVA, L. A.; PACHECO, D. A. J.; VACCARO, G.L. R.; Análise do impacto da variabilidade de fluxo no dimensionamento de kanbans; Revista de Produção, Florianópolis-SC, v.14, n. 1, p. 115-142, jan./mar. 2014.

[23] PIRES, S.R.I.; Gestão da Cadeia de Suprimentos (Supply Chain Management): Conceitos, Estratégias, Práticas e Casos. 3aㅡ. Ed. São Paulo: Atlas, 2007.

[24] PRODANOV, C. C.; FREITAS, E. C. Metodologia do Trabalho Científico: Métodos e Técnicas de Pesquisa e do Trabalho Acadêmico.

[25] 2a ed. Novo Hamburgo - Rio Grande do Sul: Feevale, 2013. Cap. 3, p. 41-118

[26] ROBLES, L. T.; Cadeia de suprimentos: administração de processos logísticos; $1^{a}$ Ed. - São Paulo: Intersaberes, 2016

[27] SANTOS N. J.; BARROS, J. G. O Kaizen nas atividades de um provedor de serviços logísticos: estudo de caso em uma montadora de automóveis. In: SIMPÓSIO DE ENGENHARIA DE PRODUÇÃO - SIMPEP. 14, 2007. Anais: Bauru, São Paulo, 2007.

[28] SLACK, N.; CHAMBERS, S.; JOHNSTON, R. Administração da produção. 3.ed. São Paulo: Atlas, 2009.

[29] SOARES, J. A. Método de implantação de sistema de abastecimento enxuto para a montagem de eletrodomésticos: um estudo de caso;1-138 f. Dissertação (Mestrado em Engenharia Mecânica) - Universidade Federal de Santa Catarina, Florianópolis - SC, 2014.

[30] SOCIEDADE BRASILEIRA DE MICROBIOLOGIA (SBM). O novo papel do microbiologista na indústria. São Paulo, 17 mai. 2016. Disponível em: <https://sbmicrobiologia.org.br/o-novo-papel-do-microbiologista-naindustria/>. Acesso em: 03 mar. 2020.

[31] TUBINO, D. F. Manual de planejamento e controle da produção. 1 a Ed. - São Paulo: Atlas, 2000. 


\section{Capítulo 14}

Aplicação da Metodologia DMAIC em uma fábrica de baterias para o controle das perdas de chumbo

\section{Daniel de Freitas Barbosa \\ André Luiz Gazoli de Oliveira \\ William Rodrigues dos Santos \\ Marco Aurélio Reis dos Santos}

Resumo: A perda de chumbo no processo de produção é um grande problema nas empresas produtoras de baterias de chumbo-ácido, afetando sua produtividade e a competitividade. No presente estudo é aplicado o método DMAIC de melhoria contínua, com o objetivo de reduzir os desperdícios de chumbo no processo produtivo. Esta pesquisa é um estudo de caso, onde foram analisados inicialmente três setores da produção de baterias de uma indústria. Através da aplicação do Controle Estatístico de Processo foi observado a ocorrência de grande volume de perda de chumbo no processo de empaste, com a operação apresentando causas especiais de variação. Após implementação de uma melhoria no maquinário, foi possível reduzir a perda em $67 \%$, representando um aumento médio de produção de 53 baterias por dia. Isso permitiu que a empresa diminua suas quantidades de chumbo que tenha que ser reaproveitado ou retrabalhado, acelere sua produção de baterias e reduza seus gastos com os acordos de entregas e parcerias com clientes. A partir dos resultados é possível concluir que a metodologia DMAIC foi eficaz em sua aplicação no estudo, trazendo um consequente aumento na produtividade da indústria e se mostrando uma ferramenta útil para compreensão de problemas complexos.

Palavras-chave: Melhoria contínua, DMAIC, Controle Estatístico de Processo, Perda de chumbo, Bateria automotiva. 


\section{INTRODUÇÃO}

A indústria de baterias se divide em dois tipos de mercados: Original Equipment Manufacturer (OEM), voltado para vendas às montadoras de veículos; e Reposição e Substituição de baterias em veículos usados (PEREIRA; BÁNKUTI, 2016).

De acordo com Castro et al. (2013), o mercado de repositores é composto em sua maioria de indústrias de pequeno e médio porte e de capital nacional. Essas empresas possuem uma fatia aproximada de $45 \%$ do market share do Brasil, enquanto os 55\% restantes são divididos entre as grandes indústrias de capital aberto como, por exemplo, a Moura e a Johnson Controls (Heliar).

A empresa analisada nesse artigo atende o mercado de reposição de baterias e, de acordo com o IBGE, é classificada como empresa de médio porte de acordo com o número de funcionários (100 a 499 funcionários). Atualmente, a empresa tem por objetivo melhorar a produtividade e a competitividade para aumentar o market share regional e competir com as indústrias que atuam na região.

Para melhorar a produtividade e competitividade, é necessário reduzir o desperdício de chumbo $(\mathrm{Pb})$ no processo produtivo. Porém, atualmente existe um desperdício previsto devido as limitações existentes nas máquinas e uma das possibilidades é o retorno desse chumbo para o início do processo para ser fundido novamente e, assim, reaproveitá-lo. Mesmo assim, a empresa perde produtividade, afetando a competitividade em relação a outras empresas da região.

Objetivando reduzir os desperdícios de chumbo $(\mathrm{Pb})$ no processo produtivo de bateria chumbo-ácido e utilizando-se como base a metodologia DMAIC, essa pesquisa busca responder a seguinte questão: Quanto o desperdício de chumbo durante o processo produtivo afeta a produtividade e qual seu impacto nos produtos acabados?

O artigo está estruturado da seguinte maneira: Capítulo 1 - apresentada uma breve contextualização da pesquisa com detalhes da empresa e finalizando com a pergunta de pesquisa; Capítulo 2 - apresenta o embasamento teórica desse artigo, enfatizando o DMAIC; Capítulo 3 - destaca os aspectos metodológicos da pesquisa, apresentando os instrumentos utilizados para a coleta de dados. Capítulo 4 - apresenta o caso, destacando cada parte do DMAIC. Capítulo 5 - apresenta as discussões dos resultados. Capítulo 6 apresentam-se as considerações finais.

\section{REVISÃO DE LITERATURA}

Segundo Carpinetti (2017), o Six Sigma teve sua origem nos anos de 1980 com o engenheiro Bill Smith funcionário da Motorola, alguns anos após o surgimento da metodologia, foi criada pelos especialistas em qualidade Mikel Harry e Richard Schroeder, a chamada Six Sigma Academy com o objetivo de difundir a metodologia Six Sigma para outras empresas. De acordo com Coutinho (2011), a metodologia seis sigmas visa a otimização de processos mediante a redução ou minimização da variabilidade e redução de desperdícios.

Para Krahembuhl (2005), DMAIC é um roteiro composto por cinco etapas, muito utilizado pela metodologia seis sigma. Carpinetti (2017, p.150) explica que "DMAIC, é um acrônimo para Define, Measure, Analyse, Improve e Control". De acordo com Harry e Schroeder (2000), o DMAIC é utilizado de forma sequencial respeitando as etapas, mas nem sempre é possível seguir a sequência direta, assim, podendo ocorrer inversões ou trocas entre as etapas. Uma ilustração que representa o funcionamento do ciclo DMAIC e de como se sequência as cinco fases desta metodologia são apresentadas na Figura 1.

0 método DMAIC é constituído por cinco etapas (WERKEMA, 2010, p. 22): “D-Define (Definir): Definir com precisão o escopo do projeto; M-Measure (Medir): Determinar a localização ou foco do problema; AAnalyze (Analisar): Determinar as causas de cada problema prioritário; I-Improve (Melhorar): Propor, avaliar e implementar soluções para cada problema prioritário; e C-Control (Controlar): Garantir que o alcance da meta seja mantido a longo prazo".

Juntamente com o DMAIC são utilizadas diversas ferramentas de apoio, em que se destaca nessa pesquisa: Diagrama de Ishikawa; Gráfico de Pareto; 5W2H; e Gráficos de controle.

De acordo com Longo (2011), quando um processo é definido como sob controle, significa que ele sofre influência apenas de variações casuais, que são variações inerentes ao processo e aparecem no processo de forma aleatória e são de difícil controle, já quando este processo está fora de controle, significa que além de variações casuais há também a presença de variações de caráter especial, que são variações que 
acontecem em momentos pontuais ao longo do processo e que ocorrem por meio de influência de fatores externos.

Figura 1 - Método DMAIC

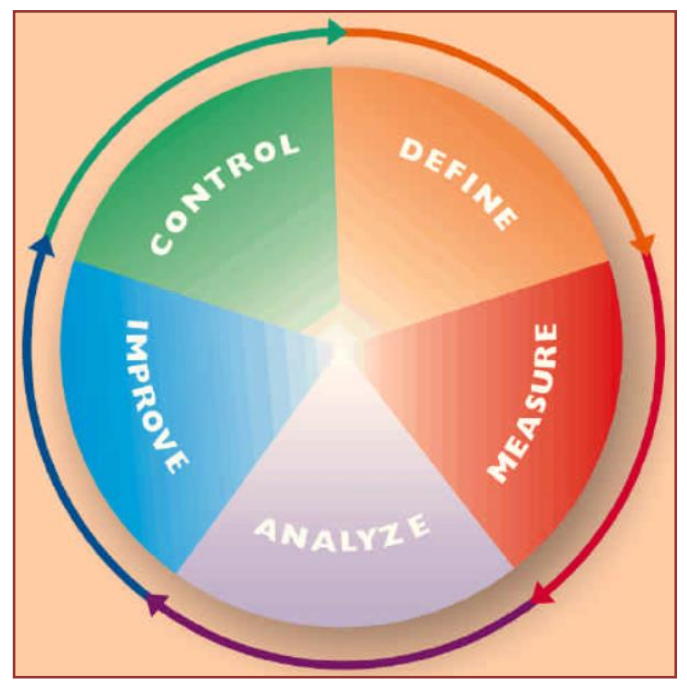

Fonte: Adaptado de Werkema (2010)

\section{ASPECTOS METODOLÓGICOS}

Esta pesquisa busca desenvolver conhecimentos científicos sobre a aplicação de métodos de melhoria contínua para resolução de problemas de qualidade. 0 estudo de caso apresentando foi desenvolvido em uma empresa, de médio porte e com mais de 50 anos, que produz baterias para veículos automotores (carros, motos, caminhões e ônibus). Neste contexto, o principal objetivo na aplicação no DMAIC foi identificar e propor soluções para os principais desperdícios que ocorrem no processo produtivo de fabricação das baterias.

\subsection{FERRAMENTAS DE COLETA E ANÁLISE DE DADOS}

O Quadro 1 resume as ferramentas utilizadas para a coleta e análise de dados.

Quadro 1 - Ferramentas utilizadas para coleta e análise de dados

\begin{tabular}{|c|c|c|}
\hline Etapas do DMAIC & Coleta de dados & Análise de dados \\
\hline Definir & $\begin{array}{l}\text { - Consulta ao histórico de desperdício de } \\
\text { produção. } \\
\text { - } \quad \text { Entrevista informal com operadores. } \\
\text { - Observação direta do processo produtivo. }\end{array}$ & $\begin{array}{l}\text { - Elaborado um gráfico do histórico de } \\
\text { desperdício para averiguar a média de } \\
\text { desperdício de chumbo, médio de } \\
\text { desperdício total, desperdício de } \\
\text { chumbo e desperdício total. }\end{array}$ \\
\hline Medir & $\begin{array}{l}\text { - Coleta de amostras do processo de } \\
\text { empaste. }\end{array}$ & $\begin{array}{l}\text { - Elaborado gráfico de controle Xbarra - R } \\
\text { (Média e Amplitude) das perdas no } \\
\text { processo. }\end{array}$ \\
\hline Analisar & Construção do Diagrama de Ishikawa & Priorização de causas. \\
\hline Melhorar & $\begin{array}{l}\text { Entrevista informal com operadores. } \\
\text { Observação direta do processo produtivo. }\end{array}$ & $\begin{array}{l}\text { - Definidas soluções de curto, médio e } \\
\text { longo prazo. }\end{array}$ \\
\hline Controlar & $\begin{array}{l}\text { - Coleta de amostras do processo de } \\
\text { empaste, porém em quantidade menor de } \\
\text { dados. }\end{array}$ & $\begin{array}{l}\text { Elaborado gráfico de controle para } \\
\text { Valores Individuais e Amplitude Móvel } \\
(\mathrm{X}-\mathrm{MR}) \text {. }\end{array}$ \\
\hline
\end{tabular}


Nesse estudo de caso, os dados foram obtidos em três momentos: (1) entrevistas informais com funcionários da empresa; (2) consulta a documentos sobre desperdícios de matéria-prima e retrabalho; e (3) observações diretas.

Ao decorrer da apresentação do caso, detalham-se as etapas do DMAIC com a apresentação da coleta e análise de dados.

\section{APRESENTAÇÃO DO CASO}

\subsection{O PROCESSO DE FABRICAÇÃO DE BATERIAS}

Conforme ilustrado na Figura 2, o processo de fabricação de baterias inicia-se com a chegada da sucata de bateria, que é moída no moinho de sucata, onde ocorre a separação do chumbo, do plástico e do ácido. 0 chumbo é reservado por alguns dias, enquanto o plástico e o ácido são reaproveitados por indústrias terceirizadas. Após ser reservado, o chumbo vai para o forno, onde é derretido e transformado em "rogues" (caixas de chumbo maciço). Em seguida, os "rogues" são levados para o refino, onde são tiradas as impurezas do chumbo e são formados os lingotes de chumbo.

Figura 2 - Etapas de produção de bateria

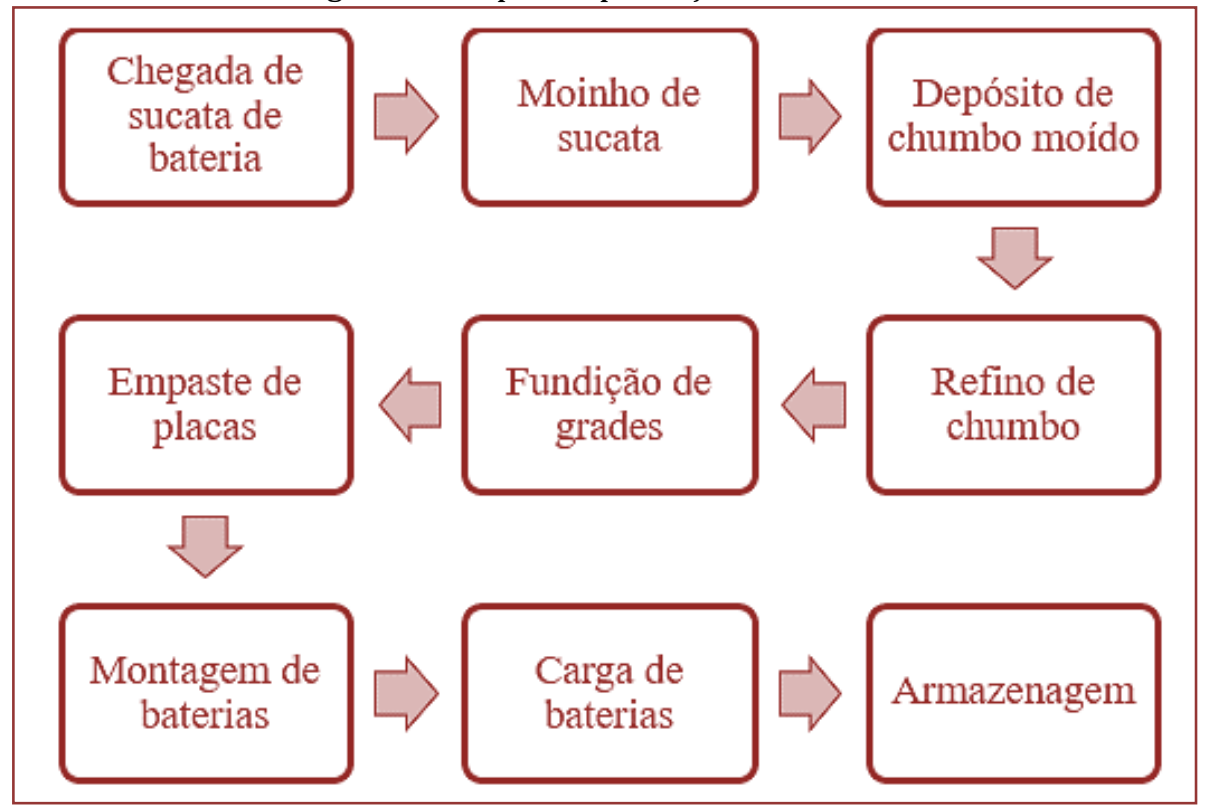

Fonte: Elaborado pelos autores (2020)

Na sequência, o chumbo é levado para a fundição, sendo uma parte utilizada para fazer as grades de chumbo e a outra parte para fazer o óxido de chumbo (PbO), que é utilizado para empastar as grades e formar as placas positivas e negativas. Em seguida, as placas vão para a estufa onde ficam por um período de 24 horas, com o objetivo de secar e fixar o oxido de chumbo ( $\mathrm{PbO}$ ) na grade.

Na sequência, as placas vão para a montagem, onde são colocadas dentro da caixa da bateria, junto com o separador (material isolante). No setor da montagem são colocadas as placas e separador na caixa plástica e são fixados as tampas e os polos da bateria. Depois de montada, a bateria recebe uma solução ácida e, em seguida, a carga. Após carregada, a bateria é levada para um estoque para descansar. Em seguida, é levada para a expedição, onde é realizado o teste de carga de cada bateria e o embalo dos lotes para a entrega.

Ao longo do processo produtivo, ocorrem perdas da matéria-prima principal, o chumbo (Pb), porém, existe a possibilidade de retrabalho, através do retorno para a fundição, onde o chumbo é derretido e refinado para retornar ao processo novamente. Os processos que geram mais perdas na indústria são a fundição de chumbo, a fundição de grades e o empaste de placas.

Inicialmente, foram coletados dados dos rejeitos para os setores de refino, fundição e montagem da bateria no mês de agosto de 2019. Essa identificação inicial dos desperdícios permite o direcionamento das atividades de melhoria com base no DMAIC. A partir da Tabela 1, observa-se que o setor com maior 
volume de desperdícios (kg) é o refino com $112.691 \mathrm{~kg}$ de material metálico rejeitado. 0 material mais rejeitado é o metálico, sendo desperdiçado tanto no refino quanto na montagem.

Tabela 1 - Resumo dos rejeitos para o mês de agosto de 2019

\begin{tabular}{|l|c|c|c|c|c|}
\hline \multicolumn{1}{|c}{ Setores } & \multicolumn{4}{c}{ Tipo de material rejeitado (kg) } & \multirow{2}{*}{ Total } \\
\hline Refino & 112691 & - & - & - & 112691 \\
\hline Fundição & - & - & 3994 & - & 3994 \\
\hline Montagem & 2266 & 12020 & - & 6531 & 20817 \\
\hline Total & 114957 & 12020 & 3994 & 6531 & 137502 \\
\hline
\end{tabular}

Fonte: Elaborado pelos autores (2020)

Apesar dos resultados, o setor de fundição foi considerado o mais crítico por fornecer a principal matériaprima para montagem das baterias. Analisando-se o processo de produção das baterias, observa-se que grande parte dos setores dependem direta e indiretamente da produção da placa de chumbo, e que as perdas que ocorrem neste setor impactam diretamente no tempo de entrega da bateria. Desta forma, levando-se em consideração o critério de tempo (tempo de produção, tempo de espera e tempo de reaproveitamento) o setor de fundição foi selecionado para o estudo. A seguir realiza-se uma breve descrição das atividades desenvolvidas no setor de fundição, detalhando os principais rejeitos.

\subsubsection{SETOR FUNDIÇÃO E OS PRINCIPAIS REJEITOS}

Para explicar o processo de fundição, elaborou-se um fluxograma, detalhado na Figura 3. 0 setor de fundição é responsável pela produção das grades de chumbo, óxido de chumbo, massa de chumbo e as placas positivas e negativas.

Figura 3 - Fluxograma do processo de fundição

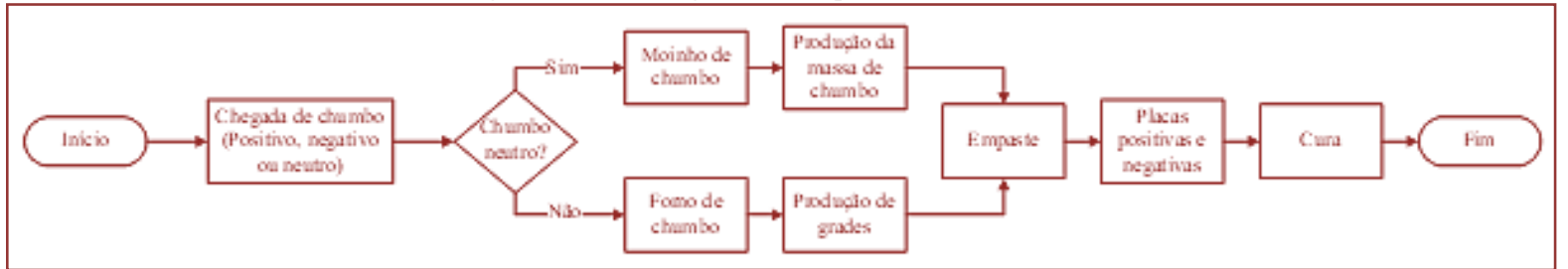

Fonte: Elaborado pelos autores (2020)

O início da produção do setor se dá com a chegada de chumbo positivo, negativo e neutro, vindo do setor de refino; o chumbo positivo e negativo são enviados para o forno para serem derretidos e transformados em grades. Já o chumbo neutro é levado para um moinho, onde é transformado em óxido de chumbo que, por sua vez, é levado para a misturadora para produzir a massa. A grade e a massa são levadas para a máquina de empaste que faz a junção dos dois materiais para produzir as placas. Em seguida, as placas são levadas para a curar por 24 horas. Saindo da cura, as placas são levadas para o setor de montagem, onde são colocadas dentro das baterias.

Os rejeitos do processo de fundição ocorrem em dois momentos: (1) retirada do chumbo derretido das panelas do forno para fazer as grades; e (2) a produção de placas defeituosas na máquina que realiza o empaste devido ao setup de produção. No primeiro rejeito, perde-se apenas no chumbo junto com suas impurezas, sendo inclusive um desperdício inerente ao processo, mas que pode ser reduzido ou eliminado. 0 segundo rejeito é mais crítico porque além de perder a massa de chumbo, perde-se também a grade que são materiais com maior valor agregado, representando a maior perda financeira e temporal da empresa.

Esclarecido o setor de fundição com seus processos e rejeitos, detalha-se a aplicação do DMAIC nas próximas páginas. 


\subsection{DMAIC: DEFINIR}

A primeira etapa do DMAIC é definir, que consiste em realizar o planejamento do estudo e definido um objetivo a ser alcançado. Analisando os dados coletados e fazendo observações diretas no chão de fábrica, foi possível averiguar que a máquina de empaste é um grande gerador de rejeito, principalmente de massa de empaste, que representa $60 \%$ do rejeito do setor de fundição, segundo informações da empresa. É possível verificar, que em média, o setor gera aproximadamente $7.336 \mathrm{~kg}$ de rejeito por mês, sendo que $60 \%$ desses rejeitos são massa de chumbo, representando uma perda média mensal de aproximadamente $4.402 \mathrm{~kg}$, as perdas do setor, nos meses de fevereiro à julho, conforme as informações expostas na figura 4 .

Figura 4 - Rejeitos da fundição

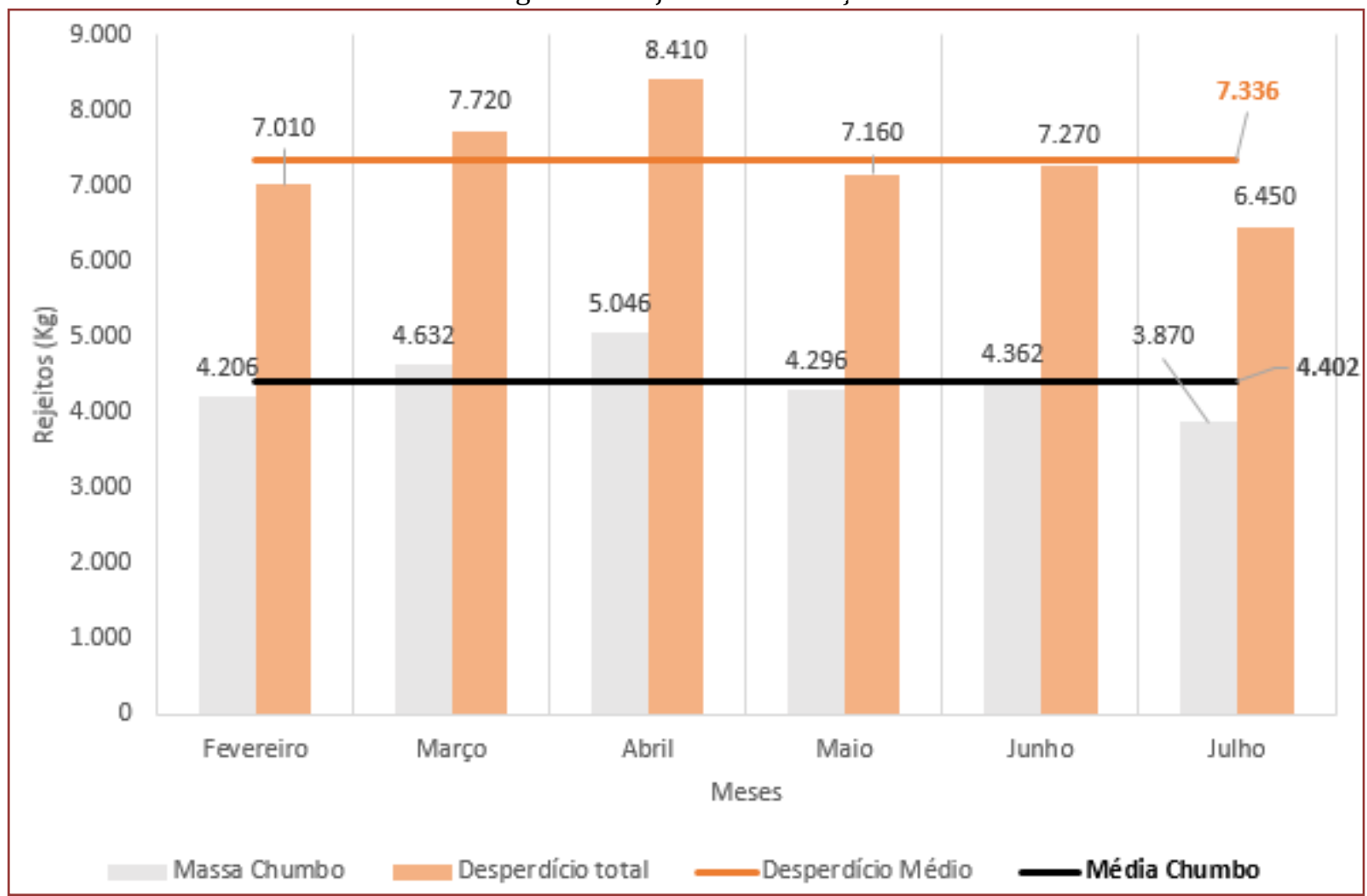

Fonte: Elaborado pelos autores (2020)

Analisando estes dados, foi definido como objetivo do DMAIC neste estudo reduzir o desperdício da massa de chumbo que reveste as grades para formar as placas de chumbo produzidas no setor de fundição, onde foi analisado que é um setor de vital importância para o funcionamento da produção e que o tempo de produção de baterias é sensível com relação a produção e perdas deste setor. 0 intuito de reduzir as perdas no setor de fundição é diminuir o tempo de produção das baterias, uma vez que quando ocorre grandes perdas de placas o setor de montagem fica incapacitado de produzir lotes inteiros, assim, atrasando a produção.

\subsection{DMAIC: MEDIR}

Com o setor e o tipo de rejeito definidos, o próximo passo é identificar os principais motivos de perda de massa de chumbo. Para esta fase, foi realizado um acompanhamento do processo de empaste. 0 processo de empaste é um processo contínuo que chega a produzir até 25.000 (vinte e cinco mil) placas em um dia. A perda de massa ocorre a cada placa produzida, que possui um tempo de empaste de aproximadamente 2 segundos por placa. 0 acompanhamento da formação de rejeitos no equipamento de empaste aconteceu por três semanas, uma vez por dia.

A coleta dos dados foi feita de maneira aleatória e foi realizada com o auxílio do operador do equipamento. Por dia, foram coletadas um total de 24 (vinte e quatro) amostras dentro de um período de uma hora. Com 
os dados coletados foi construído gráfico de controle Xbarra - R (Média e Amplitude) das perdas no processo. Para avaliar o efeito da variabilidade ao longo do processo, os dados foram agrupados em subgrupos racionais de tamanho $r=8$, resultando em 3 amostras por dia.

Analisando os gráficos na Figura 5, é possível observar que a perda média de massa de chumbo é de aproximadamente 22g por amostra, e seguindo as orientações de Montgomery (2001), pode-se concluir que o processo está fora de controle, devido ao ponto acima do Limite Superior de Controle, na amostra 15 do gráfico $\mathrm{R}$, indicando a presença de causas especiais. Além disso, pode-se observar um comportamento aleatório, variando de maneira inconstante ao longo do processo, apresentando: i) 2 pontos acima de 3 desvios padrão a partir da lista central, entre as amostra 10 e 12, e ii) 10 pontos consecutivos no mesmo lado da linha central, entre as amostras 13 e 21. Segundo Montgomery (2001), estas características também indicam que o processo está fora de controle.

Figura 5 - Gráfico de Controle Xbarra - R das perdas no processo de empaste
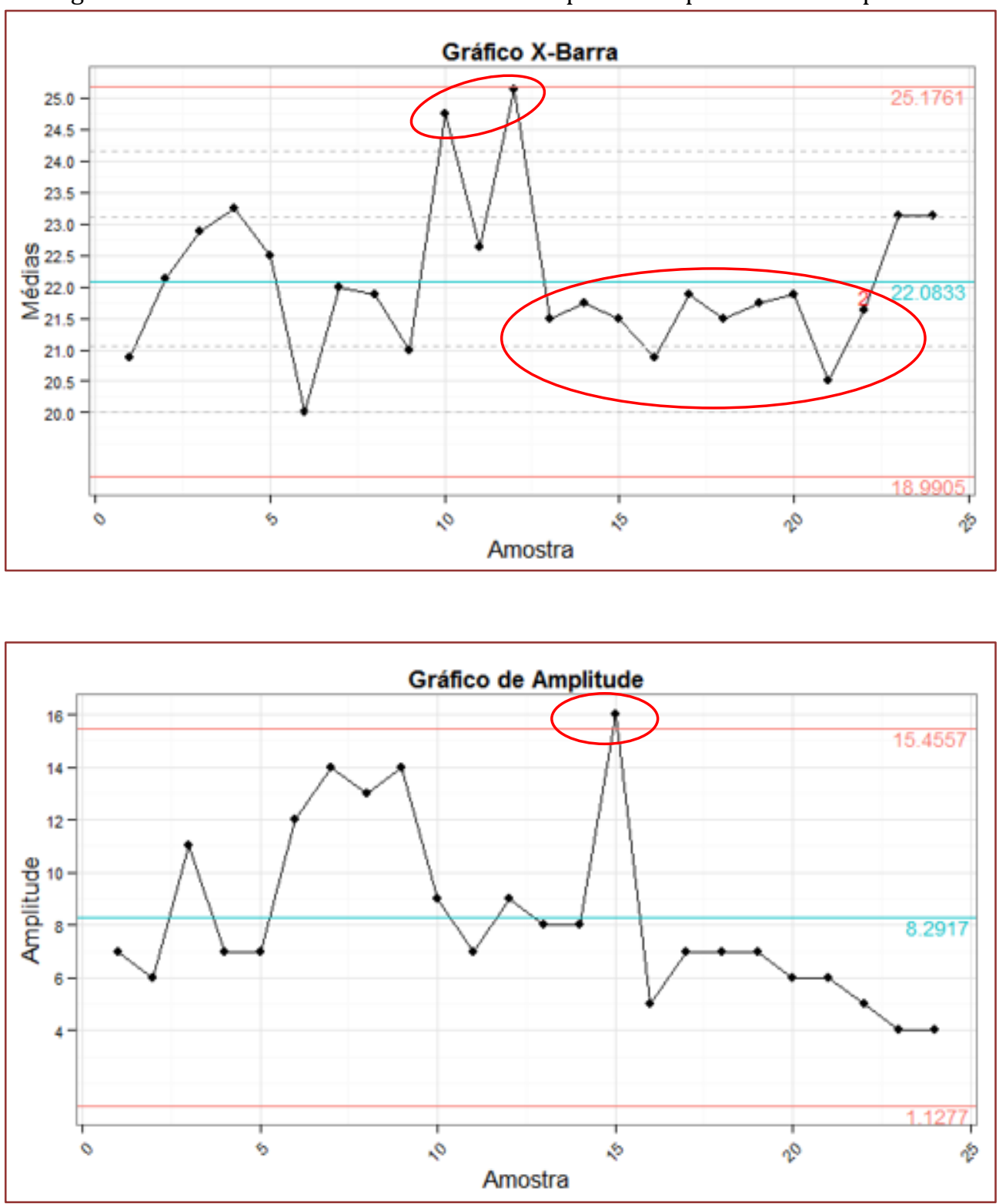

A partir da identificação do volume de perdas, foram elaboradas algumas estratégias de solução para atacar o problema de desperdício de massa de chumbo. 


\subsection{DMAIC: ANALISAR}

Considerando como referência a placa da bateria de carro, são utilizadas 88g de massa. Comparando-se com a perda média do processo, significa que a cada 4 segundos de produção, é perdido massa suficiente para se produzir uma placa, representando um grande desperdício dentro da empresa.

Atualmente, a bateria mais produzida é a bateria de $60 \mathrm{Ah}$ (Ampère-hora), que precisa de 54 placas de chumbo, sendo 30 placas positivas (ânodos) e 24 negativas (cátodos). Portanto, uma bateria de 60 Ah tem em média $4.752 \mathrm{~g}$ de placas de chumbo. Neste cenário, a cada 3,6 minutos de operação é perdido massa suficiente para se produzir uma bateria de $60 \mathrm{Ah}$. Para identificar as causas de ocorrência deste problema, foi elaborado um diagrama de Ishikawa (Figura 6) para analisar os diversos fatores potenciais, que influenciam os desperdícios e que possam ser modificados com o intuito de reduzir ou anular este problema.

Figura 6 - Diagrama de Ishikawa

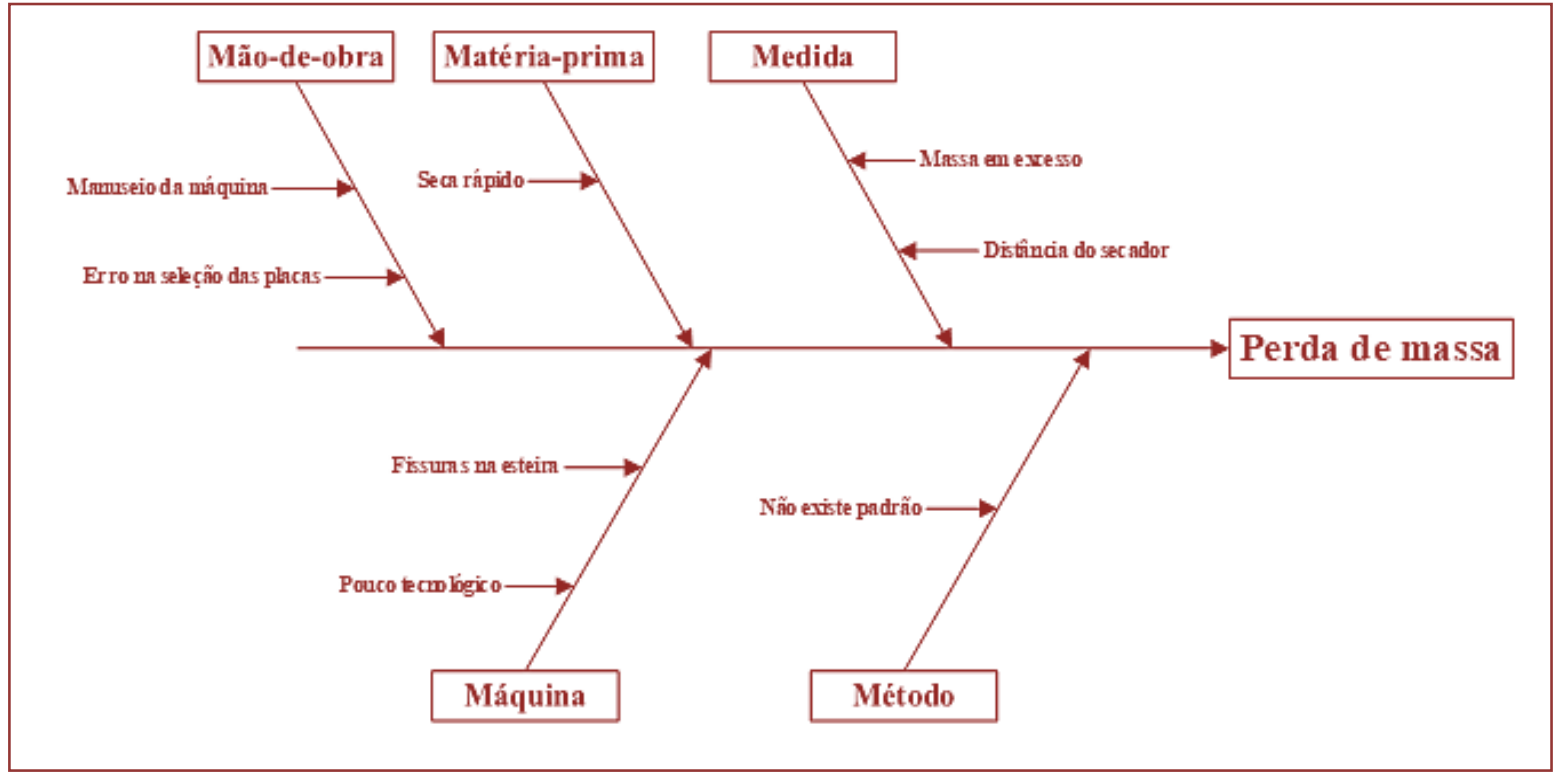

Fonte: Elaborado pelos autores (2020)

Como análise dos problemas enfrentados pelo setor e levando em consideração a dificuldade e outras características que possam impedir uma modificação para a melhora da situação atual da produção, foi selecionado como foco para análise as fissuras na esteira, pois, em observação direta da máquina observou-se que estes danos no equipamento pode estar influenciando significativamente na perda de massa de chumbo.

\subsection{DMAIC: MELHORAR}

A etapa "Melhorar" focou em elaborar possíveis formas de solução da causa anteriormente selecionado: fissuras na esteira. Estas fissuras têm como objetivo a retirada da massa em excesso das placas, para evitar que essa massa em excesso grude uma placa na outra, dificultando a separação das mesmas e ocasionando uma perda ainda maior.

Devido às fissuras serem parte do processo de produção, não pode ser feita a sua eliminação, podendo acarretar perdas maiores no processo e um atraso ainda maior na produção. Essas fissuras descartam a massa embaixo do maquinário, que acabam secando e se tornando inutilizável no processo, sendo considerada rejeito.

Com base nesse cenário, foram propostas duas soluções, levando em consideração o prazo para implementação. As soluções propostas foram nomeadas em: (1) curto prazo; e (2) médio prazo, sendo detalhadas abaixo.

A solução (1) de curto prazo consiste em acoplar um recipiente de forma fixa, abaixo das fissuras do equipamento, de modo que evite que a massa caia no chão da indústria. Esse recipiente tem uma abertura 
para que o funcionário tenha acesso rápido a matéria prima. Assim, é possível retornar a massa para a produção sem a necessidade de retrabalho. A implementação dessa solução pode ser imediata, pois os custos são baixos e objetiva evitar essa perda exagerada de massa.

A solução (2) de médio prazo consiste na instalação de uma esteira abaixo das fissuras, que faria a coleta da massa de chumbo e retornaria para o início do processo. A esteira funcionaria com a mesma fonte de energia (motor) da máquina. Neste caso, o operador da máquina precisa ficar atento também à esteira para evitar problemas com as paradas de máquina, pois pode acontecer da massa petrificar na esteira, causando um risco para o equipamento. Para a implantação da solução de médio prazo, necessita-se da análise de outras áreas da empresa, para analisar a viabilidade e a possibilidade de implementação da esteira.

\subsection{DMAIC: CONTROLAR}

Como a estratégia de curto prazo é um método de simples implementação e de baixo custo, foi possível implementar a solução proposta, utilizando um recipiente já existente na empresa, que foi acoplado à máquina. Para realizar a análise comparativa, o objetivo inicial era coletar a repetir a mesma estratégia de amostragem realizada na etapa "Medir", com 192 dados. No entanto, devido as questões organizacionais, foi coletada uma amostra diária, durante 10 dias (amostra $n=10$ ). Com os dados coletados, foi construído gráfico de controle para Valores Individuais e Amplitude Móvel (X - MR). Analisando os gráficos de controle apresentados na Figura 7 é possível observar que perda de massa de chumbo reduziu para um valor médio de 7,25 por processo de empaste. Além disso, os gráficos mostram que o processo está sob controle estatístico, apresentando apenas causas comuns de variação.

Figura 7 - Gráfico de controle X-MR para a perda do processo de empaste, após a implementação de melhoria

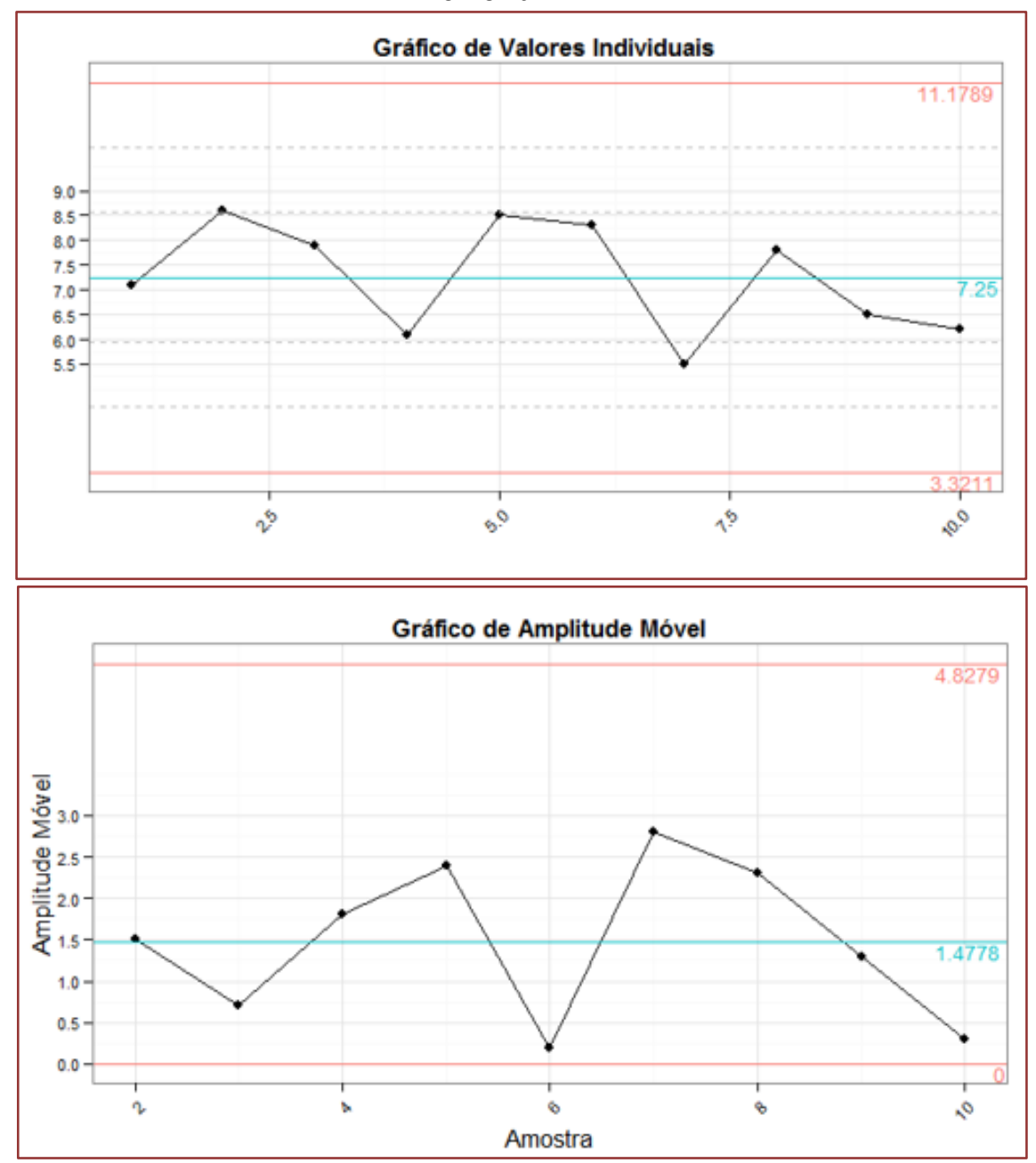

Fonte: Elaborado pelos autores (2020) 
Para que esta ação de melhoria seja efetiva ao longo do tempo, é necessário que haja a capacitação dos operadores para que sejam capazes de verificar se a massa tem condições de ser reaproveitada, ou já está seca, sendo classificada como rejeito. Essa análise é importante porque se houver massa seca no equipamento de empaste, ela pode ocasionar o entupimento do bocal do maquinário, podendo parar a produção por longos períodos e podendo ocasionar até a perda da máquina.

\section{DISCUSSÃO DOS RESULTADOS}

Os resultados mostram que a ação de implementar um dispositivo simples, como um recipiente coletor de massa, foi capaz de melhorar o processo, reduzindo a perda média de $22 \mathrm{~g}$ para 7,25 por processo de empaste, correspondendo a uma melhoria de $67 \%$ no rendimento do processo. Considerando um dia de alta produção, onde o processo de empaste funciona por 4,5h, a perda de massa era suficiente para produzir 75 baterias de 60Ah. Com a melhoria implementada, esta perda caiu para 23 baterias por dia.

As perdas de chumbo no processo de empaste, antes da instalação do recipiente coletor estavam elevadas e o processo apresentava causas especiais de variação. Após a implementação do recipiente coletor, os gráficos de controle mostraram, além da redução da perda média, que o processo se encontra sob controle estatístico. Esta condição sugere que perda atual de chumbo é causada por variações normais do processo, ou seja, para reduzir ainda mais as perdas seria necessário mudança no patamar da operação.

A estratégia de médio e longo prazo, necessita de uma análise melhor por parte da empresa, pois esta estratégia demanda de um investimento financeiro maior, além de necessitar da aprovação de diversos setores que são afetados pelo desempenho do empaste. Estes motivos tornam a aplicação mais complexa e demorada se comparada com a solução de curto prazo.

Apesar dos dados coletados, após a implementação da melhoria, serem limitados é possível analisar em termos estatísticos os ganhos obtidos. Para isto foram realizados dois testes de hipótese: i) teste " $t$ " para duas médias não-emparelhadas, considerado desvio-padrão populacional desconhecido e ii) teste " $F$ " para duas variâncias. Os testes apresentados na Tabela 2 foram realizados considerando um nível de significância de $5 \%$.

Analisando-se os resultados apresentados na Tabela 2, pode-se concluir que há evidências estatísticas para concluir que média de perda de chumbo no processo de empaste mudou com, devido ao p-valor menor que 0,05. De modo análogo pode-se concluir também que existem evidências para rejeitar $\mathrm{H}_{0}$, no teste "F", indicando que houve também uma mudança associada a variabilidade do processo.

Tabela 2 - Testes de Hipótese para o processo de empaste

\begin{tabular}{|c|c|c|c|}
\hline \multirow{2}{*}{ Média } & Hipóteses & p-valor & Resultado \\
\cline { 2 - 2 } & $\mathrm{H} 0=$ médias iguais & 0,0000 & \multirow{2}{*}{ Rejeita-se H0 } \\
\hline \multirow{2}{*}{ Variância } & $\mathrm{H} 0=$ mariân diferentes & \multirow{2}{*}{0,00184} & \multirow{2}{*}{ Rejeita-se H0 } \\
\cline { 2 - 2 } & $\mathrm{H} 1=$ variâncias diferentes & & \\
\hline
\end{tabular}

Fonte: Elaborado pelos autores (2020)

Em relação as análises realizadas, é importante observar que, os dados coletados mostram o potencial de aumento no rendimento do processo de empaste, sendo necessário a coleta de mais dados, após a implementação da melhoria, para que as análises estatísticas tenham maior confiabilidade.

É importante observar também a necessidade de capacitação dos operadores para análise da massa de chumbo que cai no recipiente. 0 operador deve ser capaz de identificar seu estado de secagem, para decidir se a massa pode retornar para o processo ou será descartada como rejeito. Essa análise é importante porque se houver massa seca no equipamento de empaste, ela pode ocasionar o entupimento do bocal do maquinário, podendo parar a produção por longos períodos e podendo ocasionar até a perda da máquina.

Por fim, destaca-se que o DMAIC é um método de melhoria contínua que considera uma abordagem quantitativa e objetiva nas suas etapas, diferenciando-o de outras abordagens como PDCA e o MASP. No entanto, permanecem escolhas subjetivas, como levantamento das possíveis causas para as perdas do processo na construção do Digrama de Ishikawa. 


\section{CONSIDERAÇÕES FINAIS}

O presente trabalho apresentou um estudo empírico de aplicação do DMAIC para reduzir as perdas de matéria-prima em um processo de fabricação de baterias automotivas, visando aumentar o rendimento do sistema produtivo. A aplicação do método mostrou que é a perda de chumbo na etapa de empaste era o principal responsável pelas perdas, tanto de material (chumbo), como também na produtividade global do processo de produção das baterias.

Foram propostas duas estratégias de solução: uma de curto prazo, para contenção do problema (implementada) e uma de longo prazo (proposta). A solução de curto prazo resultou em uma redução de aproximadamente $67 \%$ do desperdício da massa de chumbo. Com isso, a produção de baterias foi aumentada em $69 \%$ por dia, passando de uma perda de 75 para 23 baterias.

Isso permitiu a empresa acelerar sua produção de baterias e reduzir seus gastos com os acordos de entregas e parcerias com clientes.

A partir dos resultados é possível concluir que a metodologia DMAIC foi eficaz em sua aplicação no estudo, trazendo um consequente aumento na produtividade da indústria e se mostrando uma ferramenta útil para compreensão de problemas complexos.

\section{REFERÊNCIAS}

[1] ANDRADE, ESTÊVÃO. ABREU, MARIA L. SILVA, TEODOTO. CUNHA, VITALINA. Ferramentas da qualidade. 2012. (No prelo).

[2] CARPINETTI, LUIZ CESAR RIBEIRO. Gestão da Qualidade: Conceitos e técnicas. 3. ed. São Paulo: Atlas Ltda, 2017.

[3] CASTRO, BERNARDO H. RIBEIRO DE. BARROS, DANIEL CHIARI. VEIGA, SUZANA GONZAGA DA. Baterias automotivas: panorama da indústria no Brasil, as novas tecnologias e como os veículos elétricos podem transformar o mercado global. BNDES setorial. Rio de janeiro, n. 37, mar. 2013. Disponível em:< http://web.bndes.gov.br/bib/jspui/handle/1408/1511 >. Acesso em: 10 abr 2019.

[4] COUTINHO, MARCELO N. S. Aplicação do método DMAIC no processo de pintura de uma linha de montagem de ônibus. 113 f. Dissertação (pós-graduação em Engenharia mecânica) - Universidade federal de Santa Catarina, Florianópolis, 2011.

[5] HARRY, M.; SCHROEDER, R. Six Sigma: the breakthrough management strategy revolutionizing the world's top corporations. New York: 2000.

[6] KRAHEMBUHL, CARLOS E. Z. Aplicação do método DMAIC no gerenciamento de inventário. 168 f. Dissertação (Mestrado em Engenharia Mecânica) - Universidade Estadual de Campinas, Campinas, 2005.

[7] LINS, BERNARDO F. E. Ferramentas básicas da qualidade. Brasília, 1993.

[8] LONGO, GUILHERME C. Ferramentas e técnicas da qualidade. 2011. Artigo de treinamento.

[9] MONTGOMERY, D. C. Introdução ao Controle Estatístico da Qualidade. Rio de Janeiro: LTC, 2016. 572 p.

[10] PEREIRA, J. A.; BÁNKUTI, S. M. S. Estrutura de Mercado e Estratégia: um Estudo na Indústria Brasileira de Baterias Automotivas. Revista Ibero-Americana de Estratégia, v. 15, n. 1, p. 97-115, 2016.

[11] SELEME, ROBSON. STADLER, HUMBERTO. Controle da qualidade: As ferramentas essenciais. Curitiba: Ibpex, 2012.

[12] WERKEMA, Maria Cristina Catarino. Criando a cultura seis sigma. Belo Horizonte: Werkema, 2010. 253 p. 


\section{Capítulo 15}

Synergy in the management of the civil construction industry: Applicability PDCA and DMAIC

\section{Ana Celia Vidolin \\ Cezar Augusto Romano \\ Fernando Leonel Cuzzuol}

Abstract: Despite the construction industry, but all other economic sectors, managerial synergy plays an essential role in assertive and cohesive strategic management. However, in the construction industry, given the segmentation and interdependence of production processes, the volume of associated data, and the multiplicity of stakeholders, this factor is even more necessary. Synergy also contributes to the integration of the organization's sectors and the development of best practices, with sustainable growth. A company can gain prominent positions in the competitive market; if you have ordering and internal connections, to structure your processes more efficiently. This article investigates the application of the PDCA and DMAIC tools in the civil construction industry as promoting synergy in this business segment. As a method, an applied, exploratory and qualitative research was developed. In terms of results, it was found that the tools contribute to the correction, standardization, and management of processes to achieve organizational goals. PDCA and DMAIC tools continually stimulate continuous process improvement, ensuring the competitiveness of organizations in the increasingly demanding market. The fundamental understanding of PDCA and DMAIC are positive aspects and generate relevant conclusions to support decision-making.

Keywords: management, construction, efficiency, PDCA, DMAIC 


\section{INTRODUCTION}

Synergy in any business segment, be it industry or service provision, is always a prominent factor. The construction industry segment also requires its managers to reflect and seek synergy; because it is necessary to maintain management and achieve better results. The deployment of management metrics affects all areas of the company, whether in administrative or operational terms and the construction industry's case, the construction site. As a reflection of cohesion in management, reaching defined goals in the work's execution tends to be more productive. With the management scenario understood, the construction industry manager can add tools such as PDCA and DMAIC to support the investigation of problems and the correct decision-making to resolve or even extinguish them.

It is a recurring practice in other business segments, bringing measurable quantitative and qualitative contributions, and in the construction industry segment, it is equally relevant. Organizations continuously seek their activities for which they have set themselves to achieve various objectives, including full customer service, and better financial performance. When applying continuous improvement tools on the construction site, problems are analyzed, and solutions are sought. When issues are resolved, inputs such as materials, labor, equipment, among others, are used in a reasoned manner, becoming the achievement of financial projections. The increase in competition between organizations active in the productive environment of civil construction requires the organization to act more strategically to guarantee its position in the market. According to Porter $(1999$, p. 22), the intensity of competition in an industry is not a matter of coincidence or bad luck [...] competition in an industry is rooted in its fundamental economic structure".

\subsection{FORMULATION OF THE PROBLEM SITUATION}

According to CBIC (2020) - Brazilian Chamber of the Construction Industry - The construction industry sector in Brazil, in the period 2010 to 2019, presented different behaviors in terms of growth and recession. In the period from 2010 to 2013, the sector showed growth rates; however, in the period from 2014 to 2018, the sector suffered a decrease in growth. Upon reaching 2019, the sector managed to end the period with a mild signal of growth. Soon it appears that the financial condition of companies in the sector in the country, in general, has experienced alternating moments of fluidity and market retraction, and that indicates a resumption of growth, with improvement in the sectorial growth rates.

Thus, whether due to economic aspects intrinsic or extrinsic to the organization, market circumstances in the sector, technology conditions and or projects, the construction industry, through management, must seek synergy or increase it.

At the construction site is the location of the civil construction production process, where value is added. In the same way, it is at the construction site that materials and operations are wasted, which contribute financial and time commitments to the evolution of the construction stages, among others. According to Vrijhoef and Koskela (2000), inefficiency in the construction industry is related to weak or lack of management and commitment among participants. Thus, based on these conceptions, the following hypotheses are formulated:

a) Hypothesis I: Applying tools such as PDCA and DMAIC, offer analysis with methodology and underpin quality decision making.

b) Hypothesis II: identify how the synergy in management can be achieved by applying the PDCA and DMAIC tools.

A problem with its origin identified and its dynamics understood, there is the resolution with an increase in the quality of the organization's management, subsidizing synergy, and integration. This article aims to observe how the synergy in the construction industry can be achieved using PDCA and DMAIC tools in a production process. 


\section{LITERATURE REVIEW}

\subsection{BUSINESS MANAGEMENT IN THE CONSTRUCTION INDUSTRY}

Business management is essential in all business segments. The construction industry still suffers from the project's poor performance because the nature of the work is fragmented between different stakeholders and different sub-processes, forming a network that is difficult to integrate with the view of the multiple communication channels involved.

In the construction industry activity, one must understand, quantify, visualize, and simulate the components that affect construction work. There is a need for a conceptual framework to reflect on the variables that influence the construction business (DEMIRKESEN and OZORHON, 2017).

An essential aspect in terms of management is stakeholder satisfaction, as Kagioglou et al. (2001) emphasize that stakeholder satisfaction is directly associated with performance management in construction. And for Demirkesen and Ozorhon (2017), the construction industry is challenging when compared to other companies in terms of its dynamic, fragmented, and complex nature. It requires the involvement of different parties and the successful management of processes, with the development of well-defined strategies and practices to deal with uncertainties and risks. Cost and schedule variations can reduce customer satisfaction and compromise the project's product.

For Alaloul et al. (2020), the construction industry is reluctant to adopt innovative concepts, and some complications contribute to incompatibility. Within this scope, Alaloul et al. (2016), Oesterreich and Teuteberg (2016), corroborate, stating that the construction industry has complexity, uncertainty, fragmented supply chain, low efficiency, short-term thinking and challenging to manage culture, in contrast to others. Industries.

For Oesterreich and Teuteberg (2016), construction projects are complicated due to the involvement of many stakeholders in a single project. A project's uncertainty is also considered by its unpredictable environment, adding complications to the project. According to Alaloul et al. (2016), this group of characteristics is the cause of the tenuous performance faced by the sector. Thus, effective action is necessary for the success of construction projects, to reduce the dilemmas encountered and the reluctant behavior in the face of changes.

According to Saraf et al. (2007), the integration of information with customers and business partners leads to better knowledge sharing, resulting in improvements in the performance of civil construction. Berteaux and Javernick Will (2015) highlight the organizational integration of knowledge, process, and strategy, informing that organizational integration improves the project's performance. The improvement occurs through the resources developed in previous projects and innovations throughout the organization, helping the organization remain competitive.

Demirkesen and Ozorhon (2017), reinforce the idea that the integration of knowledge and processes improves the performance of the project and the organization. As the conceptualization and the effective planning of the projects are crucial, the combination appears as a critical component in the adequate coordination of the projects.

For Okonkwo and Mbachu (2015), currently, the critical objectives of the construction industry are to complete a project within a stipulated period, scope and budget, through standardization of processes and efficient use of resources. However, most construction companies face little customer satisfaction due to the non-completion of the job, according to the required standard and specification.

And according to Smetkowska and Mrugalska (2018), there is intense pressure on the organization to improve customer satisfaction and quality. The organization needs to reduce inefficiency, errors, winning and retaining customers; therefore, all different conceptions, methods, and tools must be used to maintain and quality and assist in continuous development in the company.

\subsection{PDCA}

The continuous improvement cycle or PDCA cycle aims to identify and organize tasks in a problem-solving process, a method of controlling activities (Campos, 2004; Lobo, 2010). Campos (2004) contributes that the PDCA Cycle (fig. 1) has four phases: planning, execution, verification, and corrective action. For planning, control items and goals and ways to achieve them are defined, and performance is responsible for the practices. With the data in hand, it compares with the goals, and these actions make up the verification. Finally, the identified deviations are treated with corrective actions. 
Figure 1 Cycle PDCA

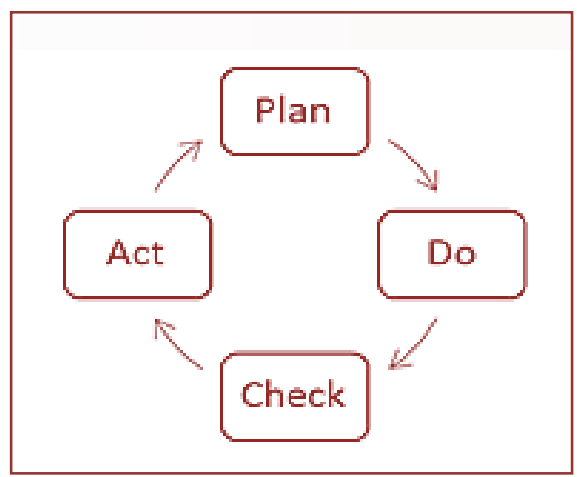

Source: The Authors (2020)

According to Dennis (2008), understanding the GTS situation (Grasping the situation) is the baseline activity for each PDCA stage. The GTS is about understanding a problem, covering the following aspects: understanding the whole situation; issues that require in-depth investigation; what happens; what should be happening; current trends and likely trends to occur in the future and how the case or item relates to the organization's values and goals.

In the same way, the PDCA Cycle is a management method for promoting continuous improvement. By reflecting based on the philosophy of constant improvement it ensures the achievement of goals for the survival of an organization. Consolidates standardization, if practiced cyclically and uninterruptedly in the organization (Marshall Junior et al. 2003; Vieira, 2014; Vieira Filho, 2019).

A process can be controlled through the PDCA cycle, and for its operationalization tools and means may be required for the collection, processing, and disposal of data. For Vieira Filho (2019), with the PDCA Cycle two types of goals.

A process can be controlled through the PDCA cycle, and for its operationalization tools and means may be required for the collection, processing, and disposal of data. For Vieira Filho (2019), with the PDCA Cycle, two types of goals can be achieved: i) goals for maintenance - standard goals: they provide predictability for the organization; and ii) goals for improvement - bring competitiveness to the organization.

According to Campos (2004) and Aguiar (2006), with the PDCA the organization has in its routine the attention focused on the production of goods and services, according to the standard operating procedures (POP) of the organization; the items that guide control are quality, quantity, and cost. The application of the PDCA Cycle while maintaining the process concerns a repetitive cycle and has a goal with an acceptable range of values (Campos, 2004).

When using the PDCA Cycle in the analysis of a problem, practice the structured methodology, avoiding decision making without reasoning and costs. The PDCA conducts the correct approach to problems, standardized continuous improvement, and generation of opportunities.

\subsection{DMAIC}

For Cogan (2012), DMAIC is an approach of the Six Sigma Quality program, which has, as its essence, the systematic of improving existing processes, such as those that are below specifications, to achieve incremental improvement. The DMAIC is represented by a cycle of steps (fig.2), which in addition to supporting a Six Sigma project, also requires the application of quality management tools and revitalized statistical means. 
Figure 2 Cycle DMAIC

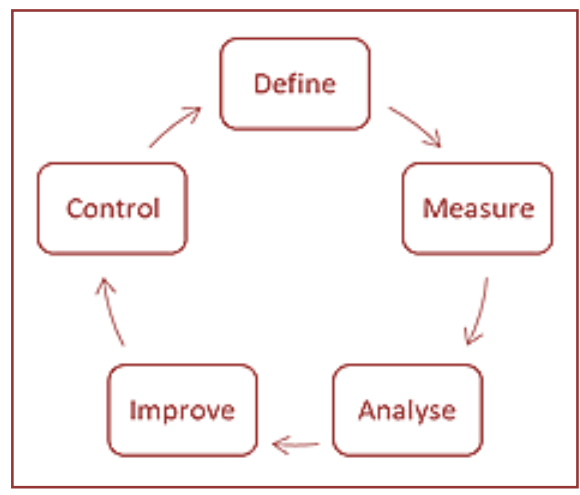

Fonte: Os Autores (2020)

According to Slack et al. (2013), Toledo et al. (2017), the DMAIC cycle begins with defining a problem or problems to meet the scope of the demand and defining the process improvement. This item is critical for quality under the analysis of the client. At this stage, it is customary to list an objective for development. The subsequent phase is of great importance because it is the measurement, and following the Six Sigma guidelines, the measures must contain accurate data from the selected processes.

The validation of this defining phase's problem is done from data refinement; you must also make sure that it is essential to solving this problem. Analyzing is the next phase of the cycle, which consists in developing hypotheses related to the problem that generate non-conformities through analysis of the process performance; whether or not they can be validated; and the first initial causes of the question under review are listed (SLACK et al., 2013; TOLEDO et al., 2017).

According to Slack et al. (2013); Toledo et al. (2017), with the identification of the real causes, actions to improve the process are into practice, with ideas to solve the problem, tests of solutions are made; the option with the best result being implemented. It is the characterization of the phase defined as improving.

With the improvement put in place, the control and monitoring phase of the recently changed process is initiated, and the limits established as acceptable are followed (SLACK et al., 2013; TOLEDO et al., 2017).

And Slack et al. (2013), highlight that the last stage in the PDCA and DMAIC Cycles represents that the cycle starts again, that is, it is to admit that in the philosophy of continuous improvement, these cycles never stop. In this way, development is part of everyone's process within the organization.

\section{RESEARCH METHOD}

To achieve the objective of identifying whether the PDCA and DMAIC tools contribute to synergy in the construction industry, applied, exploratory and qualitative research was developed. The qualitative approach for Oliveira (2010) allows the presentation of reviews, detailed descriptions of facts, and observed phenomena; being applied when information on a specific subject cannot be quantified; making the necessary interpretation (Triviños, 1987). The organization of the phases of this research employed here is shown in figure. 3 :

This bibliographic research is based on the survey of theoretical references published in physical and electronic media related to the procedures. The analysis of the data that assisted this research refers to the bibliographic, qualitative research, based on information that cannot be quantified; consequently, the interpretation is applied. The search for bibliographic material with exploratory research carried out based on Scopus and Google Scholar, was guided by the chosen keywords: PDCA, DMAIC, management in civil construction. Then, the first analysis was with the technical documents, and the second the elaboration of their interpretation and the elements under investigation. In the evaluations of the themes, it was possible to elaborate on considerations about the relationship: these aspects and their reflexes, cause, and effect relationships on managing an organization. 
Fig. 3 Etapas da pesquisa

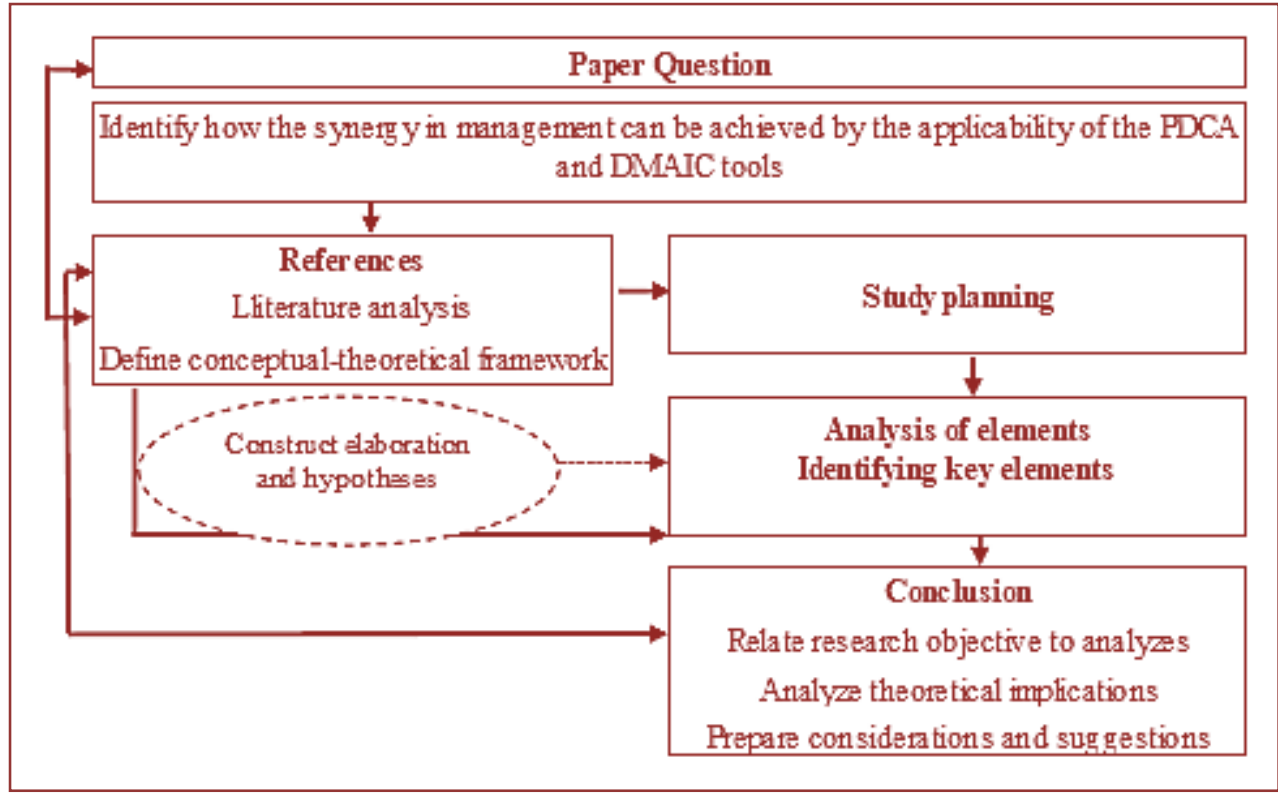

Source: The authors (2020)

\section{ANALYSIS AND RESULTS}

As discussed at the beginning of this article, two hypotheses represent the questions regarding synergy in the management of the construction industry. Thus, the hypotheses guided the research and analysis.

Top management is responsible for managing the improvement, which is related to the strategic level and focuses on organizational effectiveness. Routine management is under the responsibility of employees and seeks the organization's efficiency, applying the execution of the defined work standards to avoid changes that compromise the defined quality levels.

Hypothesis I: the application of tools such as PDCA and DMAIC can offer analysis with methodology and support quality decision making.

With the premises presented throughout this article, one can relate PDCA and DMAIC (table 1) and values that can be practiced by the organization:

Table 2 Relation PDCA and DMAIC

\begin{tabular}{|c|c|c|c|c|}
\hline Action steps & PDCA & Values & DMAIC & Action steps \\
\hline \multirow{3}{*}{$\begin{array}{l}\text { Define the problem } \\
\text { Split the problem } \\
\text { Analyze the root } \\
\text { cause } \\
\text { Establish } \\
\text { countermeasures }\end{array}$} & \multirow[b]{3}{*}{ Plan } & \multirow{6}{*}{$\begin{array}{l}\text { 1. Customer-first } \\
\text { 2. Define the purpose of the work } \\
\text { 3. Responsibility } \\
\text { 4. Confront the problem } \\
\text { 5. Judge facts } \\
\text { 6. Think and act without giving up } \\
\text { 7. Moving fast at the right time } \\
\text { 8. Follow processes with sincerity } \\
\text { 9.Comment } \\
\text { 10. Communication } \\
\text { 11.Involving all parties involved }\end{array}$} & Define & Define problem \\
\hline & & & Measure & Measure performance \\
\hline & & & Analyse & $\begin{array}{l}\text { Identify the cause of } \\
\text { process variation. } \\
\text { Identify the variable } \\
\text { for improvement }\end{array}$ \\
\hline $\begin{array}{l}\text { Implement } \\
\text { countermeasures }\end{array}$ & Do & & Improve & $\begin{array}{l}\text { Perform tests and } \\
\text { implement } \\
\text { improvements }\end{array}$ \\
\hline $\begin{array}{l}\text { Monitors results and } \\
\text { processes }\end{array}$ & Check & & & Control with \\
\hline $\begin{array}{l}\text { Standardize } \\
\text { successful processes }\end{array}$ & Act & & & $\begin{array}{l}\text { acceptable data } \\
\text { tracking limits }\end{array}$ \\
\hline
\end{tabular}

Source: Toledo et al. (p. 323, 2017) modified; Liker, Ross, (2018, p. 33), modified 
Steps and actions are equivalent in the PDCA and DMAIC tools, and they aim for the same values for the organization. It must be considered that PDCA and DMAIC are models of improvement cycles, with different characteristics and approaches, and seek to increase synergy in management, through the continuous mode of a sequence without ending analysis and action.

Thus, when analyzing Hypothesis I, the PDCA and DMAIC tools can offer elements that can be interpreted in qualitative and quantitative terms in the analysis of themes or situations in the construction industry. These elements, metrics corroborate with the organization's management, in strategic planning and strategy, respectively. They contribute to process control of the improvement and in the management of the complexity of the construction industry. There is a contribution to the maintenance of the procedures to reach the goals of the organization.

Hypothesis II: identify how management synergy can be achieved by applying the PDCA and DMAIC tools.

An organization that has collaboration, cohesion among its employees, is concerned with improving its processes and activities is driving synergy internally, which will result in good results for the organization itself.

For answering hypothesis II, synergy can be achieved by applying the PDCA and DMAIC tools, as their attributes are complete to improve their company processes. The analyzes of the PDCA and DMAIC show the congruencies and purposes as they are complementary, have the same goal of continuous improvement in operations, and consequently synergy in management. Table 2 presents some of these characteristics:

Table 3 Characteristics PDCA and DMAIC

\begin{tabular}{|l|l|l|}
\hline \multicolumn{2}{|c|}{ Tool } & \multicolumn{2}{c|}{ DDCA } \\
& Speed up and perfect tasks & Increase in processes and quality in the \\
Aspects & Identify the root cause of problems & organization \\
& Perfect controls & Enhance activities and products \\
& Integrate production steps & Guide the company to success \\
& Everyone's commitment & Offer excellent customer services \\
& Continuous process improvement & Rationally employ resources \\
\hline
\end{tabular}

Source: The Authors (2020)

The characteristics presented in Table 2, confirm that the PDCA and DMAIC tools are not antagonistic, and can even be understood as complementary to each other. Another important aspect is that the improvement cycle provides the organization with standardization processes, avoiding changes and changes as each professional, so wishes and or does so.

According to Dennis (2008), one should practice the systemic view; the standardization of work has its essential aspects such as stability in the process, organizational learning; Problems solution, employee involvement, and process improvement.

Equally relevant is the sharing of information between partners and customers and the efficient use of resources and attention to stakeholders. In this way, goals are achieved with continuous improvement, strengthening the position and the competitive condition of the business.

When applying the PDCA and DMAIC tools, there is problem-solving and standardization of operations. The regularity of the process is kept within the acceptable limits established, and maintaining these conditions; synergy is achieved in the organization. The standardization of processes and products translates synergy. The activities are carried out in a defined manner, with quality, quantity, costs, and deadline established. Another considerable aspect is the elimination or maximum reduction of rework, losses of material, time, and labor in the production process of civil construction, which contributes to the organization's economic profitability.

With the elements analyzed here from PDCA and DMAIC, there is a consolidation of attributes that positively contribute to the synergy in the construction industry. These tools do not require sophisticated elements to practice; they do need managers' decision to seek and implement ways to find improvement in the productive processes of the construction industry. Every effort and dedication in this regard is rewarded with an increase in the organization's indicators, a better strategic posture making the organization more competitive. 
It should be noted that PDCA and DMAIC do not directly represent innovation because innovation has the fundamental characteristic of being or denoting a radical and or extensive change. For a better understanding of the attributes of innovation and continuous improvement, Table 3 presents them briefly:

Table 3 Comparation innovation and continuos improvement

\begin{tabular}{|l|l|l|}
\hline \multicolumn{2}{|c|}{ Characteristics } & \multicolumn{1}{c|}{ Innovation } \\
Efect & Short and drastic dealine & $\begin{array}{l}\text { Long term, long-lasting, without being } \\
\text { radical }\end{array}$ \\
\hline Step & Big steps & Small steps \\
\hline Schedule & Intermittent and non-incremental & Continuous and incremental \\
\hline Change & Abrupt and volatile & Gradual and constant \\
\hline Involvement & Select some champions & All \\
\hline Approach & $\begin{array}{l}\text { Individualism, ideias and individual } \\
\text { efforts }\end{array}$ & $\begin{array}{l}\text { Colletivism, group efforts, system } \\
\text { approach }\end{array}$ \\
\hline Stimulus & $\begin{array}{l}\text { Technological innovation, new } \\
\text { intentions and theories }\end{array}$ & Conventional knowledge and art stay \\
\hline Risk & Focused & Scatterd \\
\hline Practical needs & $\begin{array}{l}\text { Requires large investment, but little } \\
\text { maintenance effort }\end{array}$ & $\begin{array}{l}\text { Requires little investment, but excelent } \\
\text { maintenance effort }\end{array}$ \\
\hline Effort guidelines & Technology & People \\
\hline Evaluation criteria & Results for profit & Process and effect to improve results \\
\hline
\end{tabular}

Source: Slack et al. (2013, p.470), modified

\section{CONCLUSION AND OUTLOOK}

With the diagnoses prepared here under the prism of using the PDCA and DMAIC for quality decision making in the construction industry, it is decided that these easily understood tools bring significant analytical elements to the synergy of the construction industry construction. The practice of continuous improvement, in an incremental way, offers the organization the approach from the group perspective, acting as a facilitator of processes, improving results and customer service, and participating stakeholders in the construction industry. However, the application must be accurate, such as the development of employees concerning tools and the implantation of a culture of continuous improvement. Any form of a contribution to development for quality management for the construction industry's organization is valid. Complementary practical studies with analysis of the results of the PDCA and DMAIC tools in the construction industry are recommended.

\section{REFERENCES}

[1] AGUIAR, Silvio. Integração das Ferramentas da Qualidade ao PDCA e ao Programa Seis Sigma. Nova Lima: INDG Tecnologia e Serviços Ltda., 2006.

[2] ALALOUL, Wesan Salah; LIEW, Mohd Shahir; ZAWAWI, Noor Amila B.Wan Abdullah. A Framework for Coordination Process into Construction Projects. MATEC Web of Conferences 66, 00079. DOI: 10.1051/matecconf/20166 IBCC 2016 600079.2016.

[3] ALALOUL, Wesan Salah; LIEW, Mohd Shahir; ZAWAWI, Noor Amila B.Wan Abdullah; KENNEDY, Ickx Baldwin. Industrial Revolution 4.0 in the construction industry: Challenges and opportunities for stakeholders. Ain Shams Engineering Journal. Vol 11, issue 1, March 2020. Page 225-230. doi.org/10.1016/J.ASEJ.2019.08.010.

[4] BERTEAUX, Florence, JAVERNICK-WILLl, Amy, Adaptation and integration for multinational project-based organizations. Journal of Management in Engineering. Eng. 31 (6), 04015008. 2015.

[5] CAMPOS, Vicente. Falconi. TQC- Controle da Qualidade Total (no estilo japonês) Nova Lima- MG; INDG Tecnologia e Serviços Ltda, 2004.

[6] CBIC. Câmara Brasileira da Indústria da Construção. Número de estabelecimentos na construção civil, 2020. Disponível em: <http://www.cbicdados.com.br/menu/indicadores-economicos-gerais/boletim-estatistico>. Acesso em: 18 abr 2020.

[7] COGAN, Samuel. Gestão pelos números certos: uma novela sobre a transformação da contabilidade gerencial para as empresas lean. Porto Alegre: Bookman, 2012.

[8] DENNIS, Pascal. Produção Lean Simplificada.Porto Alegre: Bookman, 2008. 
[9] DEMIRKESEN, Sevilay; OZORHON, Beliz. Impact of integration management on construction project management. International Journal of Project Management 35 1639-1654.2017. 2017.

[10] KAGIOGLOU, Michail, COOPER, Rachel, AOUAD, Ghassan, Performance management in construction: a conceptual framework. Construction Management and Economics. 19 (1), 85-95. 2001.

[11] LIKER, Jeffrey K.; ROSS, Karyn. O modelo Toyota de excelência em serviços: a transformação lean nas organizações de serviço. Porto Alegre: Bookman, 2018.

[12] LOBO, Renato Nogueira. Gestão da Qualidade. 1aed. São Paulo: Érica.2010.

[13] MARSHALL JUNIOR, Isnard. CIERCO, Agilberto Alves; ROCHA, Alexandre Varanda; MOTA, Edmarson Bacelar; LEUSNIK, Pieter Jan. Gestão de Qualidade. 2ª ed. Rio de Janeiro: Editora FGV. 2003.

[14] OKONKWO, Odinaka V.; MBACHU, Victor M. A comparative analysis of application of six sigma project management technique in small and medium scale construction companies in Nigeria. European Journal of Engineering and Technology. Vol. 3 No. 3,74-87.2015.

[15] OESTERREICH, Thuy Duong; TEUTEBERG, Frank. Understanding the implications of digitisation and automation in the context of Industry 4.0: A triangulation approach and elements of a research agenda for the construction industry. Computers in Industry,83, p.121-139. DOI10.1016/j.compind.2016.09.006. 2016.

[16] OLIVEIRA, Maria Marly de. Como fazer pesquisa qualitativa. 3.ed. Rio de Janeiro: Vozes.2010.

[17] PORTER, Michael. E. Estratégia competitiva: técnicas para análise de industrias e da concorrência. 8. ed.). Rio de Janeiro: Campus.1994.

[18] SARAF, Nilesh, LANGDON, Christoph Schlueter, GOSAIN, Sanjay.IS application capabilities and relational value in interfirm partnerships. Information Systems Research. 18 (3), 320-339, 2017.

[19] SLACK, Nigel; CHAMBERS, Stuart; JOHNSTON, Robert; BETTS, Alan. Gerenciamento de Operações e de Processos: princípios e práticas de impacto estratégico. Porto Alegre: Bookman, 2013.

[20] SMETKOWSKA, Monika; MRUGALSKA, Beata. Using Six Sigma DMAIC to improve the quality of the production process: a case study. SIM 2017/14th International Symposium in Management. Procedia- Social and Behavioral Sciences 238 (590-596). 2018.

[21] TOLEDO, José Carlos; BORRÁS, Miguel Ángel A.; MERGULHÃO, Ricardo Coser; MENDES, Glauco H.S. Qualidade: gestão de métodos. Rio de Janeiro: LTC, 2017.

[22] TRIVIÑOS, Augusto Nibaldo Silva. Introdução à pesquisa em ciências sociais: a pesquisa qualitativa em educação. São Paulo: Atlas.1987.

[23] VIEIRA, Sonia. Estatística para a qualidade.Rio de Janeiro: Editora Elsevier. 2014

[24] VIEIRA FILHO, Geraldo. Gestão da Qualidade Total: uma abordagem prática. Campinas: Editora Alínea, 2019.

[25] VRIJHOEF Ruben; KOSKELA, Lauri. The four holes of supply chain management in construction. European Journal of Purchasing \&Supply Management, vol. 6, pp 169-178, 2000. 


\section{Capítulo 16}

Tipos de polímeros utilizados como materia prima no método de manufatura aditiva por FDM: Uma abordagem conceitual

\section{Luana Machado dos Santos}

Daniela Sousa Guedes Meirelles Rocha

Marcos Lajovic Carneiro

Marta Pereira da Luz.

Resumo: 0 artigo apresenta uma abordagem conceitual dos vários tipos de polímeros que podem ser utilizados na Manufatura Aditiva com a tecnologia de Modelagem por Fusão e Deposição (FDM). Esta pesquisa inclui a analise de termoplásticos para a produção de peças resistentes, duráveis e dimensionalmente estáveis com a melhor precisão e repetibilidade. Os artigos estudados demonstram os efeitos da química e da estrutura dos polímeros, especialmente em relação a seus usos em impressoras 3D do tipo FDM. Os resultados da pesquisa apresentam cinco tipos de polímeros indicados na produção com impressoras 3D: Acrilonitrila Butadieno Estireno; Poli Ácido Lático; Polietileno de Alta Densidade; Polipropileno; e, Politereflato de Etileno.

Palavras-chave: Polímeros. Matéria Prima. Impressora FDM. 


\section{INTRODUÇÃO}

Devido às inovações tecnológicas para agregar valor no processo produtivo, muitas empresas estão atentas às mudanças do mercado, com isso, vê-se a crescente busca à tecnologia de impressão 3D, que vem se destacando por mudar a metodologia de fabricação de produtos. Também conhecida como prototipagem rápida, ela abrange uma ampla variedade de tecnologias de produção que são utilizadas para produção de protótipos e peças finais, por meio de um Computer Aided Design (CAD), realizando impressões, camada por camada, desenvolvendo uma forma final por meio de processos de adição de material (FORD E DESPEISSE, 2016; HUANG, LIU, MOKASDAR, 2013; OSEJOS, 2016; STEPHENS et al., 2013).

Para o estudo e reflexão deste tema, este artigo procura apresentar uma perspectiva a partir de levantamento bibliográfico a respeito da variedade de polímeros que podem ser utilizados na MA com a tecnologia Modelagem por Fusão e Deposição (FDM) até o momento, a fim de fornecer uma contribuição ao estado da arte, a partir de pesquisas de artigos científicos que trataram do tema.

\section{MANUFATURA ADITIVA POR EXTRUSÃO}

A Manufatura Aditiva (MA) é considerada uma das mais importantes inovações tecnológicas dos últimos anos por oferecer a oportunidade de criar objetos complexos e com a redução do lead time. Essas características têm permitido a substituição de algumas técnicas utilizadas na manufatura tradicional (DILBEROGLU et al., 2017 FORD E DESPEISSE, 2016; HAO et al., 2010; KOHTALA, 2015; MANI, LYONS E GUPTA, 2014). Com isso, a MA apresenta diversas vantagens em relação a sua aplicação, a fim de impactar e superar os desafios encontrados pela manufatura tradicional, como por exemplo: o custo, os problemas de qualidade, a limitação de material, a complexidade das peças, dentre outros desafios encontrados (MANÇANARES, 2016).

O que diferencia as tecnologias na MA são os aspectos físicos quanto ao tipo de método e a matéria prima utilizada. Por outro lado, o aspecto computacional é relativamente semelhante para todos os processos disponíveis da MA. Quanto ao seu desenvolvimento, é composto por 8 etapas para construção do modelo conforme é mostrado na Figura 1 (MARTINS et al., 2010; GIBSON, ROSEN, STUCKER 2010; GIORDANO, 2012; RAULINO et al., 2013; VOLPATO et al., 2017).

Figura 1. Etapas dos processos de MA

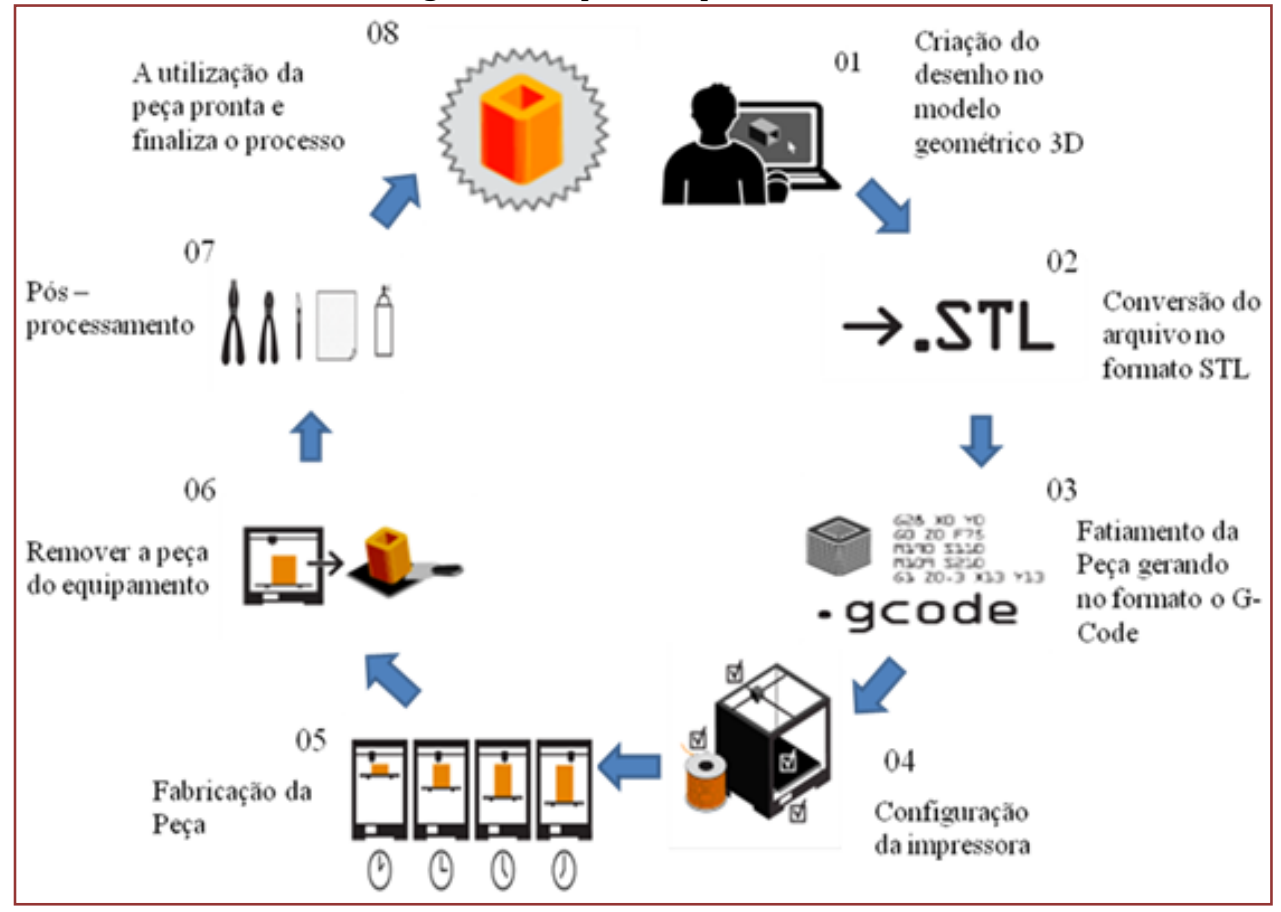

Fonte: Autoras (2018) 
0 processo de MA é composto pelas seguintes etapas, apresentadas pela Figura 1, de forma sintetizada:

- $\quad 1$ o etapa: criação de um desenho com o auxilio de um software CAD;

- 2o etapa: conversão do desenho em 3D para o formato de um arquivo STL (abreviatura proveniente do termo Stereolithography);

- $\quad 3$ o etapa: transferência do arquivo STL para outro software para realizar o fatiamento de toda a peça, mostrando como será realizada a impressão camada por camada. Assim determina-se, por exemplo, a espessura da camada, dentre outros parâmetros do objeto que será impresso. Além disso, delimita a velocidade para realizar a impressão e qual o tipo de insumo que será utilizado gerando o arquivo $G$-Code;

- 4o etapa: preparação da impressora caso haja necessidade de realizar a calibração do equipamento;

- $\quad 5^{0}$ etapa: construção do objeto em um processo automatizado, ou seja, o momento da impressão da peça;

- $\quad$ 6⿳亠口冋 etapa: remoção da peça do equipamento quando a mesma se solta da mesa com a redução da temperatura;

- $\quad$ 70 etapa: retirada de suportes que foram impressos;

- $\quad$ 8o etapa: utilização da peça na aplicação final.

A FDM é uma das técnicas mais utilizadas para fabricação de protótipos através do método de extrusão de polímeros, desenvolvida em 1988, patenteada e comercializada em 1992 pela empresa Stratasy ${ }^{\circledR}($ GIBSON, ROSEN, STUCKER, 2010; VOLPATO et al., 2017).

Esta impressora é composta por um cabeçote extrusor que se movimenta no plano horizontal no eixo X e Y, depositando o filamento derretido que passa pelo processo de extrusão sobre a plataforma aquecida que se desloca para baixo, representando assim o eixo Z. 0 material derretido que é depositado na camada vai aderindo em cima da outra camada, desta forma o processo vai imprimindo a peça até o final. A matéria prima utilizada é um filamento de material termoplástico que encontra-se em uma bobina, este é puxado por um parafuso trator e é aquecido por um resistor ligado a uma câmara de alumínio que o faz o polímero atingir o estado pastoso, e com isso inicia o processo de extrusão com o objetivo de empurrar o material através do bico (PEREIRA, 2014; VOLPATO et al., 2017).

Segundo Huang et al. (2013), Pereira (2014), Picesoftware (2014), Osejos (2016) e Volpato et al. (2017), esta tecnologia possui algumas vantagens como à facilidade da troca de insumos a serem utilizados na impressora. Outros benefícios são a redução de desperdício de material que utiliza apenas o necessário durante o processo de fabricação, bem como a facilidade na remoção manual de objeto quando há necessidade, além de possuir um baixo custo. Ainda, segundos os autores citados, a FDM também possui suas desvantagens como: a lentidão em relação aos demais tipos de impressoras; a complexidade de determinadas peças pode necessitar da inclusão de estruturas de suporte e gerar desperdício de matéria prima, além disso, a velocidade da impressão é restrita pela taxa de extrusão.

\section{POLÍMEROS UTILIZADOS COMO MATÉRIA PRIMA NA FDM}

A FDM utiliza como matéria prima os polímeros termoplásticos na forma de filamentos enrolados em uma bobina. Os polímeros termoplásticos são compostos por cadeia de moléculas, as quais quando submetidas a elevadas temperaturas tomam determinadas formas que são estabilizadas em temperatura ambiente. Verifica-se a possibilidade de serem moldados diversas vezes. Assim, realiza-se o processo de reciclagem devido às características do material que é flexível e resistente (PARENTE, 2006; SANTOS, 2006; HAMOD, 2014).

Os polímeros termoplásticos são compostos por duas fases, dependendo do grau de intermoleculares: a estrutura amorfa que é responsável pelas propriedades elásticas dos materiais, e a estrutura cristalina responsável pelas propriedades mecânicas de resistência ao impacto, bem como às altas e baixas temperaturas (HAMOD, 2014). 
Entre os materiais mais utilizados neste processo são: Acrilonitrila Butadieno Estireno (ABS), Poli Ácido Lático (PLA) e Nylon (BORAH, 2014). Outrora, estudos apresentam autores como Hausman e Horne (2014), Hunt et al. (2015), Kreiger et al. (2014) e Horvath e Cameron (2015) que pesquisaram outros tipos de polímeros que podem ser usados para impressão em 3D, como: Politereflato de Etileno (PET), Polietileno de Alta Densidade (PEAD), Polipropileno (PP), Poliestireno (PS), Policarbonato (PC). Este estudo aborda cinco dos principais tipos o ABS, o PLA, o PEAD, o PP e o PET mostrando as características da propriedade mecânica e a temperatura de extrusão para realizar a impressão da peça.

\subsection{ACRILONITRILA BUTADIENO ESTIRENO - ABS}

O polímero ABS é um tipo de plástico composto de petróleo formado por três diferentes monômeros: o Acrilonitrila que oferece uma boa resistência química e térmica, uma ótima durabilidade e possui estabilidade quando em altas temperaturas; o Butadieno que oferece uma boa resistência quanto ao impacto; e o Estireno que tem uma ótima resistência mecânica, facilidade para ser processado, um ótimo brilho e um material rígido e de fácil manuseio, com isso a partir desta junção forma-se um único polímero ABS (HAMOD 2014; ALBURQUERQUE, 2014; OSEJOS, 2016).

Este polímero é aplicado em diversas áreas da indústria, como eletrodomésticos, peças automotivas, brinquedos, matéria prima para impressoras 3D, dentre outras aplicações podendo ser processados por moldagem de injeção, extrusão, sopro (HAMOD, 2014; SANTANA, 2015; HORVATH e CAMERON, 2015).

0 filamento de ABS é um dos polímeros mais utilizados na MA devido suas propriedades mecânicas, por serem flexíveis e resistentes. As peças impressas com este material podem ser lixadas, coladas e pintados oferecendo um ótimo acabamento final do objeto (SALINAS, 2014).

Segundo Hamod (2014), a temperatura de derretimento sugerida para este material é aproximadamente entre 230 a $250^{\circ} \mathrm{C}$ e a temperatura da base aquecida da impressora 3D entre 80 à $110^{\circ} \mathrm{C}$. Por outro lado, Regadas (2017) apresenta em seu estudo que a temperatura para o inicio de extrusão é 185 a 235ํ․ Já Steinle (2016) aborda que a temperatura necessária para imprimir é de $240^{\circ} \mathrm{C}$. Entretanto, Osejos (2016) descreve que o processo de extrusão deve ser feito entre $220-260^{\circ} \mathrm{C}$.

0 material ABS pode ser produzido dentro de diversas faixas de variação de seus sub componentes, portanto, é natural que este material, quando proveniente de diferentes fabricantes, apresente distintos pontos ideais de temperatura para a sua extrusão. Outro fator que provoca variação no valor ideal de temperatura depende do tipo de cabeçote de impressão, da distância entre o elemento sensor e o elemento de aquecimento na extrusora, dentre outras características geométricas dos elementos do equipamento de extrusão (OSEJOS, 2016).

\subsection{POLI ÁCIDO LÁTICO - PLA}

O PLA é uns dos polímeros pertencentes à família de termoplásticos, o qual possui uma característica semicristalina ou amorfa. Este é um material biodegradável e sua composição é feita pela extração do milho, trigo ou cana de açúcar passando por várias etapas de produção. Por ser uma fonte renovável é extremamente vantajoso no quesito sustentável em relação a degradação na natureza, o tempo para sua decomposição é em média de 6 a 24 meses (LIM et al., 2008; BRITO, 2012; HAMOD, 2014, VINK et al., 2004; HORVATH e CAMERON, 2015; OSEJOS, 2016).

De acordo com os estudos apresentados por Soares (2012), Bijarimi (2012) e Osejos (2016) desperta-se muito interesse devido as suas propriedades mecânicas biodegradáveis, rigidas, resistentes e aptas para moldar peças no processo de extrusão, injeção, dentre outros tipos. Além disso, é um tipo de polímero encontrado em diversos lugares como, por exemplo: embalagens alimentícias, cosméticas, canetas, tampas, copos, bandejas, dispositivos médicos e filamentos de impressão 3D.

Os filamentos de PLA são considerados os insumos mais fáceis para trabalhar no processo da MA. Segundo Hamod (2014) e Matterhackers (2013) mostraram que a impressora do tipo FDM utiliza este material, mas precisa da mesa estar pré-aquecida com a temperatura de $70^{\circ} \mathrm{C}$ e o ponto de extrusão entre 160 a $220^{\circ}$ C. Não obstante, o estudo de Osejos (2016) e Pastor (2013) abordaram que a temperatura de extrusão pode alterar devido à cor do polímero. 


\subsection{POLIETILENO DE ALTA DENSIDADE - PEAD}

Polietileno (PE) é um material composto por uma cadeia de átomos de carbono ligados a átomos de hidrogênio. É um material que possui duas fases: a cristalina sob a integridade estrutural; e a amorfa com as propriedades de flexibilidade. O PE tem como principal característica o baixo custo, além de possuir uma boa resistência química, ser flexível e de fácil manuseio (CHENG, 2008).

De acordo com Hamod (2014), o PEAD é considerado um dos melhores plásticos devido a suas propriedades mecânicas, sendo resistente aos impactos e as altas temperaturas. Este material pode ser utilizado em garrafas de detergentes, bandejas, cosméticos, caixas de alimentos, peças automotivas, tampas de garrafas e filamentos para impressora 3D.

O filamento com o polímero PEAD ainda não é muito utilizado nas impressoras 3D, e não existem ainda muitos estudos que falam sobre esta aplicabilidade. Segundo Novoa (2014), é viável a utilização deste material na impressora do tipo FDM, e o ponto de extrusão fica entre 160 a $260^{\circ} \mathrm{C}$. Bastian (2012) apresenta em seu estudo que a mesa precisa estar aquecida em $70^{\circ} \mathrm{C}$ e o ponto de extrusão em $230^{\circ} \mathrm{C}$.

\subsection{POLIPROPILENO - PP}

Polipropileno (PP) é composto por átomos de carbono e hidrogênio que possui características como um polímero semicristalino, e possui uma baixa densidade, baixo custo, e é um material rígido resistente à impactos e altas temperaturas, e fácil para ser moldado (VOLPONI, 2002; SANTOS, 2006; ARAUJO, 2010).

Este polímero pode ser encontrado em diversos tipos de embalagens de alimentos, peças automotivas, placas de produtos eletrônicos e filamentos para impressora 3D (BRITISH PLASTICS FEDERATION, 2018).

O filamento com polímero PP é outro insumo que apresentam poucas pesquisas em relação a sua aplicabilidade deste na MA. Segundo Gelhausen et al. (2018), o PP possui uma melhor qualidade na impressão 3D, devido a sua característica, por ser um polímero resistente à altas temperaturas de fusão entre 205 e $215^{\circ} \mathrm{C}$, e a temperatura da mesa em aproximadamente $90^{\circ} \mathrm{C}$. $\mathrm{O}$ estudo abordado por Harada (2004) e Filament e Print (2018) abordaram que a temperatura de processamento ideal é 200 a $220^{\circ} \mathrm{C}$, e a temperatura da mesa é de 30 a $70^{\circ} \mathrm{C}$.

\subsection{POLITEREFLATO DE ETILENO - PET}

Polietileno Tereflalato (PET) é formado por reações de ácido tereftálico e o etileno glicol, sendo composto por suas fases amorfo e cristalino, e possui uma boa propriedade mecânica. Sendo um material que suporta altas resistências quanto ao impacto, é resistente a altas temperaturas, boa transparência, estabilidade dimensional, facilidade no manuseio, isolando até mesmo odores do produto. É um dos termoplásticos mais produzidos no mundo, devido as suas propriedades mecânicas, térmicas e o baixo custo (ISOLDI, 2003; ROMÃO, SPINACE, DE PAOLI, 2009; REGADAS, 2017).

Podem ser encontrados em diversos objetos como garrafas de bebidas, chapas, telhas e filamentos para manufatura aditiva. Apesar de que é uma matéria prima não muito utilizada nesta tecnologia (PARENTE, 2006; REGADAS, 2017).

Segundo Locker (2018) mostrou que é a temperatura de extrusão ideal é de 245 o C e a temperatura da mesa aquecida é de $70^{\circ} \mathrm{C}$; pode ser realizada a reciclagem deste material, inclusive com as impressões que foram detectadas falhas. Já a pesquisa de Regadas (2017), apresentou que a temperatura de extrusão é de 210 a $220^{\circ} \mathrm{C}$, e a temperatura de base é 20 a $65^{\circ} \mathrm{C}$.

\section{CONSIDERAÇõES}

A pesquisa visou apresentar vários tipos de polímeros que podem ser utilizados na MA com a tecnologia FDM, demonstrou-se que os polímeros podem ser divididos em duas categorias: termoplásticos e termofixos. Os termoplásticos são polímeros que, após a formação, podem ser fundidos e formados novamente (p. Ex.polietileno). Termofixos são polímeros que uma vez formados não podem ser derretidos e reformados. 
Na utilização dos cinco tipos de polimeros, nota-se que as impressoras 3D ao escolher um polímero termoplástico para usar em uma tecnologia do tipo FDM, existem muitas propriedades de polímeros que podem contribuir para a qualidade da impressão da peça e as propriedades resultantes da peças impressas. A temperatura de fusão afetará a temperatura na qual a extrusora precisa estar para imprimir o polímero. Mais estudos devem ser desenvolvidos no intutito de subsidiar mais informaçoes sobre as propriedades desses polímeros.

\section{AGRADECIMENTOS}

Agradeço a CAPES pelo incentivo, reconhecimento e apoio ao desenvolvimento de projetos de pesquisa científica.

\section{REFERÊNCIAS}

[1] ALBURQUERQUE, Alberto Juan. Optimización y caracterización de piezas de PLA fabricadas mediante técnicas aditivas. 2014. 138 f. TCC- Curso de Ingeniería en Tecnologías Industriales, Departamento de Ciencia e Ingeniería de Materiales e Ingeniería Química, Universidade Carlos III de Madrid, Madri, 2014.

[2] ARAÚJO, Jorge Francisco; VOLPATO, Neri; DE CAMARGO BELTRÃO, Paulo André. Estudo de propriedades mecânicas do polipropileno moldado por injeção em insertos de resinas. 2010. Tese de Doutorado. Dissertação de Mestrado, Programa de Pós-Graduação em Engenharia Mecânica e de Materiais, UTFPR. Manaus, 2010.

[3] BASTIAN, Andreas. A device to recycle thermoplastics for applications in 3D printing. 2012. Disponível: < http://andreasbastian.com/Ember-1> Acesso em: 29 de março de 2018.

[4] BIJARIMI, Mohd; AHMAD, Sahrim; RASID, Rozaidi. Mechanical, thermal and morphological properties of PLA/PP melt blends. In: International Conference on Agriculture, Chemical and Environmental Sciences (ICACES 2012). 2012. p. 6-7.

[5] BORAH, Sharmila. 3D printer filament length monitor. International Journal of Science, Technology and Society, v. 2, n. 5, p. 129-132, 2014.

[6] BRITO, Gustavo F.; AGRAWAL, Pankaj; ARAÚJO, Edcleide M.; MELO, Tomás J. A. de. Tenacificação do poli (ácido lático) pela adição do terpolímero (etileno/acrilato de metila/metacrilato de glicidila). Polímeros: Ciência e Tecnologia, v. 22, n. 2, 2012.

[7] BRISTISH, Plastic Federation. Polymer Thermoplastics. 2018 Disponível: <http://www.bpf.co.uk/plastipedia/polymers/polymerthermoplastics.aspx\#polyesters> Acesso em: 12 de abril de 2018.

[8] CHEN, D.; HEYER S.; IBBOTSON, S.; SALONITIS, K.; STEINGRÍMSSON, J.G.; THIEDE, S. Direct Digital Manufacturing: Definition, Evolution, and Sustainability Implications, Journal of Cleaner Production, 2005. doi: 10.1016/j.jclepro.2015.05.009

[9] DILBEROGLU, UM; GHAREHPAGAH, B; YAMAN, U; DOLEN, M. The role of additive manufacturing in the era of Industry 4.0. Procedia Manufacturing, v.11, p.545-554, 2017.

[10] FILAMENT 2 PRINT. Polipropileno Preto. Disponível em: https://filament2print.com/pt/pppolipropileno/742-pp-polipropileno-preto.html Acesso em: 01 de abril de 2018.

[11] FORD, S.; DESPEISSE, M. Additive manufacturing and sustainability: an exploratory study of the advantages and challenges. Journal of Cleaner Production, v. 137, p. 1573-1587, 2016.

[12] GELHAUSEN, M. G.; FEUERBACH, T.; SCHUBERT, A.; AGAR, D. W. 3D-printing for chemical process laboratories I: materials and connection principles. Chemical Engineering \& Technology, vol. 41, no 3, 2018.

[13] GIBSON, I.; ROSEN, D.W.; STUCKER, B. Additive Manufacturing Technologies: Rapid Prototyping to Direct Digital Manufacturing. Springer, 2010.

[14] GIORDANO, Veronica. La Finitura Superficiale in Fused Modeling. 2012. Tese de Doutorado - Sapienza Università di Roma, Roma, 2012.

[15] HAMOD, Haruna. Suitability of Recycled HDPE for 3D printing filament. 2014. Degree Thesis - Degree Program: Plastics Technology, Arcada University of Applied Science, Finlandia, 2014

[16] HAO, L; RAYMOND, D; STRANO, G; DADBAKHSH, S. Enhancing the Sustainability of Additive Manufacturing. ICRM - Green Manufacturing, 2010.

[17] HARADA, Júlio. Moldes para injeção de termoplásticos: projetos e princípios básicos. Artliber, 2004. 
[18] HAUSMAN, K. K; HORNE, R. 3D printing for dummies. John Wiley \& Sons, 2017.

[19] HORVATH, Joan; CAMERON, Rich. 3D printing with mattercontrol. Apress, 2015.

[20] HOSSAIN, M. S.; RAMOS, J.; ESPALIN, D.; PEREZ, M.; WICKER, R. Improving tensile mechanical properties of FDM - Manufactured specimens via modifying build parameters. In.: International Solid Freeform Fabrication Symposium: An Additive Manufacturing Conference. Austin, TX., v. 2013, p.380 - 392.

[21] HUANG, SH; LIU, P; MOKASDAR, A; HOU, L. Additive manufacturing and its societal impact: a literature review. International Journal Advanced Manufacturing Technology, vol. 67, no 5- 8, p. 1191-1203, 2013.

[22] HUNT, E. J.; ZHANG, C.; ANZALONE, N.; PEARCE, J. M. Polymer recycling codes for distributed manufacturing with 3-D printers. Resources, Conservation and Recycling, v. 97, p. 24-30, 2015.

[23] ISOLDI, Ana Beatriz Godoy; SILVA, Leonardo Gondim de Adrande e. Estudo do Efeito da Dose de Radioesterilização sobre as Propriedades do Poli (Tereftalato de Etileno)-PET-Reciclado. Revista Brasileira de Pesquisa e Desenvolvimento, 2003.

[24] KOHTALA, Cindy. Addressing sustainability in research on distributed production: an integrated literature review. Journal of Cleaner Production, v. 106, p. 654-668, 2015.

[25] KREIGER, M. A.; MULDER, M. L.; GLOVER, A. G.; PEARCE, Joshua M. Life cycle analysis of distributed recycling of post-consumer high density polyethylene for 3-D printing filament. Journal of Cleaner Production, v. 70, p. 90-96, 2014.

[26] LIM, L. -T; AURAS, R.; RUBINO, M. Processing Technologies for poly (lactic acid). Progress in Polymer Science, v.33, n.8, p.820 - 852, 2008.

[27] LOCKER, Anatol. PETG filament guide 2018: Explaine, compared \& reviewed. All 3 DP, 2018. Disponível: <https://all3dp.com/1/petg-filament-3d-printing/\#section-petg-filament-explained-and-compared> Acesso em: 28 de março de 2018.

[28] MANÇANARES, Cauê Gonçalves. Modelo de processo de avaliação para adoção de manufatura aditiva na indústria de alto valor agregado. 2016. Tese de Doutorado. Universidade de São Paulo, 2016.

[29] MANI, M; LYONS, KW; GUPTA, SK. Sustainability Characterization for Additive Manufacturing. Journal of Research of the National Institute of Standards and Technology, v.119, 2014.

[30] MATTERHACKERS. HOW TO SUCCEED WHEN PRINTING IN PLA. 2013. Disponível em: <https://www.matterhackers.com/articles/how-to-succeed-when-printing-in-pla> Acesso em: 12 de mar. 2018.

[31] MARTINS, Silvio Roberto Montenegro; BRANILSON, Luiz Santos Costa, HERMAN, Augusto Lepikson. Um Sistema CAM Para Máquinas de Prototipagem Rápida de Baixo Custo. In: Congresso Nacional de Engenharia Mecânica, 2010, Campina Grande-PB.

[32] NOVOA, Danny Mesias Cháves. Avaliação físico-química do polietileno de alta densidade processado pelo método de impressão 3D por modelagem por fusão e deposição FDM. 2014. Tese de Doutorado. PUC-Rio.

[33] OSEJOS, Jaime Vinicio Molina. Caracterización de materiales termoplásticos de ABS y PLA semi-rígido impresos en 3D con cinco mallados internos diferentes. 2016. Dissertação de Mestrado. Quito, 2016.

[34] PARENTE, Ricardo Alves. Elementos estruturais de plástico reciclado. Dissertação de Mestrado. Universidade de São Paulo, São Carlos, 2006.

[35] PASTOR, AA Relaño; GARCÍA, J. Hidalgo. Estudio comparativo de piezas de abs y pla procesadas mediante modelado por deposición fundida. Proyecto Fin de Carrera. Departamento de Ciencia e Ingeniería de los materiales e Ingeniería Química, Universidad Carlos II de Madrid, Madrid, España, 2013.

[36] PEREIRA, Frederico David Alencar de Senal. Desenvolvimento de um cabeçote para extrusão de filamento fundido aplicado a manufatura aditiva. 2014. Dissertação de Mestrado, Campinas, 2014.

[37] PICESOFTWARE. Impresoras 3D el futuro hoy. Obtenido de impresoras 3D el futuro hoy. Disponível: <http://pice-software.com/DetalleBlog.aspx?b=\%2018. Acesso em: 10 de março de 2018.

[38] RAULINO, Bruno Ribeiro; ALVARES, José Alberto; FERREIRA, João Carlos Ferreira. Sistema coação para prototipagem rápida - influência dos parâmetros de fabricação no custo. In: Congresso Brasileiro de Engenharia de Fabricação, 2013, Penedo, Itatiaia - RJ.

[39] REGADAS, Joaquim José Linhares Moreira. Otimização de uma impressora 3D Delta e desenvolvimento da impressão simultânea de 3 cores. Dissertação de Mestrado. Porto, 2017.

[40] ROMÃO, Wanderson; SPINACÉ, Márcia A. A.; PAULI, Marcos - A De. Poli (Tereftalato de Etileno), PET: Uma revisão sobre os processos de síntese, mecanismos de degradação e sua reciclagem. Polímeros, 2009.

[41] SALINAS, Richard. 3D printing with reprap cookbook. Birmingham: Packt Publishing, 2014. 346 p. 
[42] SANTANA, Leonardo. Avaliação de uma impressora 3D baseada em projeto de código aberto na fabricação de peças em PLA. 2015. Dissertação de Mestrado. Florianópolis, 2015.

[43] SANTOS, Alexandre Maneira dos. Estudo de compósitos híbridos polipropileno/fibras de vidro e coco para aplicações em engenharia. 2006. Dissertação de Mestrado. Curitiba, 2006.

[44] SOARES, Fernanda Coutinho. Laminados de Poli(Ácido Láctico)/Amido termoplástico recobertos com quitosana reticulada: obtenção e avaliação das propriedades físico - químicas. 2012. Programa de Pós Graduação em Engenharia de Materiais, Universidade Federal de Santa Catarina, Florianopolis, 2012.

[45] STEINLE, Patrick. Characterization of emissions from a desktop 3D printer and indoor air measurements in office settings. Journal of occupational and environmental hygiene, v. 13, n. 2, p. 121-132, 2016.

[46] STEPHENS, Jennie C.; HERNANDEZ, Maria E.; ROMÁN, Mikael, GRAHAM, Amanda C. Higher education as a change agent for sustainability in different cultures and contexts. International Journal of Sustainability in Higher Education, v. 9, n. 3, p. 317-338, 2008.

[47] VINK, , Erwin TH; RÁBAGO, K. R.; GLASSNER, D. A.; SPRINGS, B.; O'CONNOR, R. P.; KOLSTAD, J.; \& GRUBER, P. R. The sustainability of NatureWorks ${ }^{\mathrm{TM}}$ polylactide polymers and Ingeo ${ }^{\mathrm{TM}}$ polylactide fibers: an update of the future. Macromolecular Bioscience, v. 4, n. 6, p. 551-564, 2004.

[48] VOLPATO, N.; MUNHOZ, A. L., J.; COSTA, C. A.; AHRENS, C. H.; CARVALHO, J. de; SANTOS, J. R. L. dos; SILVA, J. V. L. da; FOGGIATTO, J. A.; LIMA, M. S. F. de. Manufatura Aditiva: Tecnologias e aplicações da impressão 3D. Primeira Edição. São Paulo: Blucher, 2017. 400 p.

[49] VOLPONI, Jose Eduardo. Utilização da Fotocalorimetria Diferencial (DPC) para a avaliação da estabilidade à luz ultravioleta do polipropileno isotático. 2002. Dissertação de Mestrado. Campinas, 2002. 


\section{Capítulo 17}

Análise de um processo de injeção de plástico para implementação das Cartas de Controle de Shewhart por Variáveis

\section{Renan Ryuji Murashita Takenaka}

Emerson José de Paiva

Ana Carolina Oliveira Santos

Tarcisio Gonçalves de Brito

Resumo: As organizações contam, atualmente, com métodos e tecnologias capazes de reduzir variabilidade produtiva visando mitigar ou eliminar desperdícios como retrabalhos, descartes e rejeições. Como resultado disso, diminuem-se os custos de operação tornando possível entregar um produto confiável e de qualidade ao cliente final. Este trabalho tem como objetivo apresentar o controle estatístico de processo como um desses métodos disponíveis. 0 CEP foi implementado em uma indústria de produtos plásticos para irrigação, a fim de agilizar a deteç̧ão de não conformidades no processo. As ferramentas do controle estatístico de processo utilizadas foram as cartas de controle de X-Barra e R, cujo intuito é monitorar a média e amplitude amostrais. Com a aplicação dos conceitos de controle estatístico de processo, constatou-se falta de controle estatístico para o processo investigado, normalmente causada por causas especiais atuantes, as quais exigem maiores investigações de causas raízes para, enfim, planejarem-se e implementarem-se ações corretivas futuras.

Palavras-chave: CEP, Controle estatístico de processo; Cartas de controle por variáveis; Controle da Qualidade. 


\section{INTRODUÇÃO}

O atual cenário competitivo requer das empresas uma constante evolução dos processos produtivos, de forma a diminuir custos e variabilidade produtiva que conferem maiores padrões de qualidade e confiabilidade ao cliente final. A criação de novas tecnologias com essa finalidade, entretanto, proporciona uma crescente quantidade de dados a serem utilizados na tomada de decisão pelos gestores, de acordo com a estratégia estabelecida pela alta direção.

De acordo com Slack, Chambers e Jhonston (2009), um processo capaz de produzir produtos de boa qualidade confere à organização uma vantagem competitiva considerável. Conforme descrito por Oliveira et al. (2020), a capacidade do processo é uma medida amplamente usada em ambientes industriais para avaliar e rastrear o comportamento da variabilidade real do processo em relação à variabilidade desejada, sendo essa última obtida pela produção de itens dentro dos limites de especificação de projeto e próximos a um valor alvo nominal.

0 impacto de uma operação ou produto que não atenda às especificações exigidas remete à variabilidade do processo produtivo acima do especificado em projeto, não conformidades no produto, descartes, geração de retrabalho, rejeições pelo cliente e altos índices de custo da não-qualidade (GALUCH, 2002). A necessidade de reduzir não conformidades, requer a rápida detecção de um desvio produtivo, assim como a elaboração e implementação de ações corretivas para evitar perdas maiores. Neste contexto, o Controle Estatístico de Processo (CEP) se apresenta como ideal para avaliar a variabilidade das operações e identificar momentos em que o sistema tende a ficar fora de controle.

Costa, Epprecht e Carpinetti (2012) afirmam que apesar de uma linha de produção passar ao controlador uma sensação de que todas as unidades são exatamente iguais, isso não é o que realmente ocorre. Em um processo de injeção termoplástica, por exemplo, a cada ciclo que a máquina realiza, verificam-se variações positivas e negativas no valor do peso das peças. 0 CEP aplicado a esse caso, poderia indicar se a produção consegue atingir seu alvo nominal e se essas variações não extrapolariam um valor mínimo aceitável.

Entre as ferramentas do CEP, as Cartas de Controle propostas por Shewhart (1931), definem a variância, a média do processo e os limites superior e inferior que permitem a identificação visual da situação do sistema, tanto em relação à variabilidade do processo, quanto à sua habilidade em se manter produzindo dentro de um alvo estabelecido. Conforme se observa nos trabalhos de LI, ZOU e WHANG (2013), JUANG e YU (2015) e FROST et al. (2013), as Cartas de Controle (ou Gráficos de Controle), desempenham um papel importante no monitoramento de processos em ambientes industriais, manufatura, etc., tendo uma ampla gama de aplicações.

0 processo de injeção plástica é descontínuo, apresentando ciclos de operação sucessivos que consistem em: fechamento do molde, injeção do material termoplástico, recalque, resfriamento, abertura do molde e extração da peça. As peças resultantes devem possuir dimensões, peso e formato conforme definidos no projeto do produto pois são requisitos que afetam diretamente na qualidade final do produto. A confiabilidade do produto está diretamente relacionada à conformidade do produto dentro de valores toleráveis em relação ao projeto.

A constante utilização dos moldes resulta em desgaste no formato do seu interior e influencia diretamente na pressão que o material termoplástico é aplicado a cada uma de suas cavidades. Além disso, variações no clima interferem no processo de injeção pois as máquinas injetoras necessitam de adequações no seu setup de operação para entregar peças conformes.

O estudo em uma indústria de produtos plásticos, localizada no interior do estado de São Paulo, apresenta uma gestão da qualidade com processos simples de medições e inspeções visuais em uma amostra igual à quantidade de peças de um ciclo de injeção de um turno de trabalho de quatro horas, realizando manutenções nas máquinas e moldes apenas quando o sistema já se encontra fora de controle, descartando diversas peças. Visto que a amostra retirada para análise era muito pequena pela quantidade de peças produzidas no turno, essa conferência se torna incapaz de detectar variações do processo ao longo da operação. Além disso, o input da quantidade de peças produzidas e encaminhadas ao estoque é baseado na relação do peso médio unitário da peça em relação ao peso da produção total de um turno e, por isso, variações no processo podem resultar em erros na quantidade inserida no sistema.

Dessa forma, e considerando não se ter conhecimento acerca dos custos da não-qualidade, refugo, retrabalho, reclamações, dentre outros, este trabalho tem o objetivo de diagnosticar o atual processo de fabricação da indústria, quanto à possibilidade de implementação de um controle estatístico de processo, por meio dos gráficos de controle de Shewhart, identificando-se causas especiais e elaborando-se recomendações que permitam a redução na variabilidade produtiva. 
Pelo fato da empresa se configurar como médio porte, o investimento na implementação de métodos e tecnologias é de grande importância na decisão da aprovação de um projeto, favorecendo o uso dos de gráficos de controle que apresenta um baixo custo de investimento e necessitando apenas treinar profissionais a serem responsáveis pela gestão da qualidade da operação.

\section{REFERENCIAL TEÓRICO}

A seguir, serão apresentados os conceitos fundamentais para a implementação do CEP, assim como os assuntos relacionados à elaboração deste trabalho que permite a compreensão dos objetos de estudo.

\subsection{DEFINIÇÃO DE QUALIDADE}

A definição de qualidade é algo incerto entre os estudiosos da área, pois existem diversas abordagens com focos em diferentes requisitos para caracterizar um produto ou serviço de qualidade. Para Juran (1962), a qualidade é resultado de duas diferentes percepções: satisfação dos clientes e conformidade às especificações de projeto.

Devido às mudanças nos padrões da indústria e questões competitivas, adotar técnicas de engenharia de qualidade para um forte suporte de operações tornou-se de extrema importância para manter e sustentar a vantagem competitiva (KUMAR, 2018).

Montgomery (2016) reforça que a qualidade se tornou um importante fator de escolha dos consumidores durante a seleção dos produtos e serviços entre as empresas que competem entre si no mercado.

Uma vez que a definição de qualidade é muito ampla e existem diversas abordagens, Garvin (1987) definiu oito dimensões que influenciam na percepção do cliente em relação a qualidade do produto ou serviço: desempenho, confiabilidade, durabilidade, assistência técnica, estética, características, qualidade percebida e conformidade com as especificações.

A discussão sobre o conceito de qualidade se estende até os dias atuais, porém, entende-se que as definições abordadas acima são diferentes formas de compreender a qualidade e sua importância nas organizações.

\subsection{CONCEITO DE CONTROLE ESTATÍSTICO DE PROCESSO}

Segundo Costa, Epprecht e Carpinetti (2012), todo processo produtivo apresenta variações em suas saídas, por mínima que seja. Entretanto, algumas causas dessas variações estão relacionadas a fatores que não foram identificados em uma análise aprofundada, denominados causas especiais. Uma caixa de leite determina, por exemplo, que a quantidade presente em seu interior é de um litro. Entretanto, é certo dizer que, ao longo da atividade produtiva, a realização de medições do seu conteúdo irá apresentar valores que variam em torno do especificado de $1000 \mathrm{ml}$. Supondo que variações maiores que $5 \mathrm{ml}$ significam a presença de causas especiais, ações corretivas precisam ser implementadas no processo.

O CEP é uma abordagem analítica, tradicionalmente utilizada em monitoramento de processos de manufatura, que emprega as cartas de controle para diferenciar causas aleatórias de especiais, que geram variações em um processo ao longo do tempo (KNAUER et al., 2018). Dessa forma, o CEP tem por finalidade a prevenção de não-conformidades, melhoria na qualidade de produtos e serviços e a redução de custos de operação pela utilização de métodos estatísticos da qualidade.

De acordo com Corrêa e Corrêa (2011), o fundamento do CEP é acompanhar o comportamento das estatísticas de suas saídas, dividindo as causas em aleatórias e especiais, auxiliando na tomada de decisões acerca das ações de correção, assim que uma causa especial for detectada.

Costa, Epprecht e Carpinetti (2012) alegam que os pressupostos para aplicação do CEP são que os dados devem ser normais e independentes, entretanto, a condição de normalidade não é restritiva, enquanto a independência dos valores seja. 


\subsection{CONCEITO DE CARTAS DE CONTROLE}

Montgomery (2016) considera que a carta de controle é uma das ferramentas mais sofisticadas do CEP, baseia-se na teoria da variabilidade de Shewhart, a qual afirma a existência de variações em todos os processos, resultantes da ação de causas aleatórias e especiais. A primeira se refere a ruídos nas operações que determinam pequenas alterações nos valores obtidos nas medições que configura um processo sob controle estatístico se apenas está for atuante no sistema. As causas especiais, por sua vez, estão relacionadas a fatores atuantes na operação de forma anormal e que, portanto, podem ser eliminados do sistema.

A carta de controle monitora o processo e verifica a presença de causas especiais (COSTA, EPPRECHT e CARPINETTI, 2012). A eficácia das cartas de controle depende da coleta, medição e inspeção de amostras ou grupos referentes à variável ou ao atributo que se pretende controlar de um determinado processo.

Segundo aponta KUMAR e WAGH (2018), dependendo do tipo de dados, diferentes cartas de controle podem ser utilizadas. Se os dados forem constituídos por variáveis, podem-se utilizar os gráficos de I-MR (subgrupos de tamanho 1), X-bar e R (subgrupos de tamanhos variando entre 2 a 10) ou X-bar e S (para subgrupos maiores que 10). Para dados constituídos por atributos, têm-se os gráficos baseados em defeitos ( $n p$ e $p$ ) e baseados em não conformidades (C e U).

Dado um valor alvo específico de uma característica de qualidade, a produção do referente produto deve ser projetada de forma que a característica de qualidade associada aos produtos seja, idealmente, igual ou muito próxima ao valor alvo. Se os produtos apresentarem variações na qualidade desejada, essa variação deve estar sob controle de acordo com algum sentido admissível.

Baseado na existência de variações normais em um processo é necessário pensar na aplicação de limites de controle em ambos os lados do valor alvo de forma que, em condições normais de operação, os limites incluam a maioria das observações (PRIYA e KANTAM, 2017).

Montgomery (2016) aponta em sua obra que cada valor amostral plotado na carta de controle por variáveis é proveniente de um subgrupo racional, uma amostra que apresenta tamanho e frequência de amostragem definidas de modo que as chances de haverem diferenças nos valores entre os subgrupos sejam maximizadas e as diferenças dentro de um subgrupo seja minimizada.

Plotados os valores dos subgrupos racionais no gráfico, o ideal é que os pontos flutuem em torno da LM indicando um processo sob controle estatístico e, quanto menor o desvio desses valores em relação a LM, mais confiável será a operação. Pontos acima de LSC ou abaixo de LIC caracterizam atenção e devem ser analisados, a fim de se verificar a existência de causas especiais atuando no processo (COSTA, EPPRECHT e CARPINETTI, 2012).

Uma característica da qualidade que pode ser expressa em termos de uma medida numérica, tal como dimensão, peso ou volume, é denominada variável (MONTGOMERY, 2016). Desta forma, visto que a variável a ser estudada é contínua (peso das peças resultantes do processo de injeção plástica), Costa, Epprecht e Carpinetti (2012) alegam que a aplicação das cartas de controle de X-Barra e R é o usual no monitoramento desse tipo de variável.

\subsection{CARTAS DE CONTROLE DE X-BARRA E R}

Sabendo-se que a variável a ser controlada é uma variável contínua, é usual o monitoramento do processo por meio da análise das cartas de controle de X-Barra e R. A primeira diz respeito à observação da centralidade da média amostral, enquanto a segunda inspeciona a dispersão da amplitude amostral (COSTA, EPPRECHT e CARPINETTI, 2012).

Soares (2001) aponta vantagens na aplicação do par de cartas de controle de X-Barra e R como a facilidade na elaboração dos cálculos e uma ótima visão da variação estatística de um processo. Entretanto, indica a variabilidade do processo com menor segurança e apresenta uma relação indireta entre limites de controle e tolerância.

Montgomery (2016) menciona que não é possível definir com exatidão o tamanho da amostra, a frequência de amostragem a ser usada e a largura dos limites de controle sem o conhecimento preciso das características estatísticas que envolvem os gráficos de controle e o custo para a sua construção e utilização. Silva et al. (2019), por outro lado, aponta que a aplicação das cartas de controle de X-Barra e R são usuais para casos em que o tamanho da amostra de cada subgrupo racional seja menor que seis. 
A construção das cartas de controle pressupõe que os dados coletados das variáveis sejam normais e independentes (COSTA, EPPRECHT e CARPINETTI, 2012). Por isso, é necessário que sejam realizados testes de normalidade e correlação dos dados antes de construir as cartas de controle.

0 desenvolvimento das cartas de controle requer a plotagem de pontos representativos das medições realizadas e o acréscimo de três linhas paralelas: uma representando a média do processo; as outras representando os limites de controle (Limite Superior de Controle - LSC e Limite Inferior de Controle LIC). Segundo Leite et al. (2018), os limites de controle para as cartas de controle por variáveis, são definidos pelas Eq. 1 a 4 :

$$
\begin{aligned}
& L S C_{R}=\left(d_{2}+3 d_{3}\right) \sigma \\
& L I C_{R}=\left(d_{2}-3 d_{3}\right) \sigma . \\
& L S C_{\bar{x}}=\mu_{\bar{x}}+3 \frac{\sigma}{\sqrt{n}} \ldots \ldots . . \\
& L I C_{\bar{x}}=\mu_{\bar{x}}-3 \frac{\sigma}{\sqrt{n}} \ldots \ldots . .
\end{aligned}
$$

Onde: $d_{2}$ e $d_{3}$ são fatores de correção para a estimativa da variância; $\sigma$ é o desvio-padrão dos subgrupos racionais, calculados pela razão da média das amplitudes e o fator de correção do viés definido por $d_{2}$ $\left(\bar{R} / d_{2}\right)$, o qual varia apenas em função do tamanho dos subgrupos racionais $(n) ; \mu_{\bar{x}}$ é a média das médias dos subgrupos racionais. Ressalta-se que os limites centrais são, respectivamente, a média das amplitudes ( $\bar{R}$, Eq. 1 e 2 ) e a média das médias ( $\overline{\bar{x}}$, Eq. 3 e 4$)$.

Os valores para $d_{2}$ e $d_{3}$ podem ser encontrados em Montgomery (2016).

\section{METODOLOGIA}

A classificação desse trabalho de acordo com a natureza, abordagem do problema, objetivo e procedimentos técnicos pode ser dada como pesquisa aplicada, quantitativa, descritiva, baseada nos conceitos de Design Science Research (DSR), respectivamente (PRODANOV e FREITAS, 2013; GIL, 2002; DRESCH, LACERDA e CAUCHICK-MIGUEL, 2019).

Destaca-se que a DSR se apresenta como um método de pesquisa, cujo objetivo é a prescrição, formalização e geração de conhecimentos acerca de projetos organizacionais, promovendo a condução de investigações voltadas à concepção, implementação e/ou melhoria nos projetos produtivos (DRESCH, LACERDA e CAUCHICK-MIGUEL, 2019).

Para facilitar a compreensão, o trabalho foi dividido em diferentes tópicos para descrição da empresa e seu processo produtivo, a elaboração do controle estatístico de processo na produção das peças termoplásticas e a coleta de dados.

\subsection{DESCRIÇÃO DA EMPRESA E SEU PROCESSO PRODUTIVO}

Este trabalho visa a aplicação do CEP em uma indústria de médio porte de produtos plásticos para irrigação, localizada no interior do estado de São Paulo, que atende a todo território nacional e se apresenta num período de expansão de sua produção para atender à crescente demanda proveniente de outros países.

O foco do trabalho está no setor da produção, onde foram encontradas oportunidades de melhorias com a aplicação das cartas de controle para o controle da qualidade das peças e produtos. 0 responsável do setor realiza a programação da produção baseada nas demandas de vendas e estoque, definindo quais peças e máquinas cada operador será responsável no dia. Durante o processo produtivo, a equipe de qualidade recolhe um "galho" referente a um ciclo de injeção de cada máquina operante, realizando as inspeções visuais e de medição. Peças com a qualidade aprovada, retornam à produção de cada máquina. Caso desvios sejam detectados, é realizada uma intervenção para identificar as causas raízes.

Segundo Andrade (2019), a máquina extrusora é a responsável pelo processo de injeção plástica. A Figura 1 apresenta um desenho esquemático de uma máquina injetora. 
Figura 1 - Desenho esquemático de uma máquina injetora plástica

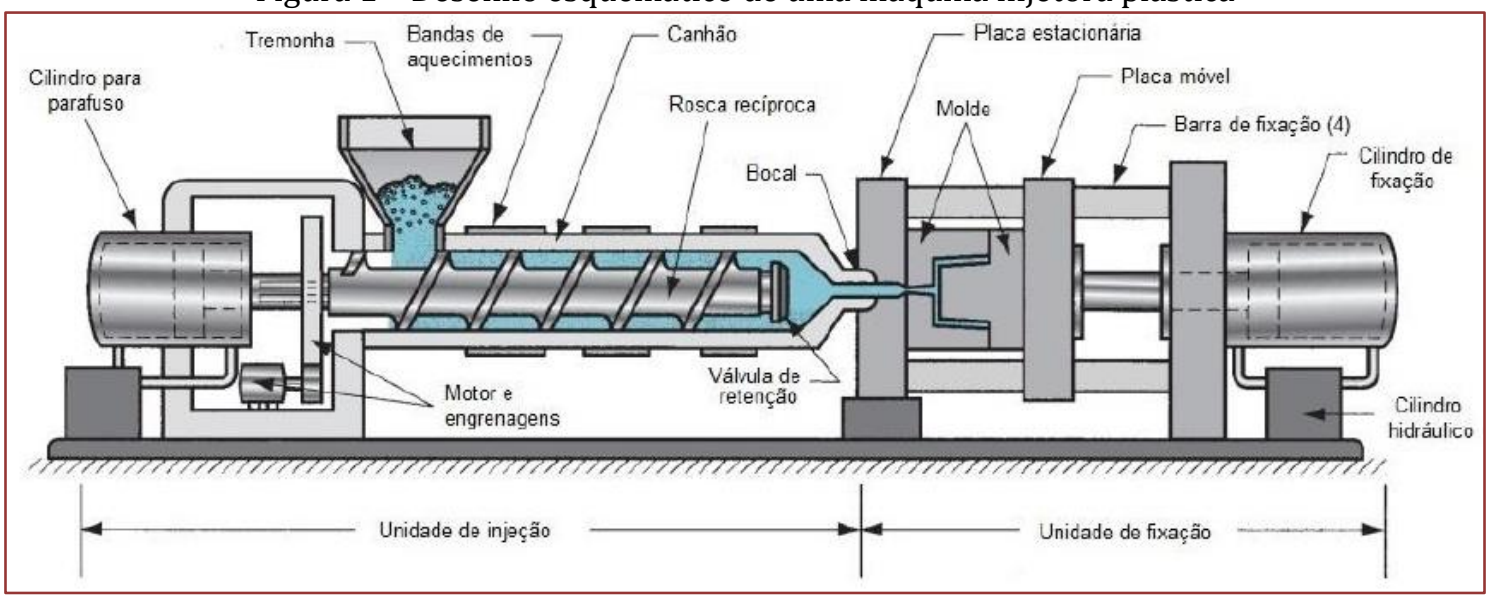

Fonte: Santos (2016)

O polímero, na forma de grão ou pó, é inserido na tremonha que o direciona ao canhão, onde existe uma rosca responsável pelo aquecimento do polímero até sua fusão ou amolecimento, homogeneização e plastificação do material e transporte ao interior do molde. No interior do molde, o polímero é comprimido recebe o processo de resfriamento, solidificando o material e, em seguida, o molde é aberto para a retirada da peça.

Ao fim do turno de trabalho, cada operador realiza a pesagem da sua produção e o cálculo da quantidade produzida é baseada na relação entre peso total e peso médio na peça. 0 valor obtido é inserido no sistema para contabilização no estoque e as peças seguem para processos seguintes como rebarbação ou montagem.

\subsection{ELABORAÇÃO DAS CARTAS DE CONTROLE DE X-BARRA E R}

O processo de aplicação do CEP consiste, inicialmente, na definição da equipe de trabalho e a escolha das máquinas para investigação, cujas peças produzidas serão pesadas, constituindo as amostras. Determinam-se o tamanho da amostra e a frequência de medição, cujos valores coletados serão adequadamente tabulados.

Sobre esses dados, testam-se os pressupostos de normalidade e independência, condições necessárias para construção das cartas de controle de X-Barra e R (MONTGOMERY, 2016; COSTA EPPRECHT e CARPINETTI, 2012).

\subsection{COLETA DE DADOS}

Para diagnosticar se o processo estava ou não sob controle estatístico, procedeu-se à pesagem das amostras de produção. A escolha da máquina e produto a ser analisado foi definido pelo responsável da produção, adotando-se como critério a boa regulagem da máquina e a produção de duas peças por ciclo de injeção.

A peça escolhida foi a denominada por C-34, instalada em uma máquina injetora automática e, assim, a coleta prosseguiu com a pesagem de cinco amostras da produção de cada uma das duas cavidades, aleatoriamente a cada trinta minutos, anotando-se os valores obtidos.

Ao fim da coleta de dados, foram obtidos 82 subgrupos racionais de tamanho 5 para cada cavidade, totalizando 820 valores. Os dados foram analisados com auxílio do software estatístico Minitab, disponível no Laboratório de Otimização e Simulação da Unifei-Itabira. Apesar de se coletarem dados das duas cavidades, serão demonstrados aqui somente os resultados atribuídos à "cavidade 1", considerando-se que esses resultados são similares aos da "cavidade 2 ". 


\section{RESULTADOS E DISCUSSÕES}

O teste de Anderson-Darling aplicado aos dados amostrais, os quais foram planejados e coletados com base na teoria dos subgrupos racionais, apresentou $p$-value inferior ao nível de significância adotado para o teste (IC 95\%). Entretanto, de acordo com o Teorema Limite Central, a distribuição de $n$ variáveis aleatórias independentes se aproxima da normal, independentemente das distribuições individuais, para amostras suficientemente grandes (MONTGOMERY, 2016). Uma vez que para cada cavidade o valor de $n$ era superior a 80, consideraram-se normais as amostras, permitindo-se a construção das cartas de controle.

Com auxílio do software Minitab as cartas de controle de X-barra e R (por variáveis) foram gerados, conforme se observa pela Figura 2.

Figura 2 - Cartas de controle Cavidade 1

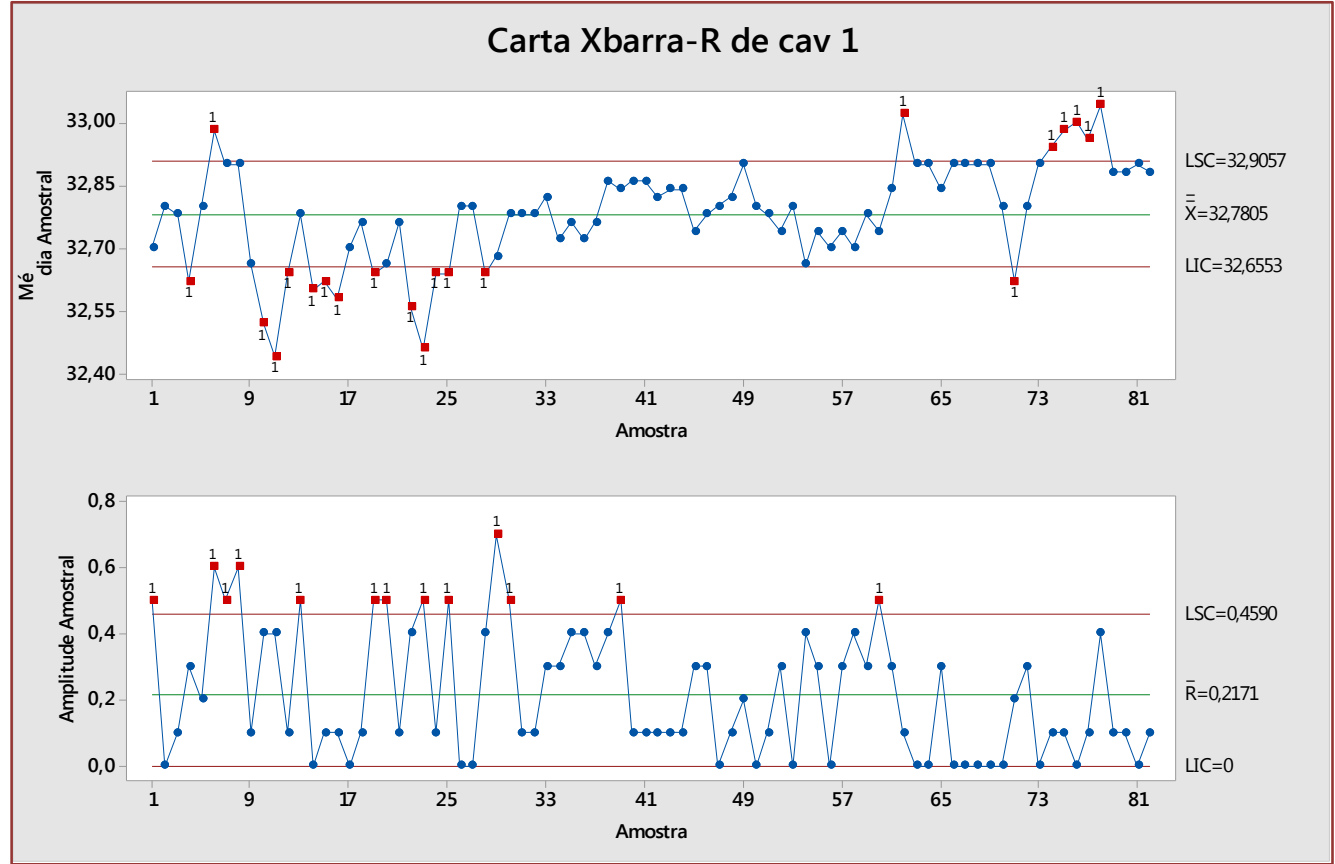

Fonte: os autores.

Analisando-se essas cartas, pôde-se constatar que o processo não se encontrava sob controle estatístico, devido ao grande número de pontos situados além dos limites de controle definidos. Entretanto, observou-se, também, que aqueles pontos fora dos limites se sucediam de pontos perfeitamente dentro do limites ou, ao menos, por um sequência de pontos com tendências aos limites, o que poderiam caracterizar alarmes falsos (COSTA, EPPRECHT e CARPINETTI, 2012). Como os pontos, em sua maioria, se distanciavam dos limites cerca de 0,2 desvios-padrão e que esse valor, segundo o setor de controle de qualidade, não impactaria significativamente na qualidade do produto, pôde-se sugerir a adequação dos limites de controle, por meio da aplicação do conceito dos limites alargados.

A expansão dos limites de controle adotado foi de um ? ?, considerado aceitável pelo controle de qualidade. A Figura 3 apresenta os novos gráficos de controle com os limites alargados. 
Figura 3 - Cartas de controle de X-Barra e R com limites alargados

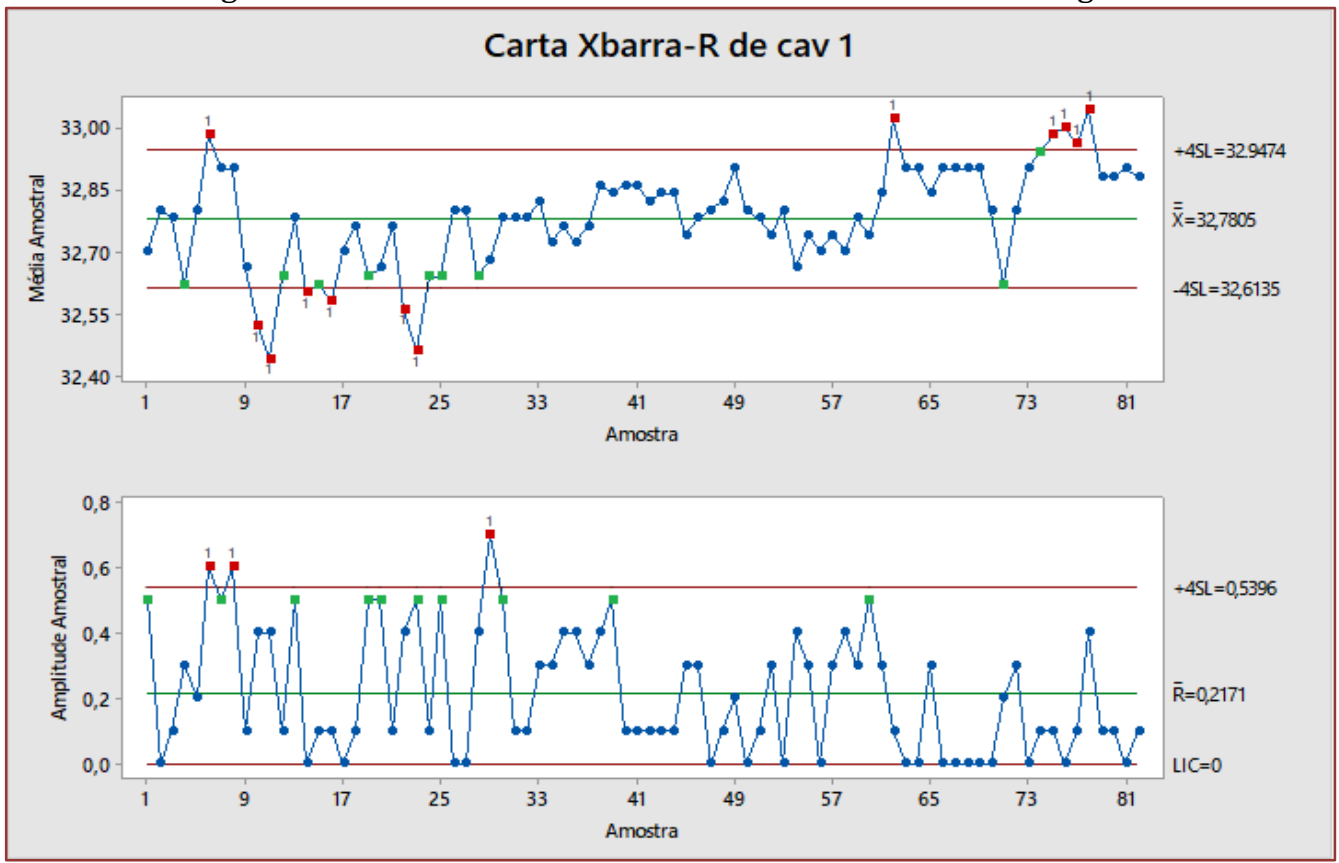

Fonte: os autores.

A análise dos novos gráficos de controle com limites alargados, confirmou a falta de controle estatístico do processo investigado, devido à existência de pontos fora dos limites. Esse resultado pressupõe uma nova investigação mais criteriosa, em busca de causas especiais que estejam atuando sobre a operação.

A avaliação anterior também se confirmou: após a extrapolação dos limites, o processo tende a retornar aos limites de controle. Isso, provavelmente, se deve à ação das injetoras automáticas, as quais são dotadas de sensores que verificam as condições de seus componentes e atuam diretamente, de forma que o sistema mantenha os parâmetros definidos pelo operador.

A qualidade das matérias primas, principalmente o plástico e corante utilizados no processo, também poderiam ser considerados como razão dos desvios. Entretanto, uma vez que existe um controle de qualidade para a matéria prima utilizada, tal hipótese foi descartada.

Alternativamente, um estudo acerca da capacidade do processo poderia ser conduzido a fim de se identificar qual a influência daqueles pontos fora dos limites sobre o processo. Entretanto, tal estudo demandaria informações dos limites de especificação oriundos do projeto de produto, os quais não se encontravam disponíveis.

\section{CONCLUSÃO}

Este trabalho apresentou conceitos sobre a aplicação das cartas de controle com o objetivo de analisar um processo de injeção plástica quanto à implementação do CEP, melhorando o sistema de gestão de controle de qualidade da empresa.

Após a realização da coleta de dados e construção dos gráficos de controle, identificou-se que o sistema não se encontrava sob controle estatístico e ações de verificação de causas especiais seriam necessárias. Os valores amostrais fora dos limites de controle eram próximos e, de acordo com a equipe de gestão da qualidade, não apresentavam casos de refugo de produtos, o que levou à adoção de limites alargados, buscando adequar os limites à real situação do processo.

Mesmo após a construção dos novos gráficos de controle de limites alargados, pontos fora dos limites ainda eram frequentes, especificamente aqueles apontados em cor vermelha nos gráficos apresentados. Esses casos deveriam ser analisados com mais atenção, buscando-se identificar as causas especiais atuantes. Ressalta-se que sempre em seguida da indicação de pontos fora dos limites de controle, observava-se uma tendência de retorno. Isso, provavelmente, devido à atuação das injetoras automáticas. 
De todo modo, como resultado desse trabalho, verificou-se se tratar de processo de manufatura fora de controle, mesmo considerando a visão menos alarmante da equipe de qualidade da organização, sugerindo-se novas etapas de pesquisa, aprofundamento na busca de causas especiais e implementação de novas ferramentas do CEP para lidar com dados considerados não-normais.

Com base nas informações e análises realizadas, sugere-se para trabalhos futuros, a análise da autocorrelação dos dados, partindo da hipótese de que os subgrupos pudessem ser formados de elementos não independentes, aplicando-se modelos auto regressivos integrados de médias móveis (ARIMA). Além desses, também o estudo sobre a capacidade do processo poderia ser realizado com intuito de respaldar os resultados das cartas de controle implementadas.

\section{AGRADECIMENTOS}

Os autores prestam agradecimentos, à UNIFEI - Universidade Federal de Itajubá, ao Laboratório de Otimização e Simulação (LOSI), por disponibilizar os softwares utilizados e ao Grupo de Estudos em Qualidade e Produtividade - GEQProd, pela sua cooperação na realização desse trabalho.

\section{REFERÊNCIAS}

[1] ANDRADE, R. D. S. Processo de reciclagem de polímeros termoplásticos. Trabalho de Conclusão de Curso (Bacharel em Engenharia de Materiais) - Universidade Federal do Rio Grande do Norte, Natal, 2019.

[2] CORRÊA, H. L.; CORRÊA, C. A. Administração de produção e operações: manufatura e serviços: uma abordagem estratégica. 2 ed. São Paulo: Atlas, 2011.

[3] COSTA, A. F. B.; EPPRECHT, E. K.; CARPINETTI, L. C. R. Controle estatístico de qualidade. 2 ed. São Paulo: Atlas, 2012.

[4] DRESCH, A.; LACERDA, D. P.; CAUCHICK-MIGUEL, P. A. Design science in operations management: conceptual foundations and literature analysis. Brazilian Journal of Operations \& Production Management, v. 16, n. 2, p. 333-346, 2019.

[5] FROST, J.; KELlER, K.; LOWE, J.; SKEETE, T.; WALTON, S.; CASTILLE, J.M.; PAL, N. A note on interval estimation of the standard deviation of a gamma population with applications to statistical quality control, Appl. Math. Modell. V. 37, n 4, pp. 2580-2587. 2013.

[6] GALUCH, L. Modelo para implementação das ferramentas básicas do controle estatístico do processo - CEP em pequenas empresas manufatureiras. 2002. Dissertação de Mestrado. Programa de Pós-Graduação em Engenharia de Produção. Florianópolis: UFSC, 2002.

[7] GARVIN, D. A. Competing on the eight dimensions of quality. Havard Business Review, v. 65, n. 6, 1987.

[8] GIL, A. C. Como elaborar projetos de pesquisa. 4 ed. São Paulo: Atlas, 2002.

[9] JUANG, J.; YU, S. Disturbance encountered landing system design based on sliding mode control with evolutionary computation and cerebellar model articulation controller, Appl. Math. Modell. V. 39, n. 19, pp. 58625881. 2015.

[10] JURAN, J. Quality handbook. 2th ed. New York: McGraw-Hill, 1962.

[11] KNAUER, W. A.; GODDEN, S. M.; DIETRICH, A.; HAWKINS, D. M.; JAMES, R. E. Evaluation of applying statistical process control techniques to daily average feeding behaviors to detect disease in automatically fed group-housed preweaned dairy calves. Journal of Dairy Science, v. 101, n. 9, p. 8135-8145, 2018.

[12] KUMAR, S.; WAGH, S. Analytical Dimension to Quality Check in Production Process through Control Charts. International Journal of Supply and Operations Management. V. 5, n. 3, pp. 283-288. 2018.

[13] LEITE, L. G.; GONÇALVES, I. A.; OLIVEIRA, C. H.; BRITO, T. G.; NEVES, S. M.; PAIVA, E. J. Analysis of surface roughness milled of steel AISI 1045 using X-bar and $\mathrm{R}$ Control Chart. International Journal of Engineering Technologies and Manegement Research, V. 5, n. 6, pp. 15-23. 2018.

[14] LI, Z.; ZOU, C.; WANG, Z.; HUWANG, L. A multivariate sign chart for monitoring process shape parameters, J. Qual. Technol. V. 42, pp. 149-165. 2013.

[15] MONTGOMERY, D. C. Introdução ao controle estatístico de qualidade. 7. ed. Rio de Janeiro: LTC, 2016.

[16] OliveirA, L. G.; OLIVEIRA, C. H.; BRITO, T. G.; PAIVA, E. J.; PAIVA, A. P.; FERREIRA, J. R. Nonlinear optimization strategy based on multivariate prediction capability ratios: Analytical schemes and model validation for duplex stainless steel end milling. Precision Engineering, v. 66, p. 229-254. 2020. 
[17] PRIYA, M. C.; KANTAM, R. R. L. Variable Control Charts-Linear Failure Rate Distribution. Pakistan Journal of Statistics and Operation Research, v. 13, n. 4, p. 715-726, 2017.

[18] PRODANOV, C. C.; DE FREITAS, E. C. Metodologia do trabalho científico: métodos e técnicas da pesquisa e do trabalho acadêmico. 2 ed. Novo Hamburgo: Feevale, 2013.

[19] SANTOS, C. D. Projeto de molde para fabricação de engrenagens por injeção de polímero. Trabalho de Conclusão de Curso (Graduação)-Universidade Federal do Rio de Janeiro, Rio de Janeiro, 2016.

[20] SILVA, A. L. F. da.; NOGUEIRA, E. L.; CAMPOS, W. S.; OLIVEIRA JÚNIOR, J. B.; ALBUQUERQUE, M. M. Uso dos gráficos de controle para variáveis. Journal of Engineering and Technology for Industry Applications, v. 5, n. 18, p. 105$112,2019$.

[21] SOARES, G. M. V. P. Aplicação do controle estatísco de processos em indústria de bebidas: um estudo de caso. 2001. Dissertação (Mestrado em Engenharia de Produção) - Universidade Federal de Santa Catarina, Florianópolis, 2001.

[22] SLACK, N.; CHAMBERS, S.; JHONSTON, R. Administração da produção. 3 ed. São Paulo: Atlas, 2009.

[23] SHEWHART, W. A. Economic control of quality of manufactured product. Toronto: D. Van Nostrand, 1931. 


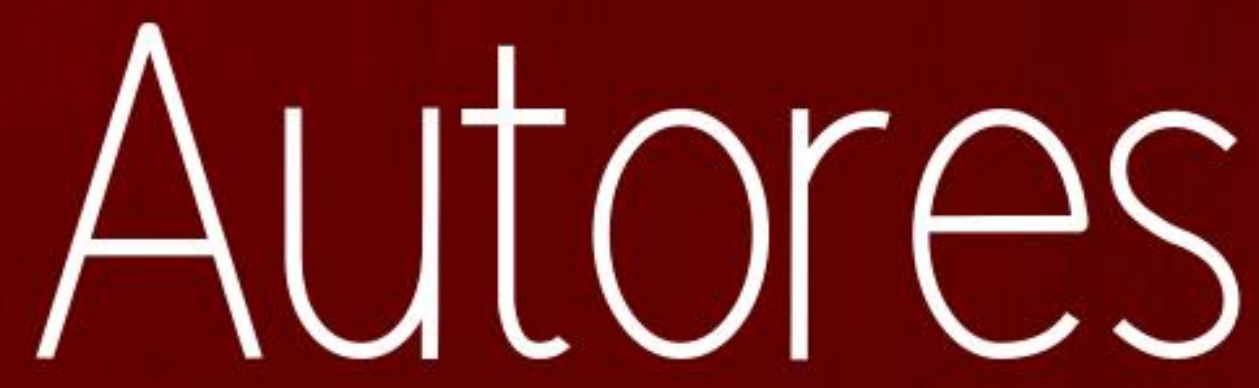




\section{RAFAEL ALVES PEDROSA (ORGANIZADOR)}

Consultor de Gestão com enfoque em Logística Portuária e de Transportes, com graduação em Administração, Comércio Exterior, Logística e Transporte Multimodal e Gestão Portuária; Pós Graduação em Gestão de Comércio Exterior e Logística; Gestão Empresarial; Gestão, Docência e Tecnologias do Ensino Superior; MBA em Docência do Ensino Superior pela Fundação Getúlio Vargas - FGV; Mestre em Sustentabilidade de Sistemas Costeiros com dissertação voltada a Dragagem de Aprofundamento do Porto de Santos/SP; Doutorado em Planejamento e Gestão pela Universidade Federal do $\mathrm{ABC}$ (UFABC) com tese voltada ao impactos da expansão portuária do Porto de Santos na integração porto/cidade. Autor e organizador de livros e capítulos de livros relacionados a sua área de atuação. Coordenador de projetos de pesquisa e revisor de periódicos ligados as áreas de Logística e Comércio Exterior e planejamento territorial e urbano. Professor conteudista de cursos superiores em EaD. Possui cursos de atualização nas áreas de Administração, Logística e Comércio Exterior, fez intercâmbio na Argentina adquirindo fluência no idioma Espanhol, além de participar constantemente de fóruns destinados a estas áreas. Coordenador do curso de pós graduação em Gestão Portuária e Operações Internacionais. Com experiências na coordenação de Logística e transportes em empresas multinacionais sendo responsável pelo planejamento de distribuição e Logística das regiões Sul e Sudeste do país. Tendo sido contemplado com o prêmio de Melhor ideia inovadora 2010 . Atuou ainda no papel de Coordenador de Operações Portuárias. Já na docência foi contemplado com o prêmio Mérito Docente por atuação acadêmica destacada e foi contemplado com o prêmio Dr. Milton Teixeira pela orientação do melhor trabalho de iniciação cientifica.

\section{ADRIANA APARECIDA DAMBROS DA SILVA}

Graduação em Ciências pela UNOESC, graduação em Licenciatura em Matemática pela UFSC, especialização em Gestão e Liderança Universitária PUCPR, mestrado em Educação pela UFSC, doutorado em Educação pela UFPR. Atualmente é Professora Titular na PUCPR, membro do Núcleo de Excelência Pedagógica e coordenadora de Pesquisa no Campus Toledo da PUCPR.

\section{ANA CAROLINA CELLULAR MASSONE}

Doutora (COPPE) e Mestre (IME) em Engenharia Mecânica, com graduação em Matemática. Professora do Centro Universitário La Salle - UniLasalle e da Universidade Candido Mendes em cursos de graduação e pós-graduação, nas disciplinas de Engenharia de Produção, Engenharia Civil e Fundamentos da Logística. Membro da equipe docente do MBA em Supply Chain Management da Universidade de Vassouras. Membro do Grupo de Pesquisa em Monitoramento Ambiental / IoT / RNA (Universidade de Vassouras) e do Grupo de Pesquisa em Energias Renováveis no Âmbito da Defesa (GPERD / CNPq). Áreas de pesquisa, com projetos desenvolvidos em: Matemática Aplicada, Dinâmica Não Linear e Caos, Energias Renováveis, Redes Neurais Artificiais e Roteamento de Veículos.

\section{ANA CELIA VIDOLIN}

Mestranda em Engenharia Civil UTFPR, linha de pesquisa gestão, produtividade e suprimentos. Atua como pesquisadora principalmente nos temas: supply chain, lean management, gestão e estratégia empresarial. Especializações em Engenharia Logística e Operações (Lean Logistics); Logística Empresarial e MBA em Gestão Empresarial, Gerenciamento e Controle da Qualidade Ambiental. Possui graduação em Engenharia Geológica e Administração. Vivência profissional no ambiente fabril em supply chain, comércio exterior, logística internacional, administração de materiais e produção; gestão organizacional e lean management. Atuação como docente em diversas faculdades na capital curitibana e região metropolitana para cursos de graduação, pósgraduação e especialização.

\section{ANDRE LUIS SHIGUEMOTO}

Possui graduação em Bacharelado em Ciência da Computação pela Escola de Engenharia de Piracicaba - EEP (2001), mestrado em Engenharia Elétrica pela Universidade Estadual de 
Campinas - UNICAMP (2004) e doutorado em Engenharia Elétrica pela Universidade Estadual de Campinas - UNICAMP (2008) com período sandwich em Molde University College - HiMolde Noruega (2006). Em 2008 ingressou como professor do Departamento de Estatística e Matemática Aplicada da Universidade Federal do Ceará - DEMA/UFC. Atualmente é professor da Universidade Tecnológica Federal do Paraná - UTFPR. Tem experiência na área de Engenharia de Produção e Computação, com ênfase em Pesquisa Operacional, atuando principalmente nos seguintes temas: meta-heurísticas, dimensionamento de lotes, controle de estoque, roteirização, logística e programação dinâmica.

\section{ANDRÉ LUIZ GAZOLI DE OLIVEIRA}

Drọ. Engō. de Produção, possui graduação em Engenharia de Produção - PUCPR (2008), mestrado em Engenharia de Produção e Sistemas - PUCPR (2012) e doutorado em Engenharia de Produção e Sistemas- PUCPR (2019). Atualmente é professor adjunto da Universidade Federal do Paraná e Vice-diretor do Campus Avançado da UFPR em Jandaia do Sul. Tem experiência na área de Engenharia de Produção, atuando principalmente nos seguintes temas: Produção Enxuta, Mass Customization, Simulação de Eventos Discretos, Planejamento e Controle da Produção e Gestão de Operações.

\section{BRUNO SILVA DE AGUIAR}

Graduado em Engenharia de Produção pela UNESA, MBA Gestão pela Qualidade Total UFF Universidade Federal Fluminense. Atuou como Analista da Qualidade em processos industriais. Interessa-se por Industria 4.0, Gestão da Qualidade, Programação e Controle da Produção e Logística.

\section{CEZAR AUGUSTO ROMANO}

Doutor em Engenharia de Produção pela Universidade Federal de Santa Catarina, graduado em Engenharia Civil pela Universidade Federal do Paraná. É Professor Titular da Universidade Tecnológica Federal do Paraná onde atua desde 1979. Atualmente é Professor Permanente em Programas de Pós-Graduação, atuando nas áreas de estratégia, planejamento e gestão, com foco na produtividade organizacional.

\section{DANIEL DE FREITAS BARBOSA}

Formando em Engenharia de Produção pela Universidade Federal do Paraná (UFPR), campus Avançado Jandaia do Sul - (2019). Possui experiência em métodos de melhoria contínua e ferramentas da qualidade. Atua como operador de biodiesel na indústria BSBIOS Marialva.

\section{DANIELA SOUSA GUEDES MEIRELLES ROCHA}

Possui mestrado em Engenharia de Produção e Sistemas pela Pontifícia Universidade Católica de Goiás (2018), pós graduação em Docência Universitária - UNOPAR (2016), graduação em Administração pela Pontifícia Universidade Católica de Goiás (2001). Atualmente é CLT na UNICEUG e FABEC.

\section{DAVI TEIXEIRA PINHEIRO}

Professor do Departamento de Construção Civil (DCC) do Instituto Federal de Educação, Ciência e Tecnologia do Ceará (IFCE), campus Fortaleza.

\section{EMMANUEL PAIVA DE ANDRADE}

Professor Titular do Departamento de Engenharia de Produção da Universidade Federal Fluminense e coordenador do Grupo de Pesquisa em Conhecimento, Pessoas e Inovação. Na Graduação, ministra disciplinas como Economia e Gestão da Inovação e CTS e no Mestrado e 
Doutorado em Sistemas de Gestão Sustentáveis, trabalha com as disciplinas de Gestão do Conhecimento e Interdisciplinaridade em Ciência, Tecnologia e Inovação.

\section{ERCILIA DE STEFANO}

Professora da UFF, onde lecionas as disciplinas de Gestão de Projetos, Gestão de Projetos de Sistemas de Produção, Empreendedorismo I, Empreendedorismo II e Gestão da Inovação Tecnológica. Pós-doutora em Engenharia Civil pela UFRJ - COPPE. Pós-doutora em Sistemas de Gestão Sustentáveis pela UFF. Doutora em Engenharia de Transportes pela UFRJ - COPPE. Mestre em Engenharia de Sistemas pela UFRJ - COPPE. MBA em Gestão Estratégica em Comércio Exterior. Especialista em Gestão Estratégica Pública. Especialista em Gerência e Desenvolvimento de Sistemas Orientado a Objetos. Graduada em Matemática. Advogada. Filiada à ABENGE e ABEPRO. Revisora de revistas e periódicos. Especialista em diferentes metodologias ativas de ensino.

\section{FABIO SEITI HADANO}

Mestre em ciências pelo programa de Pós-Graduação em Engenharia Elétrica e Informática Industrial - CPGEI da Universidade Tecnológica Federal do Paraná - UTFPR, com pesquisas voltadas ao uso de polímeros semicondutores como camada ativa para a detecção e sensoriamento de gases. Bacharelado em Engenharia Elétrica (2017) pela UTFPR com ênfase em eletrotécnica. Durante a graduação, desenvolveu pesquisas nas áreas de pesquisa operacional e sistemas elétricos de potência.

\section{FERNANDA CARLOS DA FONSECA}

Cursando o sexto período de Engenharia de Produção na Universidade Federal Fluminense (UFF), onde já atuei como gerente em um projeto de uma empresa do setor têxtil. Possuo também envolvimento com atividades acadêmicas e extracurriculares, como a participação voluntária em projetos da faculdade, publicação de três artigos e certificações em Scrum Fundamentals e Six Sigma Yellow Belt Profissional e em cursos complementares a minha formação, além de conhecimento do pacote office, inglês intermediário e cursando francês. No momento, estou estagiando em uma EdTech na área de produto, onde procuro, principalmente, levar a melhor experiência para o usuário.

\section{FERNANDO LEONEL CUZZUOL}

Graduado em Engenharia Civil pela Universidade FUMEC em 2013; Pós-Graduado em Gestão de Negócios e Projetos pelo IETEC em 2017; Certificado como Project Management Professional (PMP) pelo Project Management Institute; Mestre em Engenharia Civil nas áreas de Gestão e Sustentabilidade da Construção na Universidade Tecnológica Federal do Paraná (UTFPR).

\section{FILIPE BRITO LIMA DE MACEDO}

Mestrando em Sistemas de Gestão pela Universidade Federal Fluminense (UFF), Pós graduado em Engenharia de Segurança do Trabalho (UFF) e Graduado em Engenharia de Produção (Universidade Salgado de Oliveira), é profissional atuante e expert em Sistemas de Gestão Integrados (SGI) de Qualidade, Saúde Ocupacional, Segurança do Trabalho, Meio Ambiente e Responsabilidade Social (QSMSRS). É também Black Belt em Lean Seis Sigma e Auditor das normas internacionais de Sistemas de Gestão ISO 14001 (Gestão Ambiental), OHSAS 18001 (Gestão de Saúde e Segurança) e ISO 45001 (Gestão de Saúde e Segurança).

\section{GABRIELA HELENA BAUAB SHIGUEMOTO}

Possui graduação em Engenharia Elétrica pela Universidade Estadual de Campinas (2003) e mestrado em Engenharia Elétrica pela Universidade Estadual de Campinas (2005) e doutorado em Engenharia Elétrica pela Universidade Estadual de Campinas(2009). Tem experiência na área de Engenharia Elétrica, com ênfase em Transmissão da Energia Elétrica, Distribuição da Energia 
Elétrica e mercado de energia, atuando principalmente nos seguintes temas: fluxo de potência, sistema de distribuição e sistema de transmissão, fluxo de potência ótimo, geração distribuída.

\section{GERSON LUIZ DE ABREU HENRIQUES}

Supervisor - PCP na empresa Braziline Ind. e Com. Ltda. (Petrópolis). É graduando em Engenharia de Produção pela UFF Petrópolis. Suas experiências anteriores são: IBICT - Instituto Brasileiro de Informação em Ciência e Tecnologia - Consultor Pesquisador - Análise Processos (de Ago18 a Nov18); MRS Logística - Assistente de informação - PPCO (de Jan14 a Nov17); Estagiário de Controle Operacional - PPCO (de Abr13 a Jan14).

\section{GILSON BRITO ALVES LIMA}

Engenheiro Civil. Especialista em Engenharia de Segurança. Mestre em Engenharia Civil. Doutor em Engenharia de Produção. Professor do Ensino Superior. Atua nas áreas de Ensino, Pesquisa e Extensão, através de projetos de formação e desenvolvimento tecnológico, com ênfase nas áreas de Modelagem em Gestão Industrial de Segurança, Meio Ambiente, Riscos e Manutenção.

\section{GLICIA MARIA BARBOSA}

Graduanda em Engenharia de Produção pela Universidade Federal de Uberlândia desde 2017 e ativamente envolvida com pesquisa desde 2018. Atualmente, pesquisadora em duas linhas dentro da instituição e empresária júnior.

\section{HEBERT ROBERTO DA SILVA}

Engenheiro Mecânico UFU, 2005. Engenheiro de Segurança do Trabalho UFU, 2007. Especialista em Docência na Educação Superior UFU, 2010. Engenheiro de Soldagem UFU, 2011. International Welding Engineer, 2011. Mestrado Engenharia Mecânica UFU, 2010. Doutorado em Engenharia Mecânica UFU, 2014. Especialista em Ergonomia, SENAC, 2018. Avaliador de Atos de Autorização de Cursos de Graduação capacitado pelo INEP.

\section{JOÃO EDUARDO GUARNETTI DOS SANTOS}

Possui graduação em Engenharia Agrícola pela Universidade José do Rosário Vellano (1985), Especialização em Engenharia e Segurança do Trabalho (1990), pela Universidade Estadual Paulista -UNESP , Mestrado em Agronomia (Energia na Agricultura) pela FCA / UNESP- Campus de Botucatu (1990) . Doutorado em Agronomia (Energia na Agricultura) pela FCA/ UNESP - Campus de Botucatu (1993). Atualmente é Professor Adjunto MS5 -Livre Docente (2003) e Livre Docente II (2014) junto ao Departamento de Engenharia Mecânica da Faculdade de Engenharia -FEB/UNESP Campus de Bauru da Universidade Estadual Paulista Júlio de Mesquita Filho. È docente credenciado junto ao Programa de Pós-Graduação em Design da FAAC/ UNESP- Campus de Bauru, nível 6 Capes e junto ao Programa de Pós-Graduação em Engenharia Mecânica - FEB/UNESP Bauru, nível 4 junto a Capes. Iniciou suas atividades de Docência, Pesquisa e Extensão em 1987.

\section{JOÃO PAULO FERREIRA MARTINS}

Formado em Engenharia de Produção pela Universidade Federal Fluminense, fundador e atualmente CEO da Hashtag Treinamentos - empresa de educação online e presencial de softwares empresariais de gestão, tratamento de dados e análise.

\section{JONATHAN GONÇALVES FIGUEIREDO}

Formação técnica em Administração pelo Senac, formação técnica em Petróleo e Gás pela Electra, graduado em Engenharia de Produção pela UNESA. Organizador e coparticipante do evento EMPRENG no campus Norte-Shopping. Atuou como palestrante no Simpósio de Excelência e Gestão e Tecnologia (SEGeT) 2020. Interessa-se por Industria 4.0, Tecnologia de Informação e Logística. 


\section{JOSÉ ANTONIO POLETTO FILHO}

Graduação em Engenharia Mecânica pela Universidade São Francisco, Mestrado e Doutorado em Engenharia pela Universidade Estadual Paulista - UNESP. Especialização em Segurança do Trabalho - Unicamp, Especialização em Meio Ambiente - Unicamp, Especialização em Higiene Ocupacional - USP, Especialização em Tecnologias de Informação e Comunicação, Educação Ambiental e Gerenciamento de Recursos Hídricos - UNESP, Especialização em Ergonomia - SENAC, Licenciatura - Mecânica - Fatec, Licenciatura - Segurança do Trabalho - Fatec. Experiência de vinte e cinco anos em Engenharia Mecânica, atuando nas áreas de Refrigeração, Ar Condicionado, Conforto Ambiental, Segurança do Trabalho, Meio Ambiente e Gestão do RSU, e de vinte anos na docência e gestão universitária.

\section{JOSÉ ARTUR SOARES DE ALMEIDA FILHO}

Aluno de graduação do curso de Engenharia Civil no Instituto Federal de Educação, Ciência e Tecnologia do Ceará (IFCE) Estagiário de engenharia na Caixa Econômica Federal

\section{LARISSA BEATRIZ FONSECA TAVARES}

Técnica em Administração pelo Senac, 2016. Graduanda em Engenharia de Produção pela UFU desde 2017. Ativamente envolvida com pesquisa desde 2018. Atualmente, pesquisadora dentro da instituição e empresária júnior.

\section{LUANA MACHADO DOS SANTOS}

Mestra em Engenharia de Produção e Sistemas pela Pontifícia Universidade Católica de Goias (2019), Graduada em Administração pela Pontifícia Universidade Católica de Goiás (2014), MBA em Gestão Empresarial com Ênfase em Consultoria. 1ํ Lugar na Primeira edição do Desafio Indústria 2018 - Hack Innovation em Goiânia - GO. 2o Lugar no Desafio AgroStartup na Campus Party Goias. Professora do curso de Administração e Ciências Contábeis na FABEC nas disciplinas Gestão de Sistema de Informação; Liderança, Criatividade e Empreendedorismo; e Fundamentos de Comunicação e Informação. E do curso de Pedagogia na disciplina de Comunicação e Expressão. Professora do curso de Administração e Ciências Contábeis na Faculdade Araguaia nas disciplinas Teoria Geral da Administração I; Teoria Geral da Administração II; Administração de Recursos Materiais e Logística, E do curso de Gestão Comercial na disciplina de Administração da Produção e Logística. Professora de Pós Graduação do Instituto Consciente Goiano na disciplina de Tendencias Empresariais e Educacionais. Tem experiência nas áreas de Administração e Engenharia de Produção, atuando principalmente nos seguintes temas: Manufatura Aditiva, Industria 4.0, Sustentabilidade, Gestão da Qualidade, Lean manufacturing e Inovação.

\section{LUIZ PAULO MARQUES ASSUMPÇÃO RESINENTE}

Mestrando em Sistemas de Gestão pela Universidade Federal Fluminense (UFF), Pós graduado em Engenharia de Produção (UFF), Pós graduado em Engenharia de Segurança do Trabalho (UFF) e Graduado em Engenharia de Produção pela Universidade Estácio de Sá. Profissional com experiência na área de engenharia de produção, com ênfase em Planejamento de Projetos, Controle de Sistemas de Produção, Mapeamento de Processos, Estrutura Organizacional e Segurança do Trabalho.

\section{MARCELLO MONTILLO PROVENZA}

Possui graduação em Estatística pela Universidade do Estado do Rio de Janeiro (2007) e Mestrado em Estudos Populacionais e Pesquisas Sociais pela Escola Nacional de Ciências Estatísticas (2010). Atualmente é Professor Assistente na UERJ e doutorando do Programa de Pós-graduação em Engenharia Química da UERJ. Tem experiência na área de Probabilidade e Estatística, atuando principalmente nos seguintes temas: séries temporais, estatística aplicada e políticas públicas. 


\section{MARCO ANTONIO GAYA DE FIGUEIREDO}

Engenheiro Químico formado pela Uerj (1994), Licenciado em Quimica formado pela UERJ (1976), Especialização em processamento de Petróleo (1975 - Petrobras) Mestrado e Doutorado COPPE / UFRJ em /Engenharia de Produção (1992-97), Engenheiro de processamento Pêtrobras (1975 - 98). Professor Titular UERJ ( 1998-atual) Lecionando na Graduação em Engenharia Química disicplinas de Instrumentação e Práticas de Laboratório . No Programa de Pós Gradiuação em Engenharia Química da UERJ Avaliação de projetos e Gestão Ambiental

\section{MARCO AURÉLIO REIS DOS SANTOS}

DRo. ENGo. PRODUÇÃO, possui graduação em Engenharia de Produção Mecânica NESP/FEG(2008), mestrado em Engenharia de Produção - UNESP/FEG (2010) e doutorado em Engenharia de Produção - UNESP/FEG (2014). Atualmente é professor adjunto da Universidade Federal do Paraná. Tem experiência tanto na área de Engenharia de Produção, bem como Coordenador de Curso de Engenharia de Produção da UFPR no campus de Jandaia do Sul, onde atuou de 2018 à 2020. As ênfases de linha de pesquisa são em Pesquisa Operacional e Planejamento de Experimentos.

\section{MARCOS LAJOVIC CARNEIRO}

Graduado em Engenharia Elétrica pela Universidade Federal de Goiás (2007), Mestre em Engenharia Elétrica pela Universidade Federal de Goiás (2009), Doutor em Engenharia Elétrica pela Universidade de Brasília (UnB) e Universidade de Bordeaux I (co-tutela), pós-doutorado realizado na Université de Bretagne Occidentale (Brest - França) em conjunto com o laboratório CEA-Leti em Grenoble (França).Pela graduação e mestrado, tem conhecimento em programação de CLPs, programação em Delphi, Assembly, linguagem C, microcontroladores, inteligência artificial, otimização, fabricação de circuitos impressos. No doutorado e pós-doutorado, realizou pesquisas nos seguintes campos: comunicações móveis, simulação de circuitos não-lineares, equilíbrio harmônico, envoltória complexa, projeto de amplificadores de potência integrados, transformada Unscented e dispositivos semicondutores. Projetista de amplificadores de potência integrados e defasores de alta frequência com a técnica de ondas-lentas utilizando Cadence, Advanced Design System, Momentum, HFSS. Atualmente de professor efetivo na Pontifícia Universidade Católica de Goiás (PUC-GO), coordenador do Núcleo de Inovação Tecnológica e do Mestrado em Engenharia de Produção e Sistemas. Hoje sua pesquisas principais estão em robótica e impressão 3D.

\section{MARCOS VINICIUS WENDPAP}

Graduado em Engenharia de Produção pela Pontifícia Universidade Católica do Paraná - Câmpus Toledo e laureado com o prêmio Marcelino Champagnat pelo melhor desempenho acadêmico da turma de 2019. Atuou como monitor nas disciplinas de Introdução ao Cálculo e Cálculo I/Cálculo para Agronomia, na Pontifícia Universidade Católica do Paraná - Câmpus Toledo. Atualmente exerce a função de Encarregado de Produção na empresa Spot Light - Luminárias de Emergência, na qual implantou o programa Gerenciamento da Rotina do Trabalho do Dia a Dia e atua no desenvolvimento de produtos, mapeamento e melhoria de processos, planejamento e controle da produção, desenvolvimento e supervisão de equipes e gerenciamento da rotina.

\section{MARTA PEREIRA LUZ}

Possui graduação em Engenharia Civil pela Universidade Federal de Goiás (2001), mestrado em Engenharia Civil pela Universidade de São Paulo (2003), doutorado em Ciências Ambientais pela Universidade Federal de Goiás (2008) e pós-doutorado em Geotecnia pela Heriot-Watt University (2015).Tem experiência na área de Engenharia Civil, com ênfase em barragens, rodovias e meio ambiente. Realiza pesquisas principalmente nos seguintes temas de concentração: materiais geotécnicos com aplicação em barragens e rodovias, processos erosivos e gestão ambiental. Professora Adjunta da Pontifícia Universidade Católica de Goiás, atuando no curso de graduação em Engenharia Civil e mestrado stricto sensu em Engenharia de Produção e Sistemas. Coordenadora do Laboratório de Mecânica dos Materiais da Eletrobras Furnas. Coordenadora 
Técnica de Projetos de Pesquisa, Desenvolvimento e Inovação. Revisora dos periódicos: Journal of Environmental Management; Soils and Rocks; Revista Eletrônica em Engenharia Civil. Membro da Comissão de Estudo Especial de Solos (ABNT/CEE 221); CBDB e ABMS.

\section{NEIDE LUCIA DE OLIVEIRA ALMEIDA}

Doutoranda em Sistemas de Gestão Sustentáveis na UFF. Graduada em Comunicação Social e bacharel em Relações Públicas. Concluiu MBA em Gestão Pela Qualidade Total na UFF. É professora convidada do Programa de Pós-Graduação em Gestão e Empreendedorismo, atuando no MBA Executivo. É sócia-diretora de escola de inglês e tem experiência nas áreas de Comunicação Social, Relações Públicas e Marketing.

\section{PAULA MARTINS DE SOUZA}

Engenheira Química formada pela UERJ (2015) com mestrado em Engenharia Química pelo programa de Engenharia Quimica da UERJ (2017). Atualmente atua na área de Gestão da Qualidade com experência em processos e projetos de melhoria, inovação e padronização no mercado de varejo.

\section{PEDRO DA MATTA E ANDRADE BASILIO}

Doutor em Engenharia de Transportes pelo Programa de Engenharia de Transportes COPPE/UFRJ, Pós Graduado em Petróleo e Gás Natural pelo MBP-COPPE/UFRJ, graduado em Engenharia de Produção. Professor do Centro Universitário LaSalle - UniLasalle. Membro pesquisador do Laboratório de Otimização de Recursos, de Simulação Operacional e de Apoio à Decisões na Indústria do Petróleo - LORDE.

\section{PEDRO HENRIQUE CAMPOS DA COSTA}

Graduado em Engenharia de Produção pelo Centro Universitário La Salle - UniLaSalle.

\section{RAYSSA GABRIELLE DA SILVA SOARES}

Bacharelanda em Engenharia de Produção na UFF Petrópolis. Atualmente trabalha como Jovem Aprendiz - PMO- Processos na Comercial Milano Brasil Ltda. Atuou na FINATEC como Estagiária Processos, no período de abri/2019 - out/2019.

\section{ROBSON LUCIANO DE ALMEIDA}

Graduação em Engenharia Química pela UNIOESTE, mestrado e doutorado em Engenharia Química pela UEM na área de Desenvolvimento de Processos. Atuação em agroindústrias na função de engenheiro de processos e gerente industrial. Atualmente professor adjunto e coordenador do curso de Engenharia de Bioprocessos e Biotecnologia na UTFPR, Campus Toledo/PR.

\section{RONNIERY ILARIO PEREIRA}

Atualmente é doutorando do programa de Biologia Computacional e Sistemas do Instituto Oswaldo Cruz e graduando em Engenharia de Produção pela Universidade Federal Fluminense (UFF), possuindo mestrado no Programa de Modelagem Computacional no Laboratório Nacional de Computação Científica (LNCC) e graduação em Engenharia Química pela Universidade Federal do Ceará (UFC). Atualmente, atua na área de reposicionamento de fármacos por meios de técnicas de bioinformática e modelagem molecular, além de desenvolver pesquisas nas áreas de gerenciamento de processos e economia circular. 


\section{SARA MONALIZA SOUSA NOGUEIRA}

Graduada e Mestre em Engenharia de Pesca pela Universidade Federal do Ceará (UFC). Doutora pelo Programa de Pós-Graduação em Planejamento Energético e Ambiental (PPE) do Instituto Alberto Luiz de Coimbra de Pós-Graduação e Pesquisa de Engenharia (COPPE) da Universidade Federal do Rio de Janeiro (UFRJ). Orienta e participa de Bancas de Defesa de Trabalhos de Conclusão de Curso (TCC) do curso de MBA em Gerenciamento de Projetos do Laboratório de Competitividade, Estratégia e Organização (LabCEO) do Departamento de Engenharia de Produção (TEP) da mesma Universidade.

\section{SOPHIA TRAVESEDO CARDOSO}

Graduada em Engenharia de Produção pela UNESA. Já atuou como tutora nas disciplinas Estatística Aplicada e Planejamento e Controle da Produção (PCP) do curso de Engenharia no campus NorteShopping. Membro e coparticipante do Clube de Engenharia Brasil. Atualmente, atua como consultora e analista de backoffice para empresa privada. Interessa-se por Gestão de Projetos, Industria 4.0, Qualidade \& Inovação.

\section{STEPHANIE FELIX AMARAL}

Formada em Engenharia de Produção (UFF 2017), fez intercâmbio na Maastricht University School of Business and Economics, na Holanda, em 2016. Cursou em 2019 o curso Data Analytics Leadership, na TERA e está fazendo Pós Graduação em Administração no Insper (2020-2021). Atualmente trabalha como Consultora Sênior na BIP Brasil, uma consultoria em gestão e inovação, de origem Italiana.

\section{THIAGO GOMES BRITO LIMA}

Graduado em Engenharia de Produção pela Universidade Federal Fluminense (UFF), possui Especialização em Inteligência de Negócios pela Pontifícia Universidade Católica (PUC) do Rio de Janeiro. Atua com inteligência de dados e gestão de indicadores de performance na área de logística empresarial em uma renomada organização do Brasil.

\section{VICTOR IGOR BARROS FARIAS}

Aluno de graduação do curso de Engenharia Civil no Instituto Federal de Educação, Ciência e Tecnologia do Ceará (IFCE) Estagiário de engenharia na empresa EXP Brasil como projetista de instalações prediais

\section{WALBER SANTOS DE ASSIS}

Mestre em Sistemas de Gestão pela Universidade Federal Fluminense (2014), atuou como docente da ESAJ (Escola Superior do Judiciário - RJ) de 2011 a 2012. Desde 2002 atua no mercado como gestor de projetos de TI e Serviços de TI em organizações do setor financeiro, ONG de âmbito global e softhouse. Empreendedor atuante em startup que desenvolve soluções para residências e escritórios comerciais.

\section{WILLIAM RODRIGUES DOS SANTOS}

Possui graduação em Engenharia de Produção pela UFSCar (2011), mestrado em Engenharia em Engenharia de Produção - UFSCar (2012) e doutorado em Engenharia de Produção - UFSCar (2018). Atualmente é professor adjunto da Universidade Federal do Paraná e Coordenador do Curso de Engenharia de Produção do Campus Avançado da UFPR em Jandaia do Sul. Tem experiência de pesquisa e extensão em Projetos de Situações Produtivas, Instalações Industriais/Layout, Simulação de Eventos Discretos, Projeto do Produto, Segurança do Trabalho, Ergonomia e Projeto do Trabalho. 


\section{$\mathrm{S}^{2}-2$}

$\cdot, \frac{3}{2}$

$-a^{2} \cdot 2$

E 32

Whis 0

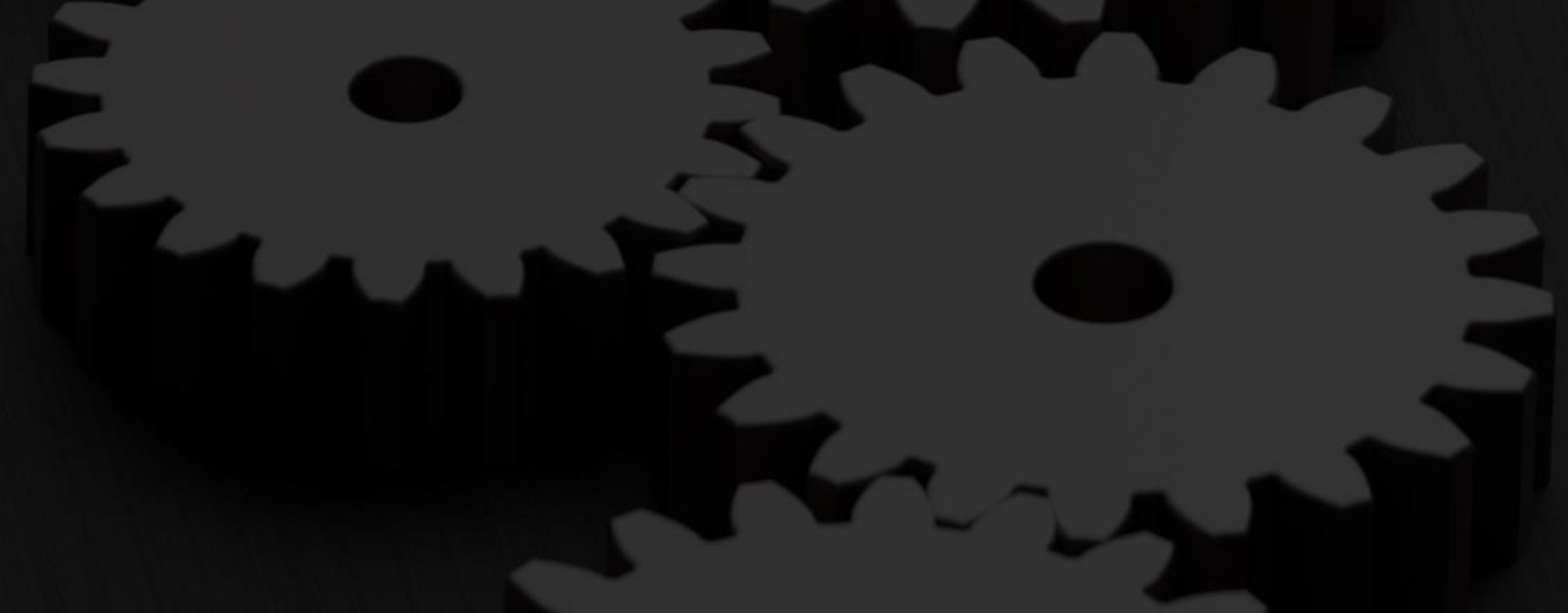

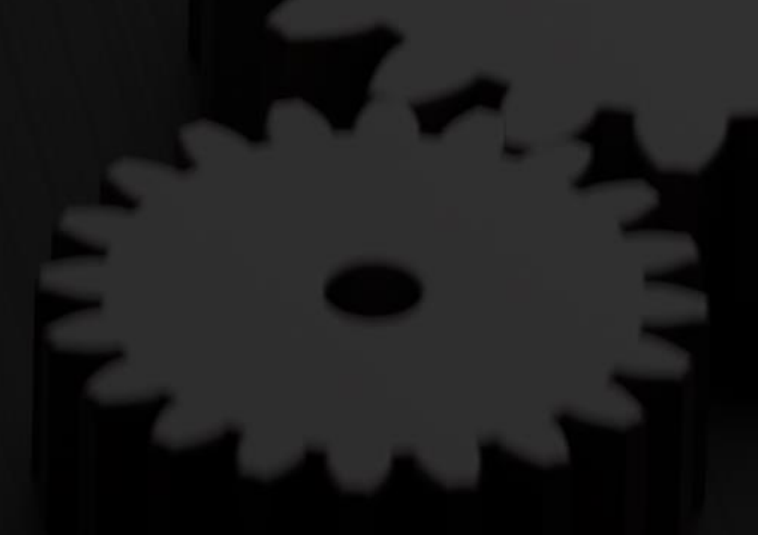

